San Jose State University

SJSU ScholarWorks

Master's Theses

Master's Theses and Graduate Research

1994

\title{
A surveys and data analysis unit for middle school students with emphasis on conceptual development and group projects
}

Mai-Phuong Thi Nguyen

San Jose State University

Follow this and additional works at: https://scholarworks.sjsu.edu/etd_theses

\section{Recommended Citation}

Thi Nguyen, Mai-Phuong, "A surveys and data analysis unit for middle school students with emphasis on conceptual development and group projects" (1994). Master's Theses. 857.

DOI: https://doi.org/10.31979/etd.dfb2-y4mn

https://scholarworks.sjsu.edu/etd_theses/857

This Thesis is brought to you for free and open access by the Master's Theses and Graduate Research at SJSU ScholarWorks. It has been accepted for inclusion in Master's Theses by an authorized administrator of SJSU ScholarWorks. For more information, please contact scholarworks@sjsu.edu. 


\section{INFORMATION TO USERS}

This manuscript has been reproduced from the microfilm master. UMI films the text directly from the original or copy submitted. Thus, some thesis and dissertation copies are in typewriter face, while others may be from any type of computer printer.

The quality of this reproduction is dependent upon the quality of the copy submitted. Broken or indistinct print, colored or poor quality illustrations and photographs, print bleedthrough, substandard margins, and improper alignment can adversely affect reproduction.

In the unlikely event that the author did not send UMI a complete manuscript and there are missing pages, these will be noted. Also, if unauthorized copyright material had to be removed, a note will indicate the deletion.

Oversize materials (e.g., maps, drawings, charts) are reproduced by sectioning the original, beginning at the upper left-hand corner and continuing from left to right in equal sections with small overlaps. Each original is also photographed in one exposure and is included in reduced form at the back of the book.

Photographs included in the original manuscript have been reproduced xerographically in this copy. Higher quality $6 "$ " 9 9" black and white photographic prints are available for any photographs or illustrations appearing in this copy for an additional charge. Contact UMI directly to order.

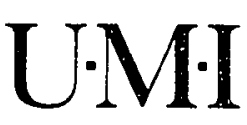

University Microfilms Internatıonal

A Bell \& Howell Information Company

300 North Zeeb Road. Ann Arbor. MI 48106-1346 USA

$313 / 761-4700 \quad 800 ; 521-0600$ 

Order Number 1959040

A surveys and data analysis unit for middle school students with emphasis on conceptual development and group projects

Nguyen, Mai-Phuong Thi, M.A.

San Jose State University, 1994

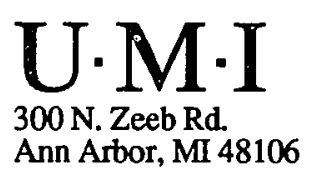





\title{
A SURVEYS AND DATA ANALYSIS UNIT FOR MIDDLE
} SCHOOL STUDENTS WITH EMPHASIS ON CONCEPTUAL

\section{DEVELOPMENT AND GROUP PROJECTS}

\author{
A Thesis \\ Presented to \\ The Faculty of the Department of Mathematics \\ and Computer Science \\ San José State University \\ In Partial Fulfillment \\ of the Requirements for the Degree \\ Master of Arts
}

by

Mai-Phuong Thi Nguyen

August, 1994 
(C) 1994

Mai-Phuong Thi Nguyen

ALL RIGHTS RESERVED 
APPROVED FOR THE DEPARTMENT OF MATHEMATICS AND COMPUTER SCIENCE

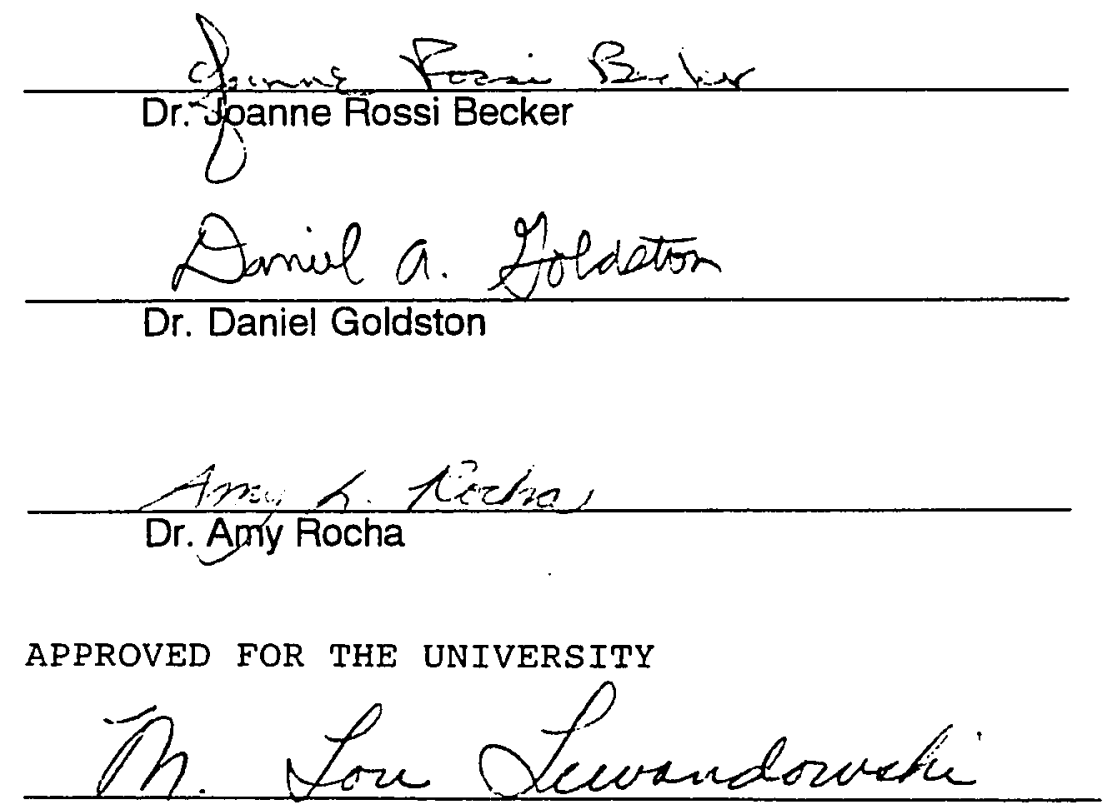




\title{
ABSTRACT
}

\section{A SURVEYS AND DATA ANALYSIS UNIT FOR MIDDLE SCHOOL STUDENTS WITH EMPHASIS ON CONCEPTUAL DEVELOPMENT AND GROUP PROJECTS}

\author{
by Mai-Phuong Thi Nguyen
}

This thesis evaluates the effectiveness of a statistics unit designed for middle school students. The statistics unit developed for this study aims to implement some recommendations to improve the teaching and learning of statistics advocated in the National Council of Teachers of Mathematics' 1989 Curriculum and Evaluation Standards for School Mathematics. The field testing of the 23-lessons unit took place in a seventh grade class at a local middle school. Student work products and an outsider's observations were employed as the means to assess the effectiveness of the unit.

Data collected from this study reveal that students developed important statistics skills and were exposed to some positive mathematics learning experiences. The findings of this study also showed a low level of conceptual understanding of the mean, mode, and median in some students. The findings of this study also lead to some suggestions for future implementations. 


\section{ACKNOWLEDGMENTS}

The writer wishes to express her appreciation to Dr. Joanne Rossi

Becker, her thesis advisor, for her valuable suggestions, constructive criticism, careful proofreading, and necessary guidance during the preparation and completion of this thesis.

To Dr. Amy L. Rocha and Dr. Daniel A. Goldston, the writer acknowledges her appreciation for their constructive comments and assistance. The writer also expresses thanks to Dr. Barbara Pence for her support.

The writer is especially indebted to Mr. Oscar Rodriguez for his participation in the study, and the members of the staff of August Boeger Middle School for their cooperation.

To $\mathrm{Ba}, \mathrm{Me}, \mathrm{Minh}$, and Trang, the writer expresses her most heartfelt appreciation for their sacrifice and support. 


\section{TABLE OF CONTENTS}

1. Introduction and Review of the Literature

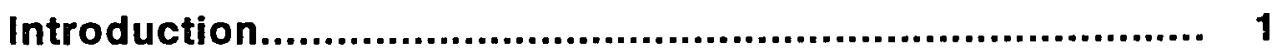

Review of the Literature....................................................... 3

Statistics Teaching Trends................................................ 3

Curricular Goals............................................................ 8

Standard 10: Statistics..................................................... 15

Chapter Summary.............................................................. 17

\section{The Study}

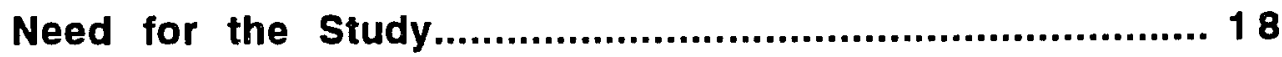

Problem and Purpose........................................................ 19

Statement of the Problem............................................... 19

Statement of the Purpose................................................. 19

Development of the Study.................................................... 20

Subjects....................................................................... 20

Application of the Unit...................................................... 21

Collection of the Data........................................................ 22

3. The Unit

Guidelines for the Unit.................................................. 24

How to Use the Unit......................................................... 25 


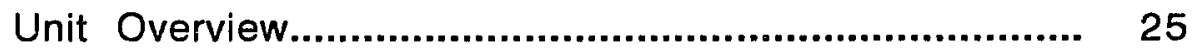

Group and Class Discussions.......................................... 26

Using Outside References................................................. 27

Using Calculators........................................................... 27

Helping Students Write Interpretations................................ 27

Cooperative Learning..................................................... 28

Student Assessment: Group Projects................................. 30

Lessons...................................................................... 32

Day 1 - Introduction to the Unit.......................................... 33

Day 2 - Surveys.......................................................... 41

Day 3 - Developing Survey Questions............................... 48

Day 4 - Population and Sample........................................ 58

Day 5 - Random Sampling................................................. 69

Day 6 - Quiz 1.............................................................. 77

Day 7 - Organizing Data in a Frequency Table...................... 81

Day 8 - Line Plots and Histograms.................................... 91

Day 9 - Stem-and-Leaf Plots........................................... 103

Day 10 - Interpreting Bar Graphs...................................... 121

Day 11 - Drawing Bar Graphs............................................ 131

Day 12 - Quiz 2............................................................ 142

Day 13 - Interpreting Circle Graphs (Pie Charts).................... 144

Day 14 - Constructing Circle Graphs (Pie Charts).................. 157

Day 15 - Scatter Plot....................................................... 168

Day 16 - Line Graphs.................................................. 184 
Day 17 - Group Projects Discussion (Optional)

Day 18 - Choosing an Appropriate Data Display.................... 195

Day 19 - Misleading Graphs............................................ 209

Day 20 - The Statistical Concepts of the Averages

(the Mode and the Median)..................................... 220

Day 21 - Developing the Statistical Concept of the Mean........ 229

Day 22 - Calculating the Average..................................... 235

Day 23 - Calculating the Average (continued)....................... 235

4. Presentation of the Study's Findings

Selection of the Students' Answers................................... 243

Students' Answers to Selected Questions on the Basic

Elements of a Survey................................................ 244

Students' Answers to Selected Questions about Their Own

Development of Mathematical Procedures................. 248

Students' Answers to Selected Questions on the Mean,

Median, and Mode.................................................... 250

Students' Projects and Writing Samples............................ 267

\section{Analysis and Conclusions}

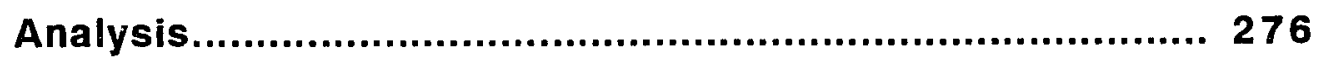

Basic Elements of a Survey.............................................. 276

Statistical Concepts of the Mean, Mode, and Median............. 277

Group Projects................................................................. 280 


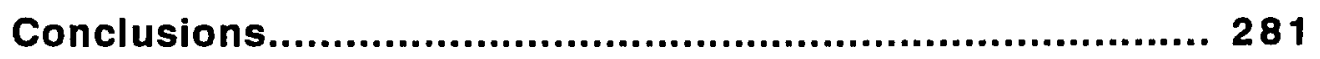

Evaluation of the Study................................................... 281

Limitations of the Study.................................................. 282

Suggestions for Future Implementation................................. 283

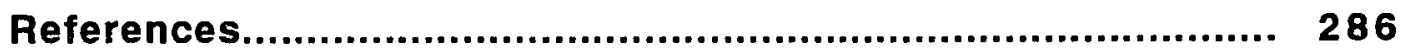

\section{Appendices}

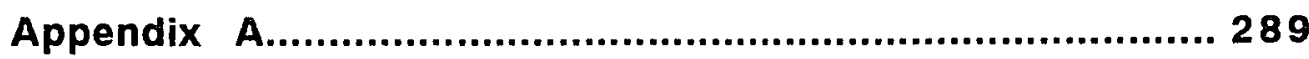

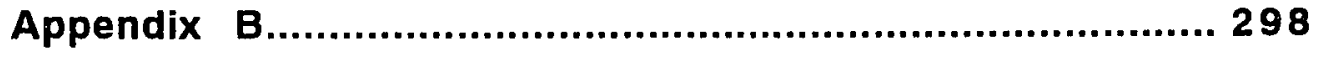




\section{LIST OF FIGURES}

1a. Students' Examples of Good Survey Questions for Their Chosen Topic.

1b. Students' Explanations of the Qualities of a Good Survey

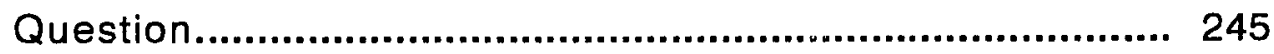

2. Students' Answers to the Question of Whether a Sample Is a Random

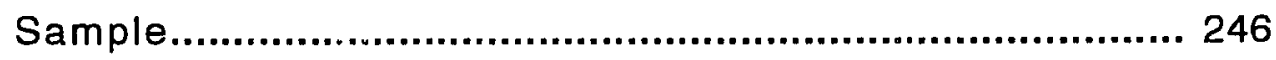

3. Students' Procedures for Drawing a Frequency Table................... 248

4. Students' Explanations of the Three Conditions for Choosing the

Intervals of a Frequency Table................................................. 249

5a. Students' Procedures for Finding the Mode of the Length of the Paper

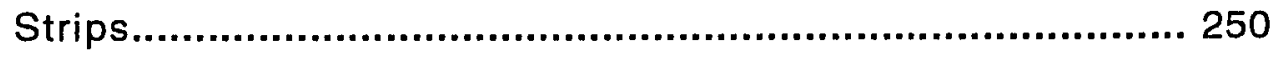

5b. Students' Answers to the Question of Whether There is More Than One

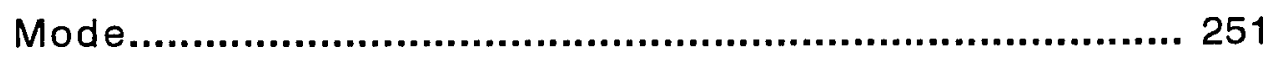

5c. Students' Procedures for Finding the Median of the Length of the Paper

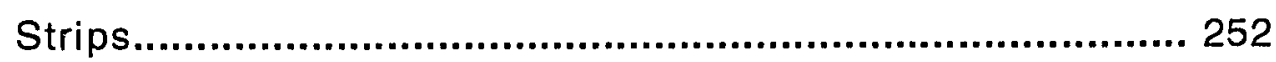

5d. Students' Answers to the Question of Whether There is More Than One

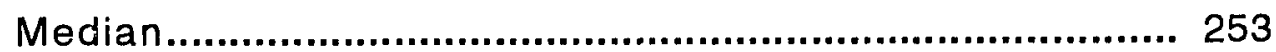

5e. Students' Procedures for Finding of the Mean of The Length of the

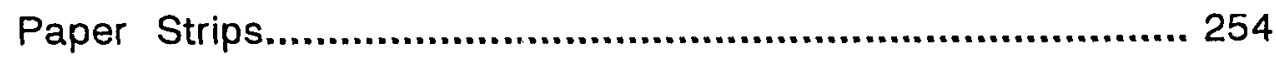

6a. Students' Procedures for Finding the Mode of a Set of Numerical

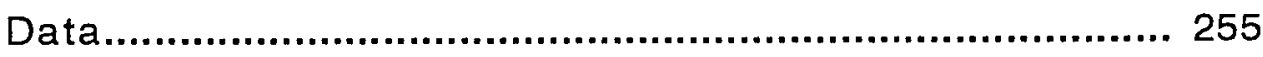


6b. Students' Answers to the Question of Whether There is More than One Mode............................................................................. 255

6c. Students' Calculations of the Median of a Set of Numerical Data.... 256

6d. Students' Answers to the Question of Whether There is More than One Median.............................................................. 256

6e. Students' Procedures for Finding the Median of a Set of Numerical

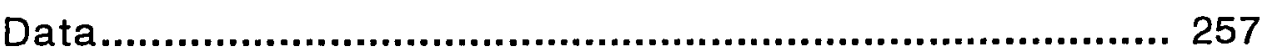

6f. Studentr' Procedures for Finding the Mean of a Set of Numerical

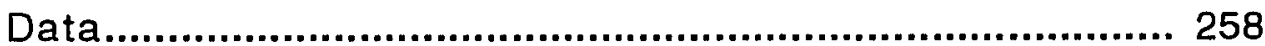

7a. Students' Procedures for Finding the Mode of a Set of Colors........ 258

7b. Students' Procedures for Finding the Median of a Set of Colors...... 259

7c. Students' Procedures for Finding the Mean of a Set of Colors....... 260

8a. Students' Procedures for Finding the Mode of a Set of Data in a Line

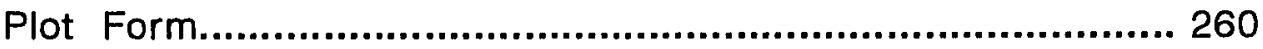

8b. Students' Procedures for Finding the Median of a Set of Data in a Line Plot Form................................................................... 261

8c. Students' Procedures for Finding the Mean of a Set of Data in a Line

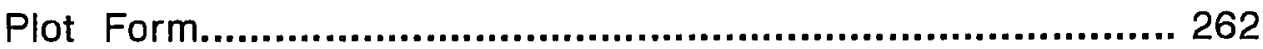

9a. Students' Explanations for Determining Whether All Sets Have a

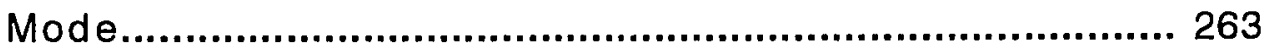

9b. Students' Explanations for Determining Whether All Sets Have a Median 
9c. Students' Explanations for Determining Whether All Sets Have a

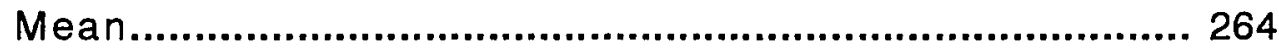

10a. Students' Calculations of the Mean and Median......................... 265

10b. Students' Explanations for their Selection of the Appropriate Mean and Median.................................................................... 267

11a. The Group Project of the Students 2, 9, and Two Other Group Members...................................................................... 268

11b. The Group Project of the Students 3, 6, and Two Other Group Members................................................................... 269

11c. The Group Project of the Students 7, 8, and Two Other Group Members............................................................................ 270

12a. A Writing Sample of the Student 3........................................ 271

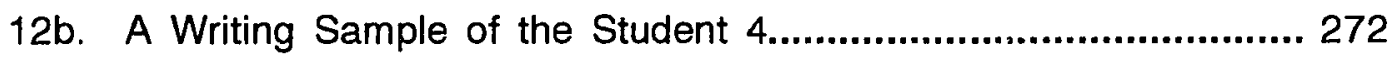

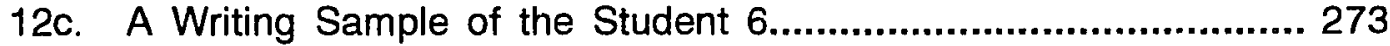

12d. A Writing Sample of the Student 7...................................... 274

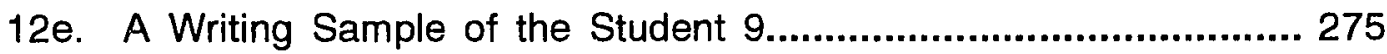




\section{CHAPTER 1 \\ Introduction and Review of the Literature}

\section{Introduction}

Statistics is traditionally taught at the university level, with some basic statistical concepts and procedures introduced to secondary schools. In recent years, however, many mathematics educators and professionals in the field have expressed strong support for the inclusion of statistics in school mathematics as early as the middle school level. In March 1989, the National Council of Teachers of Mathematics adopted the Curriculum and Evaluation Standards for School Mathematics (the Standards), which provides a vision and framework for strengthening the mathematics curriculum for kindergarten through grade 12 in North American schools. This text presents a set of standards for mathematics curricula and for evaluating the quality of the curriculum and student achievement. Since the release of the Standards, there has been a need for supporting publications that provide teachers with ideas and materials for implementing the standards. The statistics unit used in this study was designed to implement some of the recommendations.

This document is a report on the field testing of a non-traditional statistics unit designed for middle school students. The unit, a collection of modified lessons from several teaching sources, is different from a traditional statistics unit in its method of instructional delivery, which emphasizes cooperative learning and students' active role in doing mathematics; and in its method of student assessment, which employs group projects and teacher observations. The 23-lesson unit was taught to a class of seventh graders at a San José 
middle school. Student work products and performance observations were used to evaluate the effectiveness of this curriculum unit.

The first chapter of this document explores the background and needs for the development of a statistics unit for middle school students. Specifically, the chapter discusses related literature regarding the past and current trends in teaching K-12 statistics (grades 5-8 statistics in particular), and reports some results from an international study on the teaching and learning of statistics in the U.S. The chapter ends with a discussion of the National Council of Teachers of Mathematics' four curricular goals and the statistics standard for grades 5-8.

The following chapter discusses the need for the study, states the problem and the purpose of the study, and describes the methodology applied in this study.

The third chapter consists of the guidelines for the unit and the lessons themselves. The guidelines discuss several important features of the unit including group and class discussions, outside references, students' writing interpretations, cooperative learning, and student assessment. The descriptive lessons follow the discussion of the guidelines. Each lesson includes worksheets, keys, and a descriptive lesson plan that outlines the lesson's objectives, materials, and activities.

Chapter 4 lists the results of the study. Samples of students' answers and group projects are displayed in this chapter.

The final chapter, Chapter 5, interprets the study's major findings and draws conclusions. This chapter concludes with some implications for future revisions. 
Review of the Literature

Statistics Teaching Trends. Over the past twenty years, interest in teaching statistics has increased due to recognition of the importance of working with data in many business and scientific fields. The research physician conducts experiments to determine the effects of various drugs under controlled environmental conditions on humans in order to infer the appropriate method of treatment of a particular disease. The engineer samples a product quality characteristic along with various process variables to assist in identifying important factors related to product quality. The agriculturist uses crop forecasts and the results of agricultural field trials to improve productivity. Since statistical applications are more visible in advanced business and scientific fields, statistics has traditionally been considered as a curriculum objective only for students pursuing those careers. As a result, in the past statistics has mostly been taught at the university level, with little more than the basic measures of averages for secondary schools.

In the past years, numerous recommendations for the inclusion of statistics in the K-12 mathematics curriculum were formulated at national and international education conferences. The Commission on Mathematics organized in the United States in 1955, the Royaumont Seminar (the famous seminar on mathematics teaching organized by the Organisation for European Economic Co-operation) in 1959, the Conference on Mathematics Education organized by the Organisation for Economic Co-operation and Development in 1963, and the Cambridge Conference on School Mathematics in 1963 recommended that statistics should be introduced to all students at ail mathematics levels. (Rade, 1985) 
In recent years, the inclusion of statistics in the curriculum also received endorsement from the mathematics community in general. In its 1982 and 1983 reports concerning mathematics curriculum, the Conference Board of the Mathematical Sciences considered elementary data analysis and statistics more important than current advanced mathematics topics and recommended that these topics shouid be included as early as the middle school curriculum.

In spite of this strong support from the mathematics education and the mathematics community in general, students until very recently spent very little class time learning statistics. Data from the Second International Mathematics Study Summary Report for the United States indicated that only 4 to 5 days per school year are allotted for teaching probability and statistics (Crosswhite, Dossey, Swafford, McKnight, and Cooney, 1985). The lack of statistics in most middle school curricula are probably due to two main reasons: content of mathematics textbooks and teachers' traditional view of teaching this subject.

In U.S. mathematics classes, the textbook largely determines mathematical topics as well as the strategies used in teaching them. Furthermore, the textbook almost always defines the boundaries for instruction even when it does not actually determine the content of instruction. According to the participating teachers in the Second International Mathematics Study (SIMS), exclusion of a content representation from the textbook or little of it virtually eliminates that representation from being taught (Crosswhite et al., 1985). A study of popular mathematics textbooks for grades K-9 indicates that only about 30 percent of the content of the seventh and eighth grade books consist of new materials, the lowest percentage in the K-9 span (Flanders, 1987). Consequently, new materials such as statistics, probability, geometry, 
and pre-algebra, are either excluded from the seventh and eighth grade texts or presented sparingly. Thus, it is no surprise that many middle school teachers often skip the section on statistics.

The availability of new material, however, does not guarantee allotted time for teaching them. This tendency to neglect new materials at the middle school level seems to be a consequence of a mathematics curriculum characterized by an emphasis on repetition and review. The U.S. eighth grade teachers' reports of anticipated percentage of class periods devoted to various topics reveal an eighth grade curriculum that spends most of its class periods on fractions, ratios, proportions, and percent (Crosswhite et al., 1985). This curriculum resembles a curriculum of the last years of elementary school. As one mathematics educator has observed, "The propensity of U.S. schools to prolong the teaching of arithmetic beyond the elementary grades reflects our evidently compelling need to continue instruction on the subject until mastery is obtained" (McKnight, Crosswhite, Dossey, Kifer, Swafford, Travers, and Cooney, 1987). Following that tradition, teachers often consider teaching statistics as an opportunity for improving students' computational skills in arithmetic rather than an opportunity for teaching a thorough understanding of the underlying mathematical concepts.

These factors directly affect the U.S. students' performance in the area of statistics, especially in the traditional middle school statistics topics: mean, median, and mode. The SIMS report shows most eighth grade students can compute an arithmetic average of a finite set of whole numbers (Crosswhite et al., 1985). This level of performance, however, declines in problems that require computation involving decimal numbers, and even in problems that 
replace the term average by the more precise term mean (Carpenter, Corbitt, Kepner, and Reys, 1981). Most students also find difficulty in solving problems that demand more than a straight forward calculation of the average of a set of data. For example, only 16 percent of thirteen-year-olds can find a missing piece of data entry when the average and all other data are provided (Carpenter et al., 1981). Furthermore, students' reference to the process of calculating the mean as its definition shows that for many students the mean is a computational rather than a conceptual act. What other answer can these students give when one of the popular textbooks defines the mean as "the sum of the data items divided by the number of items?" (Gardella, Fraze, Meldon, Weingarden, and Campbell 1992)

The Second Mathematics Assessment of the National Assessment of Educational Progress shows more than half the thirteen-year-olds in the United States are unable to find the median of a set of data arranged from least to greatest (Carpenter et al., 1981). A study by G.V. Barr (1980) reveals that more students make mistakes in locating the median when the list of data is reported in non-numerical order or in a frequency table. Students' mistakes in these cases, choosing the middle number regardless of the order of the data pieces, seem to imply the careless use of the definition of the median as "the middle of something."

Thirteen-year-olds in the U.S. do not understand the meaning of the mode any better than they do of the mean and the median. Over 30 percent of the eighth graders in the U.S. have no knowledge of what a mode is; only 25 percent can correctly identify the mode of a list of data; and only 12 percent are able to identify the appropriate use of the mode in a realistic application 
(Carpenter et al., 1981). There is also evidence that many students oversimplify the definition of the mode. Students in these cases simply choose the "most" as their definition for the mode, rather than identify the piece of data that occurs the most frequently.

In general, the "arithmetic-driven" eighth grade curriculum makes statistics an area of little growth compared with other mathematics topics. The achievement data from the SIMS report indicate only a 4 percent increase of scores from the pre-test given at the start of a school year to those from tho posttest given at the end of the same school year in statistics (Crosswhite et al., 1985). These results call for the re-examination and revision of the middle school curriculum for statistics. In 1989, the National Council of Teachers of Mathematics (NCTM) answered the call for reform in the teaching and learning of statistics, among other mathematics topics, with the Curriculum and Evaluation Standards for School Mathematics (the Standards). In this document, the NCTM concluded:

In this age of information and technology, an ever-increasing need exists to understand how information is processed and translated into usable knowledge. Because of society's expanded use of data for prediction and decision making, it is important that students develop an understanding of the concepts and processes used in analyzing data. A knowledge of statistics is necessary if students are to become intelligent consumers who can make critical and informed decisions. (p. 105) As for grades 5-8 statistics, the NCTM suggests that grade 5-8 students should expand the grades K-4's statistical concepts of gathering data, organizing them in charts or graphs, and reading information from display data. 
Middle school students also need to be "actively involved in each of the steps that comprises statistics, from gathering information to communicating results" (p. 105). The next portion of this chapter focuses on the curricular goals and the recommended features for the statistics unit.

Curricular Goals. The vision of the Standards is that problem solving, communication, reasoning, and connection permeate the mathematics curricula.

Problem Solving. Mathematics problems have been included in the curriculum at least as far back as the Ancient Egyptians, Chinese, and Greeks. Until relatively recently, teaching problem solving meant introducing problems and usually including an example of a specific solution technique. This method of teaching problem solving prompted over 80 percent of the eighth-graders participating in the SIMS to express the opinion that there is always a rule to follow in solving a mathematics problem. Almost one-half of these students believed that they can solve mathematics problems by memorizing procedures and only one-half of these students agreed that trial and error can often be used to solve a mathematics problem (McKnight et al., 1987). Clearly, these conceptions of problem solving in mathematics is different from those of people who use mathematics professionally.

The Standards (1989) defines problem solving in grades 5-8 as "the process by which students experience the power and usefulness of mathematics in the world around them" (p. 75). Problem solving, the Standards continues, is also "a method of inquiry and application" that must be interwoven throughout the curriculum standards "to provide a consistent context for learning and applying mathematics" (p. 75). The Standards recommends that the 
mathematics curriculum for grades 5-8 should provide experiences that enable students to:

Use problem-solving approaches to investigate and understand mathematical content. Using problems and applications to introduce new mathematical content benefits students in two ways: (1) they can develop both an understanding of concepts and a facility with procedure, and (2) they can apply and review processes they have already learned. When dealing with a situation for which students have no readily available solution techniques, the learning process requires students to analyze the situation in terms of their existing knowledge, to develop appropriate mathematical techniques based on known procedures, and subsequently to apply these new techniques to solve the problem. Since students are so much involved in this learning process, they are very likely to internalize the mathematical concepts and procedures that were introduced to them.

Formulate problems from situations within and outside mathematics. Concrete and empirical situations remain a focus throughout grades 5-8. However, student experiences should be balanced between problems from the real-world setting and problems arising from mathematical ideas. Real-world problems, the Standards states, will better prepare students to solve problems they are likely to encounter in their daily lives. Problems arising from mathematics itself can help students see that their mathematical thinking contributes to their mastery of other mathematical ideas. 
Develop and apply a variety of strategies to solve problems. Realworld and mathematics-originated problems must provide a context in which students can learn the problem-solving process. Mathematics curriculum must incorporate lessons that help students develop the ability to understand and apply a variety of strategies such as guess and check, make a table, and look for patterns. Students then must work with others to examine a variety of approaches and learn to evaluate appropriate strategies for a given situation. The instructiona! goal is that students will build an increasing repertoire of strategies, approaches, and familiar problems. This repertoire will give students at least a starting point when they face a new problem situation.

Reflect on the problem and the means of solution. Once students have obtained a solution, teachers need to encourage them to reflect on the problem and the means of solution. This is the time when students should check results with respect to the original problem and generalize solutions and strategies for future problem-solving activities. Students must learn to verify their thinking instead of depending on teachers or answers in the back of books.

Communication. The Standards (1989) urges that the mathematics curriculum create many opportunities for middle school students to use language to communicate their mathematical ideas.

Mathematical language is similar to spoken language. As the development of spoken language depends on the association between words and their meanings, the development of mathematical language depends on the connection between mathematical concepts and the symbols representing 
them. Like the process of learning spoken language, the process of learning mathematical language relies on a regular diet of mathematical talks, writing, drawing, graphing, symbols, numbers, and tables to help students transform mathematical symbols into meaningful items, rather than into unrelated objects to be memorized for a short period of time.

The similarities between the two languages lead to an interrelation between mathematical language and spoken language as well as between mathematical thinking and everyday thinking. In their mathematics classes students will encounter not only a distinct mathematics vocabulary but also a process of thinking that may not be similar to that of their everyday life. Students can grasp concepts and relate technical words more easily if they can associate these new terms with their existing vocabulary and ideas. In the same way, as students use mathematical language and reason mathematically inside mathematics classes, they are likely to mold daily thinking according to mathematical thinking and bring common sense into their mathematical reasoning when occasions arise (California Department of Education, 1992).

The increase of students' sophistication in ability to communicate mathematics cannot happen without deliberate instruction. According to the Standards (1989), teachers should carefully pose problem situations that engage students in group and class discussions. Small groups create a protective environment in which students can afford to try new ideas, to ask questions, to discuss strategies, and to offer constructive criticism. Large group discussions afford the opportunity for students to share discoveries, to evaluate strategies, and to construct arguments for selected solutions. Discussions together with oral and written presentations are some of the methods used to 
create an environment in which students learn mathematics through communication.

Reasoning. Reasoning, the Standards states, plays a fundamental role in the mathematics discipline. It, after all, constitutes the standard of evaluation on which new mathematical theories and discoveries are judged. Therefore, for students truly to experience the essence of mathematics, problems which emphasize mathematical reasoning rather than numerical answers should play an important role in the mathematics curriculum.

Mathematics, due to its use of logical reasoning, is assumed to improve people' $s$ thinking. Recent studies have shown otherwise. Data from the SIMS reveal that most eighth and twelfth graders in this study, especially those in the eighth grade, "regarded mathematics as a large fixed, rule-oriented body of knowledge to be acquired through memorizing and learning to apply rules" (Crosswhite et al., 1985). In a separate study, Allen Schoenfeld (1989) discovered evidence supporting the observation that students often solve mathematical problems from memorization and knowing how to apply rules. According to Schoenfeld, students develop this attitude about mathematics probably because they learn through classroom activities that mastery of mathematical procedures helps them to obtain the expected answers and brings them reward in the classroom. As far as students are concerned, learning mathematical rules and procedures is the mathematics they are supposed to learn. Schoenfeld suggested that combining helping students to master the mathematical tools with "helping students develop the appropriate sense of what the discipline is" will remedy this situation. This suggestion means the mathematics curriculum must teach students the two integral 
elements of the learning and doing of mathematics: to form conjectures (through problem-solving strategies) and to check conjectures by mathematical reasoning.

Identifying patterns is not only a recommended strategy for problem solving but it is also a powerful method for forming conjectures. The teaching of patterns identification at the grades 5-8 level should foster students' ability to develop abstract mathematical ideas. Students then should be encouraged to validate these ideas by constructing logical arguments. There are several levels of sophistication of mathematical arguments. However, middle school students should at least know how to defend their conjectures by using previously learned properties, or by using counterexamples, or by analyzing graphs.

This emphasis on reasoning is especially important in the mathematics curriculum for middle school students. Middle school students are children in a stage of transition. These students have just left the primary program that emphasizes mathematical thinking as concrete, informal, and playful. Now they are on the verge of the formal and abstract thinking of the secondary mathematics program. They must learn to validate their thinking by logical reasoning instead of depending on the teachers' approval.

In conclusion, students in grades 5-8 should learn to reason constantly about what is happening in their study of mathematics and why. After all, that is what mathematics is all about.

Mathematical connections. For many students, middle school mathematics is either an extension of the computational work taught in earlier classes (arithmetic) or an introduction of new topics having little in common with 
their previous learning (algebra). Mathematics, the NCTM concluded, should be introduced to students as an integrated whole, reflecting how mathematics really is. The NCTM wanted the theme of mathematical connections to permeate the curriculum "... to help students broaden their perspective, to view mathematics as an integrated whole rather than an isolated set of topics, and to acknowledge its relevance and usefulness both in and out of school" (p. 84).

There are many ways teachers can draw connections among mathematical ideas. Mathernatical concepts can be interpreted in terms of various mathematical strands which include: number, measurement, geometry, patterns and functions, statistics and probability, logic, algebra, and discrete mathematics. For example, fractions can be interpreted in terms of measurement, ratios, or algebraic ideas. Relationships between a particular topic with other topics should be employed in highlighting the mathematical connections. The most immediate result of recognizing and drawing connections among topics is to foster in students an expectation that the mathematical ideas they learn can be used to solve other problems and to explore other mathematical concepts. This result creates a tremendous incentive for students to accumulate their repertoire of strategies for problem solving.

Students should also have numerous opportunities to observe how mathematics interacts with other school subjects and with daily society. For example, the idea behind the problem "How many handshakes will occur at a party if every one of the 15 guests shakes hands with each of the others?" (NCTM, 1989) can be used to explain why airlines use "hub cities" to form routes among cities they serve. As grades 5-8 students develop an awareness 
of their surroundings, statistics gives them an example of how mathematics is employed to pose and solve daily problems. Seeing the extent to which mathematics has played a role in our lives, students may realize that mathematics is not just a collection of concepts and procedures memorized for a particular test, but a set of valuable ideas, tools, and techniques that people use to solve real-life problems.

Standard 10: Statistics. There are eleven curriculum standards for grades 5-8. Standard 10 for these grades discusses how a statistics unit should be implemented to encompass the four unifying themes: problem solving, communication, reasoning, and mathematical connections, of the mathematics curriculum. The NCTM is convinced that an improved statistics unit should allow students to "...generate information from data related to their interests by describing the data numerically or visually, drawing inferences on the basis of careful analysis, and communicating that information in a convincing way" (NCTM, 1989, p. 105).

Traditionally, a statistics unit for grades 5-8 usually consists of " finding a range of data, constructing simple graphs, computing the average, and reading data points as answers to specific questions about the data" (NCTM, 1989, p. 105). In some classes, due to the effort to improve students' scores on the California Test of Basic Skills or other similar standardized tests, more emphasis is placed on computing the average, especially of integers and fractions, and reading data points from charts and graphs. The unit described above introduces some important ideas in statistics; however, these ideas do not present the full objective of data analysis, which is what statistics is about. Furthermore, the data typically presented are contrived, limited, and of little 
interest to students. As a result, this type of unit on statistics is actually no more than just an extension of arithmetic computation.

Attempting to introduce statistics the way it is practiced in the real world, the NCTM recommended students in grades $5-8$ should be "actively involved in each of the steps that comprise data analysis." The activities should include:

1. collecting and organizing data;

2. constructing and interpreting tables and graphs;

3. drawing inferences to describe trends;

4. developing convincing arguments; and

5. evaluating the arguments of others.

The NCTM is convinced that like other life experiences, only personal involvement in the learning process can help students develop the critical skills to question, analyze, and interpret data in the classroom and data from outside sources.

Dealing With Data and Chance, a book in the Curriculum and Evaluation Standards for School Mathematics Addenda Series, suggests that middle school students can be actively involved in the entire process of data analysis through surveys, experiments, and simulations (Zawojewski, 1991). Surveys usually require that students only write effective survey questions and find valid means of obtaining answers for the survey questions. Experiments are slightly more sophisticated than surveys because students must design experiments according to the scientific method so that they can collect usable data. Simulation is the most sophisticated method among the suggested three. Simulation involves a special type of experiment that uses random number device--number cubes, spinners, random number tables, and computer 
programs--to represent or model real-world situations. Middle school students' interest in themselves, their peers, and their surroundings makes surveys the most appropriate and interesting method to introduce statistics to these students.

\section{Chapter Summary}

An examination of the literature pertinent to the statistics teaching and learning of statistics in the U.S. was undertaken in this chapter.

The first portion of the chapter traced the past recommendations for the inclusion of statistics in the K-12 school levels. Even back in the 1950s, several national and international mathematics education organizations strongly suggested that statistics should be introduced to all students at all levels.

The second portion of the chapter discussed why statistics has not established a prominent place in the school curriculum despite the strong support from the national and international organizations mentioned in the first part. This portion also reported some results from an international survey on the teaching and learning of statistics, those in the U.S in particular. These results show that the lack of time allotted for teaching statistics in the U.S. has a tremendous effect on the U.S. students' performance.

The last portion of this chapter described how the National Council of Teachers of Mathematics answered to the call for the reform of the teaching and learning of mathematics, the teaching and learning of statistics in particular, by publishing the Curriculum and Evaluation Standards for School Mathematics. This document stresses the importance of statistics in the mathematics curriculum and provides recommendations for improving the level of statistics teaching in grades 5-8. 


\section{CHAPTER 2}

\section{The Study}

\section{Need for the Study}

In March 1989, the National Council of Teachers of Mathematics (NCTM) released the Curriculum and Evaluation Standards for School Mathematics (the Standards). This document provides a framework to support the NCTM's vision of strengthening the mathematics curriculum of grades K-12 in North American schools. The document presents a contrast between traditional mathematics curriculum and evaluation, which failed to improve students' understanding of mathematics, with recommended practices for improving instruction and evaluation supported by current educational research.

Following the release of the Standards and on the basis of the recommendation of the NCTM Task Force on the Addenda, several writing teams were formed to develop addenda providing teachers with classroom ideas for translating the NCTM's recommendations into classroom practices. As a result, Dealing with Data and Chance (Zawojewski, 1991), one of the books in the Grades 5-8 Addenda Series, was published in 1991. This book presents teachers with several topics and activities that illustrate the practices advocated in the Standards. This book, however, does not provide homework assignments or testing materials like regular mathematics text books. Teachers, during the period of waiting for new texts to be published, must develop the NCTM's recommendations into suitable lessons for their students. Furthermore, these teachers must also adopt a system of evaluation standards to support the new instructional activities. The immediate concern for these teachers is 
locating a text that fits their need. The unit developed for this study aims to fulfill that need.

\section{Problem and Purpose}

Statement of the Problem. This study was to evaluate the effectiveness of a modified statistics unit for seventh grade students.

The basic elements of the study were:

1. Searching for the existing teaching materials for middle school statistics and modifying them according to the NCTM's recommendations for improved mathematics instruction;

2. Applying the experimental unit taught into the school situation;

3. Collecting and analyzing the data gathered during the teaching; and

4. Evaluating the effectiveness of the unit in implementing the NCTM's standards and providing suggestions for future revisions.

Statement of the purpose. The purpose of this study was to provide answers to the following questions concerning the experimental unit.

1. How much will the unit help students to understand the statistical concepts of the mean, median, and mode?

2. How much will the unit help students to combine all mathematical concepts to produce a mathematical project?

3. How much will the unit help students to use induction to develop their own mathematical procedures?

4. How does the new system of multiple means of assessment affect students' work products and performance? 
Development of the Study

Subjects. Following the release of the Curriculum and Evaluation Standards in 1989, many mathematics teachers in the U.S. have searched for new teaching materials that translate the standards into classroom practice. Among this group are some mathematics teachers at August Boeger Middle School. In the Spring of 1993, the investigator proposed to three seventh and eighth grade mathematics teachers the idea of teaching a statistics unit in their classes. They all approved the proposal. However, due to the investigator's preference for small classes (less than 35 students per class) and the prerequisite for the unit (some knowledge of Pre-Algebra), there was only one seventh-grade class available for field testing.

August Boeger Middle School is a junior high school with seventh and eighth graders. It is the only junior high school in Mt. Pleasant School District, which is located in the eastern foothills of Santa Clara County. The average school population is estimated at 530 students. Of these students, $48 \%$ are Hispanic, 21 percent are White, 10 percent are Black, 10 percent are Asian, 9 percent are Filipino, and 2 percent are American Indian and Pacific Islander. The 1993 Comprehensive Test of Basic Skills results show that seventh grade and eighth grade reading levels are equivalent to grades 7.7 and 9.0 respectively. The CTBS also indicates the mathematics levels of seventh and eighth graders are equivalent to grades 8.3 and 9.2 in that order (August Boeger Junior High School, 1993).

The test class consisted of 32 seventh grade students whose ages range from 12 to 13 years. Among them, there were 13 female and 19 male students. There were 3 Limited English Proficient students who were grouped together for 
translating purposes. On an average day, about two or three students were absent. Before the statistics unit was introduced to this class, the teacher and students had covered a wide variety of units including patterns, algebra, geometry, integers, and graphing.

Application of the Unit. A rough draft of the lessons was given to the teacher for review a few weeks before the starting date. The actual lessons and teaching materials were given to the teacher a week before the lessons were taught. On a few occasions, however, the teacher received some lessons only two or three days in advance due to the need to revise these lessons to fit student mathematics and reading levels.

The teacher was expected to assume all responsibilities of teaching and grading. The teacher was asked to follow the guidelines for instructional activities and methods of assessment as closely as possible. However, when necessary, the teacher had the freedom to make minor adjustments to the guidelines to do the most effective job. The teacher and the investigator consulted with each other before making any major changes to the lessons. The teacher and the investigator often held informal meetings to discuss teaching methods, student observations, and any issues that arose during class activities.

During this period, the investigator was in the classroom almost every day to prepare teaching materials, observe students, and assist the teacher with class activities if needed. The investigator was also responsible for revising lessons to fit the students' level of understanding and the time constraints. At the end of the unit, the investigator combined student work products, the 
teacher's comments, and personal observations to evaluate the effectiveness of the unit.

Collection of the Data. Traditionally, standardized testing was the primary (if not the sole) source of information for (among other purposes) reporting the effectiveness of a curriculum. This method of evaluation may provide some important and useful data, but it also emphasizes negative classroom practices. These include: no consideration (or credit) given to the student's strategies and processes; emphasis on speed and accuracy rather than mathematical thinking and reasoning; and no oral or written communication skills counted in student performance (EQUALS, and California Mathematics Council Campaign for Mathematics, 1989). Since this experimental unit aims to promote problem solving, mathematics communication, mathematical reasoning, and mathematics connections, appropriate means of student assessment must be used to accurately evaluate students' complete performance. This study employs student work products and observations as the means to assess its experimental statistics unit. These two methods of assessment will be discussed in depth in chapter 3 , the Unit.

Student products are work that students have generated. The list of student products that can be used to evaluate a curriculum is endless; however, this study adopted group project as one of its means for the evaluation of the unit. Group project was chosen because it: (1) allows students the opportunity to demonstrate their understanding of mathematical ideas and their creativity; and (2) encourages students to learn to work with others to achieve a common goal. 
Observation is the second method used to evaluate the effectiveness of this statistics unit. In this study, observations were made by the teacher and by the investigator. Students were observed either individually or as they worked in a group. Students in this study were assessed on the following attributes: mathematical concepts, students' disposition toward learning, mathematics communication, and group work. 


\section{CHAPTER 3}

\section{The Unit}

\section{Guidelines for the Unit}

This unit serves as an introduction to statistics for middle school students.

From it students will learn how to develop, conduct, and analyze surveys.

Students can become involved in learning and doing mathematics through surveys. Surveys are widely used to gather information concerning the likes and dislikes, circumstances, or plans of groups of people. Middle school students, who are curious about themselves, their peers, and their surroundings, will find surveys an ideal way to investigate their interests in the above issues. Due to the embedding of all four themes of the Standards in their process, surveys naturally constitute an appropriate choice for a mathematics unit that aims to promote those themes. Holding discussions on reasons for conducting surveys, types of surveys, methods of conducting surveys, and techniques of representing and interpreting the results afford students the opportunity to develop a better understanding of the entire process of surveying. As a result, students will become more critical in examining surveys from outside sources.

From the data analysis section of the unit, students will learn how to make various kinds of graphs, including some that have not traditionally been included in a middle school statistics unit. Students will also learn how to select the appropriate types of graphs for a given set of data. Finally, students will learn how to examine the graphs in order to describe the data, recognize patterns in them, make conjectures about them, and determine whether the graphs offer misleading representations. 
After learning about surveys and the techniques of analyzing the results, students should be able to analyze the surveys and data that they come across in and out of the classroom.

How to Use the Unit. The two major goals of this unit are to help students understand how surveys are developed and learn how to interpret data by using various plots and graphs. In a traditional statistics unit, students have not experienced the planning and conducting of surveys. As a result, they may not recognize the importance of the lessons on writing survey questions or selecting samples for a survey. In the activities in the first part of this unit, students will depend on group and class discussions to discover not only the basic elements of a survey but also the characteristics of an effective survey.

This unit's emphasis on the interpretations rather than the techniques of graphing may seem strange to many students. Traditionally, students have been taught that there is only one right answer for a mathematics problem. This practice, however, is not always true in statistics. We have seen that two different interest groups can provide two different interpretations of the same set of statistical data. The approach of this unit is to show students that two students may write entirely different descriptions and yet may get full credit.

Unit Overview. Lessons for the first six days focus on the basic elements of a survey and the characteristics of an effective survey. The day 1 lesson begins by introducing students to different fields that employ statistics and group organization. The day 2 lesson focuses on the basic elements of a survey and types of surveys. In the day 3 lesson, students learn to develop guidelines for writing survey questions and use them to write survey questions for their group projects. The day 4 lesson allows students to examine how the 
size and nature of a sample can affect the result of a survey. In the day 5 lesson, students must rely on their reasoning ability to decide whether a sampling method is a random sampling. Day 6 is reserved for the first quiz and group planning for the group project.

The remaining lessons concentrate on organizing and analyzing data. The day 7 lesson introduces students to frequency tables with intervals. In the day 8 lesson, students learn to transfer the data in a frequency table into the displays of a line plot and a histogram. The focus of the day 9 lesson is stemand-leaf plots. The day 10 lesson concentrates on the interpretation of bar graphs. The day 11 lesson extends this skill by having students draw their own graphs. Day 12 is the day for the second quiz and additional discussion on group projects. Interpreting and drawing circle graphs are the objectives of the day 13 and day 14 lessons. Scatter plots are featured in the day 15 lesson. The third quiz and group projects are the activities for day 17 . In the day 18 and day 19 lessons, students must use their reasoning abilities and problem-solving skills in choosing an appropriate display for data, and analyzing given graphs for misleading information. The day 20 and day 21 lessons present the concepts of mode, median, and mean. The decision-making strand continues in the day 22 and day 23 lessons, as students combine the calculation of the averages with the selection of the most appropriate statistical average to represent a set of data. Students will turn in their group projects a week from day 23.

Group and Class Discussions. Students should know that group members (through group discussions) and classmates (through class discussions) are their primary source of information. Students will request the 
teacher's help only when there is no one in their group or in the class able to figure out what to do. Teachers should also restrain from giving the answers immediately. Instead, teachers should ask students what they have achieved and offer leading questions for further examination.

\section{Using Outside References}

Teachers. To prepare for this unit, teachers should collect as many different kind of surveys, charts, graphs as they can from newspaper, magazines, and other resources. (The newspaper, USA Today, is a good source for the day-19 lesson.)

Students. There are some homework assignments that require students to do some outside research in almanacs, encyclopedias, or other reference books to obtain a better examination of data. For example, students need outside resources to find out why the winning long jump in the 1968 Olympics is so much longer than previous jumps.

Students may show some resentment over this extra work outside of the mathematics class. Teachers can reduce the level of dissatisfaction by pointing out the detective aspect of the research or giving extra credits for the extra work.

Using Calculators. The only lessons in this unit that require some tedious computation are lessons for days 20-23. Nevertheless, students should be allowed to use a calculator whenever they wish. Class time should consist mainly of discussions and exploration of mathematical ideas, not working out computations using pencil and paper.

Helping Students Write Interpretations. Writing interpretations of statistical data is difficult for almost all students. In traditional statistics assignments, students have often provided either numerical values or short 
answers to statistical questions. Thus, the requirement of writing short paragraphs to interpret data undoubtedly creates some problems for many students. Teachers can help to improve this situation by asking that students to provide any observations they have about the plot, recording them on the board or the overhead, and then helping students organize them into short paragraphs. The observations can be simple such as "The largest value is 18" or sophisticated like "There must be a reason for the former world record in long jump (1968) to last such a long time." Repeat this practice a couple of times to ensure that all students grasp the idea of writing statistical interpretations. Emphasize the fact that there are no unique, correct answers. In fact, encourage students to investigate questions that they may not be able to answer directly from the data, such as "Why is there such a drastic difference in infant mortality rates between countries in Europe and Africa?" Raise your level of expectation as students become familiar with the writing assignments.

Cooperative Learning. Judging from the data collected, eighth grade U.S. students devoted the majority of their class time to one of two types of activities: listening to teacher lectures or doing individual work with minimal interaction with the teacher. Also very little time was allotted for working in small groups in which students are more likely to generate questions and discuss new ideas. (McKnight et al., 1987) This mathematics class setting is completely different from the mathematics-related workplace setting. In mathematicsrelated business and industry, people who do genuine mathematical work often collaborate with others to solve problems and attain common objectives. For students to fully experience the working environment in society, in particular the 
mathematics-related setting, students should have the opportunity to collaborate with other students in mathematics classes.

Students receive many benefits from working collaboratively in mathematics. Working with peers from various backgrounds to obtain common goals, whether grades or the sake of learning mathematics, encourages students to find ways of working together effectively. Teachers' careful guidance will help students develop proper social and communication skills for group cooperation.

In addition to students' development of social and communication skills, cooperative learning affords students alternative ways to learn and do mathematics. In many mathematics classrooms, learning is perceived as a process in which students passively absorb information, and store whatever is left from their short term memory. Research findings on learning from psychology disputes this perception. Meanwhile, other authorities on learning believe that there is an increasingly interrelated nature of language and cognition as children grow (Zawojewski, 1991). Students in cooperative groups, being forced to defend their views against challenges from their peers, must learn to formulate their thoughts so that these thoughts can reflect the students' understanding of concepts and procedures. This activity, according to a discussion in Dealing with Chance and Data (Zawojewski, 1991), helps students internalize concepts.

Students participating in cooperative learning in mathematics are more likely to be exposed to different points of view than students learning mathematics in an individual-setting environment. Understanding different 
points of view allows students to learn more problem-solving strategies.

Consequently, students can accumulate more experiences in problem solving.

Effective cooperative groups require more than just telling students to form groups and work with each other. According to D.W. Johnson and R.T. Johnson (1990), non-structured groups do not create an environment that encourages learning and communicating mathematics and may lead to the development of unwanted characteristics. For example, less-able members may let others complete the group's assignments and more-able members may want to dominate all group discussions. Johnson and Johnson concluded that group efforts may be more productive than individual efforts if the groups have the following basic elements. The first basic element is positive interdependence. Students in groups must depend on one another for positive mathematical and social development. The second ingredient is one-to-one interaction. Positive interdependence among students leads to supportive interaction and verbal exchange among students. The third component for effective cooperative learning is individual accountability. All students in cooperative groups are responsible for learning the material. The fourth element focuses on the proper social skills needed for group cooperation. These skills must be taught in class as purposely and precisely as academic skills. Finally, students must have time to assess their group performance. Group assessing is the opportunity for students to evaluate how well group members learn mathematics and maintain a working relationship among members.

Student Assessment: Group Projects. A new way of mathematics instruction requires a new way of performance assessment. Traditional 
practices depend on objective, multiple-choice tests to indicate the quality of mathematical performance. This approach, however, is no longer adequate for assessing many of our new goals. Everybody Counts-A Report to the Nation on the Future of Mathematics Education (Everybody Counts) discusses this issue:

Experience in evaluating student writing shows that readers judging whole essays produce results more aligned to the goal of high-quality writing than do objective exams of grammar and vocabulary. Similar experiences show that one can reliably judge scientific understanding by observing student teams in laboratory. Effective means of assessing operational knowledge of mathematics must be similarly broad, reflecting the full environment in which employees and citizens will need to use their mathematical power. (National Research Council, 1989, p. 69) Everybody Counts proceeds to suggest that "a teacher needs to use a mixture of means: essays, homework, projects, short answers, quizzes, blackboard work, journals, oral interviews, and group projects" to assess student mathematical product (National Research Council, 1989). This unit employs homework, short answers, quizzes, blackboard work, and group projects to evaluate student performance. Among the chosen methods of assessment, group projects is the newest alternative that needs some explanation.

Group projects are designed to achieve the following purposes: encouraging student collaboration, creating a connection between mathematics and students' real-world experiences, and testing students' ability to select appropriate mathematical tools and techniques and to use them effectively. Since these group projects are larger than past assignments, students need to 
work together in and out of class to complete their work. This is consistent with the NCTM's suggestion that students should have the opportunity to collaborate with others in solving problems and attaining common objectives. Given the fact that students are responsible for selecting topics of their interest, students will have the opportunity to observe that mathematics can be applied to numerous real-world situations. As a result, students may recognize the goal their mathematics teachers want them to see: the connection between mathematics and their daily lives.

A guideline for students' mathematics projects is described in Appendix A: Student Assessment Packet.

\section{Lessons}

The lessons are from page 33 to page 242 . 


\section{DAY 1 - INTRODUCTION TO THE UNIT Objectives}

1) Present students with work (using film, newspaper or magazine clippings) that employs statistics

2) Form groups and discuss group organizing

\section{Materials}

Handouts:

Green Sheet (individual)

Student Assessment Packet (individual)

Group Organization (individual plus one copy for each group)

List of Students and Card Selection (teacher only)

Homework-1 (individual)

Other materials

Samples of work that use statistics

Futures, Statistics and Sports Performance (the first 15 minutes)

A TV monitor and VCR player

\section{Procedure}

1) Form New Groups: [15 minutes]

Most activities of the unit require students to work together in small groups of at least two and at most four, preferably four. Set up your classroom so that students sit in groups of four. There are several ways to randomly select members for groups. One way is asking each student to pick a card from a deck so that each group will correspond to a particular rank, or "number." For example, if you have a class of 32 students, take 32 cards from Ace through 8 
(four of each corresponding to the four suits). Have students take a card from the deck without looking. Students who draw the same rank will form a group.

Circulate the List of Students and Card Selection for students to record their names, ranks, and suits for record keeping. Distribute copies of Group Organization to groups so that the number of copies per group is one more than the number of group members. Discuss the positions mentioned in this handout and have students record their roles on all copies for the records. Group members will keep one copy for themselves and hand in the extra copy to the teacher. In the case of a group with less than four students, the group facilitator can also be the group reporter.

Suggest to students that they may want to exchange phone numbers with group members. This will allow them to contact each other to discuss the project or to find out what they missed in case of absences.

2) Introduction to the Unit: [25 minutes]

Inform students that statistics is a branch of mathematics dealing with the collection, analysis, interpretation, and presentation of masses of data. Show students the poster displaying some articles from newspaper and magazines that apply statistics to support their points. The film that students are going to watch will also give them an idea how statistics is usually used. Here you may want to talk a little bit about Jaime Escalante, the teacher in the film, before showing it.

After the film ends, distribute one sheet of paper to each group. Have the groups report what they learned from the film. This activity not only gives 
students the opportunity to familiarize themselves with group members but also gives the teacher the chance to assess their writing skills. Remind students to write all group members' names on their report.

If time permits, let students volunteer to present their group report. Otherwise, collect them. Distribute Homework-1, Green Sheet, and Student Assessment Packet (see Appendix A). 


\section{GROUP ORGANIZATION}

\section{Name}

1)

2)

3)

4)

\section{Facilitator}

1) makes sure everyone understands instruction

2) makes sure all group members participate

3) calls the teacher if no one in the group knows the answer

4) makes sure that all members of the group get the help they need

\section{Recorder}

1) makes sure group has notes or diagrams from the discussion

2) makes sure everyone completes an individual report

\section{Reporter}

1) organizes the group's report to the class

2) discusses with the group what will be reported

3) briefly summarizes the activity to introduce the report to the class

\section{Resource}

1) collects whatever materials are needed to complete the activity

2) makes sure group makes use of the resource materials

3) looks up relevant information in reference works, text, and other materials available to the group 
LIST OF STUDENTS AND CARD SELECTION

Name

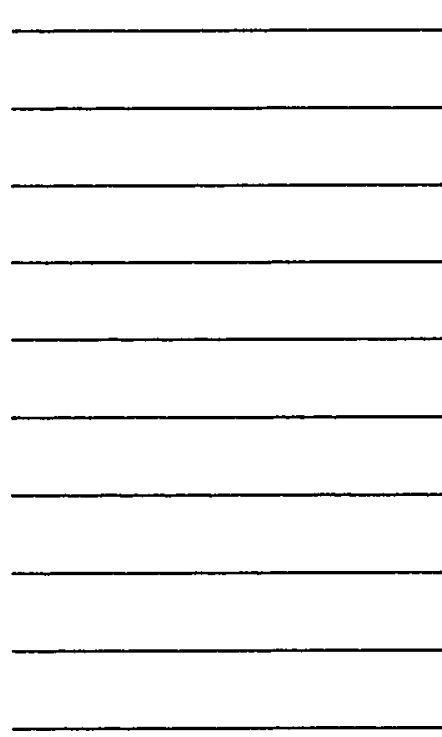

Rank of card Suit of card Group
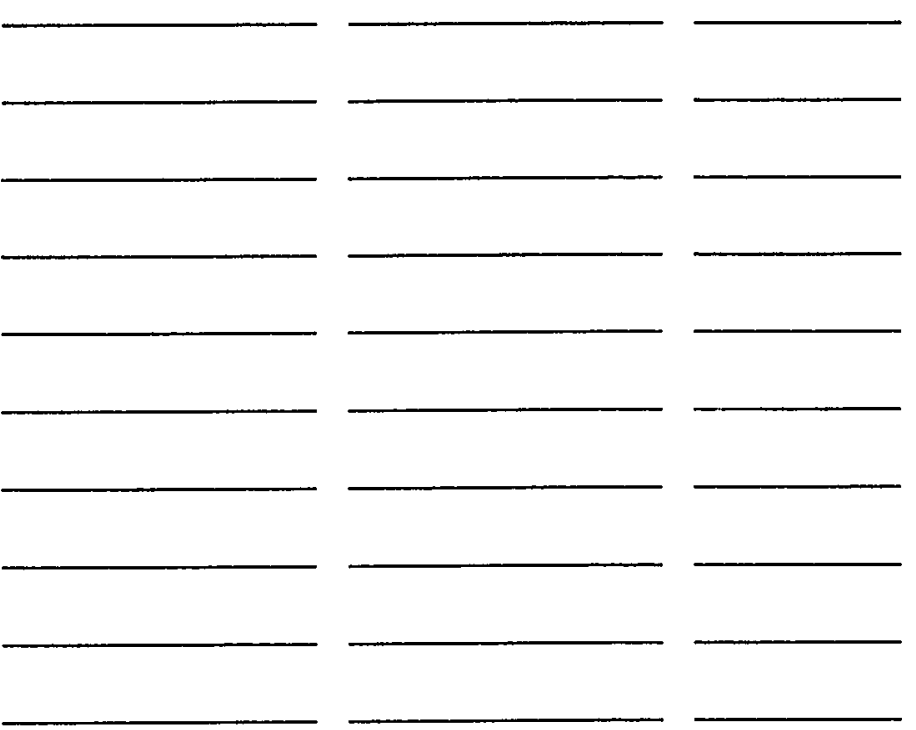
GREEN SHEET

Semester:

Teacher:
Unit: Statistics

Room:

Time:

Text: Exploring Statistics In a Middle School Classroom

UNIT OBJECTIVES: Students will learn what a statistician does in his or her job.

In other words, students will learn to collect, analyze, interpret, and present

data. Students will learn how to choose appropriate graphs, appropriate

statistical measures (mean, mode, median) to describe data collected.

Students will also learn how to interpret data collected by themselves and also

by others. Students then will be asked to make reasonable decisions based on their analysis of data.

UNIT REQUIREMENTS: To complete the unit the following requirements must be met:

1) Students are responsible for all individual classwork, homework, and any work that must be done outside the class.

2) Students shall attend and actively participate in lectures, class and group discussions.

3) Students must revise (do) and resubmit any work that is returned with comments like: Revision Needed, Do within 3 days starting on the day the work is returned.

UNIT GRADING: Student unit grade will be determined by the following:

1) Student mathematical products: classwork (group, individual), homework, student portfolio, quizzes (pair, individual), group final project. 
2) Student performance: teacher's observation (group observation, individual observation), group's presentation.

Details of the assessment system are discussed in the Student Assessment Packet (see Appendix A). 
HOMEWORK-1

Individual

1) Read the Green Sheet and the Student Assessment Packet carefully.

2) Write a letter to a classmate who could not attend class today so that he or she knows what we did. 


\section{DAY 2 - SURVEYS}

\section{Objectives}

1) Discuss what a survey is

2) Examine different types of surveys

\section{Materials}

Handouts

Worksheet-2A (group)

Worksheet-2B (individual)

Homework-2 (individual)

\section{Other materials}

Clippings of actual surveys such as: class survey using questionnaire, mailed questionnaire, telephone survey, personal interview. Be sure that the clippings are appropriate for student reading level.

\section{Homework Discussion}

Green sheet: There is no homework to be discussed; however, you may want to spend a few minutes to discuss the Green Sheet. Make sure students understand what is expected of them during the time allotted for this unit.

\section{Procedure}

1) Introduce surveys: [5 minutes] Have students share their knowledge of polls and surveys with the class. Common answers include predictions for presidential elections, TV ratings, and opinions on social issues. Ask students for their personal, informal use of polls or surveys. For example, in deciding what TV show to watch, they may have asked all family members what show they liked or did not like and then decided on the channel that the entire family could enjoy. 
2) Worksheet-2A: [15 minutes] Distribute Worksheet-2A to all students. Have students work in groups to answer the questions in this worksheet in writing. Students then put their answers on the chalkboard in the space provided. You may want to divide the chalkboard into columns, one column for each question. Hold a class discussion on Worksheet-2A. You may want to use the background provided in the Notes to Teachers section for additional information.

3) Worksheet-2B: [30 minutes] Distribute Worksheet-2B to all students and a clipping of a survey to each group. Students will have about 15 minutes to complete Worksheet-2B. Encourage students to work together to find the answers, but they must write up their own answers.

Have the group reporters present what they have found in their respective articles. Be sure to display the transparency of each article so that all students will have an idea of how that article about a survey appears in a newspaper or a magazine. Use the students' findings to introduce four different types of surveys, also the advantages and disadvantages of these surveys.

Divide the chalkboard in such a way that comparison among the surveys can be easily observed.

Collect all worksheets for checking so you can check for students' abilities to express themselves in writing. This is also an opportunity for you to see how students work with other students to obtain answers.

4) Homework-2: [1 minute] Distribute Homework-2. This homework is selfexplanatory; however, if time permits, you may want to have students join you in reading it over. 


\section{Notes to Teachers}

People often use surveys to gather information concerning likes and dislikes, the circumstances, or plans of groups of people. In daily iife, surveys are often used in an informal way such as helping people to decide what TV show the entire family will watch, to decide what kind of pizza the family will order for dinner, or to decide what type of music will be played at a birthday party. Formally, surveys are conducted by federal, state, and local governments, as well as by private enterprises, universities, political candidates, and non-profit groups. These people use results of surveys to help plan for the future in their respective fields. For example, the US government uses the information obtained from the census to determine the number of seats of each state in the 435-member House of Representatives, to estimate the level of unemployment, income, education, and other measures. Another popular type of survey is the opinion poll. The leading polling organizations-Gallup, Roper, Harris, New York Times/CBS- ask a sample of people about their opinions on politics, consumer products, religion and education. These organizations then use the results to predict the opinions of the larger population on the issues of concerns.

Surveys are differentiated according to methods of collecting data.

1) Class survey (questionnaire)

a. Advantages: quick and complete, questions worded the same.

b. Disadvantages: short time to think of response, not taken seriously, influenced by friends.

2) Mailed surveys (questionnaire) 
a. Advantages: time to think when responding, questions worded the same.

b. Disadvantages: not all surveyed will respond.

\section{3) Telephone survey}

a. Advantages: surveyors can call repeatedly until a response is made, time of survey can be fixed.

b. Disadvantages: surveys are not taken seriously, short time to think of response, intrusion of privacy.

\section{4) Personal interview}

a. Advantages: a good percent of people surveyed respond, surveys are taken more seriously.

b. Disadvantages: Interviewers need training, interviewers may influence response or be inaccurate in recording responses, it is a slow process to obtain answers. 
WORKSHEET-2A

Group

What is a Survey?

Answer the following questions. Answers must be recorded by the group's reporter.

1) What is a poll or a survey? A poll or a survey is a sampling or collection of opinions on a subject.

2) Why would someone want to conduct a survey? They want to gather information concerning likes and dislikes, the circumstances, or plans of groups of people.

3) What kind of questions do you think they ask? Answers vary. For example: What is your favorite fast food? Do you feel safe at home? Should we establish curfew for teenagers in a particular city? Do you approve of the way the president is handling his job? 4) What kind of information is obtained from the poll or the survey? Answers vary. For example: people's political opinions, their views on religion and education, their favorite products.

5) How do you think the results are used? The results are used for everything from planning a presidential candidate's campaign strategy to deciding the flavor of a new toothpaste. 
Use the survey given to your group to answer the questions below. Group discussion is allowed; however, each student must turn in his or her own written worksheet. Use the back of the handout if you need more space.

1) Name of the newspaper or magazine. Date of print. Answers vary.

2) Why was the survey conducted? The purpose of a survey may not be stated in the supplied article. If the purpose of the given survey is not written, you may want to suggest that students guess the purpose based on the data collected.

3) What is (are) the survey question(s)? Answers vary.

4) How many people were surveyed? Who were they? Answers vary.

5) How were the data collected? (by telephone, by questionnaire, etc...)

\section{Answers vary.}

6) What are the advantages of the above method of collecting data? What are the disadvantages? Answers vary. Check the "Notes to Teachers" section.

7) What are the results of the survey? Answers vary.

8) Was there any graph used to display the data? If there is, describe the graph. Answers vary.

9) How do you think the results will be used? Answers vary. 


\section{HOMEWORK-2}

Individual

Part A: Collect a clipping from a newspaper or magazine that contains a survey. Staple the clipping to the back of this paper and answer the following questions. If you need additional space for your answer, use the back of this paper.

1) Name of newspaper or magazine. Date of print. Answers vary.

2) What questions were asked in the survey? Answers vary.

3) How many people were surveyed? Who were they? Answers vary.

4) What was the method of survey? What are the advantages and disadvantages of this method? Answers vary.

5) What are the results of the survey? Answers vary.

6) Is there any graph used to display the data collected in each survey? If there is, describe it. Answers vary.

7) How do you think the results will be used in each survey? Answers vary.

Part B: Select a topic and develop a plan for a survey you may want to conduct.

1) What is your goal? Answers vary.

2) What is your survey question? (one question only) Answers vary.

3) How many people do you plan to survey? Why? Answers vary.

4) Who are the people you plan to interview? Why did you choose them?

\section{Answers vary.}

5) How will you contact these people? What are the advantages and disadvantages of this method of obtaining answers? Answers vary. 6) What problem do you foresee in conducting your survey? Answers vary. 


\section{DAY 3 - DEVELOPING SURVEY QUESTIONS}

\section{Objectives}

1) Develop guidelines for writing survey questions

2) Write survey questions

\section{Materials}

\section{Handouts}

Worksheet-3A (individual)

Worksheet-3B (group)

Worksheet-3C (individual)

Homework-3 (individual)

\section{Homework Discussion}

Homework-2: [5 minutes] Have students compare newspaper or magazine surveys with group members and select one that has the most interesting results. Groups' reporters summarize the chosen surveys to the class. You may want to limit the number of reports to two or three due to the length of today's lesson.

\section{Procedure}

1) Worksheet-3A: [20 minutes] As part of the unit on surveys, students need to develop techniques for writing effective survey questions to use in their individual projects. The activities in today's lesson help students become aware of important issues concerning survey questions and develop their own guidelines for writing survey questions.

Furnish each student with Worksheet-3A. Ask students to complete the Student Questionnaire and answer the questions that follow the questionnaire. Students will need approximately 10 minutes to complete this first worksheet. 
Hold a 10-minute discussion on Worksheet-3A. This discussion should include answering questions on the worksheet and helping students to:

a. Recognize different types of data [Numerical (Quantitative) and Qualitative]

b. Recognize different types of questions [Response is fact or opinion, response is quantitative or qualitative]

2) Worksheet-3B: [20 minutes] Distribute Worksheet-3B to all students. Plan to give students about 10 minutes to complete this assignment and to spend about 10 more minutes to share answers and ideas. Before letting students work in groups, you may want to pose the following questions to guide students through the first pair of survey questions.

a. Which team do you think the writer prefers? Why do you think so?

b. Will the results accurately reflect the comparative feeling people have for the 49ers and the Raiders?

c. Which question may influence people to answer differently from what they really think? Why?

d. What rule in writing effective survey questions does this example suggest?

Hold the class discussion on Worksheet-3B. You may want to write all guidelines that were developed by students on the board or the overhead projector. Remind group reporters that they must make sure everyone in the groups has notes on guidelines for writing survey questions.

Students may develop several rules. Nevertheless, their guidelines should at least include the following points: 
a. Try to avoid using words or extra information that may influence or change a person's thinking.

b. Use terms that everyone will understand the same way.

c. Write questions that are not too long and should be easily understood.

d. Make sure that there is one and only one answer for each survey question.

3) Worksheet-3C: [ 5 minutes] If there is time, spend about 5 minutes on Worksheet-3C. Otherwise, students will complete Worksheet-3C as a part of their homework. Distribute Homework-3.

\section{Notes for Teachers}

There are two attributes of questions:

1. Response is fact or opinion.

2. Response is quantitative or qualitative.

There are two types of data we can gather:

1. Data are numerical (Quantitative).

2. Data are non-numerical (Qualitative).

An effective survey question must be exact, clear, and unbiased. 
WORKSHEET-3A

Individual

\section{Student Questionnaire}

1) Circle: Male or Female

2) In what country were you born ?

3) What is your height?

4) What is your favorite fast food restaurant?

5) What is your favorite TV program ?

6) How long do you spend talking on the phone each day?

Watching TV? School night weekend

Listening to music? (round to the nearest 15 minutes)

7) How many hours of homework did you do yesterday? (round to the nearest 15 minutes) Hour(s) Minutes

8) Which of the following occupations would you most like to pursue after high school? Mark $\mathbf{X}$ next to your choice.

— barber/beautician

_ food service worker

_ pilot

_ homeworker

_ salesperson

— Other

_ computer programmer

_ bookkeeper

_ teacher

_law enforcement officer

_ engineer

_ scientist

_ nurse

_mechanic

_ entertainer

_ doctor

veterinarian

- lawyer

_truck driver

_ flight attendant

9) Why did you choose your profession? 
WORKSHEET-3A (Continued) Individual \& Group

Work with your group's members to answer the following questions.

1) Were all the questions clear to you? Explain. Answers vary.

2) Did you always know what to answer? Why? Answers vary.

3) Do you think everyone else answering the survey questions would know what to answer? Why or why not? Answers vary.

4) What type of responses were required in the questionnaire? Multiple choice?

Numerical value? Short answer? Fill-in-the-blank? Responses can be multiple choice, numerical value, short answer, or fill-in-the-blank.

5) What do you think the data (the answers) will look like when they are combined and organized? Data can be quantitative or qualitative.

6) What questions do you think the writers of the questionnaire are going to try to answer with the information they obtain? Answers vary.

7) How do you think the data will be used? Answers vary. 


\section{WORKSHEET-3B}

Group

\section{Analyze survey questions}

This worksheet contains pairs of potential questions for a survey. You and your group's members are to pick the item that you would prefer to use on your own survey, defend your choice, and try to develop guidelines for writing effective survey questions.

Pair A: 1) On a scale of 1 (low) to 10 (high), how well do you like the great football team San Francisco 49ers that won 4 Super Bowls in the 1980 s?

2) On a scale of 1 (low) to 10 (high), how well do you like the football team Los Angeles Raiders?

Your answer: question (2).

Why: The word "great" in question (1) can influence people to answer the question differently from what they really think.

Guidelines for writing effective survey questions: Try to avoid including words or extra information that may influence or change the way a person thinks. Surveys are usually conducted to find out how people think on their own.

Pair $B:$ 1) How many brothers and sisters do you have?

2) Are you a member of a large family? Yes No

Your answer: question (1).

Why: "large family" can be interpreted in different ways.

Guidelines for writing effective survey questions: Make sure that you use terms that everyone will understand the same way. 
Group

Pair C: 1) Should the explosion in today's technological capabilities have an impact on school curriculum involving applications in mathematics? Yes No

2) Should school-aged children be allowed to use calculators for problem solving in mathematics class? Yes No

Your answer: question (2).

Why: The first question is very long and not easy to understand. Guidelines for writing effective survey questions: A survey question should be easily understood and not too long.

Pair D: 1) Should elementary school or high school students be allowed to use calculators on all their mathematics assignments? Yes No 2) Should calculators be allowed on all mathematics assignments
a. in elementary school?
Yes
No
b. in high school?
Yes
No

Your answer: question (2).

Why: A person may feel differently about elementary school and high school uses of calculators.

Guidelines for writing effective survey questions: A survey item should ask only one question. The person responding should never feel that there may be two different answers. 
WORKSHEET-3C

Individual

Biased Versus Non-biased Questions

Topic: Violence in schools

1) Create a non-biased question about the topic above.

Answers vary.

2) Change the question in part (1) so that it becomes a biased question.

Answers vary. A sample is biased when a group of a population is being "favored" over other groups.

3) Explain how people can recognize your biased question. Answers vary. 
HOMEWORK-3

Part A: These items are the first draft of a survey prepared by a seventh-grade class. Read each question carefully. Rewrite each item as you think it should appear on the final draft. Explain any changes you make.

\section{Survey on Calculators in the Junior High School}

1) How old are you?

2) Do you consider yourself a good mathematician? Yes No

3) Which type of calculator do you prefer to use?
a. solar powered
b. battery powered
c. scientific
d. other:

4) How often do you use a calculator and for what purposes?

5) Based on recent research, it has been found that technological advancement in today's society will eventually affect the pedagogical ideology relating to the use of electronic devices in schools. Do you agree or disagree?

$$
\text { agree disagree }
$$

6) No student who has not demonstrated success in basic skills should be permitted to use a calculator in the classroom. Do you agree or disagree?

$$
\text { agree disagree }
$$

7) Should immature junior high school students be exposed to the mindless activity of using a calculator to solve mathematical problems?

$$
\text { yes no }
$$


Individual

8) When should calculators be used in school?

Part B: Suppose you were asked to select one of the following ideas to investigate in a survey of students at your school.
a) your dream car
e) favorite brand of soft drinks
b) favorite school subject
f) things that make you happy
c) favorite recreational place
g) things that make you sad
d) favorite type of music
h) what you would want in change about your math class

1) Give 3 examples of good survey questions on your chosen topic. Why are they considered to be good survey questions? Good survey questions should follow the four guidelines developed in Worksheet-3B. 2) List 3 qualities of a good survey question. Check Worksheet-3B. 3) Give 3 examples of poor survey questions on your topic. Why is each of them considered to be a poor survey question? Check Worksheet-3B. 


\section{DAY 4 - POPULATION AND SAMPLE}

\section{Objective}

Examine how the size and nature of a sample group can affect the results from

a survey.

\section{Materials}

\section{Handouts}

Worksheet-4A (individual)

Worksheet-4B (individual)

Homework-4 (individual)

\section{Other materials}

A transparency of Class Data-Food / Gender

Newspaper or magazines that contain articles that use sampling to make a prediction (They should be available for Homework-4).

\section{Homework discussion}

Homework-3: [5 minutes] Discuss part (A) in detail. It is important for students to participate in this discussion because their answers will give you an idea of how much they understand the importance of effective survey questions. Since today's lesson contains many activities, you may want to check part (B) yourself. This part will give you an idea of how much each student understands the lesson on writing effective survey questions.

\section{Procedure}

1) Introduction: [10 minutes] Usually the data from a survey are collected from a small group of people, called a sample, but the goal is to predict something about a larger group of people, called the population. You may want to give 
students a hypothetical situation which vill help students to recognize that surveying a well-chosen sample is better than surveying the entire population in terms of time and money. The following example is one of several hypothetical situations.

a. Situation: August Boeger school wanted parents' opinions on the issue of a longer school year. The question "Do you favor a longer school year?" would be posed to August Boeger parents. There are approximately 500 students at August Boeger. How many parents should the school survey on this issue?

b. Leading questions: What is the advantage of surveying parents of all 500 students? [Obtaining the exact answers] - What is (are) the disadvantage(s) of surveying all parents? [Time consuming, some parents cannot be contacted directly, mailed survey may not be returned]

c. Conclusion: A manageable and representative sample instead of the entire parent population should be surveyed.

In today's activities, students will learn how the size and nature of a sample determine whether the results from a survey can be used to make reliable predictions about the larger population. Suppose the school administrators decide to survey a sample of parents. Let's examine some samples.

Pose the following questions:

\section{A. Size of a sample}

a. What do you think about the results of a sample for the above survey in which we asked 20 parents? [The results of a small 
sample may not reflect the majority opinions of the population.]

b. What do you think would happen if you decide to survey all 500 parents? [A large sample could become a costly and tedious project.]

c. Conclusion: Samples must be large enough to be controlled and to reflect the majority opinions of the population.

B. A sample for a survey must also be representative

a. What would happen if we only use the basketball team members' parents in our survey of the longer school year issue? [Answers will not reflect the majority of the population. These parents may want a longer school year so that their children have a place to practice their sports.]

b. What would happen if we only survey parents who are teachers (not necessarily at August Boeger)? [These parents may not want a long school year for a long school year means a shorter summer which will lead to less time for professional enrichment and vacation.]

c. Conclusion: Samples must not consist only of parents of some special-interest groups. They must reflect the typical members of the population.

2) Worksheet-4A: [20 minutes] Furnish each student with a copy of Worksheet4A. Students must complete the survey and answer questions pertaining to their respective groups (questions $1,2,3$ ). 
Form larger groups by combining two regular groups. Students will have about 10 minutes to combine data and complete questions (4), (5), (6) of Worksheet-4A.

Spend the next 15 minutes gathering data for the entire class, allowing students to answer the remaining questions on Worksheet-4A (questions 7,8 , 9), and conducting a discussion on questions (7), (8), (9). This discussion should help students to realize that a sample must be large enough in order for the results to be representative of the population.

3) Worksheet-4B: [5 minutes] If time permits distribute Worksheet-4B to all students. If not, students will complete Worksheet-4B as a part of their homework.

4) Homework-4: [5 minutes] Do not collect worksheets because students will need their classwork in order to do their homework. Distribute Homework-4 and go over the homework with students. Remind students that there are newspapers available for them to take home for today's homework.

\section{Notes for Teachers}

CLASS DATA

\begin{tabular}{|l|l|l|l|}
\hline FOOD/GENDER & FEMALE & MALE & CLASS TOTAL \\
\hline & & & \\
\hline & & & \\
\hline & & & \\
\hline
\end{tabular}




\section{Fast Food Survey (Size of Sample)}

Alma Alvarez, a reporter for the August Boeger Bobcats, was writing an article on a typical student at August Boeger Middle School. Since all students must take a mathematics class, Alma Alvarez sent the following survey to some math classes. The results of this survey helped this reporter to know which fast food a typical August Boeger student likes.

Let's duplicate her survey, using the class as the population. Your task is to predict what type of fast food the students in the class, or the population, prefer. You will make your prediction based on surveying different groups of selected students, or different samples.

1) Have all students complete the following survey.

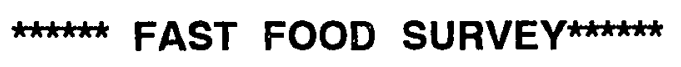

Period Grade Age Math class Check one: male female

What is your favorite fast food? 
Individual \& Group

2) One-group survey: Organize the responses from your group to show results for females, males, and all members in your group. Record the responses in Table 1.

Table 1:

\begin{tabular}{|l|l|l|l|}
\hline Food / Gender & Female & Male & Total \\
\hline Hamburger & & & \\
\hline Pizza & & & \\
\hline Fried Chicken & & & \\
\hline Hot Dog & & & \\
\hline
\end{tabular}

3) Based on the data from Table 1, make predictions about the class' answers. For example, if your data show that more female group members like pizza than male group members, you may want to predict that more female classmates like pizza than male classmates.

a. What is the favorite fast food of the entire class?

b. What is the favorite fast food of the female students?

c. What is the favorite fast food of the male students?

4) Two-groups survey: Combine the data from your group with a neighboring group. Record the responses in Table 2. 
Table 2:

\begin{tabular}{|l|l|l|l|}
\hline Food / Gender & Female & Male & Total \\
\hline Hamburger & & & \\
\hline Pizza & & & \\
\hline Fried Chicken & & & \\
\hline Hot Dog & & & \\
\hline
\end{tabular}

5) Use the data from Table 2 to make predictions about how your entire math class would respond to the survey.

a. What is the favorite fast food of the entire class?

b. What is the favorite fast food of the female students?

c. What is the favorite fast food of the male students?

6) Class survey: Organize data from all groups and record them in Table 3.

Table 3:

\begin{tabular}{|l|l|l|l|}
\hline Food / Gender & Female & Male & Total \\
\hline Hamburger & & & \\
\hline Pizza & & & \\
\hline Fried Chicken & & & \\
\hline Hot Dog & & & \\
\hline
\end{tabular}

a. What is the favorite fast food of the entire class?

b. What is the favorite fast food of the female students?

c. What is the favorite fast food of the male students? 
Individual \& Group

7) Compare the three predictions from part (3) with the three answers from part (6). How well do the data from your one-group sample predict the responses of the whole class? Answers vary.

8) Compare the three predictions from part (5) with the three answers from part (6). How well do the data from your two-group sample predict the responses of the whole class? Answers vary.

9) Can you predict the responses for the whole class based on answers from only a group of four? Why or why not? Answers vary. 


\section{Fast Food Survey (How Representative the Sample Group Is)}

1) Can you predict the responses of the whole class based on the answers from the female students only? Why or why not? Answers vary. However, students should know that the data collected do not represent the entire population's responses.

2) Can you predict the responses of the whole class based on the answers from the ESL (English As Second Language) students only? Why or why not?

Answers vary. Students should know that this type of sample is not representative.

3) The chosen sample must result in data that are typical of the entire class population (representative). How would you select students for your sample group? Answers vary. Students should know that a random sample may not be representative. 
HOMEWORK-4

Individual

Part A: Use the "Fast Food Survey" to survey 5 students in school. Tally the data and record them on your own paper. You will share your data with the entire class in the next meeting.

\begin{tabular}{|l|l|l|l|}
\hline Food / Gender & Female & Male & Total \\
\hline Hamburger & & & \\
\hline Pizza & & & \\
\hline Fried Chicken & & & \\
\hline Hot Dog & & & \\
\hline
\end{tabular}

Conclusion:

Part B: Understanding population and sample.

1) Define population and sample. Give an example. A population is a group of people whose opinions or views are of interest to someone else.

2) Suppose your math class has been hired by Alma Alvarez, an entrepreneur who wishes to open some type of fast-food restaurant near your school. It will be your job to find out what kinds of fast food August Boeger students prefer. The results of your investigation will help this entrepreneur to decide on the type of fast-food restaurant she will open.

Your task is to predict what type of fast food the students at August Boeger, or the population, prefer. You will complete this task by surveying selected students, or the sample. 
Individual

a. There are about 500 students attending August Boeger Middle School. How big must your sample be in order for the results to be true to the population? (Size of a sample) Answers vary.

b. What type of results would you get if you only survey eighth graders? (Representative sample) Answers vary. The results do not reflect the responses of the population.

3) Will the information from the survey question be what is needed for Ms. Alvarez to determine which fast food to serve? Why or why not? Answers vary.

4) Is there other information that should be collected? Suggest improvements for the questionnaire. Answers vary. The prices: how much the students are willing to pay for fast food items.

Part C: Find a newspaper or a magazine article, or photocopy a portion of a reference book that uses sampling to make prediction. Describe the size and type of people in the population, and those in the sample that was used.

Answers vary. 
DAY 5 - RANDOM SAMPLING

\section{Objective}

Decide if a sampling method is a random sampling

\section{Materials}

Handouts

Worksheet-5 (individual)

Homework-5 (individual)

\section{Other materials}

Class activity 1: 2" $\times 2 "$ orange blank cards. Number of these cards is equal to the number of the students in the class

Activity 1 : Ten 2"x2" red cards. Number them 1 to 10

Activity 2: Two sets 2"x2" yellow cards. Number the first set from 1-X, where $X$ is the number of female students, and the second set from 1-Y, where $Y$ is the number of male students

Activity 3: 2"x2" green cards. Number these cards from 1 to $(X+Y)$, where $X$ is the number of female students and $Y$ is the number of male students

\section{Homework Discussion}

Homework-4: [5 minutes] Tally part (A) data collected by students. Ask students for their prediction based on the result of this survey. You may want to ask students for their opinions on the validity of their predictions. Part $(B)$ can be used to measure individual understanding of population and sample. 


\section{Procedure}

1) At the beginning of the class, distribute ten 2 "x2" red cards (numbered from 1 to 10$)$ to the first ten students who enter the classroom. Tell students to hold on to the cards for they will need these cards for Activity 1, Worksheet-5.

2) Introduction: [15 minutes] After determining the size and the types of subjects for a sample, statisticians must develop a process for selecting people to be in the sample so that their opinions closely reflect the opinions of the targeted population. There are several types of selection processes; however, in this unit we examine only one type of selection process, the random sampling. Today's activities will discuss what random sampling is and when a selection process can be called a random sampling.

Give a short introduction about random samples and random sampling. At this time all students must take notes for later use. You may want to remind students what a sample is before introducing this lesson.

Random sample: A sample is random if it is selected so that:

a. Each member of the population is equally likely to be chosen.

b. The members of the sample are chosen independently of one another.

Random sampling: is a selection process that produces a random sample

Use the following examples to demonstrate your point. The first one gives a random sample and the second one does not.

Class Activity 1: Inform students that we want to select a random sample of 10 students from this class for a survey on favorite singers. Distribute $2 " \times 2 "$ orange cards to all students. Have students put their names on the cards (tell 
them not to fold the cards). Put the cards in a box, mix them up, and draw 10 cards. Record the names of the selected students on the overhead.

Pose the following questions to students (it is important for the students to answer these questions themselves):

a. Does each student have the same chance of being chosen? [Yes, all students are equally likely to be chosen.]

b. Did we let best friends staple their cards together? [No] Did we do anything to interfere with drawing cards individually? [No. Therefore, the members are independently chosen.]

The answers "yes" for part (a) and "no" to part (b) allow students to conclude that the sample is a random sample. Since the selection process produces a random sample, it is called a random sampling.

Class Activity 2 : Let's select the ten students in the first class activity by choosing the first ten students who raise their hands. Pose the following question to students:

Question: Does everyone have the same probability to be chosen? [No, some students are shy so they do not raise their hands. Thus, they have no chance of being chosen. Since not all students have the same chance to be selected, the sample is not a random sample.] 3) Worksheet-5: [15 minutes] Distribute Worksheet-5. Inform students that the whole class will do the three activities in Worksheet-5 together; however, they will be responsible for duplicating the procedures of these activities in writing for Worksheet-5.

Activity 1:

Goal: Select the first ten students to enter the room. 
Procedure: Hand out ten cards, each one has one number between 1 and 10 on each of them, to the first ten students who enter the class [This task was performed at the start of class]. Ask those ten students to write their names on the board, under the column "Activity 1 The first ten."

\section{Activity 2.}

Goal: Suppose there are $X$ female students and $Y$ male students in the class. Select a sample of 10 students from the class by randomly picking 5 female students out of $X$ and 5 male students out of $Y$.

Procedure: Assign the male students with numbers from 1 to $Y$. From a box that contains "2x2" yellow squares with numbers from 1 to $Y$, randomly select 5 numbers. The male students with these numbers are in the sample. Assign the female students with numbers from 1 to $X$. From a box that contains "2x" 2 yellow squares with numbers from 1 to $X$, randomly select 5 . Write the names of these 10 students on the board, under the column marked "Activity 2-Five students from each set." Activity 3 :

Goal: Suppose the class has $X$ female students and $Y$ male students. Select a sample of 10 students by randomly picking their assigned numbers from a box.

Procedure: Assign each student a number from 1 to $(X+Y)$. The girls get the numbers from 1 to $X$ and the boys the numbers from $(X+1)$ to $(X+Y)$. Mix 2"x2" green squares with numbers from 1 to $(X+Y)$ on them in a box, and randomly select 10 squares from the box. Place the names of 
students whose numbers were picked on the board, under the column "Activity 3-Ten students from one set."

Remind students of the two criteria for a sample to be a random sample (It is a good idea to leave the definition for a random sample on the board).

Students now work in groups to decide which of the above methods of selection produces a random sample.

4) Group presentation: [10 minutes] Each group is responsible for presenting one activity. Collect the worksheets.

5) Homework-5: [5 minutes] Distribute Homework-5. Be sure that the students understand the questions in the homework.

Notes to Teachers

No notes. 
For each of the five activities, complete parts $a, b$, and $c$.

\section{ACTIVITY 1:}

1) Goal: Select ten students.

2) Procedure: Select the first ten students entering the classroom.

3) Does this selection process produce a random sample? Why or why not? No, students whose previous classrooms are far away are unlikely to be the first to enter the classroom.

\section{ACTIVITY 2:}

1) Goal: Select ten students.

2) Procedure: Select ten students from the class by randomly picking five female students from the female population and five male students from the male population.

3) Does this selection process produce a random sample? Why or why not? Not a random sample. The number of female (male) students in the sample is restricted.

\section{ACTIVITY 3:}

1) Goal: Select 10 students.

2) Procedure: Randomly pick their assigned numbers from a box.

3) Does this selection process produce a random sample? Why or why not? Yes, the sample satisfies the two conditions required for a random sample. 
HOMEWORK-5

Individual

1) Describe how you would select a sample of 50 eighth graders from the school population of 500 students using random sampling. Answers vary. 2) Which of the following sampling methods produce a random sample from a class of 36 students? Explain.

a. Select the first six students to enter the room. Not random.

b. Select those students whose phone numbers end with the digit 4.

\section{Random.}

c. Suppose that the classroom has six rows of chairs with six chairs in each row. Assign the rows the digits 1 through 6 . Throw a die and place all the students in the row corresponding to the number on the die in the sample.

\section{Not random}

d. Suppose the class has 18 boys and 18 girls. Assign each student a number from 1 to 36 . The girls get the numbers 1 to 18 and the boys the number from 19 to 36 . Write numbers 1 to 36 on each of the 36 pieces of paper and put the paper in a box. Select six pieces. Place the students with the chosen numbers in the sample.

\section{Random.}

3) A newspaper article began, "Almost half of the USA's secretaries would rather work for a man than a woman, even though a male boss is more likely to ask them to clean the coffeepot, says a Working Women Survey" (USA Today, April 23, 1986). This is the result of a "poll of 1,100 readers in the magazine's May issue." Of these readers, $46 \%$ prefer to work for a man, $5 \%$ for a woman, $49 \%$ say it doesn't matter. 
Individual

a. Is this a random sample? Explain. No, because the survey depends on the people who return the questionnaire.

b. What population do the results apply to, according to the newspaper?

\section{U.S. secretaries.}

c. Will all USA secretaries have the chance to be included in this poll?

(Hint: What kind of secretaries would not read Working Women?)

No, male secretaries may not read Working Women. 
DAY 6 - QUIZ 1

Objectives

1) Assess students' understanding of developing survey questions, choosing reasonable samples, and selecting subjects for random sampling.

2) Discuss group projects

Materials

Handouts

Quiz 1 for pairs and for individuals

Other materials

Student Assessment Packets

Homework Discussion

Homework-5: [10 minutes] Conduct a class discussion on all questions in Homework-5. If time permits conduct a review of previous lessons.

\section{Procedure}

1) Pair Quiz: [15 minutes] Divide students into groups of two. Furnish each group with 2 copies of Test 1 (the pair version). Remind students to turn in only the final work of the pair test with the names of both members on it.

2) Individual Quiz: [10 minutes] When students hand in their pair quiz, they can pick up the individual quiz and start working on it. Collect all individual quizzes.

3) Projects: [15 minutes] Discuss the details of students' projects. All information regarding the project is in the Student Assessment Packet; however, students may need you to go over all details carefully.

4) Homework-6: Distribute Homework-6. Remind students that they will be asked to provide details about their group projects. 


\section{QUIZ 1 - DEVELOPING A SURVEY}

Pair

Suppose you and your partner are on the organizing committee of the 1995 class's graduation trip. Develop a survey plan that would help the committee to find out what the 1995 class wants to do about its graduation trip. In addition to describing the steps in your survey, you must also provide an explanation for each of the steps in this survey. You may want to know that there are approximately 500 students at August Boeger Middle School and among them there are 200 seventh graders who are expected to graduate in 1995. 
QUIZ 1 - DEVELOPING A SURVEY

Individual

Suppose you are a reporter of the August Boeger Bobcats newspaper and have been chosen to conduct a survey on violence on school campus. Describe your plan for the survey. There are approximately 500 students at August Boeger; 200 of them are seventh graders 
HOMEWORK-6

Individual

\section{Your group project}

Select a topic and develop a plan for a survey your group may want to conduct.

1) Topic:

2) What is your goal for conducting this survey? (Hint: What do you want to find out?) Answers vary.

3) What is your survey question? Answers vary. Survey questions should be easy to understand, unambiguous, and unbiased.

4) How many people do you plan to survey (size of sample)? Why do you want to survey this many people? Answers vary. Reasonable sample size for the chosen population.

5) Who are the people you plan to interview? Why did you choose them?

Answers vary.

6) How will you contact these people? Answers vary. Methods of data collection must be easy to execute.

7) What problem do you foresee in conducting your survey? Answers vary.

GROUP PROJECT: Confer with your group members on a topic for your group project. In the next class meeting, your group will be asked to provide details of your group project. 


\section{Day 7 - ORGANIZING DATA IN A FREQUENCY TABLE. Objective}

Organize data in a frequency table with intervals.

\section{Materials}

\section{Handouts}

Warm-up 1 (for half of the class)

Warm-up 2 (for the remaining half of the class) and a transparency

Worksheet-7 (Individual)

Homework-7 (individual)

\section{Other materials}

Rulers

\section{Homework Discussion}

Homework-6: [5 minutes] Have students discuss their group projects. Collect one homework from each group (the topic that was chosen by the group members). Inform students that you will return these paper with comments as soon as possible.

\section{Procedure}

1) Warm-Up Exercises: [10 minutes] Distribute the warm-up exercises: one half of each group will receive Warm-up 1 and the other half will receive Warm-up 2. Students will have 5 minutes to work on this exercise individually. When all students complete this exercise, have them work in their respective groups to discuss the following question: Which method of entering data helps you to answer the questions in the exercise quickly? Why? You may want to write these questions on the overhead. Hold a 5-minute class discussion to share 
answers and ideas. The class discussion should help students to recognize that:

a. data presented in a list are usually not well organized.

b. a frequency table is more effective than a list of numbers [Since the data in a frequency table are ordered and tallied, they can be summarized and analyzed easily.]

2) Introduction: [5 minutes] Display the transparency of the Warm-Up Exercise 2 and use it to introduce frequency tables. From this introduction students should:

a. know what a frequency table shows (it shows intervals, tallies, frequencies), know what frequency means (it is the number of times that an item occurs), know what an interval is (it is a group of consecutive numbers.)

b. understand why a frequency table is more effective than a list of numbers (Since the data in a frequency table are ordered and tallied, they can be summarized and analyzed easily.)

Be sure to define the parts of the table.

3) Table Construction: [10 minutes] Show students how to construct a frequency table, using the number of people per student's household as the set of data. While making the table, you may want to write down the procedure for making a frequency table so all students can copy it into their notes.

To make a frequency table.

Step 1: Make a table with three columns.

Step 2: List the intervals in the first column. Label this column "Intervals." 
Step 3: Label the second column "Tally." Make a tally mark in the second column next to each interval for every score that falls within that interval.

Step 4: Label the third column "Frequency." Record the total number of tally marks for each interval in the third column.

Step 5: Title the frequency table.

4) Worksheet-7A: [25 minutes] Distribute copies of Worksheet-7A to all students. Students will have about 10 minutes to complete this worksheet.

Hold class discussion to share conclusions and ideas. The main goals of this discussion are for students to:

a. know that all intervals must have the same size; i.e., each interval must have the same number of units. Like intervals show how the data are distributed. Intervals with different sizes will distort the distribution of the data.

b. know that the intervals must be continuous. If the intervals were discontinuous, some data might not be recorded in the table.

c. know that the intervals cannot overlap since overlapping allows an item to be recorded more than one time.

5) Homework-7: Distribute Homework-7.

\section{Notes to Teachers}

No notes. 
WARM-UP 1

Individual \& Group

\section{Scores on a math test.}

Mr. Smith's class took a math test on addition of integers. Mr. Smith then put the test scores into his computer as follows.

Scores on a Mathematics Test: $65,70,70,85,69,85,100,81,70,83,81,90,82$, $87,96,68,94,100,95,81,83,100,66,81,83,96,84,85$.

Mr. Smith gives an $A+$ for $100+$, an $A$ for $90-99$, a $B$ for $80-89$, a $C$ for $70-79$, a D for 60-69, and an $F$ for 59 and lower.
a) How many As are there? There are 8 As.
b) How many Bs are there? There are 13 Bs.
c) How many Cs are there? There are 3 Cs. 
WARM-UP 2

Individual \& Group

Scores on a math test.

Mr. Rodriguez's class took a math test on addition of integers. Mr. Rodriguez then put the test scores into his computer in a frequency table.

\begin{tabular}{|c|c|c|}
\hline Score & Tally & Frequency \\
\hline $60-69$ & 111 & 4 \\
\hline $70-79$ & 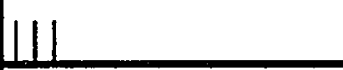 & 3 \\
\hline $80-89$ & ШUل & 13 \\
\hline $90-99$ & 111 & 5 \\
\hline $100+$ & Ш & 3 \\
\hline
\end{tabular}

Mr. Rodriguez gives an $A+$ for $100+$, an $A$ for $90-99$, a $B$ for $80-89$, a $C$ for $70-$ 79, a D for 60-69, and an F for 59 and lower.

a) How many As are there? There are 8 As.

b) How many Bs are there? There are 13 Bs.

c) How many Cs are there? There are $3 \mathrm{Cs}$. 
The following is the result of a pushup contest at San Jose State University: 20, $43,17,37,39,35,32,52,21,43,18,50,29,34,58,19,2118,50,29,34,58,19$, $21,18,24,47,30,18,29,22,23,21,56,43,27,22,30,20,25,34,52,40,36,28$, $40,43$.

Complete the following frequency tables:

Table 1

\begin{tabular}{|l|l|c|}
\hline Intervals & \multicolumn{1}{|c|}{ Tally } & Frequency \\
\hline $16-18$ & IIIII & 5 \\
\hline $19-21$ & IIII III & 8 \\
\hline $22-24$ & IIII & 4 \\
\hline $25-27$ & II & 2 \\
\hline $28-30$ & IIII I & 6 \\
\hline $31-33$ & I & 1 \\
\hline $34-36$ & IIII & 5 \\
\hline $37-39$ & II & 2 \\
\hline $40-42$ & II & 2 \\
\hline $43-45$ & IIII & 4 \\
\hline $47-49$ & I & 1 \\
\hline $50-52$ & IIII & 4 \\
\hline $53-55$ & & 0 \\
\hline $56-57$ & 1 & 1 \\
\hline $58-60$ & II & 2 \\
\hline
\end{tabular}


Table 2

\begin{tabular}{|c|l|c|}
\hline Intervals & Tally & Frequency \\
\hline $15-25$ & IIII IIIII IIIII III & 18 \\
\hline $26-36$ & IIIII IIIII III & 13 \\
\hline $37-47$ & IIIII IIII & 9 \\
\hline $48-58$ & IIIII II & 7 \\
\hline
\end{tabular}

Answer the following questions:

1) Consider the items in the recorded data and Table 1.

a. What is the smallest number in the recorded data? the largest number? Smallest: 17 / Largest: 58.

b. What is the starting number of the intervals in the first table? the ending number? Starting: 16 / Ending: 60.

c. What is the starting number of the intervals in the second table? the ending number? Starting: 15 / Ending: 58.

d. How would you choose the starting number and the ending number for intervals in a frequency table knowing the smallest and the largest numbers in the recorded data? The starting number is at most as large as the smallest number and the ending number is at least as large as the largest number.

2) Let's consider the first three consecutive intervals in Table 1.

a. What is the relationship between the last number of the first interval and the first number of the second interval? They are consecutive positive integers. 
Individual \& Group

b. What is the relationship between the last number of the second interval and the first number of the third interval? They are consecutive positive integers.

c. What can you conclude about the answers in parts (2a) and (2b)? The ending number of one interval and the starting number of the next intervai must be consecutive numbers.

3) What would happen if the intervals are not equal? (Example: 15-25, 26-29) Comparing two unequal intervals brings inaccurate results.

4) What would happen if we have two discontinuous intervals? (Example: 1618, 20-22) A value, 19 for example, may be excluded from being tallied.

5) What would happen if the first frequency table had two overlapping intervals? (Example: 16-18 and 18-20.) A value, 18 for example, may be counted more than once.

6) Compare the two frequency tables. Which frequency table provides detailed information? Explain. Table 1. The large intervals in Table 2 do not provide detailed information. For example, the interyals in Table 2 do not show that there is no one who can do 53-55 pushups. 
HOMEWORK-7

Individual

1) List the steps of a procedure which can be used to draw a frequency table.

Any list of steps that is similar to the list of steps in the "Procedure" section.

2) Three points to remember when choosing the intervals for a frequency table are that they should be equal, they should be continuous, and they should not overlap. Write a paragraph to explain why each of these points is important.

Answers are in the "Procedure" section.

3) Examine the table below. Do you notice anything wrong with this table?

Explain. The intervals overlap.

Scores on a biology test

\begin{tabular}{|c|c|c|}
\hline Scores & Tally & Frequency \\
\hline $60-70$ & Ш & 4 \\
\hline $70-80$ & $\amalg \amalg \amalg$ & 7 \\
\hline $80-90$ & ШШ & 5 \\
\hline $90-100$ & ШШШ & 10 \\
\hline
\end{tabular}

4) Make a frequency table for each set of data. For each frequency table, write a paragraph to describe what you see in that table.

a. Compact Disc Prices (Dollars): 7.99, 7.99, 10.99, 12.99, 10.99, $12.99,14.99,15.49,14.99,15.49,14.99,12.49,12.99,12.99,11.99$, $11.99,13.99,13.99,13.49,14.49$. 
Individual

Table 1

\begin{tabular}{|l|l|c|}
\hline Intervals & Tally & Frequency \\
\hline $7.00-8.99$ & II & 2 \\
\hline $9.00-10.99$ & II & 2 \\
\hline $11.00-12.99$ & IIIII II & 7 \\
\hline $13.00-14.99$ & IIIII II & 7 \\
\hline $15.00-16.99$ & II & 2 \\
\hline
\end{tabular}

b. SAT Math Scores (The maximum score is 800 and the minimum is 200): $350,420,430,510,600,375,385,310,610,620,500,475,409$, $420,450,540,480,525,495,475,650,585,490,620,535,520,610$, $390,425,610$.

\begin{tabular}{|l|l|c|}
\hline \multicolumn{2}{|c|}{ Table 2 } \\
\hline Intervals & Tally & Frequency \\
\hline $300-399$ & IIIII & 5 \\
\hline $400-499$ & IIII IIII I & 11 \\
\hline $500-599$ & IIII II & 7 \\
\hline $600-699$ & IIII II & 7 \\
\hline
\end{tabular}


DAY 8 - LINE PLOTS AND HISTOGRAMS

\section{Objectives}

1) Draw line plots and histograms.

2) Recognize the similarities and the differences among frequency tables, line plots, and histograms.

\section{Materials}

\section{Handouts}

Worksheet-8A (individual)

Worksheet-8B (individual)

Homework-8 (individual)

Other materials

Boxes of materials including rulers, markers, glue (one box per group)

9" $\times 12$ " construction paper (one per student)

Regular graph paper (one per student)

Bags of $1 " x 1 "$ one-color squares (the number of squares in each bag should be as many as the number of students in the class. Each student will get one bag.)

\section{Homework Discussion}

Homework-7: [5 minutes] Have different students read their answers for parts 1 , 2, 3. As for part 4, call for 3 volunteers to draw their frequency tables on the board; then have them defend their choices for intervals. You may want to let all three of them work simultaneously to save time.

\section{Procedure}

1) Worksheet-8A: [25 minutes] The goal of this activity is for students to see that data displayed in a frequency table can also be displayed in a line plot or a 
histogram. This activity also helps students recognize the similarities and the differences among frequency tables, line plots, and histograms.

Distribute Worksheet-8A, one sheet of construction paper, and one sheet of graph paper to each student. Have students spend about 10 minutes to complete this worksheet. Have students tape their graph paper on the chalkboard so that paper from the same group can be grouped vertically with only one paper is in each row.

Hold a 10-minute class discussion on this worksheet. It is important for the students to:

a. Recognize that it is easier to compare the data when they are displayed on a line plot.

b. Develop their own procedure for drawing a line plot.

2) Worksheet-8B [20 minutes] Give students about 15 minutes to complete this worksheet. Have students tape their histograms next to their line plots on the chalkboard.

Conduct a 10-minute discussion to share conclusions and ideas. Teacher may want to emphasize the following points:

a. Knowing the procedure for drawing a histogram.

b. Knowing the advantages and disadvantages of using the histogram [advantage: easy to compare intervals of data; disadvantage: not displaying enough details].

3) Homework-8. Collect the worksheets and distribute today's homework.

Notes to Teachers

A histogram (or a line plot if data are graphed on a number line) indicates the number of times that a value or range of values occurs in a set of 
data (the frequency of a value or range of values). Both graphical representations can be used to display data in frequency tables. A histogram can be drawn vertically and horizontally, but in line plots the number line is usually horizontal). The difference between a histogram and a bar graph (Day \# 10) is that in a histogram, there are no spaces between consecutive bars.

\section{To draw a line plot.}

Step 1: Draw a horizontal line.

Step 2: Use a ruler to put a scale of numbers on this line. This scale of numbers must include all numbers between the largest and smallest numbers of the given data.

Step 3: Put an $X$ above a number for each time that number occurs in the data.

Step 4: Label the line plot.

\section{To draw a histogram.}

Step 1: Draw the axes. Decide which data to graph along each axis. The vertical axis is usually used to display frequencies.

Step 2: Choose a numerical scale for the horizontal axis. Use a ruler to mark off this scale on the horizontal axis. Make sure that the chosen scale includes all numbers between the largest and smallest numbers of the first set of data, and the distances between each number on the scale and the next number are equal (this also applies to the case in which data on this axis are divided into intervals).

Step 3: Repeat the procedure in step 2 for the vertical axis.

Step 4: Draw a bar graph for each entry. If the vertical axis is used as the frequency axis, use the scale on it to decide where to end the bars (use 
the scale on the horizontal axis if the horizontal axis is used to display frequencies.)

Step 5: Label the numerical axes and title the graph. 


\section{To draw a line plot}

Under your teacher's direction, collect the number of students in your class born in each of the 12 months. For each student who was born in January, February, or March, record one tally mark "l" for the interval "1-3." For each student who was born in April, May, or June, record one tally mark "l" for the interval "4-6;" and so forth. Add the tally marks to find the frequency of each interval.

\begin{tabular}{|c|c|c|}
\hline Intervals & Tally & Frequency \\
\hline $1-3$ & & \\
\hline $4-6$ & & \\
\hline $7-9$ & & \\
\hline $10-12$ & & \\
\hline
\end{tabular}

1) On your construction paper, draw a horizontal line that is one inch from the bottom edge of the page. Label it "Intervals of months."

2) Use a ruler to mark off a scale on the horizontal line so that the scale has four intervals of 1 inch in length. Leave no space between intervals. Starting from left to right, label the first interval "1-3," the second interval "4-6," the third interval "7-9," and the last interval "10-12."

3) For each interval on the construction paper, draw from the bottom up as many $X s$ as the number of frequency corresponding to that interval. For example, draw five Xs directly above the interval "1-3" if the frequency number corresponding to that interval is 5 . 
Individual \& Group

4) The graph that you created is called a line plot. Answer the following questions.

a. In which quarter of the year (a year is divided into 4 quarters; a quarter has 3 months) was the greatest number of students born? In which quarter was the least number of students born? Answers vary. b. Where in the frequency table would you find the answers for part (a)? The "Frequency" column.

c. How would you use the line plot to find the answers for part (a)? The number of $X s$ in each interval.

d. How can you be sure that all students in the class have been accounted for? The sum of the frequencies and the total number of $\mathrm{Xs}$ marks must equal the number of students. e. Describe a procedure for drawing a line plot. Any procedure that is similar to the one in the lesson plan. 


\section{To draw a histogram}

1) For each interval of your line plot draw a rectangle that covers all the $X \mathbf{s}$ completely. For example,

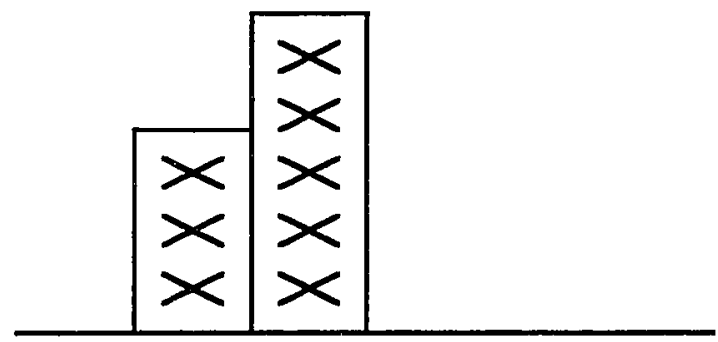

2) To the left of the interval "1-3" draw a vertical line. Label it "Number of students." For each rectangle, count the number of Xs inside the rectangle and write that number on the vertical line and parallel to the corresponding rectangle. This graph is called a histogram.

3) Use your histogram to answer the following questions.

a. What does each column (bar) tell you? The number of students who were born in a particular quarter.

b. What are the differences and the similarities between the line plot and the histogram? The similarity is that they are two graphs of a frequency table. The difference between the line plot and the histogram is their physical appearance.

c. How do you transform a line plot into a histogram? Replace Xs by rectangles.

d. Write a procedure for drawing a histogram for a set of data. Check the procedure in the "Notes to Teachers" section. 
HOMEWORK-8

Individual

Part A: The 1988 Winter Olympics were held in Calgary, Alberta, Canada. The table below lists the total number of gold, silver, bronze medals won, by country.

\begin{tabular}{|l|l|c|}
\hline \multicolumn{1}{|c|}{ COUNTRY } & CONTINENT & TOTAL MEDALS \\
\hline Austria & Europe & 10 \\
\hline Canada & North America & 5 \\
\hline Czechoslovakia & Europe & 3 \\
\hline Finland & Europe & 7 \\
\hline France & Europe & 2 \\
\hline Germany, East & Europe & 25 \\
\hline Germany, West & Europe & 8 \\
\hline Italy & Europe & 5 \\
\hline Japan & Asia & 1 \\
\hline Liechtenstein & Europe & 1 \\
\hline Netherlands, the & Europe & 7 \\
\hline Norway & Europe & 5 \\
\hline Soviet Union (former) & Europe \& Asia & 29 \\
\hline Sweden & Europe & 6 \\
\hline Switzerland & Europe & 15 \\
\hline United States & North America & 6 \\
\hline Yugoslavia (former) & Europe & 3 \\
\hline
\end{tabular}


Individual

1) Finish the column "CONTINENT."

2) Make a line plot of the total medals. Hint: make a frequency table for the total medals.

Frequency table
\begin{tabular}{|c|l|c|}
\hline Intervals & Tally & Frequency \\
\hline $1-5$ & IIIII III & 8 \\
\hline $6-10$ & IIIII I & 6 \\
\hline $11-15$ & I & 1 \\
\hline $16-20$ & & 0 \\
\hline $21-25$ & I & 1 \\
\hline $26-30$ & I & 1 \\
\hline
\end{tabular}

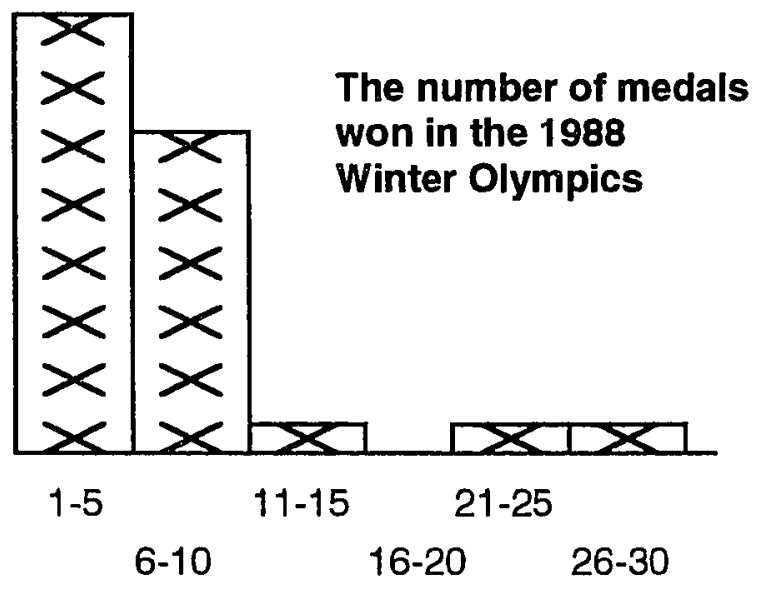


Individual

3) Make a histogram for the total medals. Hint: Use the line plot in part (2).

\section{Check for the answer in part (2).}

4) How many countries won only 1 medal ? 2.

5) How many countries won 10 or more medals ? 4.

6) Do the countries seem to fall into clusters on the line plot? No.

7) Describe how the US compares with other countries. The U.S. earned six medals. Among the medalled countries, eight of them earned fewer medals than the U.S. and five earned more medals than the U.S.

8) Write a paragraph describing all you learned about the medal winners of the 1988 Winter Olympics. Answers vary.

Part B: There are specific ranges of test scores associated with each letter grade. For example, a grade of $\mathrm{C}$ is sometimes given for any score in the interval 70-79. Since histograms show frequencies of data of different intervals, histograms are often used to display test scores.

1) Make a histogram for the data below using intervals such as $60-69$.

Scores on a Mathematics Test: $87,66,74,74,88,97,89,78,68,84,75,85,77$, $69,93,65,73,76,83,85,79,80,96,84,88$.

\section{Frequency table}

\begin{tabular}{|c|c|c|}
\hline Intervals & Tally & Frequency \\
\hline $60-69$ & IIII & 4 \\
\hline $70-79$ & IIIIII III & 8 \\
\hline $80-89$ & IIIIII IIIII & 10 \\
\hline $90-99$ & III & 3 \\
\hline $100+$ & & 0 \\
\hline
\end{tabular}




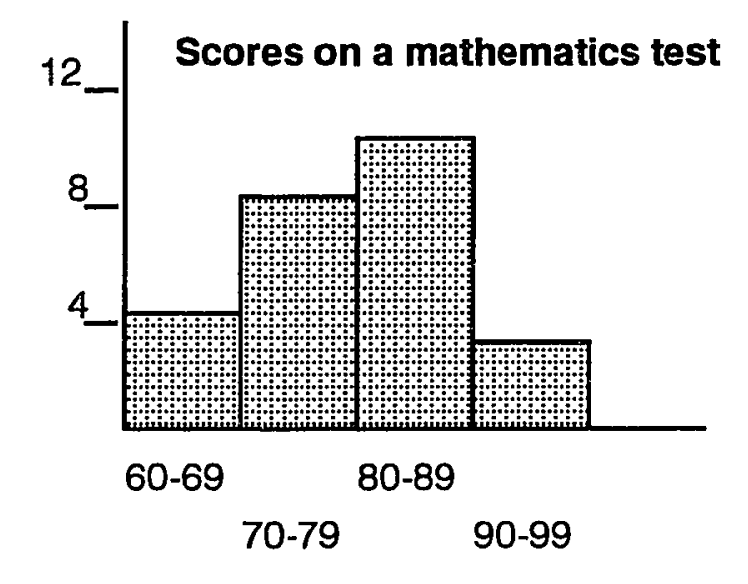

Individual

2) What letter grade corresponds to each interval in the histogram?

60-69: D, 70-79: C, 80-89: B, 90-100: A.

3) How many students received a grade of $C$ on the test? a grade of $B$ on the test?

Grade C: 8 students, grade B: 10 students.

4) What grade did the most number of students receive? Grade B.

5) Based on the grades, how do you think these students performed on this test? (You must write at least 5 sentences.) Answers vary.

Part C: The chart provided is a histogram of the scoring of the Chicago Bulls in their first home game of the 1991 season against the Philadelphia 76ers. Use the chart to answer the following questions.

1) How many points did Scottie Pippen score? 27 points.

2) How many point did Michael Jordan score? 30 points.

3) What was the team score? 118 points.

4) The $76 e r s$ scored 90 points. Which team won? The Chicago Bulls. 
Individual

Number of baskets

\section{Bulls' Scores}

\begin{tabular}{|c|c|}
\hline Pippen & $\begin{array}{l}\star \star \star * * * * \star * * * * \\
\text { \#\# \# \# \# }\end{array}$ \\
\hline Grant & $\begin{array}{l}\star * * * * * * \\
\#\end{array}$ \\
\hline
\end{tabular}

$\overline{\text { Cartwright }}$ **

\begin{tabular}{|c|c|}
\hline Paxson & $\hbar \star \star$ \\
\hline Jordan & 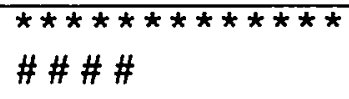 \\
\hline$\overline{\text { King }}$ & 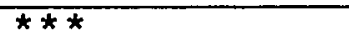 \\
\hline
\end{tabular}

\begin{tabular}{|c|c|}
\hline Armstrong & 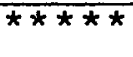 \\
\hline Hodges & $\begin{array}{l}\# \star \bar{\star} \\
\# \#\end{array}$ \\
\hline Levingston & $\star \star$ \\
\hline Perdue & $\star \star$ \\
\hline Hopson & $\star$ \\
\hline
\end{tabular}

Randall

* Field Goal (2 points) \# Free Throw (1 point) 


\section{DAY 9 - STEM-AND-LEAF PLOTS}

\section{Objectives}

1) Construct stem-and-leaf plots.

2) Recognize and interpret 3 common types of distributions.

\section{Materials}

\section{Handouts}

Worksheet-9A (individual)

Worksheet-9B (individual)

Worksheet-9C (individual)

Homework-9 (individual)

Other materials

Blank transparencies used in showing students how to construct stemand-leaf plots

Three transparencies, each shows one type of distribution. The masters for these transparencies are in the Notes to Teachers section

Encyclopedias and any books that provide some information on presidents of the US (for students who are interested in checking them out for homework).

\section{Homework Discussion}

Homework-8: [10 minutes] Since the homework for the Line Plots and Histograms lesson requires students to obtain facts from references other than their mathematics books, you may want to give students about 5 minutes at the beginning of the class to hold discussions in groups. After the groups' discussions, a whole class discussion should be held to share answers, and conclusions about the homework. Even though there are 3 parts to this 
homework, the teacher may want to skip the second part since it is similar to an in-class problem. As a result of this, the teacher only needs at most 10 minutes to conduct the homework discussion.

The class discussion should concentrate on the following:

a. Students can construct line plots and histograms. Students should be able to express their conclusions about the given data in writing.

b. Students can interpret information given to them in another form of histogram.

\section{Procedure}

1) Lecture: [15 minutes] Line plots and histograms only show the frequencies of data; they do not show the values of each piece of data. An alternative display to substitute for the less informative line plots and histograms is the stem-andleaf plot. Today's activities consist of two parts: in the first part students will learn how to construct stem-and-leaf plots with the teacher's instructions; in the second part, students will examine the shapes of 3 common stem-and-leaf plots and learn how these common plots provide additional information regarding the given data.

Introduce stem-and-leaf plots. For this part, have students copy everything from the overhead projector.

a. Define stem-and-leaf. Write down the definitions.

b. Construct the stem-and leaf plot. Use the heights of students in the class as the given set of data (These values can be obtained from the student questionnaires. They should be displayed at a location that is visible to students all the time.) 
c. Define largest values, smallest values, outliers, clusters, gaps, and range. Have students copy the definitions of all terms.

2) Worksheet-9A, 9B, 9C: [25 minutes] Distribute Worksheet-9A, Worksheet-9B, Worksheet-9C, one to each group. There may be more than one group working on the same worksheet. Students will have about 10 minutes to complete these worksheets.

Hold a 15-minute class discussion on the second activity. From this discussion, introduce the 3 common types of distributions and their characteristics. Have students copy everything regarding the distributions for later use.

3) Homework-9: Collect written work from the students. Distribute today's homework.

\section{Notes to Teachers}

A frequency table with intervals, a line plot, or a bar graph will not show you the value of each piece of data. An alternative display in which no information is lost is the stem-and-leaf plot. In this type of display, each number is represented by a stem and a leaf. The stems are the digit(s) in greatest place value(s) of the data values. The remaining digits in the data values are the leaves. For example, if the data are two-digit numbers, the numbers in the tens place would be used for the stem and the numbers in the ones place would be used for the leaf. In the case of three-digit data values, there are two possible ways to determine the stems and the leaves for the data values. The first way is to choose the numbers in the hundreds place as the stems; thus, the numbers in the tens and ones places are the leaves. In the second way the stems are the 
digits in the hundreds and tens places, while the leaves are the numbers in the ones place.

For example, 486 might be recorded as:

$4 \underline{86} \quad$ or $\quad 48 \underline{6}$

Stem Leaf Stem Leaf

Example: Consider the scores on a science test: $78,74,80,84,99,65$, $81,80,62,95,100,91,75,82,76,92,80,75,100,82,77,70,79,85,90,95,86$, $82,75,69,83,97$.

A stem-and-leaf plot for the above scores is shown below.

Scores on a Science Test

\begin{tabular}{l|lllllllllll} 
Stem & \multicolumn{3}{|l|}{ Leaf } & & & & & & & & \\
6 & 5 & 2 & 9 & & & & & & & & \\
7 & 8 & 4 & 5 & 6 & 5 & 7 & 0 & 9 & 5 & & \\
8 & 0 & 4 & 1 & 0 & 2 & 0 & 2 & 5 & 6 & 2 & 3 \\
9 & 9 & 5 & 1 & 2 & 0 & 5 & 7 & & & & \\
10 & 0 & 0 & & & & & & & & &
\end{tabular}

Key: $6 \mid 5$ means a score of 65 .

To draw a stem-and-leaf plot.

Step 1: Find the highest and lowest values of the data. Determine the stems.

Step 2: Write the stems in order from the least to the greatest to the left of a vertical line. 
Step 3: Write each leaf to the right of its stem. You may want to rearrange the leaves for each stem in order from the least to the greatest.

Step 4: Title the stem-and-leaf plot.

From a stem-and-leaf plot, many features of the data that were not apparent from the list become apparent . They will provide students additional information to interpret the data. These features include:

a. Outliers: data values that are substantially larger or smaller than the others.

b. Clusters: Isolated groups of points. Members of a cluster often share common characteristics.

C. Gaps: large spaces between points.

d. Range: the difference between the largest and smallest values.

The shape of a set of data is called a distribution. Some common types of distributions are:

\section{Stem-and-leaf 1}

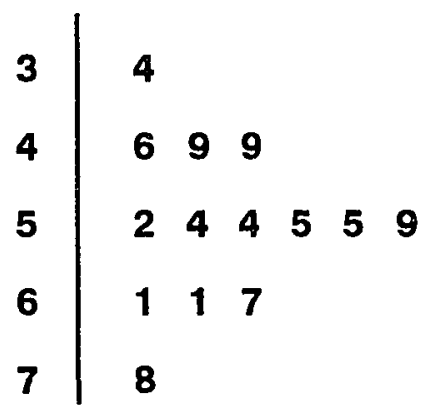

BELL-SHAPE

\section{Stem-and-leaf 2}

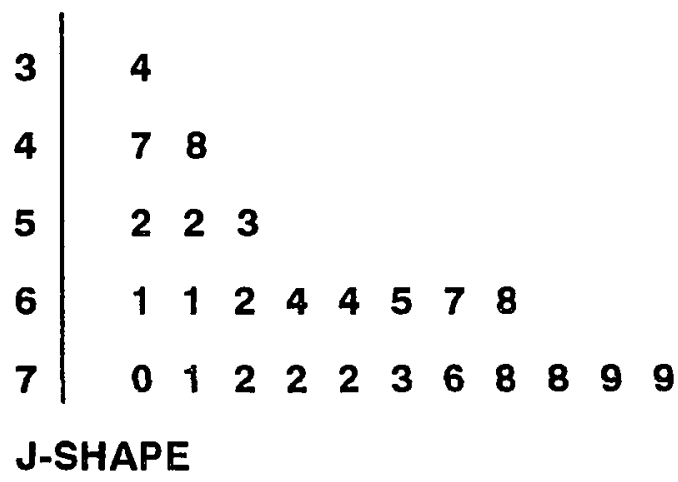




\section{Stem-and-leaf 3}

\begin{tabular}{l|llllllllll}
\hline 2 & 5 & 5 & 8 & & & & & & \\
3 & 2 & 3 & 4 & 4 & 5 & 9 & & & \\
4 & 6 & 7 & 7 & & & & & & \\
5 & 4 & & & & & & & \\
6 & 1 & 1 & 3 & 8 & & & & & \\
7 & 0 & 1 & 3 & 4 & 4 & 5 & 6 & 8 & 8 \\
8 & 2 & 3 & 5 & 5 & & & & &
\end{tabular}

\section{U-SHAPE}

The mound-shape distribution (bell-shaped) is a shape that occurs often. The data values are fairly symmetrical, with small values balancing the large values. If the data take a U-shaped distribution, it may be because there are really two underlying groups, each of which is mound-shaped. Thus, when there is a U-shaped distribution, examine the data to see if there is any reason to treat the data values as two separate groups. Typically, the J-shaped occurs because it is impossible to collect data above (or below) a particular limit. For example, lifetime distributions of objects or people are often $\mathrm{J}$-shaped (backward). Thus, if the data values shows a J-shaped distribution, try to determine if there is a limit, what it is, and why it is there. Examining the distribution of a set of data sometimes lead to questions and possibilities about the problems that are not apparent from the list of data. 


\section{WORKSHEET-9A}

Individual \& Group

\section{Stem-and-leaf plots}

Consider the following scores on a pre-algebra test: $34,73,53,62,47,78,72$,

$64,70,64,78,71,65,72,67,68,72$.

1) Construct a stem-and-leaf plot.

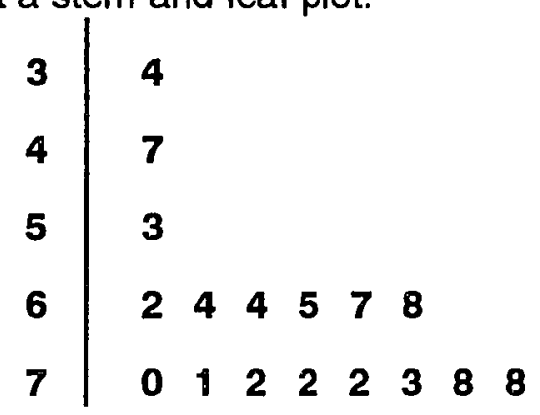

2) Identify: outliers, clusters, gaps, range.

Outliers: none Clusters: none

Gaps: none Range: $\mathbf{4 4}$

3) What kind of shape does your plot look like? J-shape

4) Write a description of the information displayed in the stem-and-leaf plot above. Answers vary.

5) THIS PART CAN BE DONE ONLY AFTER THE TEACHER EXPLAINS ABOUT THE 3 DISTRIBUTIONS. Can you think of another example that gives us this type of distribution? Answers vary. For example, any set of numerical data that has a pre-determined upper limit. 


\section{Stem-and-leaf plots}

Consider the following scores on a pre-algebra test: $25,63,85,74,54,85,46$, $28,61,78,33,71,28,34,47,61,78,74,32,82,39,68,33,75,76,83,34,35$, 73,47 .

1) Construct a stem-and-leaf plot.

$$
\begin{array}{l|llllllll}
2 & 5 & 8 & 8 & & & & & \\
3 & 2 & 3 & 3 & 4 & 4 & 5 & 9 \\
4 & 6 & 7 & 7 & & & & \\
5 & 4 & & & & & & & \\
6 & 1 & 1 & 3 & 8 & & & & \\
7 & 1 & 3 & 4 & 4 & 5 & 6 & 8 & 8 \\
8 & 2 & 3 & 5 & 5 & & & &
\end{array}
$$

2) Identify: outliers, clusters, gaps, range.
Outliers: none
Clusters: none

Gaps: none Range: 60

3) What kind of shape does your plot look like? U-shape

4) Write a description of the information displayed in the stem-and-leaf plot above. Answers vary.

5) THIS PART CAN BE DONE ONLY AFTER THE TEACHER EXPLAINS ABOUT THE 3 DISTRIBUTIONS. Can you think of another example that gives us this type of distribution? Answers vary. For example, any set of numerical data that has two distinct subgroups. 


\section{Stem-and-leaf plots}

The table below gives the amount of fat in each serving of various fast food items.

ITEMS

FAT (gm)

\section{Hamburgers}

Burger King Whopper

41

Jack-in-the-Box Jumbo Jack

28

McDonald's Big Mac

33

Wendy's Old Fashioned

22

\section{Sandwiches}

Roy Rogers Roast Beef

12

Burger King Chopped-Beef Steak

13

Hardee's Roast Beef

17

Arby's Roast Beef

Fish

Long John Silver's

McDonald's Filet-O-Fish

Burger King Whaler

Chicken

Kentucky-Fried Chicken Snack Box

21

Specialty Entrees

Wendy's Chili

09

Pizza Hut Pizza Supreme

Jack-in-the-Box Taco 
1) Construct a stem-and-leaf plot.

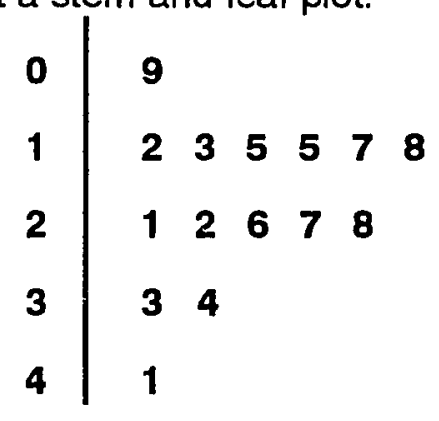

2) Identify: outliers, clusters, gaps, range.

Outliers: none Clusters: none

Gaps: none Range: 60

3) What kind of shape does your plot look like? Bell-shape

4) Write a description of the information displayed in the stem-and-leaf plot above. Answers vary.

5) THIS PART CAN BE DONE ONLY AFTER THE TEACHER EXPLAINS ABOUT THE 3 DISTRIBUTIONS. Can you think of an example that gives us this type of distribution? Answers vary. 


\section{HOMEWORK-9}

Individual

\section{Stem-and-leaf plots}

Part A: The attached table lists the presidents of the US and the years in which they died.

PRESIDENT

1) George Washington

2) John Adams

3) Thomas Jefferson

4) James Madison

5) James Monroe

6) John Quincy Adams

7) Andrew Jackson

8) Martin Van Buren

9) William H. Harrison

10) John Tyler

11) James K. Polk

12) Zachary Taylor

13) Millard Fillmore

14) Franklin Pierce

15) James Buchanan

16) Abraham Lincoln

17) Andrew Johnson

18) Ulysses Grant

19) Rutherford B. Hayes

20) James A. Garfield
BORN

02/22/1732

10/30/1735

$04 / 13 / 1743$

$03 / 16 / 1751$

04/28/1758

$07 / 11 / 1767$

03/15/1767

12/05/1782

02/09/1773

03/29/1790

11/02/1795

$11 / 24 / 1784$

01/07/1800

$11 / 23 / 1804$

04/23/1791

02/12/1809

12/29/1808

04/27/1822

10/04/1822

$11 / 19 / 1831$
DIED

12/14/1799

07/04/1826

07/04/1826

06/28/1836

07/04/1831

$02 / 23 / 1848$

06/08/1845

$07 / 24 / 1862$

$04 / 04 / 1841$

01/18/1862

06/15/1849

07/09/1850

03/08/1874

10/08/1869

06/01/1868

04/15/1865

07/31/1875

07/23/1885

$01 / 17 / 1893$

$09 / 19 / 1881$
AGE

67

91

83

85

73

81

78

80

68

72

54

66

74

65

77

56

67

63

71

50 


\section{4}

Individual

21) Chester A. Arthur

22) Grover Cleveland

23) Benjamin Harrison

24) Grover Cleveland

25) William McKinley

26) Theodore Roosevelt

27) William $H$. Taft

28) Woodrow Wilson

29) Warren G. Harding

30) Calvin Coolidge

31) Herbert C. Hoover

32) Franklin D. Roosevelt

33) Harry S. Truman

34) Dwight D. Eisenhower

35) John F. Kennedy

36) Lyndon B. Johnson

37) Richard M. Nixon

38) Gerald R. Ford

39) James E. Carter, Jr.

40) Ronald W. Reagan

41) George H. W. Bush

42) William J. Clinton
10/05/1830

$03 / 18 / 1837$

08/20/1833

03/18/1837

$01 / 29 / 1843$

$10 / 27 / 1858$

09/15/1857

$12 / 28 / 1856$

11/02/1865

07/04/1872

$08 / 10 / 1874$

$01 / 30 / 1882$

05/08/1884

$10 / 14 / 1890$

05/29/1917

08/27/1908

$01 / 09 / 1913$

$07 / 14 / 1913$

10/01/1924

$02 / 06 / 1911$

06/12/1924

$08 / 19 / 1946$
11/18/1886

56

06/24/1908

71

03/13/1901

68

06/24/1908

71

09/14/1901

58

01/06/1919

61

03/08/1930

73

02/03/1924

68

08/02/1923

58

01/05/1933

61

10/20/1964

90

04/12/1945

63

$12 / 26 / 1972$

88

$03 / 28 / 1969$

79

11/22/1963

46

$01 / 22 / 1973$

65

05/17/1994

81 
Individual

1) Calculate the age at death of each president. See the above list.

2) Make a stem-and-leaf plot of the ages of the presidents at death.

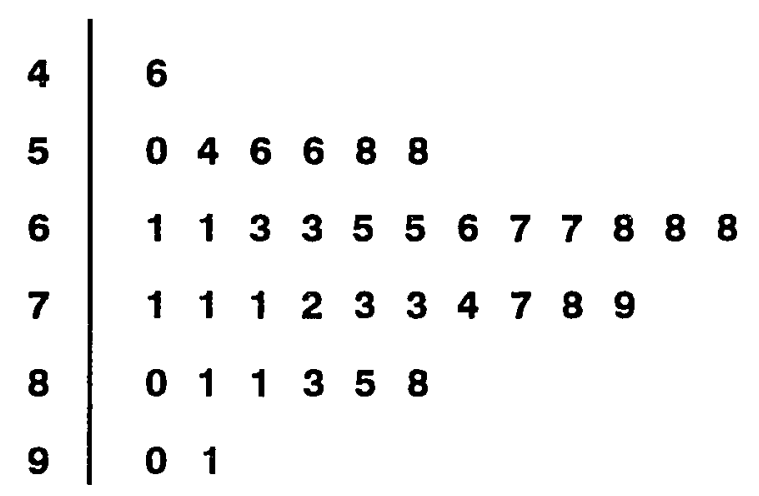

3) Answer the following questions:

a. Is the number of presidents the same as the number of pieces of data? No, some former presidents are still alive.

b. How many presidents died in their 40's or 50's ? 7.

c. Who lived to be the oldest? John Adams.

d. Label the 4 presidents who were assassinated. Lincoln (56), Garfield (50), McKinley (58), Kennedy (46).

e. What is the shape of this distribution? Bell-shaped.

f. Write a one-paragraph description of the information shown in the stem-and-leaf plot, including information about the presidents who were assassinated. Answers vary.

PART B: Sometimes we need to compare 2 sets of data using a display method that provides as much information as possible. In this case the back-toback stem-and-leaf plots is the most useful method. Before making comparisons, however, check to see that both sets have the same number of 
Individual

data pieces. Also make sure that the plot is drawn accurately with each leaf taking the same amount of space. The above checkings are important because we compare data through comparing the number of leaves on both sides. If one side has more data values or each leaf takes more space on one side than on the other, it can be difficult to make accurate comparisons. (Helpful note: to get the sizes correct, it helps to construct your plot on graph paper.) Study the infant mortality rates of the countries listed in the attached handout and complete the following steps. (Note: the infant mortality rate is the number of infant deaths per 1,000 live births.)

1) Use the Atlases to complete the column "CONTINENTS."

2) Draw a back-to-back stem-and-leaf plot of the countries whose names are printed bold versus the countries whose names are printed in italics. Some of these data were plotted for you.

\section{Back-to-back stem-and-leaf plot}

Leaf 1 (Plain Text)

\section{Stem}

$\begin{array}{lllllllllllll}3 & 5 & 6 & 6 & 7 & 7 & 7 & 7 & 7 & 8 & 8 & 8 & 8\end{array}$

44

33

3

13
0

1

2

3

4

5

7

8

Leaf 2 (Bold Face)

38

5 
Individual

Leaf 1 (Plain Text)

9

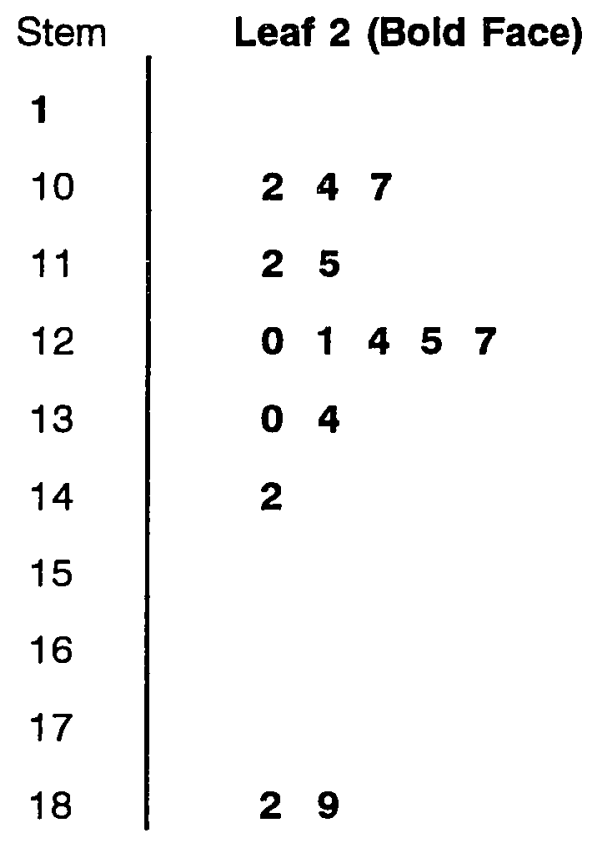

3) What is the shape of this plot? The plain text has a 1 -shape. The bold face has a shape that is almost like a bell shape.

4) Which continent has the most number of countries with infant mortality rate at least $90 / 1000$ ? Which continent has the most number of countries with infant mortality rate at most 30/1000? Africa, Europe.

5) What can possibly be the reason for the difference of the infant mortality rates between the two continents mentioned above? Answers vary.

6) What do you think dictated the division of the two groups of countries? The developed countries were grouped together while the third world countries formed the other group.

7) Write a paragraph (at least 5 sentences) describing what you learned from your plot. Answers vary. 
Individual

8) In your opinion, how much must the infant mortality rate of a country be in order for that country to be considered as a country with high infant mortality rate? Why? Answers vary.

\section{EXTRA CREDITS}

1) Choose a country whose infant mortality rate is at least as large as the number chosen in question (7). Write a one-paragraph description of this country (Use encyclopedias, geography books, and any available materials). 2) Why do you think this country has such a high infant mortality rate ? Suppose you were in charge of the health department of this country. What would you do to improve the situation? 
INFANT MORTALITY RATES OF SOME COUNTRIES IN THE WORLD

Country

Continent

Population

(to the nearest ten

thousand)

Afghanistan

Australia

Bangladesh

Bhutan

Cambodia

Canada

Chile

China

Costa Rica

Egypt

El Salvadore

Ethiopia

Finland

France

Germany

Haiti

Honduras

India

Japan

Laos

Liberia
Asia

Australia

Asia

Asia

Asia

North America

South America

Asia

C. America

Africa

South America

Africa

Europe

Europe

Europe

South America

South America

Asia

Asia

Asia

Africa
$16,900,000$

$16,900,000$

$17,800,000$

$111,400,000$

700,000

$9,100,000$

$27,400,000$

$13,600,000$

$1,165,800,000$

$3,200,000$

$57,758,000$

$5,400,000$

$54,300,000$

$5,000,000$

$56,900,000$

$80,600,000$

$6,400,000$

$5,500,000$

$882,600,000$

$124,400,000$

$4,400,000$

$2,800,000$
Infant mortality

rate (per 1000)

172

8

120

142

127

7

17

34

15

29

55

131

6

7

8

106

69

91

5

112

144 


\begin{tabular}{|c|c|c|}
\hline Liechtenstein & Europe & 30,000 \\
\hline Madagascar & Africa & $11,900,000$ \\
\hline Mexico & North America & $87,700,000$ \\
\hline Netherlands & Europe & $15,300,000$ \\
\hline Nicaragua & South America & $3,900,000$ \\
\hline Norway & Europe & $4,300,000$ \\
\hline Saudi Arabia & Africa & $16,100,000$ \\
\hline Singapore & Asia & $2,800,000$ \\
\hline Somalia & Africa & $8,300,000$ \\
\hline Soviet Union & Europe \& Asia & $284,110,000$ \\
\hline Spain & Europe & $39,300,000$ \\
\hline Sudan & Africa & $26,500,000$ \\
\hline Sweden & Europe & $8,700,000$ \\
\hline Tanzania & Africa & $27,400,000$ \\
\hline Togo & Africa & $3,800,000$ \\
\hline $\begin{array}{l}\text { United Arab } \\
\text { Emirates }\end{array}$ & Africa & $2,500,000$ \\
\hline United Kingdom & Europe & $57,500,000$ \\
\hline United States & North America & $255,600,000$ \\
\hline Yemen & Africa & $10,400,000$ \\
\hline
\end{tabular}




\section{DAY 10 - INTERPRETING BAR GRAPHS Objectives}

1) Explore bar graphs using manipulatives

2) Distinguish between bar graphs and histograms

3) Interpret bar graphs

\section{Materials}

\section{Handouts}

Worksheet-10 (individual)

Homework-10 (individual)

\section{Other materials}

A world map to be used during homework discussion

Boxes of materials including rulers, markers, glue (one box per group).

9"x12" construction paper (one for each student)

Bags of different-colors $1 " x 1$ " squares (30 squares in each bag. One bag for each student)

\section{Homework Discussion}

Homework-9: [15 minutes] Since part (A) of this homework requires students to follow the same procedure that was used in the previous lesson, you may want to spend at most 5 minutes discussing the questions in part $A$. One way to speed up this discussion is to ask one student to complete the age chart on the overhead projector and another student to draw his or her stem-and-leaf plot on the chalkboard. Be sure to check that the number of data pieces in the chart and in the plot are matched. Part A of this homework was designed for students to achieve two goals: one is to practice drawing stem-and-leaf plots and the 
other is for students to see that sometimes they themselves must decide which piece of information is relevant enough to use in their plots.

Part (B) of this homework asks students to take the method of drawing stem-and-leaf plots one step further. Students probably will not have any problem with the construction. However, you may want to remind them that for the back-to-back stem-and-leaf plots to work, they must do the following: check whether the 2 sets of data have the same number of values, make certain that the plot is drawn accurately with each leaf taking the same number of spaces (the first leaf of the first stem must be in the same column with the first leaf of the second stem and so on). Before starting to answer the questions in part $B$, you may want to expand this homework from dealing with ratio (infant mortality rate) into dealing with proportion ( estimating the number of infant deaths of a particular country if its population is known).

\section{Procedure}

1) Worksheet-10: [35 minutes] Ask students if they have ever participated in a survey outside of this class. Results of a political survey may compare a president's popularity at the beginning of his term with that at the end of his first year. Record producers may be interested in a survey that compares the types of music preferred. In most cases bar graphs are used to show comparisons. Today's lesson focuses on the three following points: construction of bar graphs using manipulatives, differentiating bar graphs and histograms, and interpreting bar graphs.

Distribute the following items to each student: Worksheet-10, 1 bag of squares, one sheet of construction paper. Students in a group must share a 
box of materials including rulers, markers, glue. Students will have about 15 minutes to complete this assignment.

Hold a 20-minute class discussion. This discussion should include the following points:

a. Introduce bar graphs. Use one of the groups' bar graphs as an example to show parts of a bar graph.

b. Differentiate bar graphs and histograms. Display a transparency that shows a bar graph next to a histogram. Have students point out the similarities and the differences between the two. Students will give a variety of answers; nevertheless, be sure that their answers include:

- bars in a histogram are drawn next to each other, while bars in a bar graph are separated.

- both axes in a histogram are labeled with numbers, while only one axis in a bar graph is labeled with numbers. - should always start with 0 on the numerical axis in a bar graph.

c. Discuss questions that were created by students. Should include questions that ask about comparisons.

d. Introduce double bar graphs. While students may be familiar with single bar graphs, the double bar graphs may be new to them. Use the example in the "Notes to Teachers" to show what a double bar graph is, and how it can be used to compare data.

2) Homework-10: Collect groups' work and distribute today's homework. 
Notes To Teachers

A bar graph is a graph in which data can be displayed as vertical or horizontal parallel bars of appropriate length. A bar graph has two axes. One axis is labeled with a numerical scale. The other is labeled with the categories of a set of data. Bar graphs may be most appropriate when there is a need for comparison of data of distinct categories. When reading a bar graph, one may often find it necessary to estimate where the bars end.

Bar graphs often appear in the forms of a single bar graph (one bar for each category) or a double bar graph (two bars for each category). The constructions of these two types of bar graphs are the same, except a legend must be included in the double bar graph to identify the two types of bars. Single bar graphs and double bar graphs may appear as follows:

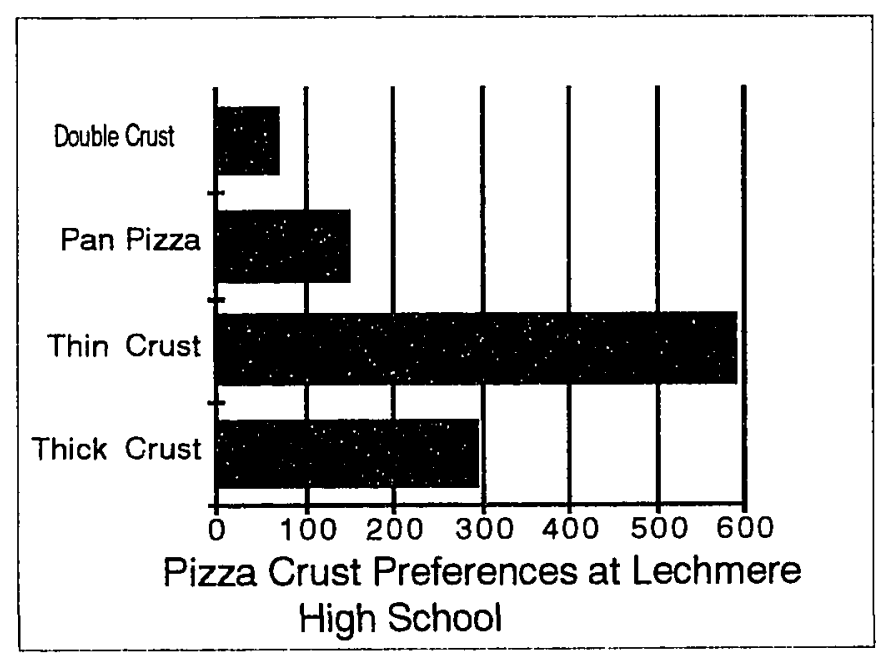

A single bar graph 


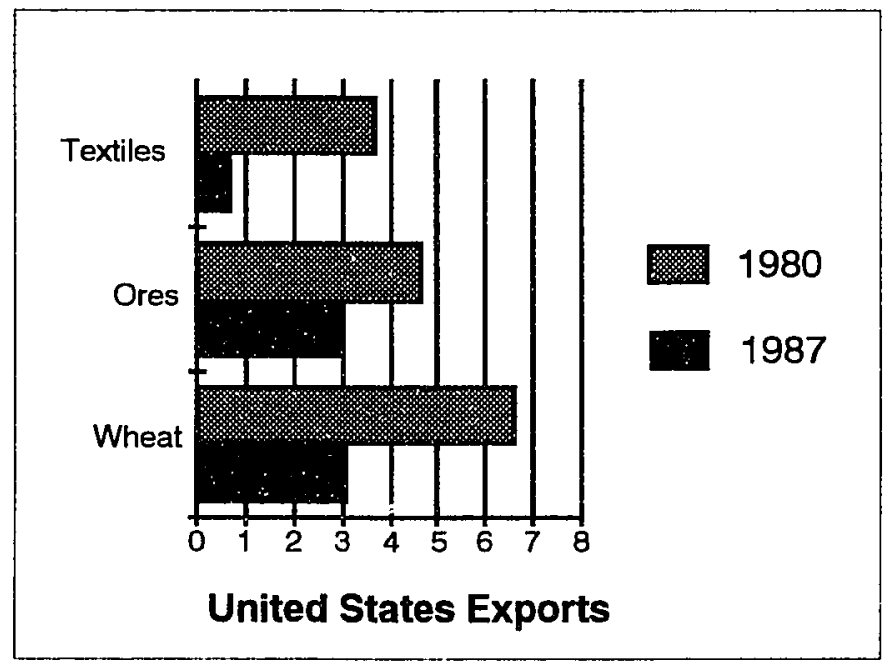

A double bar graph

\section{To make a bar graph.}

Step 1: Draw the axes. Position the categories on either one of the axes. (Positioning the categories on the vertical axis will make it easier to read the words.)

Step 2: Choose a numerical scale. Position this scale on the other axis. (The frequency of intervals on this scale affects the precision of data that appearing on the graph. Numerically smaller (more frequent) intervals are appropriate when more precise interpretation of the data is required.) Step 3: Draw a bar graph for each entry (two bars for each entry on the graph). Use the scale to decide where to end the bars.

Step 4: Label the numerical axis and title the graph. Include a legend on the double bar graph to identify the two types of bars. 


\section{Bars of Squares}

1) Pick up a bag of squares and a box of materials.

2) Group your squares according to their colors.

3) On your construction paper, draw a horizontal line that is 1 " from the bottom edge of the page. Label this line "COLORS."

4) 1" from the left edge of the page, draw a vertical line. Label it "NUMBERS OF BEADS."

5) Starting from the horizontal line, glue squares of like colors to form vertical bars. Be sure to leave some space between consecutive bars. Under each bar of squares write down the squares' color.

6) Count the total number of squares in each bar and write this number left of the vertical line. Be sure to write this number straight across from the last bead of the corresponding bar.

7) The graph that you created is called a bar graph. Name your bar graph. 8) Develop 3 questions to share with the class. Be sure that your 3 questions can be answered by analyzing the bar graph. 


\section{All About Bar graphs}

Part A: Use the bar graph below. Estimate the number of balls for each sport.

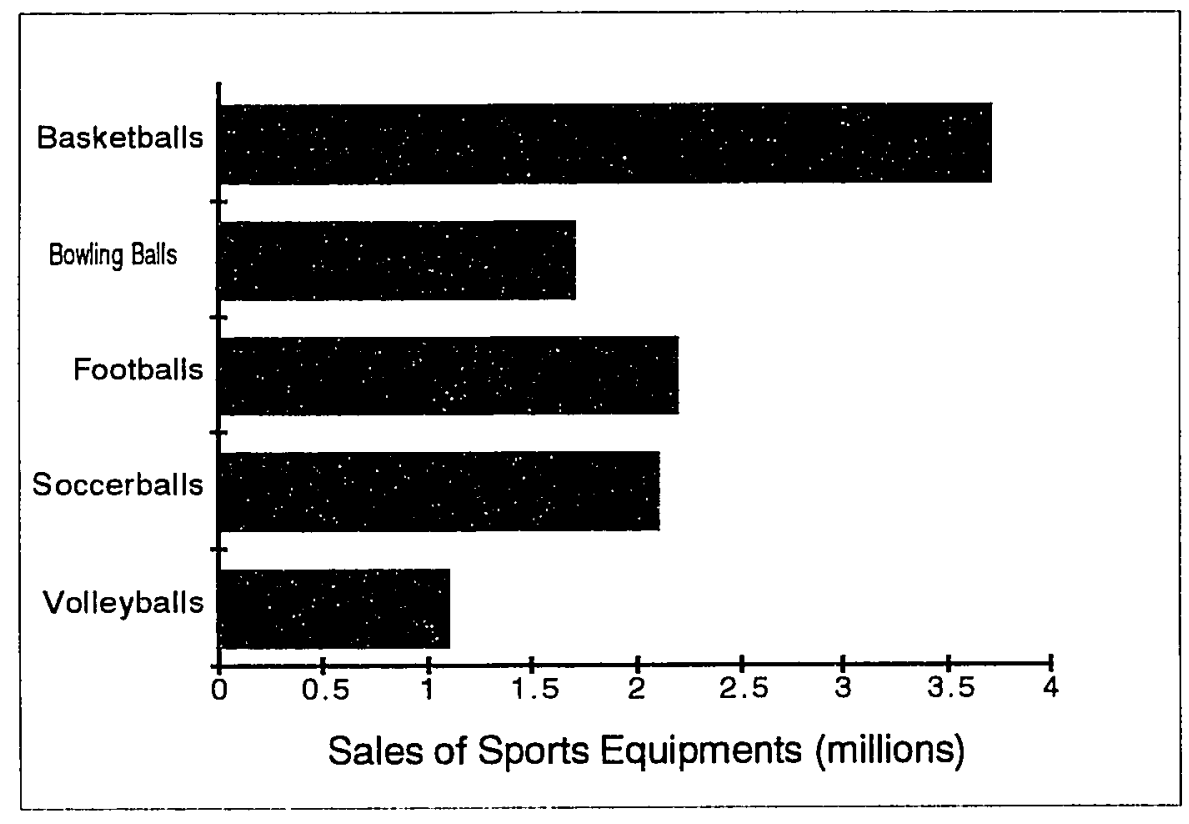

$\begin{array}{ll}\text { 1) soccer } 2.1 \text { million } & \text { 2) football } 2.2 \text { million }\end{array}$
3) basketball
3.7 million
4) volleyball 1.1 million

5) Name all the sports for which fewer than 2 million balls were sold.

\section{Volleyball and Bowling.}

6) About how many times as many soccer balls were sold as volleyballs?

2 times. Point out to students that the length of the soccer-balls bar should also be as twice as long as that of the volleyballs.

7) About how many more basketballs were sold than bowling balls? 2 million.

8) Would you want to guess which is the most popular sport from this graph?

Explain. Answers vary. Point out to students that the answer depends on which criterion we want to use: a sport can be the most 
popular sport in terms of the number of spectators, or in terms of the number of athletes.

PART B: The graph below is called a double bar graph. A double bar graph has two bars for each category. The constructions of a single bar graph and a double bar graph are the same, except a legend must be included in the double bar graph to identify the two types of bars.

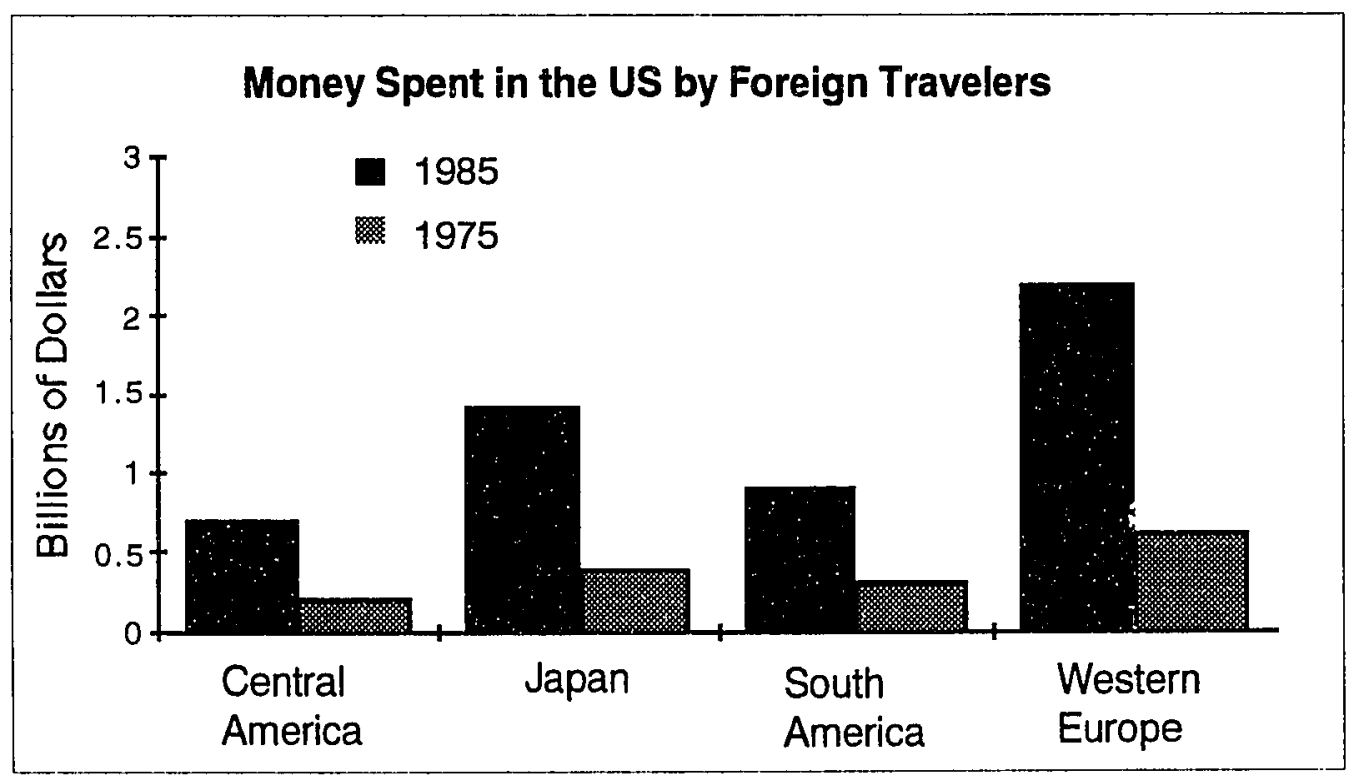

9) In 1975, travelers from which region spent about $\$ 0.6$ billion in the United

\section{States? Western Europe.}

10) In 1985, travelers from which region spent about $\$ 0.6$ billion in the United States? Central America.

11) About how much more did travelers from Japan spend in the United States in 1985 than in 1975 ? 1 million or 3.5 times more. 
Individual

12) Travelers from which region increased their spending in the United States the most between 1975 and 1985? Western Europe (absolute scale) or Japan (percentage).

PART C: Newspaper and magazines often put the numerical fact at the end of each bar on a bar graph and omit the scale. This type of graph is called an annotated bar graph.

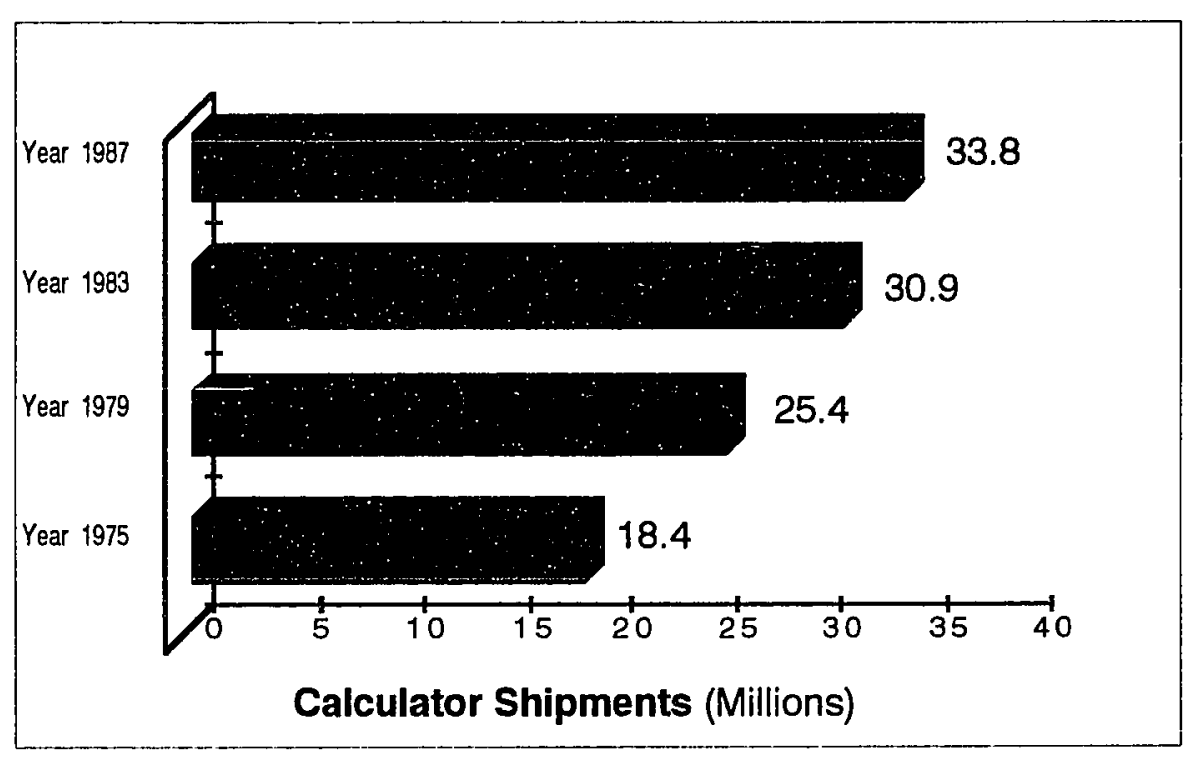

13) How many more calculators were shipped from the US to some foreign countries in 1987 than in 1975 ? 15.4 million.

14) In which four-year interval did the number of calculators shipped increase by less than 3 million? $1983-1987$.

15) Estimate the income from the sales of all the calculators shipped in 1975 if the typical price for a calculator in 1975 is $\$ 63$. Approximately $\$ 1,134,000,000$. 
Individual

16) Estimate the income from the sales of all the calculators shipped in 1987 if the typical price for a calculator in 1987 was $\$ 25$. Approximately $\$ 1,000,000,000$.

PART D: Clip out a bar graph (single or double) from a newspaper or a magazine. Create 5 questions that can be answered from the graph. At least one of the questions should require drawing a conclusion. A written explanation of your conclusion should be included in Part (D). 


\section{DAY 11 - DRAWING BAR GRAPHS}

\section{Objectives}

1) Draw single bar graphs (in class) and double bar graphs (homework).

2) Learn to assess a set of data before creating a scale for the bar graph.

3) Use bar graphs to compare items in data.

\section{Materials}

\section{Handouts}

Worksheet-11A (for half of the class)

Worksheet-11B (for the other half of the class)

Homework-11 (individual)

Other materials

A collection of clippings of different types of bar graphs (Check US News and World Reports)

Boxes of materials mentioned in previous lessons

9"x12" construction paper (one for each student)

Wrappers of 5 different kinds of single-serving potato chips (for

Worksheet-11B)

\section{Homework Discussion}

Homework-10: [10 minutes] After obtaining answers for parts $A, B, C$, have several students present different bar graphs that they found. Present your own collection of bar-graph clippings if students did not find many different types of bar graphs.

\section{Procedure}

1) Lecture: [10 minutes] Today's lesson focuses on two goals: a procedure for drawing bar graphs and assessing a set of data to determine the appropriate 
intervals for the numerical scale. To start the lesson, ask students to define a bar graph based on what they have seen so far. Their answers may vary; nevertheless, accept any answer that describes a bar graph as a graph in which the data can be displayed as vertical or horizontal parallel bars of appropriate length.

Inform students that a vertical bar graph is another way of displaying data as a bar graph and it can be constructed by using the same method of constructing horizontal bar graphs. Have students copy this instruction into their notebooks.

Example: There are several counties in the U.S. that were named afier the former presidents of the United States. Below are the number of counties that were named after the first three presidents of the United States.

\begin{tabular}{|c|c|}
\hline County's Name & Number of counties \\
\hline Washington & 32 \\
\hline Adams & 12 \\
\hline Jefferson & 25 \\
\hline
\end{tabular}

\section{Procedure to draw a bar graph.}

Step 1: Draw the axes. Position the names of the presidents on the vertical axis.

Step 2: Choose a scale. Determine the greatest number. Label a scale from 0 to a number that is larger than the greatest number on the list, using intervals of appropriate size (5 in this case).

Step 3: Draw a bar for each entry in the table. Use the scale to decide where to end the bars (Be sure that all bars have the same width). 
Step 4: Label the horizontal axis and name the graph.

Ask students what they would do to change the horizontal bar graph in the above example into a vertical bar graph.

2) Worksheet-11A, 11B: [30 minutes] Distribute Worksheet-11A to one half of the class and Worksheet-11B to the remaining half. At the same time distribute a box of materials and about six sheets $9 " x 12^{\prime \prime}$ construction paper to each group. Students will have about 15 minutes to complete their worksheet.

Since Worksheet-11A requires students who are responsible for this worksheet to obtain answers from other students who at the same time work on a different project, you may want to organize your own traffic directions so that you can minimize unnecessary social activities. Designating one student from each group instead of everyone in the group to collect responses is one of many ways to reduce the amount of unnecessary social activity.

As for Worksheet-11B, some students may not be familiar with the display of nutrition information on labels of food; however, let them work among themselves to determine ways to record data. Only offer help when the entire group has problem.

Spend the remaining 15 minutes on class discussion. Call on 2 groups of students to present their reports, one for Worksheet-11A and one for Worksheet-11B. Be sure that you guide students to recognize that the graphs with more intervals per unit will be more precise. Use the comparisons in both worksheets to emphasize the importance of choosing appropriate intervals for bar graphs.

Collect all worksheets.

3) Homework-11: Hand out today's homework. 


\section{Notes To Teachers}

\section{To make a bar graph.}

Step 1: Draw the axes. Position the categories on either one of the axes. (Positioning the categories on the vertical axis will make it easier to read the words.)

Step 2: Choose a numerical scale. Position this scale on the other axis. (The frequency of intervals on this scale affects the precision of data that appearing on the graph. Numerically smaller (more frequent) intervals are appropriate when more precise interpretation of the data is required.) Step 3: Draw a bar graph for each entry (two bars for each entry on the graph). Use the scale to decide where to end the bars.

Step 4: Label the numerical axis and title the graph. Include a legend on the double bar graph to identify the two types of bars. 
Why Might You Volunteer?

\begin{tabular}{|l|l|}
\hline \multicolumn{1}{|c|}{ RESPONSES } & NUMBERS \\
\hline a) I could learn something from volunteering & \\
\hline b) It would make me feel useful & \\
\hline c) I could gain experience for a future job & \\
\hline d) I would like to help people & \\
\hline e) I could use my skills & \\
\hline f) I have extra free time & \\
\hline g) Others & \\
\hline
\end{tabular}

1) You and your group's members must obtain answers to the above question from all of your classmates. Check all the answers that each person gives, and add any new ones. Keep track of the number of people you ask.

2) Tally the total number of people who chose each answer. Place these numbers in the right column of the above table.

3) Display the data you gathered in step 2 in three different bar graphs, using intervals of $1,5,10$ respectively.

4) Use your list of data and your bar graphs to answer the following questions:

a. What were the most popular answers?

b. What was the total number of responses? Is this the same as the number of people who answered the question? Why or why not?

c. Which bar graph is the most accurate? Why? 


\section{What Would You Buy?}

Nutrition information is included on the labels of most canned fruits, fish, vegetables, soups, etc. and on boxes of cereal, and crackers. Use the attached labels for 5 brand names of the chosen food item to complete the following table.

\begin{tabular}{|l|l|l|l|l|}
\hline BRAND NAME & CALORIES & $\begin{array}{l}\text { GRAMSOF } \\
\text { PROTEIN }\end{array}$ & GRAMS OFFAT & $\begin{array}{l}\text { GRAMS OF CAR- } \\
\text { BOHMRATES }\end{array}$ \\
\hline & & & & \\
\hline & & & & \\
\hline & & & & \\
\hline & & & & \\
\hline & & & & \\
\hline
\end{tabular}

Select a set of data collected, complete the following:

1) Draw 3 bar graphs (both vertical or both horizontal) on the construction paper provided using intervals of $1,5,10$ respectively. Name your bar graphs as "Bar Graph 1," "Bar Graph 2," and "Bar Graph 3."

2) Compare the bar graphs. Which bar graph do you think is the most accurate bar graph? Explain.

3) Use the bar graph that you think is the most accurate graph. Compare the data among the 5 brands in this graph. Explain which brand your group would purchase and why. 
HOMEWORK-11

Individual

Part A: Major Earthquake (1920-1990)

\begin{tabular}{|l|c|l|}
\hline Place & $\begin{array}{l}\text { Richter-Scale } \\
\text { Reading }\end{array}$ & $\begin{array}{l}\text { Number of } \\
\text { Deaths }\end{array}$ \\
\hline 1990 Iran & 7.7 & 50,000 \\
\hline 1989 U.S. & 7.1 & 67 \\
\hline 1985 Mexico & 8.1 & 25,000 \\
\hline 1976 China & 8.4 & 242,000 \\
\hline 1970 Peru & 7.7 & 50,000 \\
\hline 1935 India & 7.5 & 50,000 \\
\hline 1932 China & 7.6 & 54,000 \\
\hline 1927 China & 8.3 & 200,000 \\
\hline 1923 Japan & 8.3 & 140,000 \\
\hline 1920 China & 8.3 & 100,000 \\
\hline
\end{tabular}

1) Draw 2 bar graphs, one to display the Richter-scale magnitudes of the major earthquakes versus the years in which the earthquakes took place and one to display the resulting deaths versus the years in which the earthquakes took place. One of your graphs must be a vertical bar graph and the other one must be a horizontal bar graph. Answers vary. Some examples are demonstrated below. 
Individual
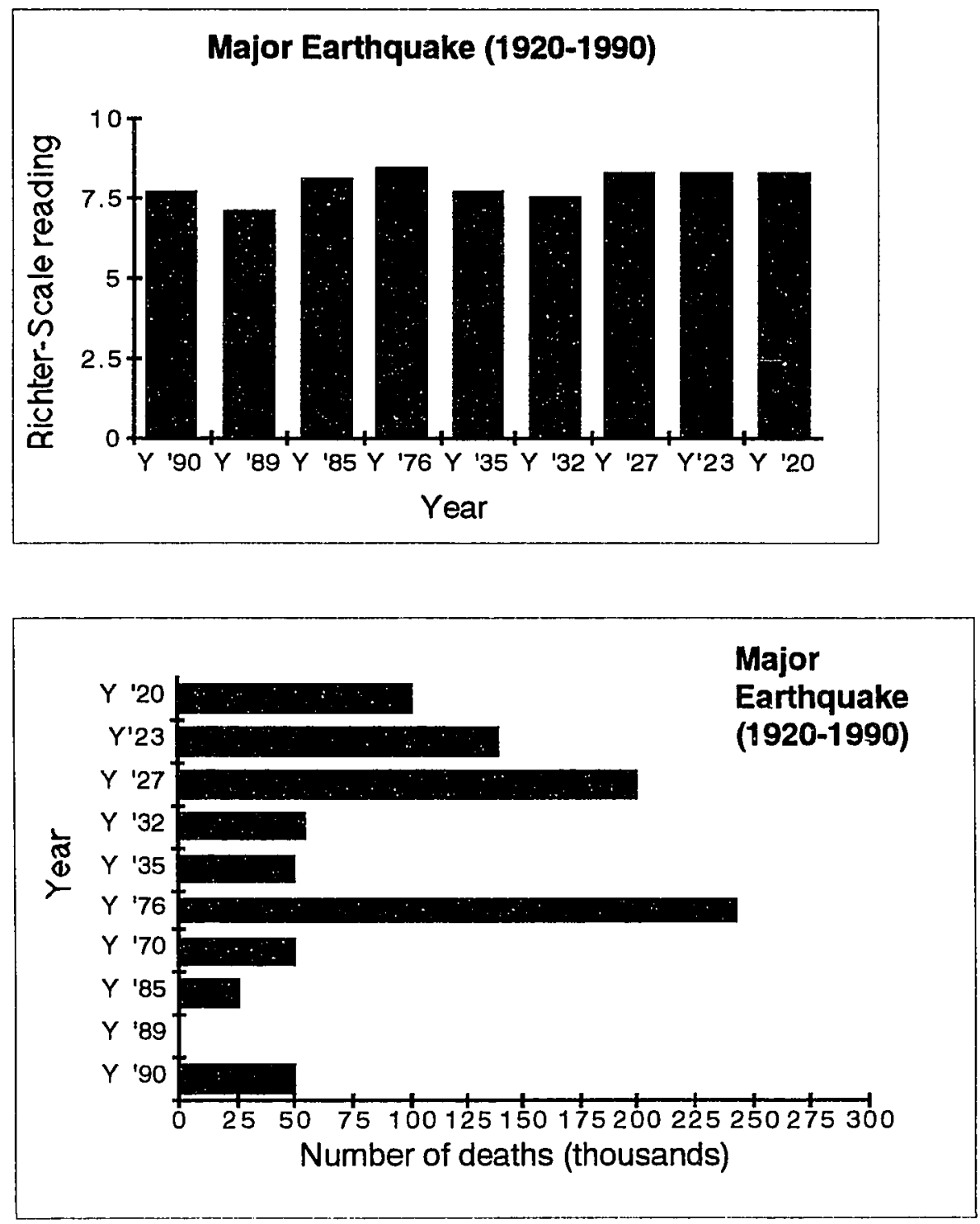

2) Do you think your graphs display the given data precisely? Why or why not? Answers vary. 
Individual

3) How would you determine the intervals for a bar graph so that your graph accurately reflects given data? Let the starting number be a number that is less than the smallest number and the ending number be a number that is more than the largest number. Find the quotient of the range of the starting and ending numbers and the number of data items. Let the length of each interval equal this quotient. 4) Use the table and your bar graphs to answer the following question.

a. When and where did the quake that caused the fewest number of deaths occur? What was the Richter-scale reading for this quake? 1989 in the U.S. (67 deaths).

b. Where and when did the quake with the highest Richter-scale reading occur? How many deaths resulted from that quake? 1976 in China (242,000 deaths).

c. What country was hit by four major quakes? What is the difference between the largest and the smallest number of resulting deaths?

China / The difference is 241,933 deaths.

d. Is there a relationship between the Richter-scale magnitude of an earthquake and the number of resulting deaths? Explain.

Answers vary. It seems as if the higher the Richter-Scale reading recorded, the more deaths resulted. However, there are three earthquakes with $\mathbf{8 . 3}$ Richter-Reading scale but the resultant deaths are not the same. 
Individual

\section{PART B: US WOMEN IN HIGHER EDUCATION.}

\section{Fields of Studies by Gender}

Degrees conferred on women, by field of study, USA, 1980, percentages.

1) Draw a double bar graph to display the number of $B A s$ and $P h D s$ degrees awarded for each field.

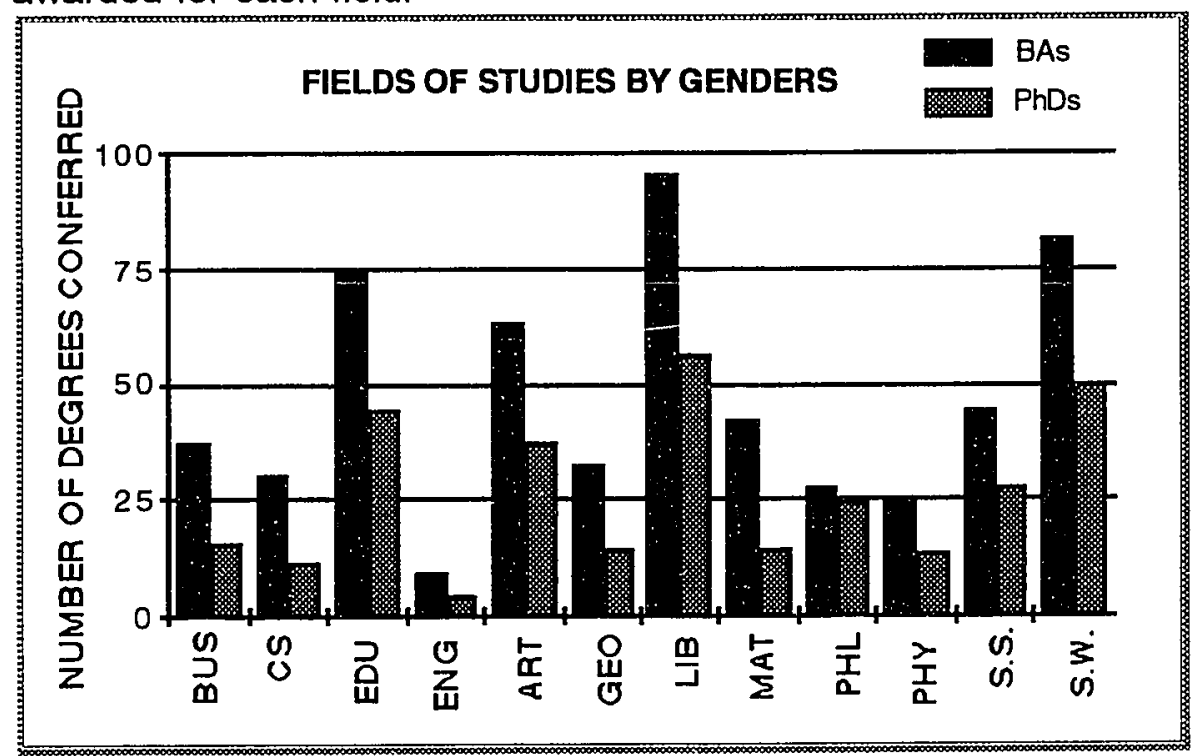

2) Which field of study awarded the least number of BAs and PhDs? Which field of study awarded the most number of BAs and PhDs? Engineering and Library Science.

3) These statistics were collected in 1980. Do you think that there have been any changes in term of the number of degrees awarded to women in the fields of study mentioned in question 2? Explain. Answers vary.

4) Why do you think there are so few women pursuing PhDs in engineering, math, and the physical sciences? Answers vary.

5) What might be done to encourage more women to enter these fields? Answers vary. 
Individual

\begin{tabular}{|l|c|c|}
\hline \multicolumn{1}{|c|}{ Field of study } & Bachelor (BA) (\%) & Doctor of Philosophy (PhD) (\%) \\
\hline Business/Management & 37 & 15 \\
\hline Computer Science & 30 & 11 \\
\hline Education & 74 & 44 \\
\hline Engineering & 9 & 4 \\
\hline Fine \& Applied Arts & 63 & 37 \\
\hline Geography & 32 & 14 \\
\hline Library Science & 95 & 56 \\
\hline Mathematics & 42 & 14 \\
\hline Philosophy & 27 & 24 \\
\hline Physical Sciences & 24 & 13 \\
\hline Social Sciences & 44 & 27 \\
\hline Social Work & 81 & 50 \\
\hline
\end{tabular}


DAY 12 - QUIZ 2

\section{Objectives}

1) To make a frequency table and to draw a histogram

2) To communicate through writing what students learn in this investigation

Materials

Handouts

Quiz 2 for pairs

Other materials

One bag of 40 pennies for each pair of students

$8^{\prime \prime} \times 11^{\prime \prime}$ construction paper for each pair of students

Rulers

Calculators

Homework Discussion

Review for Quiz 12.

Procedure:

1) Quiz 12 : [as much time as the students need] Distribute a copy of Quiz 12, a sheet of construction paper, a ruler, and a bag of pennies to each pair. Have students read Quiz 12 with you so you can clarify any questions that might come up. Remind students to keep track of the total pennies in their bag, .

2) Quiz 12 Report: : Have students display their histograms where they are visible to all students. If time permits, have students read their paragraph to the entire class. Discuss any unusual points from students' reports.

3) Collect all quizzes. 


\section{QUIZ 2}

\section{The Age of Pennies in Circulation}

1) You and your partner will need a bag of pennies, a sheet of construction paper, a calculator, and a ruler for this investigation.

2) Calculate the age of each penny and record it in the space below. Hint: the age of a penny is equal to the difference between the current year and the year printed on the penny.

3) Make a frequency table of the age of pennies.

\begin{tabular}{|l|l|l|}
\hline Intervals of age & Tally & Frequency \\
\hline & & \\
& & \\
& & \\
\hline
\end{tabular}

4) On your construction paper draw a histogram supporting the above frequency table. Hint: A histogram has two axes: one is the intervals axis and the other is the frequency axis.

5) Write a paragraph (at least 5 sentences) on what you learned during this investigation. 


\section{DAY 13 - INTERPRETING CIRCLE GRAPHS (PIE CHARTS) Objective}

Read and interpret circle graphs (pie charts).

\section{Materials:}

Handouts

Worksheet-13A, 13B, 13C, 13D, 13E, 13F (individual)

Homework-13 (individual)

\section{Other materials}

Samples of different circle graphs for your introduction

Calculators

\section{Homework Discussion}

Since the previous day is a test day students will not have any homework to be discussed.

\section{Procedure}

1) Worksheet-13A: [15 minutes] Distribute Worksheet-13A to all students. The whole class will work together to collect data used in part $(A)$. Students will then complete the second part (drawing a bar graph) individually. You may want to ask one volunteer to construct his or her bar graph on the overhead projector. The third part of Worksheet-13A requires you to give a short lecture on circle graphs. This lecture must include the following points:

a. When you use circle graphs to display your data.

b. Show students some examples of circle graphs (masters for these examples are in the "Notes To Teachers" section). Pose some questions that can be answered by observing the graphs. 
c. Define parts of a circle graph, including sectors, central angles; also how a circle graph is labeled (either with the data items or with percents). Display the data on favorite food as a circle graph. At this time students should take notes on circle graphs for future use. 2) Worksheet-13B: [10 minutes] Distribute Worksheet-13B. Even though students may have seen these mathematical concepts, they may not remember precisely what the concepts are. Thus, expect to see some incomplete worksheets. Spend the next five minutes to go over the answers of this worksheet with the class. Make sure that students correct their mistakes immediately.

3) Worksheet-13C: [5 minutes] Distribute Worksheet-13C. Give students a few minutes to find the answers; then with the help of students, work this problem out in detail.

4) Worksheet-13D: [5 minutes] Hand out Worksheet-13D. Repeat step (3).

5) Worksheet-13E: [5 minutes] Distribute Worksheet-13E. Repeat step (3).

6) Wvorksheet-13F: Distribute Worksheet-13F. Students will use the remaining time of the class to complete this worksheet. If the class runs out of time, have students complete this worksheet as part of their homework.

7) Homework-13: Distribute Homework-13.

\section{Notes To Teachers}

A circle graph, sometimes referred to as a pie chart, relates portions of data to the total. In a circle graph the circle represents the total, and pie-shaped sectors represent portions of data. A circle graph is the most appropriate graph to use when the data have the following attributes: the sum of the data is shown, 
and the portions of data are disjoint (data can be divided into categories that do not overlap).

When constructing a graph, one divides the circle into sectors. Each sector represents a percent of the data while the entire circle represents $100 \%$ of the data. Geometrically, each sector of a circle forms a central angle that has the center of the circle as its vertex and the sector's two radii as its sides. The measure of a central angle represents the same percentage of 360 degrees (the sum of all central angles of a circle is 360 degrees) as the sector represents of the entire data.

\section{To draw a circle graph.}

Step 1: Find the total number of data.

Step 2: Determine the number of parts.

Step 3: Calculate the percent of the data represented by each part.

Step 4: Determine the measures of the central angles corresponding to the percents.

Step 5: Draw a circle. Draw a radius. Draw the central angle for each sector.

Step 6: Label each sector with either the percent or the data item. Include a title on the circle graph. 
WORKSHEET-13A

Individual

Part A: What is your favorite food?

1) Collect answers for the above question and tally them in the table below.

As a class choose 4 main types of food for your table, other types of food will be placed in the category "Other."

\begin{tabular}{|l|l|l|}
\hline Type of food & Tally & Total number \\
\hline & & \\
\hline & & \\
\hline & & \\
\hline & & \\
\hline Other & & \\
\hline
\end{tabular}

2) The most appropriate data display for you to visually compare the number of students who like one type of food with the number of students who like other types of food is the bar graph. In the space below draw a bar graph to display the data in the table. 


\section{WORKSHEET-13A (Continued)}

148

3) When you want to compare the number of students who like one type of food with the total number of students in the class, you should use a visual representation called a circle graph. Today we will focus on reading and interpreting circle graphs. You must copy all information provided for future use. 
Review

1) Ratio: is a comparison of two numbers by division. The ratio of two numbers $a$ and $b(b \neq 0)$ can be written in three ways.
a to $b$
$\mathbf{a}: \mathbf{b}$
$\frac{\mathbf{a}}{\mathbf{b}}$

2) Proportion: is a statement that two ratios are equal. If a statement is a true proportion, the cross products of the terms are equal.

$$
\frac{a}{b}=\frac{c}{d} \text { is equivalent to } a d=b c,(b \neq 0),(d \neq 0)
$$

3) Percent: percent is a ratio that compares a number to 100 .

4) Use proportions to solve the following problems:

a. What is $25 \%$ of 30 ?

$$
\begin{aligned}
\frac{25}{100} & =\frac{x}{30} \\
x & =\frac{750}{100}=7.5
\end{aligned}
$$

b. What percent of 30 is 20 ?

$$
\begin{aligned}
\frac{x}{100} & =\frac{20}{30} \\
x \% & =\frac{2000}{30} \sim 67 \%
\end{aligned}
$$


WORKSHEET-13C

Individual \& Group

\section{What is your favorite food?}

The circle graph below shows the results of a survey conducted at Hoday

Junior High School. One of the survey questions asked students to list their favorite food. Of the total number of students surveyed, 154 students responded to the question and 23 did not. Determine the number of students in each category.

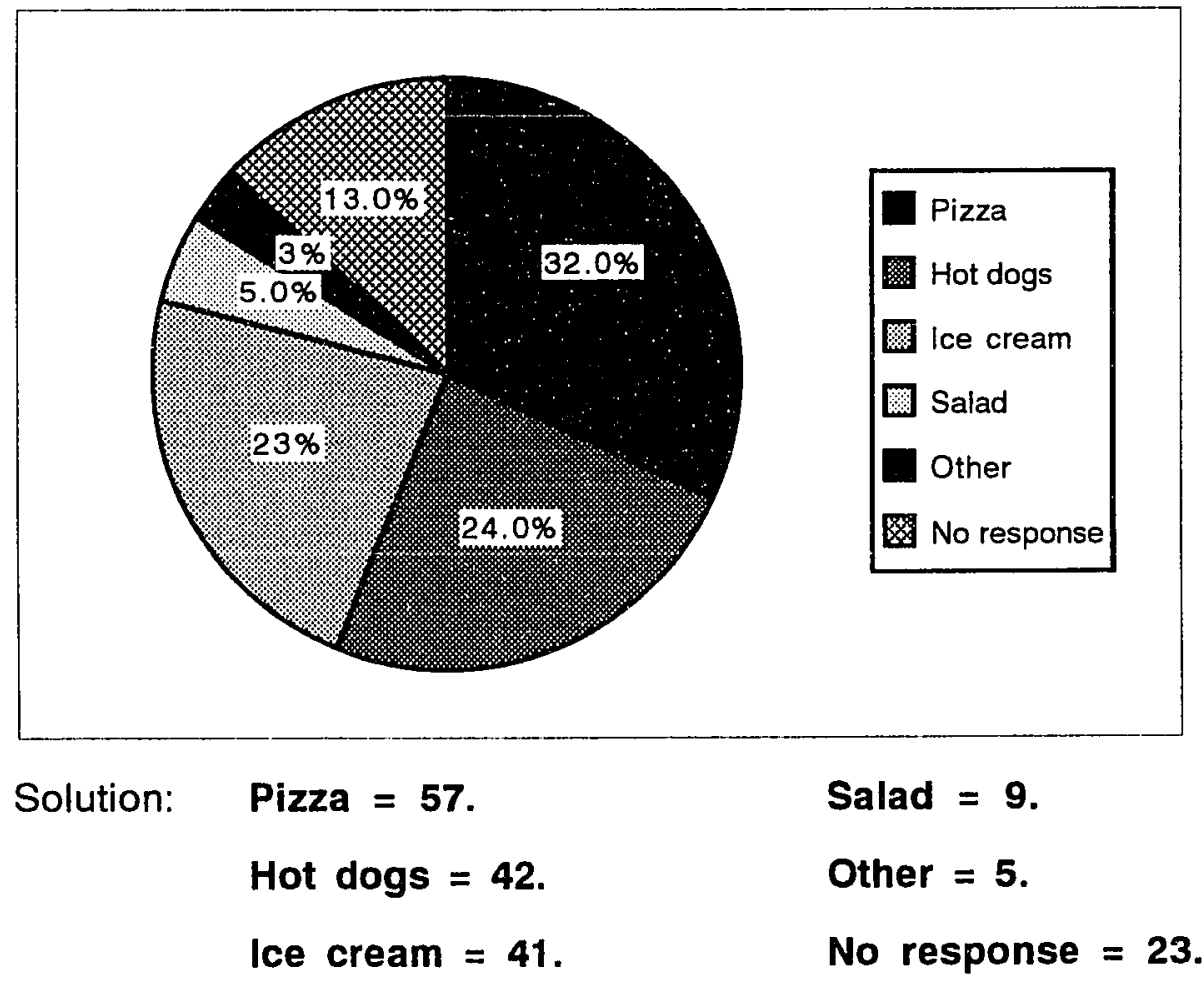




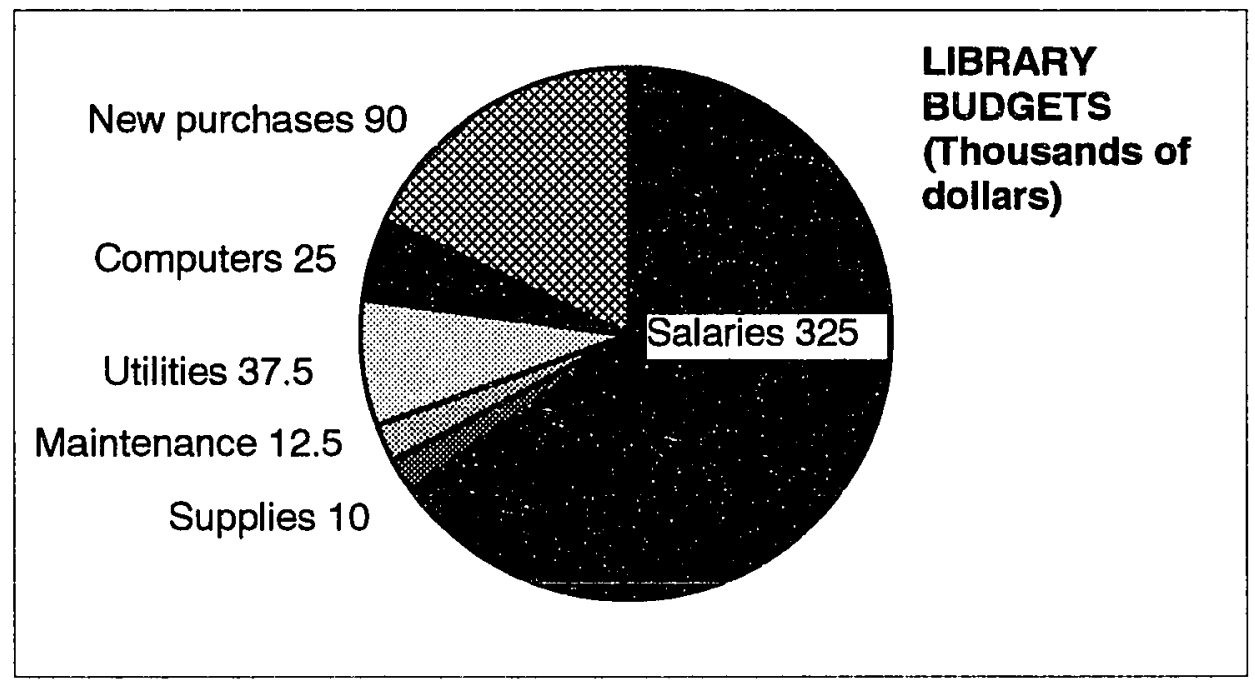

Use the circle graph above.

1) What was the total budget? $\$ 500,000$.

2) What percent of the budget was spent on utilities? $\mathbf{7 . 5 \%}$.

3) What percent of the budget was spent on new purchases? $18 \%$. 


\section{Annual football budget}

The athletic director at State University analyzed how the annual football budget was spent. The results were presented to the budget director in a circle graph like the one below.

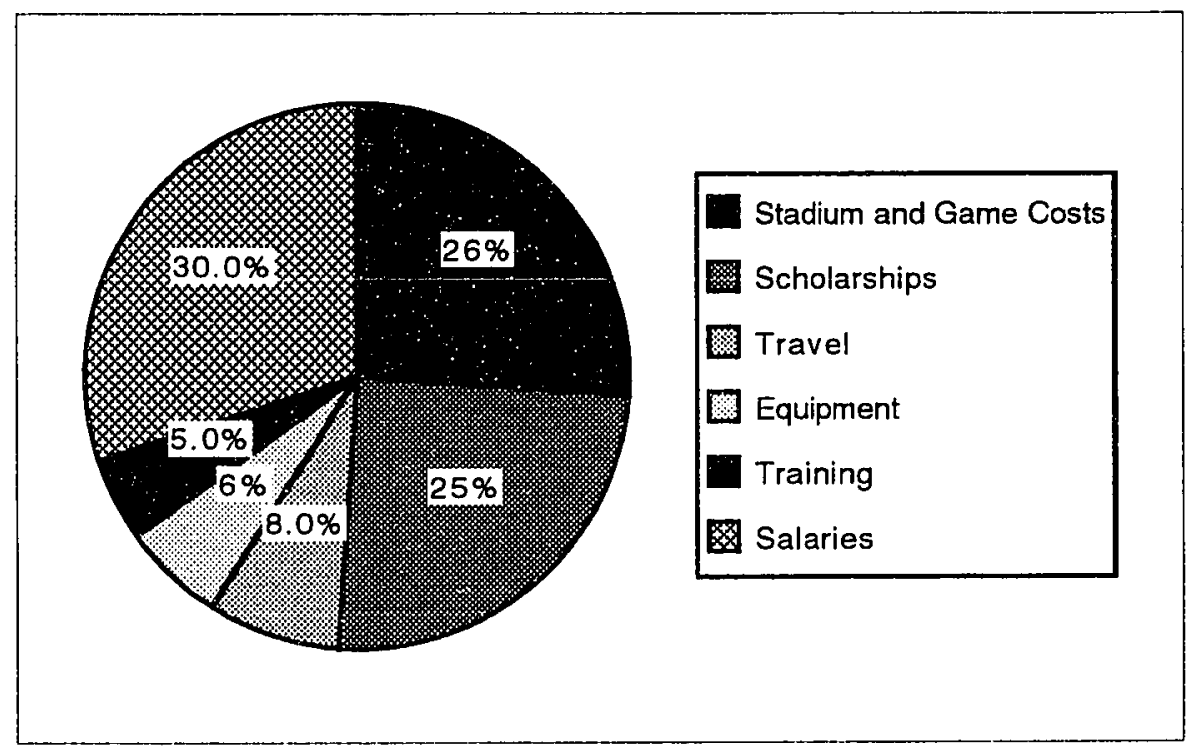

1) If the total budget was $\$ 3,500,000$, how much was spent on scholarships? $\$ 875,000$.

2) If $\$ 1,500,000$ was spent on salaries, how much was the total budget? $\$ 5,000,000$. 
1) What percent is represented by the entire circle in a circle graph? $100 \%$.

2) What are the two ways that you can label the sectors in a circle graph?

The sector in a circle graph can be labeled with the data items or percents.

Use the graph below.

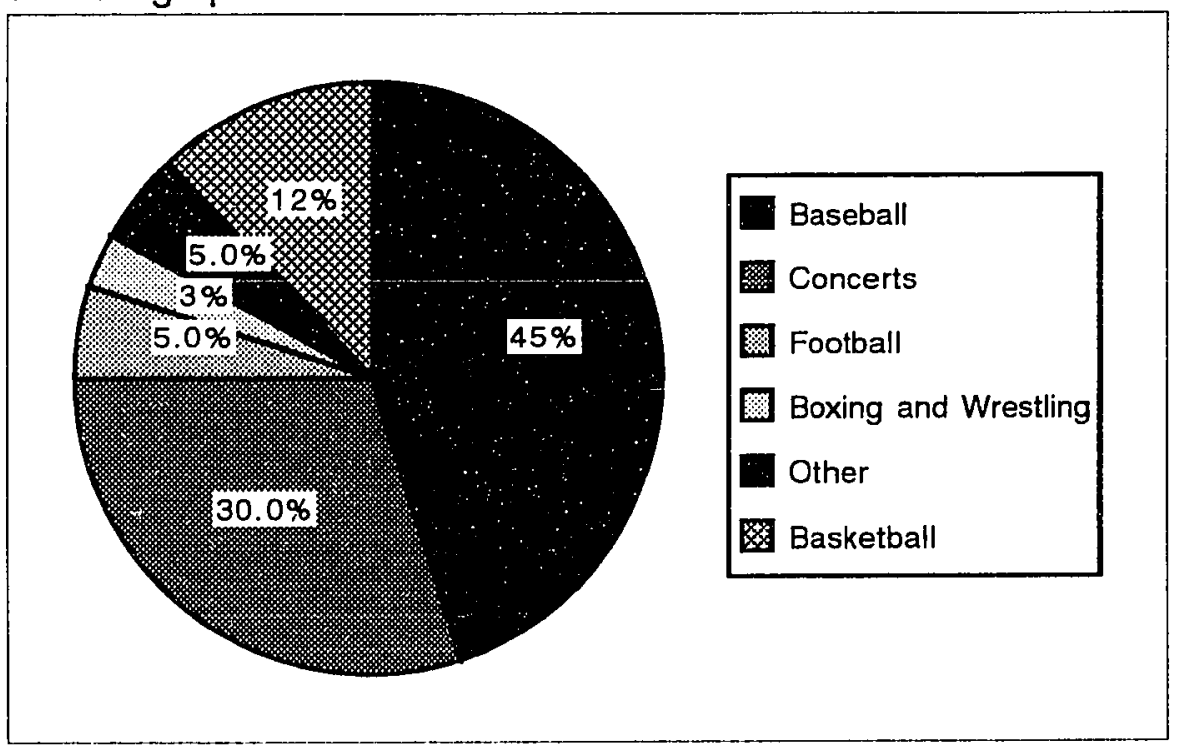

3) What percent of the events were not concerts? $70 \%$.

4) If there was a total of 300 events at the stadium, how many were basketball events? 36.

5) If there were a total of 240 events at the stadium, how many were baseball events? 108.

6) If there were 36 concerts at the stadium, how many events were there in all?

\section{0.}

7) If there were 12 boxing and wrestling events at the stadium, how many events were there in all? 400. 
HOMEWORK-13

Individual

Part A: Use the table below.

\begin{tabular}{|l|c|c|c|}
\hline Student & Mary & Mai & Francisco \\
\hline Weekly Income & $\$ 24.00$ & $\$ 18.00$ & $\$ 33.00$ \\
\hline Savings & $\$ 8.00$ & $\$ 4.00$ & $\$ 8.25$ \\
\hline Food & $\$ 5.00$ & $\$ 3.00$ & $\$ 11.00$ \\
\hline Clothes & $\$ 7.00$ & $\$ 6.00$ & $\$ 6.60$ \\
\hline Videos & $\$ 0.00$ & $\$ 2.00$ & $\$ 3.30$ \\
\hline Other & $\$ 4.00$ & $\$ 3.00$ & $\$ 3.85$ \\
\hline
\end{tabular}

1) Calculate the percentage of each dollar amount spent by each student. Write your answers in the table provided. You must show all your work.

\begin{tabular}{|l|c|c|c|}
\hline Student & Mary & Mai & Francisco \\
\hline Weekly Income & $100 \%$ & $100 \%$ & $100 \%$ \\
\hline Savings & $33 \%$ & $22 \%$ & $25 \%$ \\
\hline Food & $21 \%$ & $17 \%$ & $33 \%$ \\
\hline Clothes & $29 \%$ & $33 \%$ & $20 \%$ \\
\hline Videos & $0 \%$ & $11 \%$ & $10 \%$ \\
\hline Other & $17 \%$ & $17 \%$ & $12 \%$ \\
\hline
\end{tabular}

2) Use the two tables above to answer the following questions:

a. Which student spent the greatest percent on food? Francisco.

b. Which student saves one third of his or her income? Mary.

c. Which student saves the most money? Mary. 
Individual

d. Which student spends one third of his or her income on clothes? Mai.

e. Which student spends the least percent on videos? Mary.

f. Which student spends the same percent of his or her income on food as he or she does on "other" things? Mai.

g. Which students spend the same percent on "other" things? Mary and Mai.

Part B: Comparing bar graphs and circle graphs.

Both bar graphs and circle graphs convey information in visual fashion. Both use geometric shapes, and both are very common in advertising and in news features. Because they are used so often, it is important to be able to understand these displays. It is also important to be able to see the relative strengths and weaknesses of each kind of display and to be able to decide which is more appropriate for a given set of data.

Find each answer.

1) What geometric shape is used to display the data value for each category in a bar graph? Rectangles.

2) What geometric shape is used to display the value for each category in a circle graph? Sectors.

3) Both bar graphs and circle graphs give you a visual display of relative size. In which type of display is it easier to compare the sizes of two categories visually? Bar graphs.

4) In which type of display do you have a better sense of what fraction of the total falls in a given category? Circle graphs. 
Individual

5) Write a few sentences about when you think it might be appropriate to use a bar graph, and when a circle graph would be more appropriate. A circle graph may be most appropriate when you want to visually compare parts of a set of data to whole. A bar graph may be most appropriate when the data fall into distinct categories and you want to compare the totals. 


\section{DAY 14 - CONSTRUCTING CIRCLE GRAPHS (PIE CHARTS) Objective}

Construct circle graphs.

\section{Materials}

\section{Handouts}

Worksheet-14A (individual)

Worksheet 14-B (individual)

Homework-14 (individual)

Other materials

Bags of different colors beads ( 40 beads per bag. One bag for each student)

Strings (one string per student)

20 "X20" construction paper (one for each student)

Boxes of materials that include protractors, colored pencils, rulers, markers, compasses, calculators (one box per group)

\section{Homework Discussion}

Homework-13: [10 minutes] Have students check the numerical answers of section 1 in part $A$ with their respective group's members. You may want to ask one or two students to show their computational work. Discuss section 2 in part A with the entire class. It is important to hold a discussion on part $B$ of the homework because the answers in this discussion will help students to start thinking about appropriate choices for data displaying.

\section{Procedure}

1) Worksheet-14A: [25 minutes] Ask students to picture a whole pizza. Each slice of the pizza represents a part of the entire pizza. If the slices are taken out 
and then put back next to one another, the whole pizza can be constructed. Today we will use this idea to represent data that are parts of a whole. This type of representation is called a circle graph.

Distribute Worksheet-14A, a sheet of 20"x20" construction paper, and a piece of string to each student and a box of materials to each group. Give students about 15 minutes to complete this worksheet.

Hold a ten-minute discussion about the worksheet. It is important for the students to know the following points:

a. When you construct a circle graph, you divide the circle into sectors. Each sector forms an angle and the sum of the angles formed by the sectors of a circle is 360 degrees. These angles are called central angles because they each have a vertex at the center of the circle. The construction of a circle graph, thus, depends on the construction of its sectors; or more accurately depends on the construction of the central angles formed by the sectors.

b. The percentage of each type of bead is approximately the same as the percentage of the degree of the corresponding central angle (comparison between columns "Percentage X\%" and "Percentage $Y \% ")$. For any circle graph we will use this observation to determine the degrees of the central angles of that circle graph.

2) Worksheet-14B: [15 minutes] Hand out Worksheet-14B. Students will work on this worksheet under the step-by-step instruction of the teacher. The teacher should: 
a. Pose the question: Can you use the construction method in Worksheet-14A to construct a circle graph in Worksheet-14B? Why?

(No. Expect a variety of reasons including: time consuming, large circle graph, too many items... As a result, students must learn methods to construct circle graphs without using actual items).

b. Repeat the observation in question 10 of Worksheet-14A: the percentage of the beads in each sector is approximately the same as the percentage of the degrees of the central angle. Since we decide that it is too tedious to draw the M\&Ms circle graph by actual M\&Ms, we will use this observation to construct it. The steps are:

- Find the percentage of the number of M\&Ms of each color, using proportion:

$$
\frac{\text { Number of M\&Ms of each color }}{\text { Total number of M\&Ms }}=\frac{X}{100}
$$

- Find the degrees of each central angle of a sector, using the following proportion:

$$
\frac{\text { Percentage of M\&Ms }}{100}=\frac{Y \text { degrees }}{360 \text { degrees }}
$$

- Draw a circle. Draw a radius. Use a protractor to draw the central angle for each sector.

- Label each sector with the corresponding type of M\&Ms and the number or the percent of M\&Ms of that type.

- Name the circle graph.

3) Homework-14: Collect Worksheet-14A. Distribute Homework-14. 
Notes To Teachers

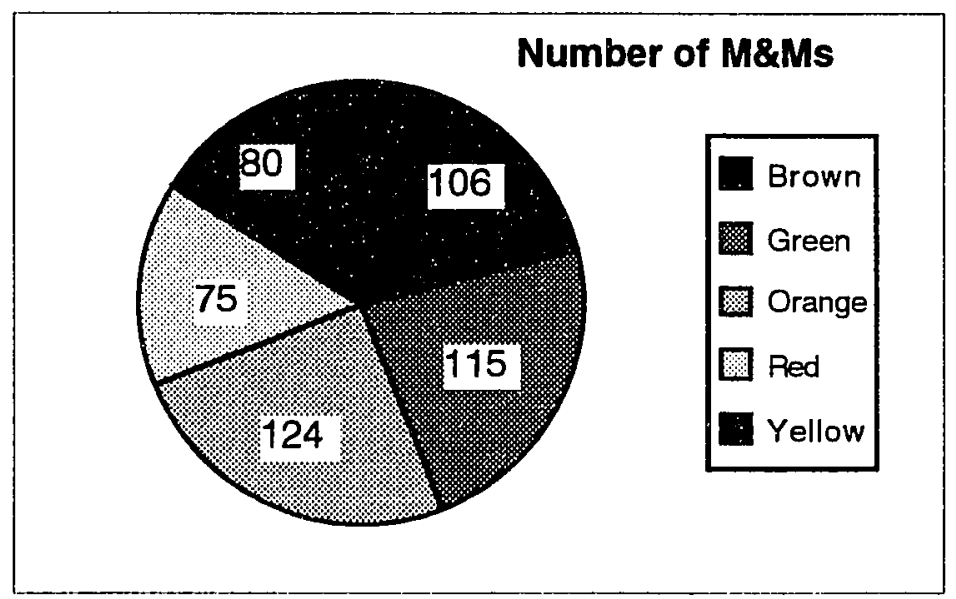




\section{1}

WORKSHEET-14A

Individual \& Group

\section{Part A: Construct a beads graph.}

1) Obtain a bag of beads, a box of materials, a sheet of 20 "x 20 " construction paper for your group.

2) Sort the beads out by color and then count the total number of beads for each color. Record them in the table provided.

3) Thread the beads on a string so that like colors are together.

4) Use your string of beads to form a circle on your construction paper. Trace along the beads to record this circle on the construction paper. Be sure to mark the beginning and the end of each part of like-color beads.

5) Remove the string of beads. Locate the center of the circle on the construction paper. Connect the two ends of each segment of like-color beads with the center of the circle.

6) Use colored pencils to color the corresponding sectors of the circle.

\section{Part B: Calculation}

7) Use a protractor to measure the central angle of each sector. Record this degree measure in the table provided.

\begin{tabular}{|l|l|l|l|l|}
\hline Color & Number of beads & $\mathrm{X} \%$ & Degrees & $\mathrm{Y} \%$ \\
\hline & & & & \\
\hline & & & & \\
\hline & & & & \\
\hline & & & & \\
\hline & & & & \\
\hline
\end{tabular}


Individual \& Group

8) Complete the column "X\%." Calculate the percentage of beads for each color using the following formula (where $\mathrm{X} \%$ represents the percentage of beads of a particular color.)

$$
\frac{\text { Number of beads of each color }}{\text { Total number of beads }}=\frac{X}{100}
$$

9) Complete the column "Y\%." Calculate the percentage of the degrees of each central angle using the following formula (where $Y \%$ is the percentage of the number of degrees of each angle):

$$
\frac{\text { Number of degrees of each angle }}{360 \text { degrees }}=\frac{Y}{100}
$$

10) Compare the columns "X\%" and "Y\%." What are your conclusions? 
WORKSHEET-14B

Individual \& Group

Draw a circle graph to display the number of five different colors of M\&Ms in a bag.

Numbers of M\&Ms

\begin{tabular}{|l|l|l|l|l|l|}
\hline Color & Brown & Green & Orange & Red & Yellow \\
\hline Number & 106 & 115 & 124 & 75 & 80 \\
\hline
\end{tabular}

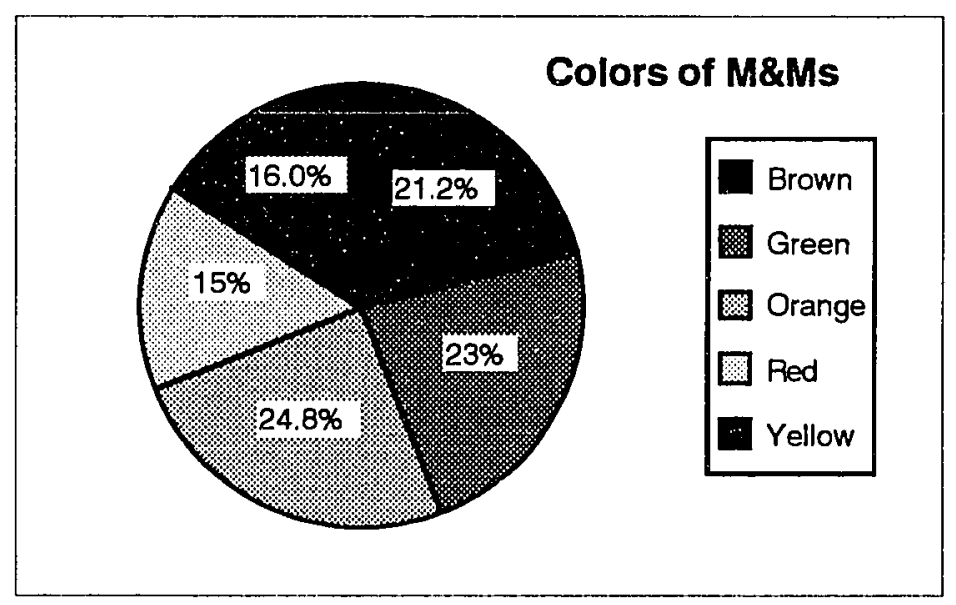




\section{HOMEWORK-14}

Individual

Part A: Numbers of M\&Ms

The degrees of a central angle in a sector can be found by another type of proportion. For example, the degrees for a central angie in Worksheet-14B can be computed by the following proportion:

$$
\frac{\text { Number of M\&Ms of a color }}{\text { Total number of M\&Ms }}=\frac{X \text { degrees }}{360 \text { degrees }}
$$

Use the above proportion to complete the chart below as if you were going to draw a circle graph to display the data. Show all your computational work.

\begin{tabular}{|l|c|c|}
\hline Type of Movie & Number of Movie & $\begin{array}{l}\text { Degrees of Central } \\
\text { Angle }\end{array}$ \\
\hline comedy & 100 & $\mathbf{7 2}$ \\
\hline mystery & 200 & $\mathbf{1 4 4}$ \\
\hline musical & 60 & $\mathbf{4 3}$ \\
\hline action/adventure & 125 & $\mathbf{9 0}$ \\
\hline other & 15 & $\mathbf{1 1}$ \\
\hline
\end{tabular}

Part B: Whom Do High School Students Admire Most? (Parade Magazine, May 2, 1993)

Connie Chung, the TV journalist, is the woman most admired by the high school Class of '93. The most admired man is Michael Jordan, the Chicago Bulls basketball star. 
Individual

Those were the findings in a recent survey of 3500 seniors by Careers and College magazine and the National Association of College Admissions Counselors. The college-bound students were given a list of four men and four women, then asked to name the one on each list they most admired.

Chung received $47 \%$ of the vote for women, followed by tennis star Monica Seles (25\%); the actress Tori Spelling of Beverly Hills, 90210, Fox-TV's popular show about high school (15\%); and Rep. Patricia Schroeder of Colorado (13\%).

Jordan got $57 \%$ of the men's vote, trouncing the competition: Gov. Mario Cuomo of New York (17\%); Microsoft CEO Bill Gates (14\%); and the actor Luke Perry (12\%), Spelling's Beverly Hills, 90210 co-star.

1) Read the above article and set up 2 charts (one for women and one for men) that shows the categories, the percentage of each category, the number of votes for each category, and the degrees of the central angle of the corresponding sector.

\begin{tabular}{|l|c|c|c|}
\hline \multicolumn{1}{|c|}{ Name } & Percentage & Number of votes & Degrees of angle \\
\hline Connie Chung & $47 \%$ & 2590 & 169 \\
\hline Rep. P. Schroeder & $13 \%$ & 455 & 47 \\
\hline Monica Seles & $25 \%$ & 875 & 90 \\
\hline Tori Spelling & $15 \%$ & 525 & 54 \\
\hline
\end{tabular}


Individual

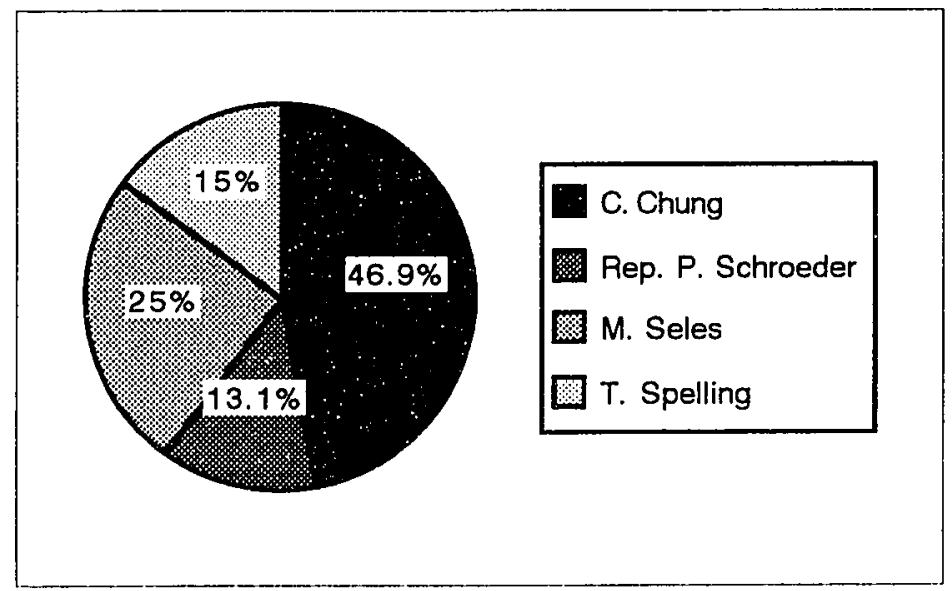

\begin{tabular}{|l|c|c|c|}
\hline \multicolumn{1}{|c|}{ Name } & Percentage & Number of votes & Degrees of angle \\
\hline Gov. Mario Cuomo & $17 \%$ & 595 & 61 \\
\hline CEO Bill Gates & $14 \%$ & 490 & 50 \\
\hline Michael Jordan & $57 \%$ & 1995 & 205 \\
\hline Luke Perry & $12 \%$ & 420 & 43 \\
\hline
\end{tabular}

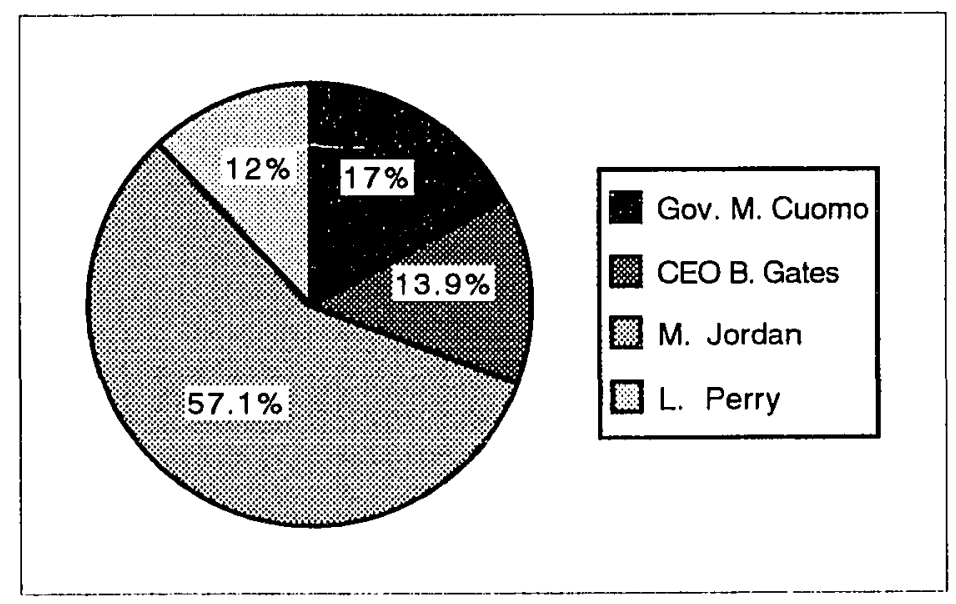


Individual

2) Use the above information to draw 2 circle graphs to display the data in the article. See above.

3) Do you think the results of this survey reflect the opinions of most high school seniors in the US? Why or why not? No, because the choices are limited. 
DAY 15 - SCATTER PLOTS

\section{Objective}

Interpret and construct scatter plots

\section{Materials}

Handouts

Worksheet-15A (individual)

Worksheet-15B (subgroups)

Worksheet-15C (individual)

Homework-15 (individual)

\section{Other materials}

Transparencies of the graphs of Examples 1, 2, 3

Tape measures

Graph paper

\section{Homework Discussion}

Homework-14: [5 minutes] Due to the length of today's lesson, you may want to grade the homework yourself or let group members grade each other's homework as a part of today's homework.

\section{Procedure}

1) Lecture: [5 minutes] People who analyze data sometimes encounter problems that require them to determine if a relationship exists between two sets of data. One of many methods that these people use is creating scatter plots.

Use Example 1 (plot that shows positive association) in the Notes to Teachers section to discuss the motivation for drawing scatter plots. Show a transparency of the scatter plot for this example and ask students if they think 
there is a relationship between the set of number of minutes studied and the set of test scores. If students cannot recognize the relationship you may want to guide them by suggesting students to: imagine what the shape of the graph reminds them of, examine the coordinates of the plotted points. Students should recognize that there is a positive association between the two data sets; i.e., the more hours you study the better grade you get. You may want to have students discuss the validity of the above conclusion.

Show transparencies of different scatter plots (Examples 2 and 3 in the Notes to Teachers section). Talk about the relationship between the two variables in each scatter plot and the name given for each relationship. Remind students that a scatter plot is a type of graph that requires two sets of data.

2) Worksheet-15A: [10 minutes] Distribute Worksheet-15A to each student. Since this worksheet requires students to interpret a given scatter plot, students may need a short review on graphing points. After a review on graphing points, give students about 5 minutes to complete the worksheet. Students can either work by themselves or with their groups' members. Discuss Worksheet-15A with the class. Do not spend more than 5 minutes on the discussion.

3) Worksheet-15B: [15 minutes] Furnish each group with two copies of the "Box Office Hits," one copy of Worksheet-15B (Subgroup 1), one copy of Worksheet15B (Subgroup 2), all graph paper needed for all group members. Each group then will divide itself into two subgroups: one subgroup will be working on Worksheet-15B (Subgroup 1), and the other will be working on Worksheet-15B (Subgroup 2). Make sure that each subgroup has at least two students and at 
most three students. Give students about 10 minutes to complete their worksheets.

4) Worksheet-15C: [15 minutes] Have all original groups reform. Distribute Worksheet-15C. Students will need approximately 10 minutes to compare their answers from Worksheet-15B and answer the questions in Worksheet-15C. Hold class discussion.

5) Homework-15: Collect worksheets and distribute Homework-15.

\section{Notes To Teachers}

Scatter plots are most useful for determining if there is a relationship between two variables. For example, scatter plots can be use to determine a relationship between the number of minutes studied and the test scores, or to determine if a relationship exists between the heights and weights of a target group of people. In a scatter plot, the data are represented by points, which are determined by ordered pairs of horizontal $(X)$ and vertical $(Y)$ coordinates. Unlike line graphs, which are discussed in the next lesson, points in a scatter plot are not connected. Furthermore, a scatter plot may have more than one point for a given horizontal or vertical coordinate; however, in line graphs, there is only one point for any given X-coordinate.

The points on a scatter plot usually do not lie on a line. However, the points on some scatter plots lie near a line. The line that lies near most of the points on a scatter plot is called the trend line. It can be used to make predictions about the data. If the trend line slopes upward to the right, there is a positive association between the sets of data. If the trend line slopes downward to the right, there is a negative association. Some scatter plots do not show any association (no recognizable slope); thus, no trend exists. 
Example 1: In the search for effective ways of improving mathematics performance of students, Ms. Green asked her students to write down the average number of minutes they spent studying math each school night. Later, she paired the study time of each student with the score on the most recent test. On her paper, Ms. Green recorded those two numbers in ordered pairs $(X, Y)$, where $X$ is the number of minutes studied and $Y$ is the test score. The results appear as follow: $(0,20),(10,24),(15,30),(17,30),(25,20),(30,40),(32,36)$, $(40,38),(36,40),(44,42),(45,46),(47,34),(50,38),(55,42),(50,44),(58$, $50),(62,38),(64,40),(67,44),(63,46),(65,48),(66,49),(65,50)$. The scatter plot for this collection of ordered pairs is shown below.

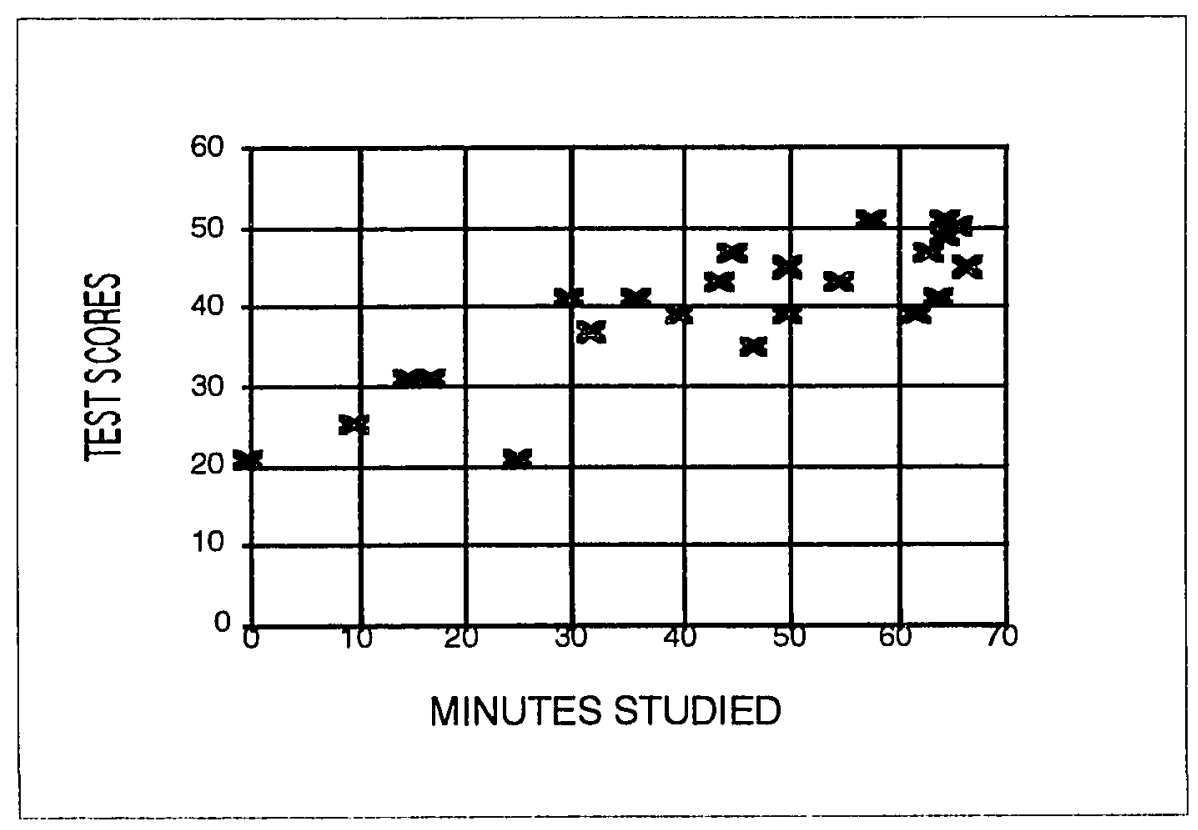


Example 2: This example demonstrates a negative association between the number of movies attended and a person's age. You may want to ask some questions which help students to recall what they learned about coordinates of points and how to graph them (moves they have to make to locate a point).

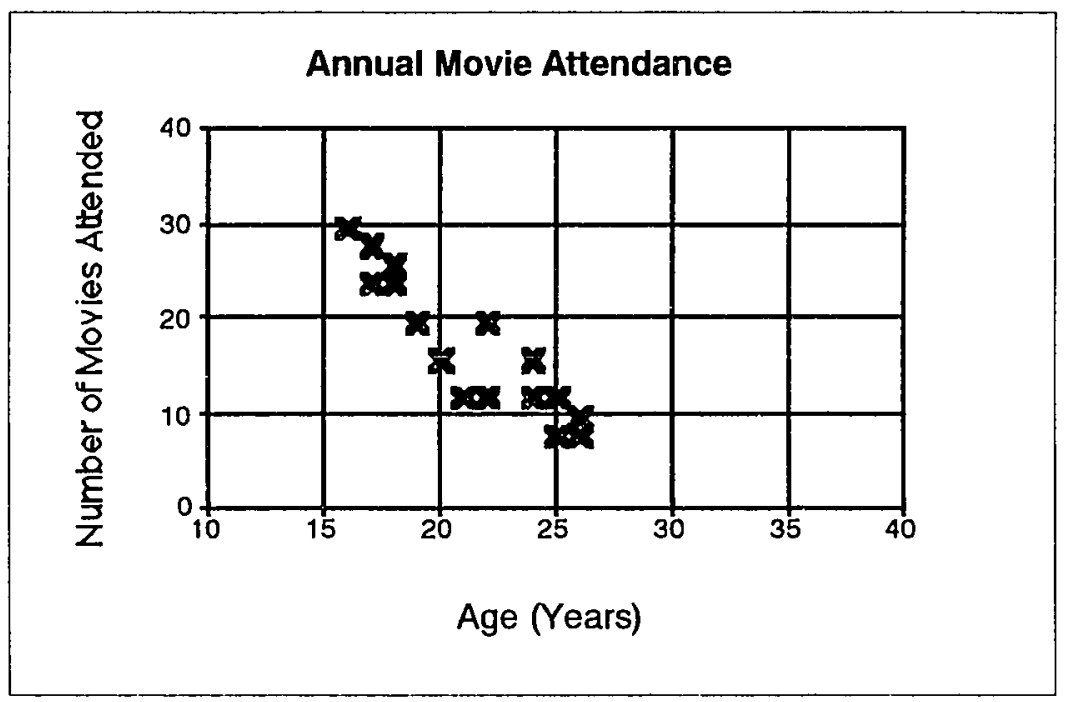

Example 3: The graph below shows a no association scatter plot.

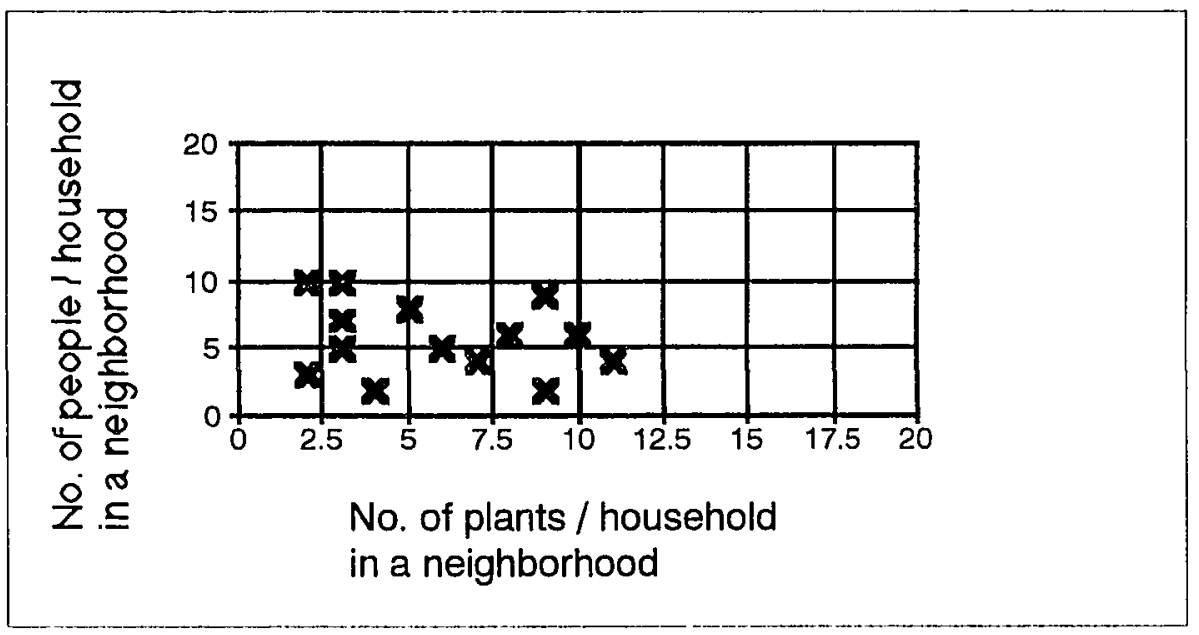


To draw a scatter plot.

Step 1: Draw two perpendicular axes - one to represent each set of data.

The horizontal axis can represent either set of data as the vertical axis.

Step 2: Divide the horizontal axis into equal interval distances so that all data values can be included on this axis. Repeat this procedure on the vertical axis (it is not necessary that the interval distances on the horizontal axis be equal to the interval distances on the vertical axis).

Step 3: Plot the points on the graph.

Step 4: Label the axes and title the graph. 
More Study Time, Higher Test Score?

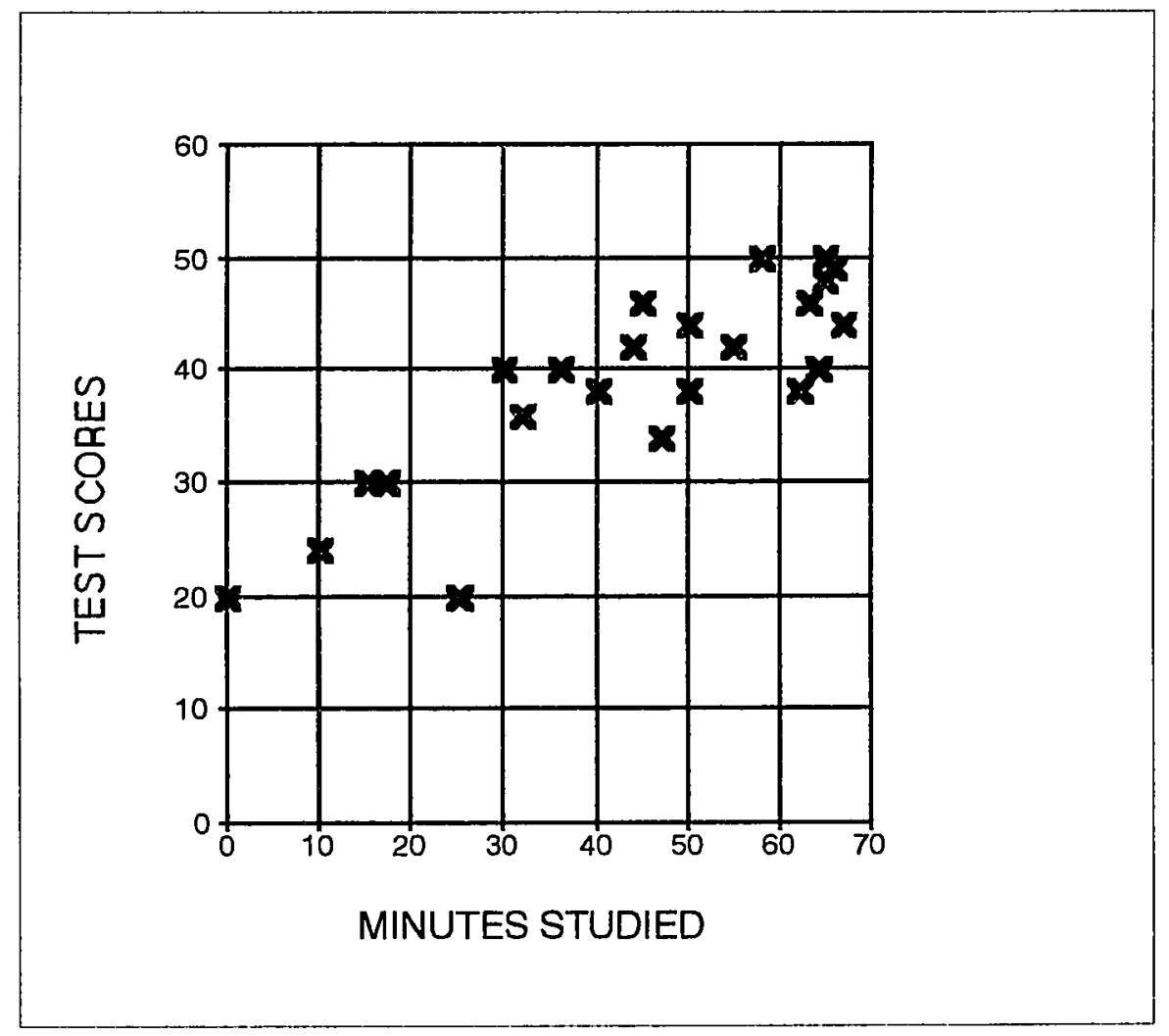

Use the above scatter plot to answer the following questions.

1)What was the test score of the student who studied for 45 minutes? How did you obtain this score? Approximately 46.

2) How many students studied more than 60 minutes? How did you get this number? Seven students.

3) Predict the test score for a student who studies for 70 minutes. 52. 
BOX OFFICE HITS

Individual \& Group

The table below shows production costs, promotion costs, and gross ticket sales for twelve of the most popular "dumb" movies of the year 1984. The box office grosses were obtained from studios and are estimated.

\begin{tabular}{|c|c|c|c|c|}
\hline Title & Year & $\begin{array}{l}\text { Production } \\
\text { Costs } \\
\end{array}$ & $\begin{array}{l}\text { Promotion } \\
\text { Costs } \\
\end{array}$ & $\begin{array}{l}\text { Worldwide } \\
\text { Ticket Sales }\end{array}$ \\
\hline "Animal House" & 1978 & $\$ 2.9$ million & $\$ 3$ million & $\$ 150$ million \\
\hline "Meatballs" & 1979 & $\$ 1.4$ million & $\$ 2$ million & $\$ 70$ million \\
\hline "Caddyshack" & 1980 & $\$ 4.8$ million & $\$ 4$ million & $\$ 60$ million \\
\hline "Stripes" & 1981 & $\$ 10.5$ million & $\$ 4.5$ million & $\$ 85$ million \\
\hline "Spring Break" & 1982 & $\$ 4.5$ million & $\$ 5$ million & $\$ 24$ million \\
\hline "Porky's" & 1982 & $\$ 4.8$ million & $\$ 9$ million & $\$ 160$ million \\
\hline $\begin{array}{l}\text { "Fast Time At } \\
\text { Ridgemont High" }\end{array}$ & 1982 & $\$ 5$ million & $\$ 4.9$ million & $\$ 50$ million \\
\hline $\begin{array}{l}\text { "Porky's II-The Next } \\
\text { Day" }\end{array}$ & 1983 & $\$ 7$ million & $\$ 7.5$ million & $\$ 55$ million \\
\hline "Hot Dog-The Movie" & 1984 & $\$ 2$ million & $\$ 4$ million & $\$ 22$ million \\
\hline "Bachelor Party" & 1984 & $\$ 7$ million & $\$ 7.5$ million & $\$ 38$ million \\
\hline $\begin{array}{l}\text { "Revenge of the } \\
\text { Nerds" }\end{array}$ & 1984 & $\$ 7$ million & $\$ 7.5$ million & $\$ 42$ million \\
\hline "Police Academy" & 1984 & $\$ 4.5$ million & $\$ 4$ million & $\$ 150$ million \\
\hline
\end{tabular}


WORKSHEET-15B

\section{Total Costs versus Worldwide Tickets Sales}

1) On the graph paper provided, follow the steps below to make a scatter plot for total costs and worldwide tickets sales.

a. Draw 2 perpendicular axes. Label the horizontal axis "TOTAL COST IN MILLIONS OF DOLLARS" and the vertical axis "SALES IN MILLION OF DOLLARS."

b. Determine the smallest and largest values of the total costs in millions of dollars. Divide the horizontal axis into equal intervals such that all the numbers between the smaliest and the largest values can be included on the axis.

c. Determine the smallest and largest values of the sales in millions of dollars. Mark the vertical axis into equal intervals so that all values between the smallest and the largest can be included on the axis. d. Plot the points on the graph. Remember: a point is determined by an ordered pair $(x, y)$; in this case, $x$ is the total cost in millions of dollars and $y$ is the sales in millions of dollars. This point can be located on the graph as follows: starting at the origin (the intersection of the 2 axes), move $\mathrm{x}$ steps horizontally and then move $y$ steps vertically; the final destination of the vertical move is the point we want to graph.

e. Name your graph. 
Subgroup 1

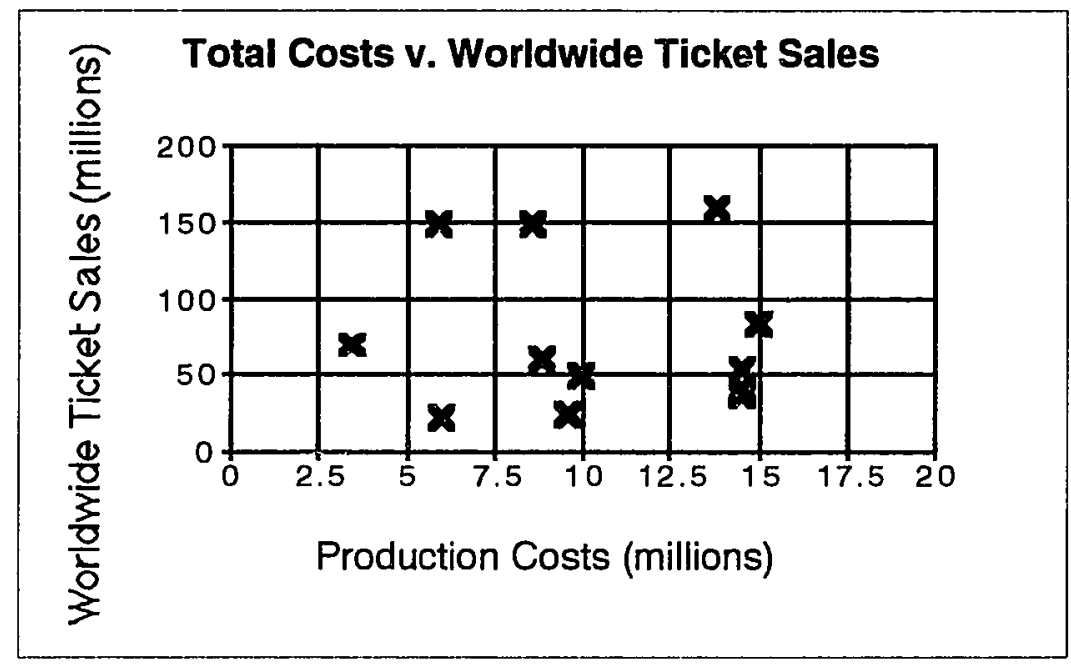

2) Use your graph to answer the following questions.

a. For a given number on either axis, does the scatter plot have more than one point? If it does, what can you say about the coordinates of these points? Yes. The points on the same horizontal (vertical) line have the same $y$-coordinate ( $x$-coordinate). b. Can you detect a relationship between the two data sets? If there is, how are the two sets related? No.

c. Can you draw a line that is near all points on the graph? If the answer is "Yes", draw the line. If the answer is "No", explain why. No. A line can be drawn through the points in the top half of the plot; however, this line is not anywhere near the points in the bottom half of the plot. A similar argument applies to a line to be drawn near the points in the bottom half. A line that separates the top and bottom halves does not go through any plotted points. 
WORKSHEET-15B

Subgroup 2

\section{Production Costs versus Promotion Costs}

1) On the graph paper provided, follow the steps below to make a scatter plot for the production costs and the promotion costs.

a. Draw 2 perpendicular axes. Label the horizontal axis "PRODUCTION COST IN MILLIONS OF DOLLARS" and the vertical axis "PROMOTION COST IN MILLIONS OF DOLLARS."

b. Determine the smallest and largest values of the production costs in million of dollars. Divide the horizontal axis into equal intervals such that all the numbers between the smallest and the largest values can be included on the axis.

c. Determine the smallest and largest values of the promotion cost in million of dollars. Mark the vertical axis into equal intervals so that all values between the smallest and the largest can be included on the axis. d. Plot the points on the graph. Remember: a point is determined by an ordered pair $(x, y)$; in this case, $x$ is the production cost in millions of dollars and $y$ is the promotion cost in million of dollars. This point can be located on the graph as follows: starting at the origin (the intersection of the two axes), move $x$ steps horizontally and then move $y$ steps vertically; the final destination of the vertical move is the point we want to graph. e. Name your graph. 


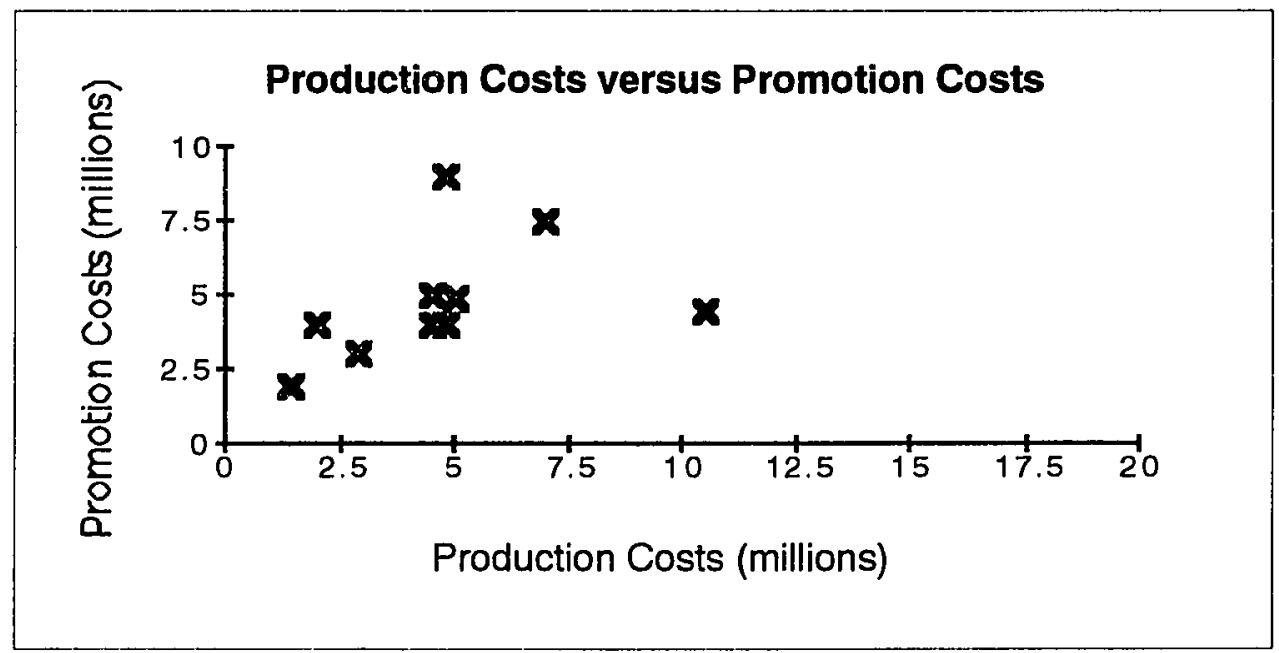

2) Use your graph to answer the following questions.

a. For a given number on either axis, does the scatter plot have more than one point? If it does, what can you say about the coordinates of these points? Yes. The points on the same horizontal (vertical) line have the same $y$-coordinate (x-coordinate).

b. Can you detect a relationship between the two data sets? If so, how are the two sets related? Yes, positive association.

c. Can you draw a line that is near all points on the graph? If the answer is "Yes," draw the line. If the answer is "No," explain why. Yes. 
Use the scatter plots of both subgroups to answer the questions below.

1) Is there positive association, negative association, or no association between total costs and worldwide ticket sales? No association.

2) Which movie(s) would you say did the best when costs are compared to ticket sales? Animal House, Police Academy, Porky's.

3) Which movie(s) would you say did the worst when costs are compared to ticket sales? Bachelor Party.

4) Is there a positive, negative, or no association between production costs and promotion costs? If the right most point (an outlier) is not considered there seems to be a positive linear association. If this point is included there seems to be a non-linear association (neither negative or positive).

5) If a studio spends $\$ 4$ million on production costs, about how much money would you expect the studio to spend promoting the movie? 4-5 millions. 6) Write a description of the information displayed by the two scatter plots.

\section{Answers vary.}




\section{HOMEWORK-15}

Part A: Protein versus Fat.

The following scatter plot shows the grams of fat versus the grams of protein in individual servings of lunch and dinner items sold at various fast food restaurants.

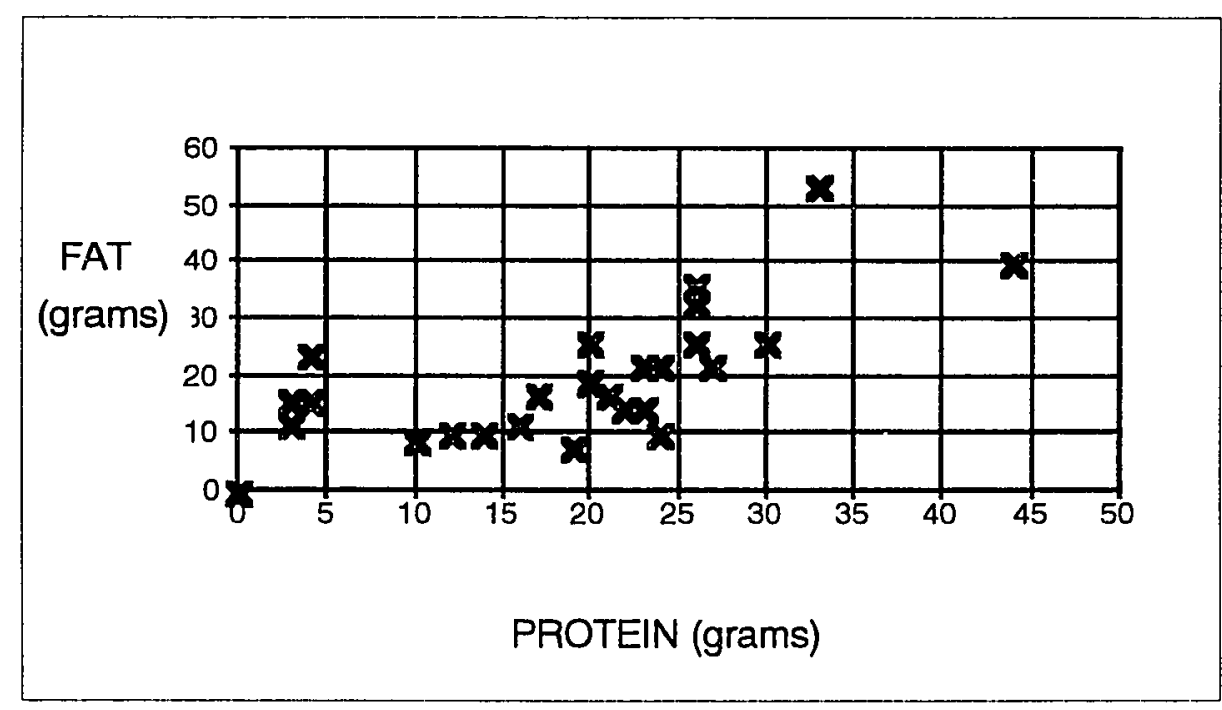

1) Suppose you want protein without much fat. Give the number of grams of protein and the number of grams of fat in the item that you would select.

$19 \mathrm{~g}$ of protein and $8 \mathrm{~g}$ of fat or $24 \mathrm{~g}$ of protein and $10 \mathrm{~g}$ of fat.

2) What is the largest number of grams of protein in any item? $44 \mathbf{g}$.

3) What is the number of grams of fat in the item in question 2 ? $40 \mathrm{~g}$.

4) Does the item in question 2 have an unusually large amount of fat considering how much protein it has? No, because there is an item that has only $26 \mathrm{~g}$ of protein but contains about $39 \mathrm{~g}$ of fat.

5) What is the smallest number of grams of protein in any item? $3.5 \mathrm{~g}$.

6) How many grams of fat did the item in question 5 have? $11 \mathrm{~g}$. 
Individual

7) Is there a positive, negative, or no association between grams of protein and grams of fat? Positive association.

8) If a new item has 32 grams of protein, how many grams of fat would you expect it to have? $35-40 \mathrm{~g}$.

Part B: Solar system.

Here is some information about the planets in our solar system:

\begin{tabular}{|c|c|c|c|c|c|}
\hline Planet & $\begin{array}{l}\text { Diameter } \\
\text { (miles) }\end{array}$ & $\begin{array}{c}\text { Distance from sun } \\
\text { (miles) }\end{array}$ & Moons & $\begin{array}{l}1 \text { rotation } \\
\text { (earth time) }\end{array}$ & $\begin{array}{c}\text { Orbit } \\
\text { (earth time) }\end{array}$ \\
\hline Mars & 4218 & 142 million & 2 & $24.4 \mathrm{hrs}$ & 687 days \\
\hline Earth & 7926 & 93 million & 1 & $24 \mathrm{hrs}$ & 365 days \\
\hline Jupiter & 89,400 & 483 million & 16 & $10 \mathrm{hrs}$ & 11.86 years \\
\hline Mercury & 3,100 & 36 million & 0 & 59 days & 88 days \\
\hline Neptune & 30,000 & 2.8 billion & 3 & $18-22$ hrs & 165 years \\
\hline Pluto & 1,900 & 3.7 billion & 1 & 6.4 days & 248 years \\
\hline Saturn & 75,000 & 886 million & 20 & $10.4 \mathrm{hrs}$ & 29.46 years \\
\hline Uranus & 32,300 & 1.8 billion & 15 & $17 \mathrm{hrs}$ & 84 years \\
\hline Venus & 7,500 & 67 million & 0 & 243 days & 225 days \\
\hline Sun & 870,000 & - & - & - & - \\
\hline
\end{tabular}

1) Make a scatter plot using data from two different columns in the above chart. Is there any irend in your scatter plot? If there is, draw the trend line.

2) Write a paragraph describing what you observe about your scatter plot . 
Individual

Here are some ideas for your plot .
a. planet diameter and distance from the sun
b. planet diameter and number of moons
c. planet diameter and time for one orbit (or one rotation)
d. distance from the sun and number of moons
e. distance from the sun and time for one orbit (or one rotation)
f. number of moons and time for one orbit (or one rotation)
g. time for one rotation and time for one orbit. 


\section{DAY 16 - LINE GRAPHS Objective}

Interpret and graph line graphs

\section{Materials}

\section{Handouts}

Worksheet-16A

Worksheet-16B

Homework-16

Other materials

A world map and a poster of the Olympics flag

\section{Homework Discussion}

Homework-15: [10 minutes] Discuss Worksheet-15C and Homework-15 as much as possible. Make sure that students can recognize positive association, negative association, and no association scatter plots.

\section{Procedure}

1) Lecture: [ 5 minutes] Spend about 5 minutes to introduce the history of the Olympics. During this introduction you may want to point out the locations of the places mentioned in the story on the world map [Information on the Olympics is in the "Notes to Teachers" section.]

Show students how a line graph can help people make decisions for the future. Ask students to imagine that they are members of the US Olympic Committee in a meeting preparing for the 1996 Summer Olympics in Atlanta, Georgia. At the front of the room, on the overhead, is a chart with a crooked line showing the number of athletes participating in past Olympic games (Chart and data are in the Notes To Teachers section). The committee members should be 
able to observe that the line on the graph moves up from left to right, showing that the number of participating athletes is increasing.

Pose the following questions:

a. How might this line graph affect the committee's decisions regarding the preparation for the games? [Number of athletes in the 1996 games is more than that of the 1994 game. Therefore, there should be more rooms in the athletes' village; more security to protect athletes].

b. Is there a possibility that the number of athletes participating the 1996 game would be less than that of the 1994 game? [Yes, due to the world's unstable political condition.]

2) Worksheet-16A: [25 minutes] Break students into their learning groups. Distribute copies of Worksheet-16A (Individual) to all students and one copy of Worksheet-16A (Individual \& Group) to each group. Have one student in the group read the questions, the other students look at their copies of line graphs and provide the answers. The student who reads the questions is also in charge of recording the group's answers onto Worksheet-16A's questions copy.

Hold a 10-minute discussion. Students must be able to recognize increasing and decreasing trends. Students also must be able to predict what may happen in the future based on the trend of the graph.

3) Worksheet-16B: [10 minutes] Hand out Worksheet-16B to all students. Have students complete this worksheet individually. Students may ask their group's members if they have any questions; however, each student must complete the final work himself or herself. Due to the complicated data, students may need 
more than 10 minutes to complete this assignment. If this is the case, students will finish Worksheet-16B in addition to today's homework.

4) Homework-16: Distribute Homework-16.

\section{Notes To Teachers}

1) History of the Olympic games: The most famous of the 4 great national festivals of the ancient Greeks is the Olympian Games; the other three are the Isthmian, the Pythean, and the Nemean games. The first recorded Olympian Games were held in 776 B.C., on a plain by the River Alpheus (now the Ruphia), outside the little town of Olympia in Greece. From this date, the Greeks began to keep their calendar by "Olympiads," the four-year spans between the celebrations of the Olympian games.

The Olympian Games continued until A.D. 394, when they were finally suppressed by a Roman emperor. In 1896, as a result of the efforts of the French sportsman and educator, Baron Pierre de Coubertin, a modified revival

of the Olympian games was organized in Athens, Greece. The modern Olympic games motto is "Citius, Altius, Fortius," - "Faster, Higher, Stronger." The Olympic symbol is 5 interlocking circles colored blue, yellow, black, green, and red on a white background, representing 5 continents. At least one of these colors appears in the national flag of every country.

The 1994 Winter Olympics was held in Lillehammer, Norway and the 1996 Summer Olympics will be held in Atlanta, Georgia.

2) A line graph shows an amount and a direction of change in data over a period of time. In a line graph, the data are represented by points. These points are connected by line segments. 
If a series of segments on a line graph slopes upward over a given interval, there is an increasing trend in the data over that interval. If a series of segments slope downward, there is an decreasing trend over that interval. 
WORKSHEET-16A

Individual \& Group

\section{Part A: Women's Olympic High-Jump Winners}

Use the line graph below to answer the following questions.

1) What was the lowest high-jump made by an Olympic winner since 1948 ?

When was it made? 63 in., 1928.

2) What was the highest high-jump made by an Olympic winner since 1948 ?

When was it made? 80 in., 1988.

3) What is the difference between the lowest high-jump and the highest highjump made by Olympic winners since 1948? How long did it take Olympics high jumpers to reach the highest high-jump recorded? 17 in., 60 years.

4) Observe the line graph. Does the line graph slope upward or downward? What does the direction of this line graph tell you? Upward. The height of future jumps will likely be higher.

5) Do you think the women's Olympic high-jump record will reach 7 feet by the year 2000? Why? Answers vary.

\section{Part B: Women's Olympic 100m-Dash Winners.}

Use the above line graph to answer the following questions.

1) What was the slowest time run by an Olympic winner? When was it made?

12 seconds, 1928.

2) What was the fastest time run by an Olympic winner? When was it made?

10.30 seconds, 1988. 
Individual \& Group

3) What is the difference between the slowest time and the fastest time run by Olympic winners? How long did it take Olympic $100 \mathrm{~m}$-dash runners to run below 11 seconds? 1.30 seconds, 60 years.

4) Observe the line graph. Does the line graph slope upward or downward? What does the direction of this line graph tell you? Downward.

5) Do you think the women's Olympic 100m-dash runners will run below 10 seconds by the year 2000? Why? Answers vary. 

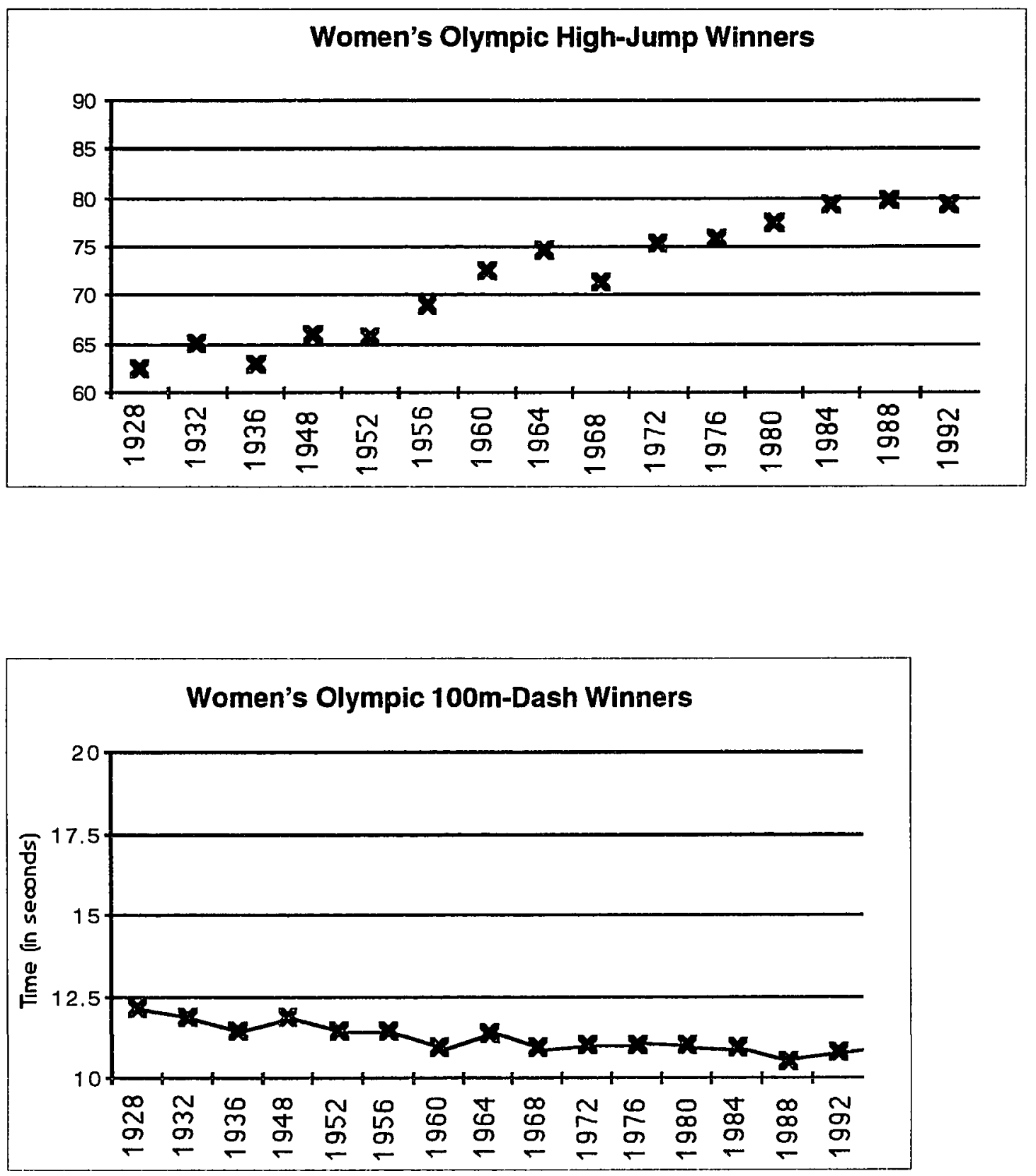
WORKSHEET-16B

Individual \& Group

1) On your graph paper make a line graph using the following data.

\section{Men's Long Jump Olympics Winners}

\begin{tabular}{|c|c|c|}
\hline NAME & YEAR & DISTANCE \\
\hline Ellery Clark, USA & 1896 & $20 \mathrm{ft} 93 / 4 \mathrm{in}$. \\
\hline Alvin Kraenzlein, USA & 1900 & $23 \mathrm{ft} 67 / 8$ in. \\
\hline Myer Prinstein, USA & 1904 & $24 \mathrm{ft}$ \\
\hline Myer Prinstein, USA & 1906 & $23 \mathrm{ft} 71 / 2 \mathrm{in}$. \\
\hline Frank Irons, USA & 1908 & $24 \mathrm{ft} 61 / 2 \mathrm{in}$. \\
\hline Albert Gutterson, USA & 1912 & $24 \mathrm{ft} 111 / 4 \mathrm{in}$. \\
\hline William Petterssen, Sweden & 1920 & $23 \mathrm{ft} 51 / 2 \mathrm{in}$. \\
\hline DeHart Hubbard, USA & 1924 & $24 \mathrm{ft} 51 / 8 \mathrm{in}$. \\
\hline Edward B. Hamm, USA & 1928 & $25 \mathrm{ft} 43 / 4$ in. \\
\hline Edward Gordon, USA & 1932 & $25 \mathrm{ft} \quad 3 / 4 \mathrm{in}$. \\
\hline Jesse Owens, USA & 1936 & $26 \mathrm{ft} 55 / 16$ in \\
\hline Willie Steele, USA & 1948 & $25 \mathrm{ft} 8$ in. \\
\hline Jerome Biffle, USA & 1952 & $24 \mathrm{ft} 10$ in. \\
\hline Gregory Bell, USA & 1956 & $25 \mathrm{ft} 81 / 4 \mathrm{in}$. \\
\hline Ralph Boston, USA & 1960 & $26 \mathrm{ft} 73 / 4 \mathrm{in}$. \\
\hline Lynn Davies, Great Britain & 1964 & $26 \mathrm{ft} 53 / 4 \mathrm{in}$. \\
\hline Bob Beamon, USA & 1968 & $29 \mathrm{ft} 21 / 2 \mathrm{in.}$ \\
\hline Randy Williams, USA & 1972 & $27 \mathrm{ft} \quad 1 / 2 \mathrm{in}$. \\
\hline Arnie Robinson, USA & 1976 & $24 \mathrm{ft} 73 / 4 \mathrm{in}$. \\
\hline
\end{tabular}




\begin{tabular}{|l|l|l|}
\hline Lutz Dombrowski, E. Germany & 1980 & $28 \mathrm{ft} \mathrm{1/4} \mathrm{in.}$ \\
\hline Carl Lewis, USA & 1984 & $28 \mathrm{ft} 1 / 4 \mathrm{in}$. \\
\hline Carl Lewis, USA & 1988 & $28 \mathrm{ft} 71 / 4 \mathrm{in}$. \\
\hline Carl Lewis, USA & 1992 & $28 \mathrm{ft} 51 / 2 \mathrm{in}$. \\
\hline
\end{tabular}

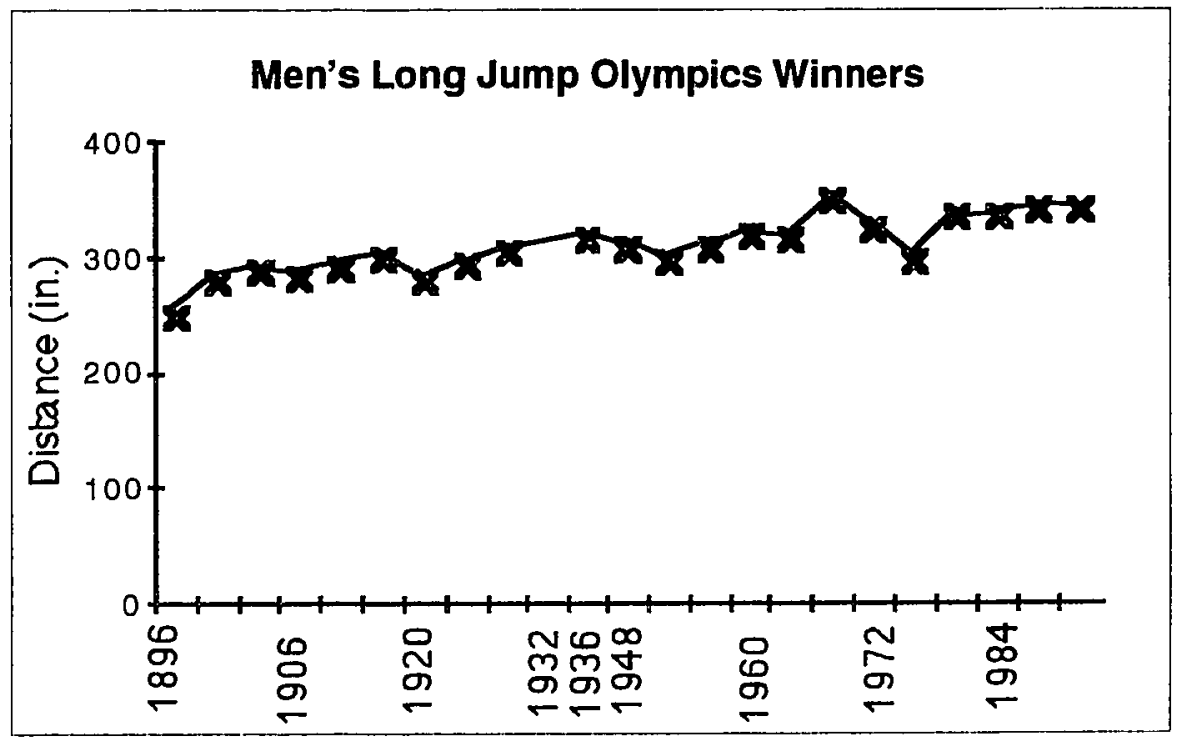

2) Make up 3 questions that can be answered based on your graph. Answers vary. 


\section{HOMEWORK-16}

Individual

1) Observe the graph of the Women's Olympic High-Jump Winners. What do you think is the reason for the drop in the women's Olympic high-jump record in 1968? Hint: the location of the Olympics site plays an important role.

2) Average number of WHMC listeners

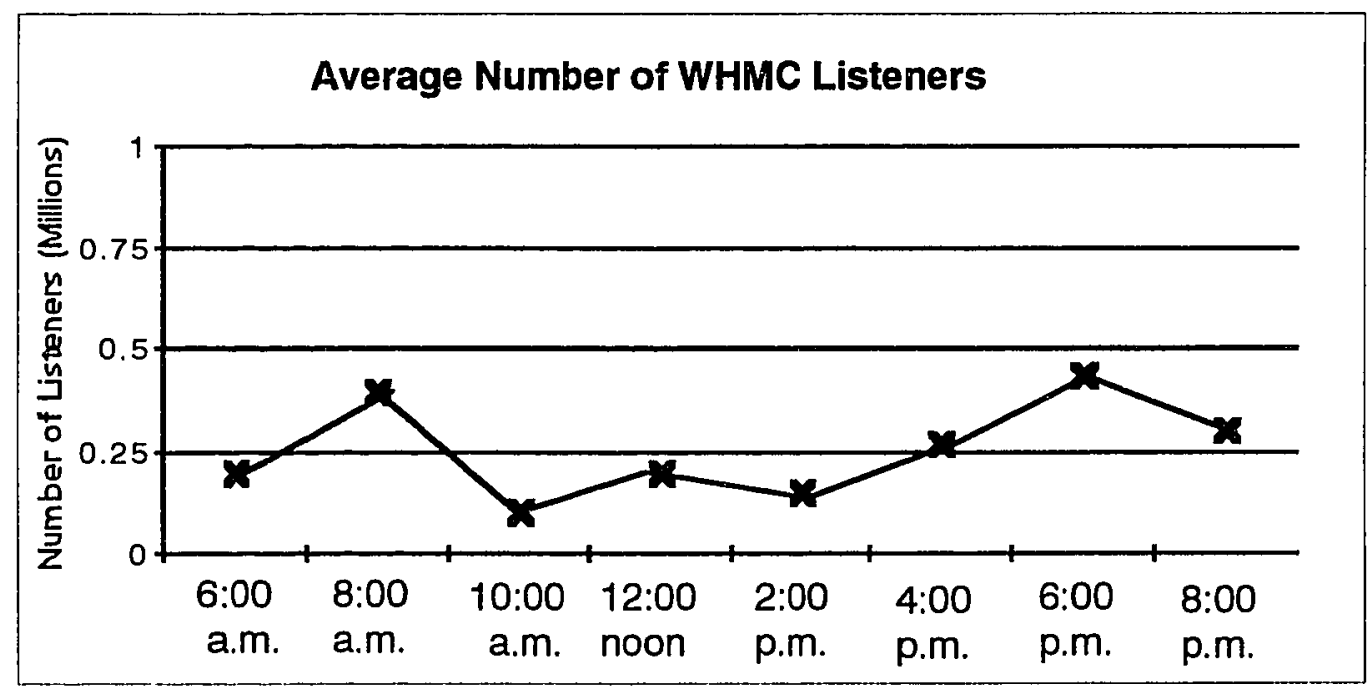

a. About how many people listen to WHMC at 5:00 pm? How do you find the answer for part (a)? $\quad 350,000$.

b. Estimate the decrease in the number of listeners from 8:00 am to 10:00 am. How do you find the answer for part (b)? 300,000 .

3) Double line graphs such as the one below are useful for comparing trends in 2 sets of data. Use the given graph to answer the following questions.

a. Estimate the number of morning newspapers in 1982.400.

b. Describe the overall trend in the number of evening newspapers.

Decreasing. 
Individual

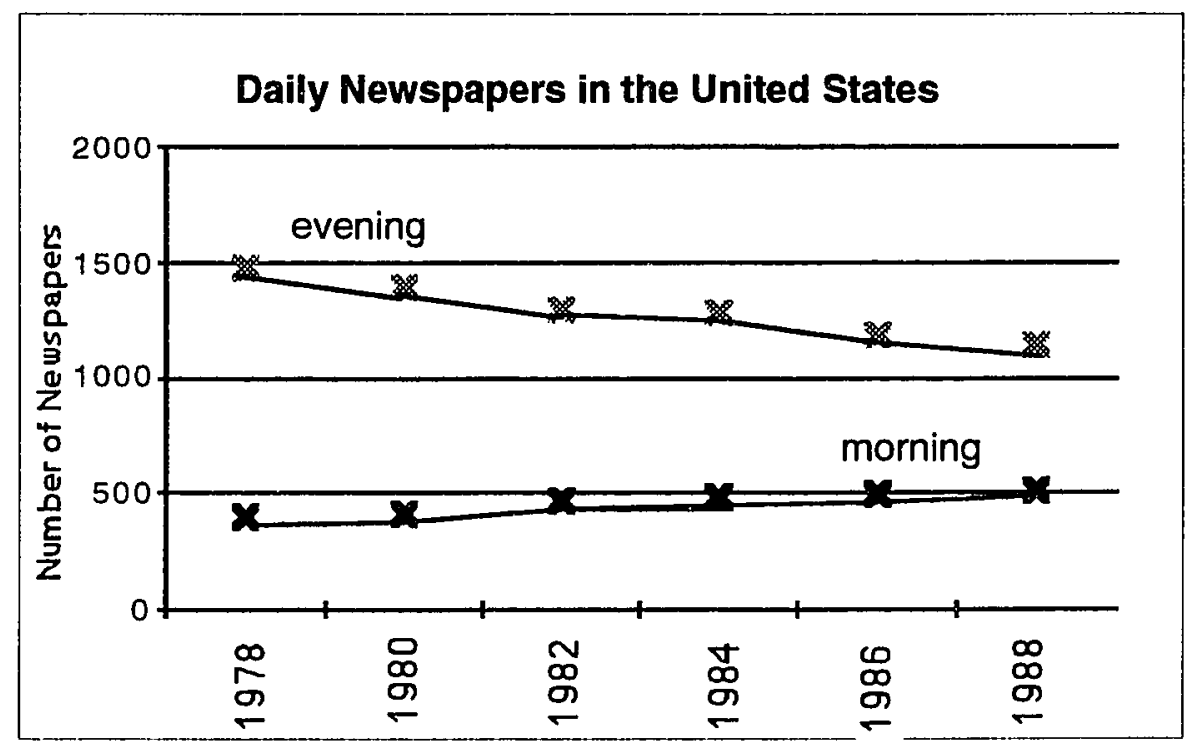

4) The line graph below has no title or labels. Use it to create your own graph by adding a title and labels. Be prepared to explain your graph to the class.

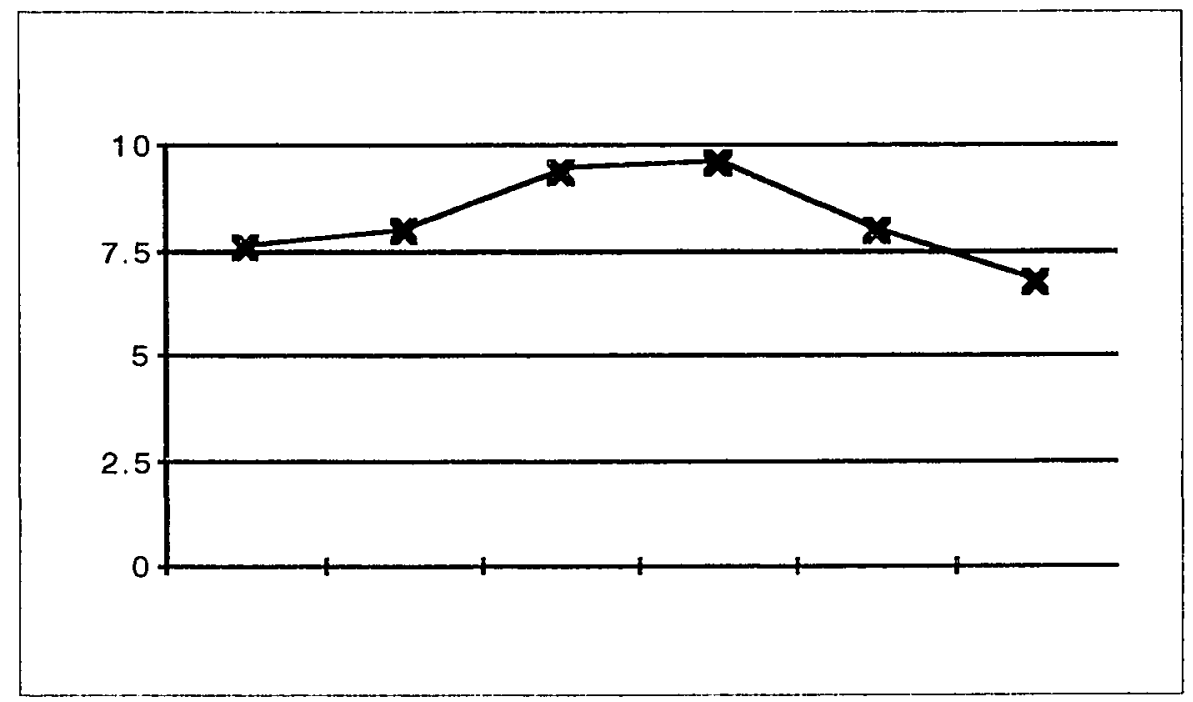

Answers vary. 


\section{DAY 18 - CHOOSING AN APPROPRIATE DATA DISPLAY Objective}

Decide appropriate method for displaying data

\section{Materials}

Handouts

Worksheet-18A, 18B, 18C, 18D, 18E

Homework-18

\section{Other materials}

Each group will get rulers, pencils, markers, graph paper (one side is graph paper, one side is blank)

\section{Homework Discussion}

Since the previous day is a test day students will not have any homework to be discussed.

\section{Procedure}

1) Review: [10 minutes] Have a representative from each group review one method of display on the board (This review is a part of the day-17 homework). Each review must contain pictorial representation, when this display is appropriate. In the case where there are more methods of display than the number of groups, allow volunteers to show their reviews of the remaining displays. Group members are free to assist their groups' representatives. After the representatives complete their reviews, ask students if they have any additional information they want to include in the reviews. Be sure that students' answers contain at least the information about the displays in the "Notes To Teachers" section. 
2) Worksheets: [25 minutes] Have each group's leader pick a letter from a hat (letters A-E). Hand out copies of the corresponding worksheets to the groups. Distribute graph paper, a box of materials, and one copy of Worksheet-18 to each group. Remind students that if they finish the worksheet early, they should use the remaining time to practice their presentation.

3) Group presentation: [15 minutes] Be sure that each group answers all questions listed on the worksheet.

Notes To Teachers

When you have data to display, you must decide which type of display is appropriate.

a. A histogram may be most appropriate when you want to visually compare the frequencies at which specific data items or groups of data items occur.

b. A circle graph may be most appropriate when you want to visually compare parts of a set of data to the whole.

c. A scatterplot may be most appropriate when you want to display the association between two sets of paired data.

d. A bar graph may be most appropriate when the data fall into distinct categories and you want to compare the totals.

e. A line graph may be most appropriate when you want to emphasize trends in data that change over time.

f. A line plot may be most appropriate when you want to visually compare the frequencies at which specific data items or groups of data items occur. 
g. A stem-and-leaf plot may be most appropriate when you want to display the individual data items in an ordered and concise manner. 
WORKSHEET-18A

Group

The results below were gathered from a survey conducted by a journalism class at Exeter High School. The students asked 100 of the school's 2000 students about their smoking habits.

\section{Exeter High School Smoking Survey}

$38 \quad$ Never smoked

11 Current smoker who has smoked less than 1 year

24 Current smoker who has smoked more than 1 year

18 Quit smoking less than 1 year ago

9 Quit smoking more than 1 year ago

On the construction paper provided write an article for the school newspaper describing the smoking survey. Include two appropriate graphs and other ideas from your group discussions. Be ready to defend your choice of the two graphs.

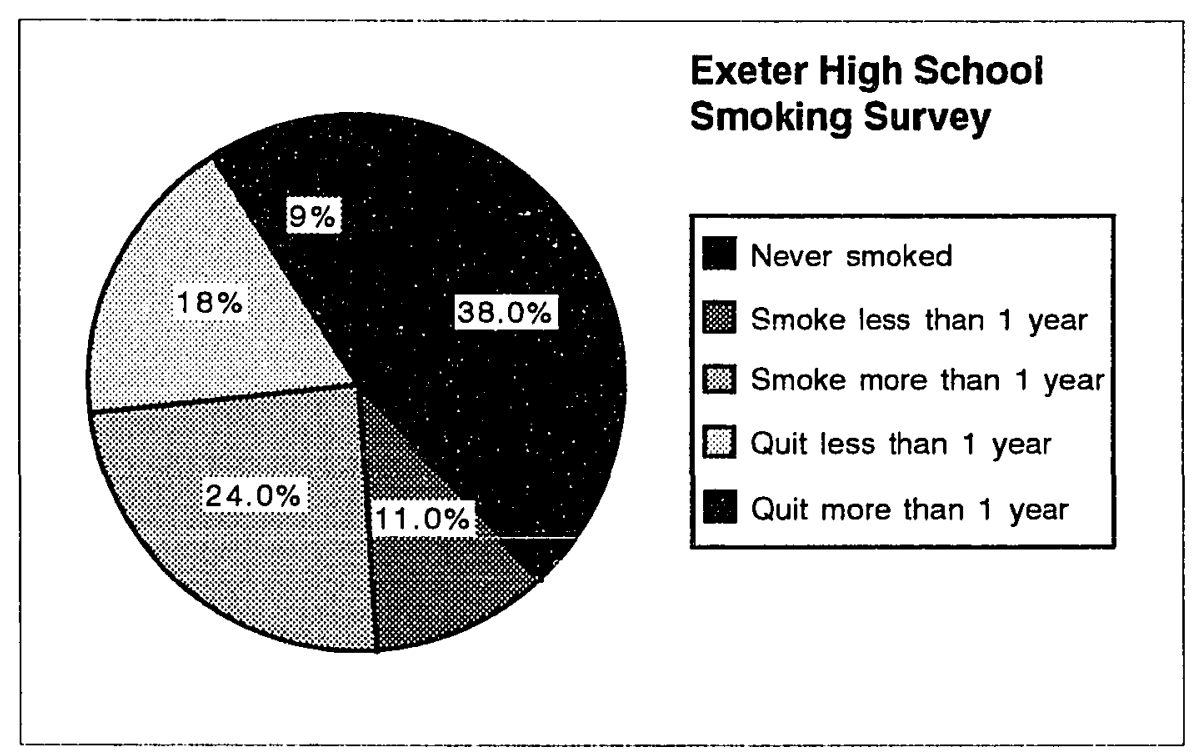




\section{Group}

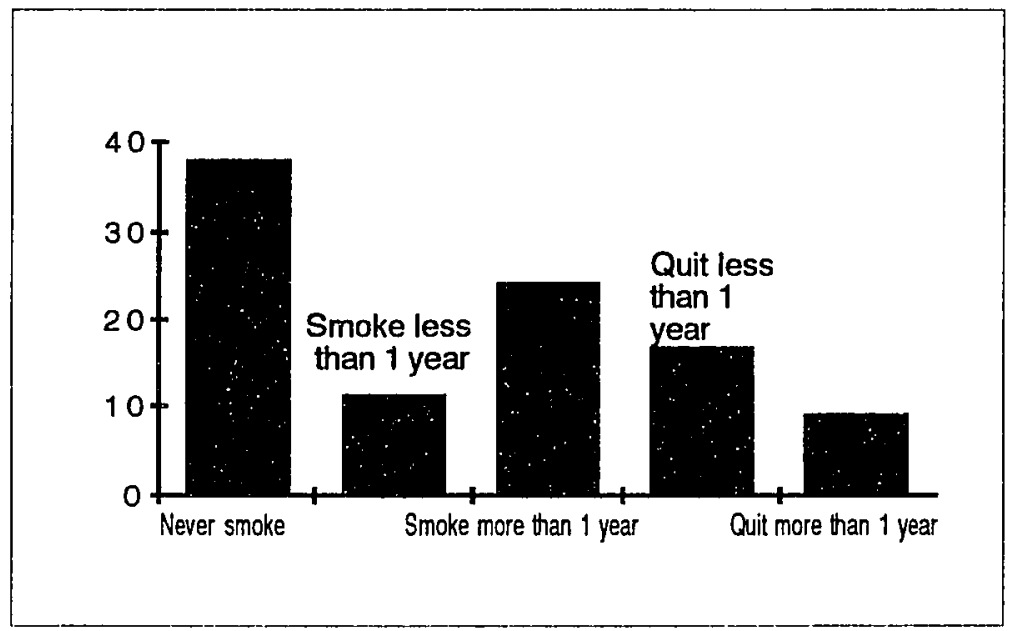


WORKSHEET-18B

Group

The following daily maximum temperatures were recorded in San Diego in the months of July and August. On the construction paper provided, design a travel brochure describing the temperature a tourist can expect in San Diego during the summer. Use two appropriate graphs and other information in the brochure to attract these tourists to San Diego. Be ready to defend your choice of the two graphs.

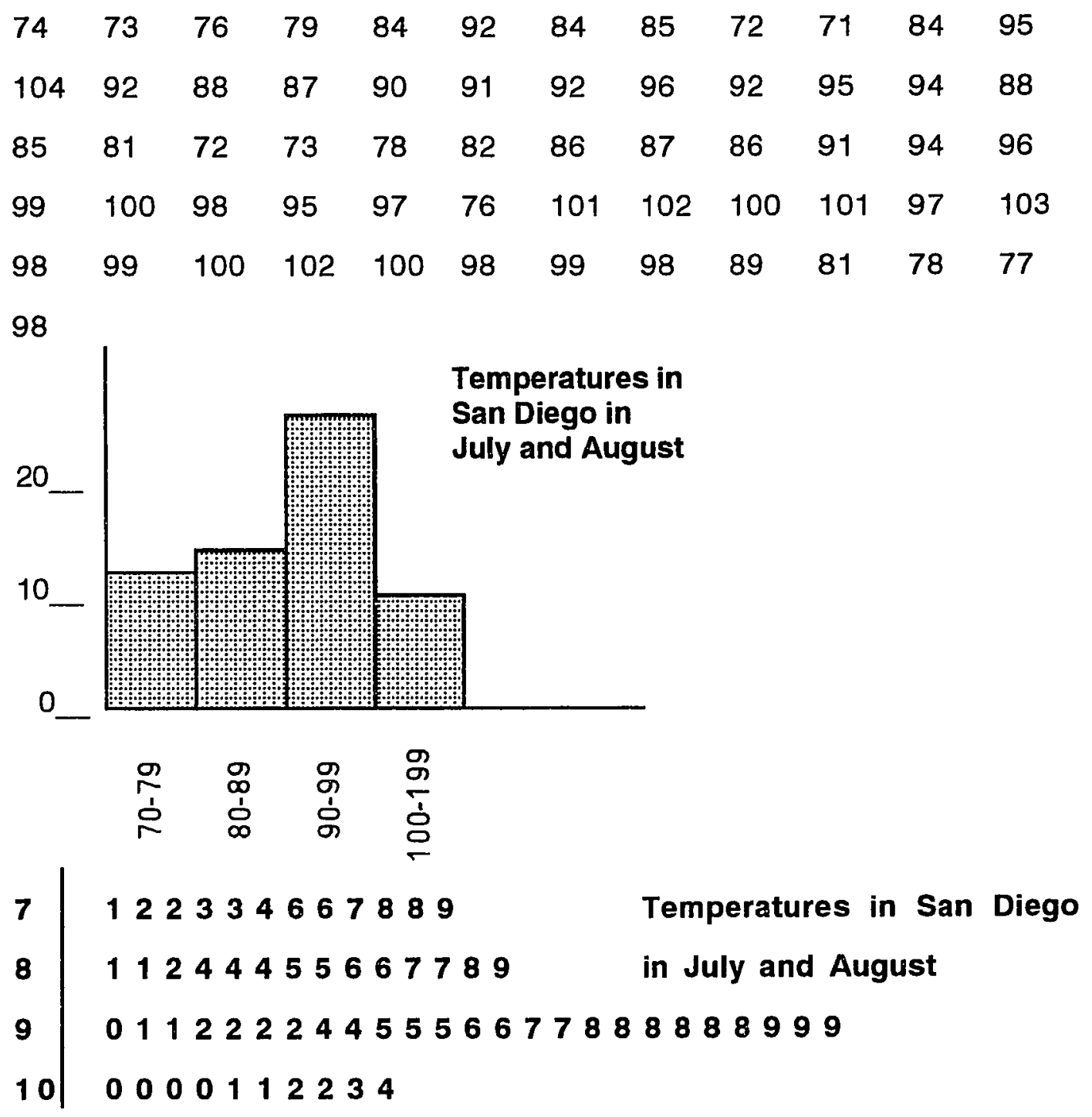


WORKSHEET-18C

Group

The table below reports the average driving speed of cars on California freeways from 1970 through 1991 with a posted speed limit of 55 miles per hour, and the number of deaths from freeway car accidents for each 100 millions miles.

\begin{tabular}{|c|c|c|c|c|c|}
\hline Year & mph & $\begin{array}{c}\text { Fatalities per 100 } \\
\text { million miles }\end{array}$ & Year & $\mathrm{mph}$ & $\begin{array}{c}\text { Fatalities per 100 } \\
\text { million miles }\end{array}$ \\
\hline 1970 & 59 & 3.8 & 1981 & 57 & 2.4 \\
\hline 1971 & -- & 3.2 & 1982 & 57 & 2.1 \\
\hline 1972 & 61 & 3.2 & 1983 & 56 & 2.0 \\
\hline 1973 & -- & 3.0 & 1984 & 57 & 2.0 \\
\hline 1974 & 55 & 2.2 & 1985 & 58 & 1.9 \\
\hline 1975 & 56 & 2.2 & 1986 & 57 & 1.9 \\
\hline 1976 & 57 & 2.3 & 1987 & 57 & 1.8 \\
\hline 1977 & 57 & 2.4 & 1988 & 58 & 1.8 \\
\hline 1978 & 58 & 2.6 & 1989 & 57 & 1.7 \\
\hline 1979 & 58 & 2.5 & 1990 & 57 & 1.5 \\
\hline 1980 & 56 & 2.5 & 1991 & 58 & 1.3 \\
\hline
\end{tabular}

On the construction paper provided, write an article for the school newspaper analyzing the above data. Include two appropriate graphs and other ideas from your group discussions. Be ready to defend your choice of the two graphs. 

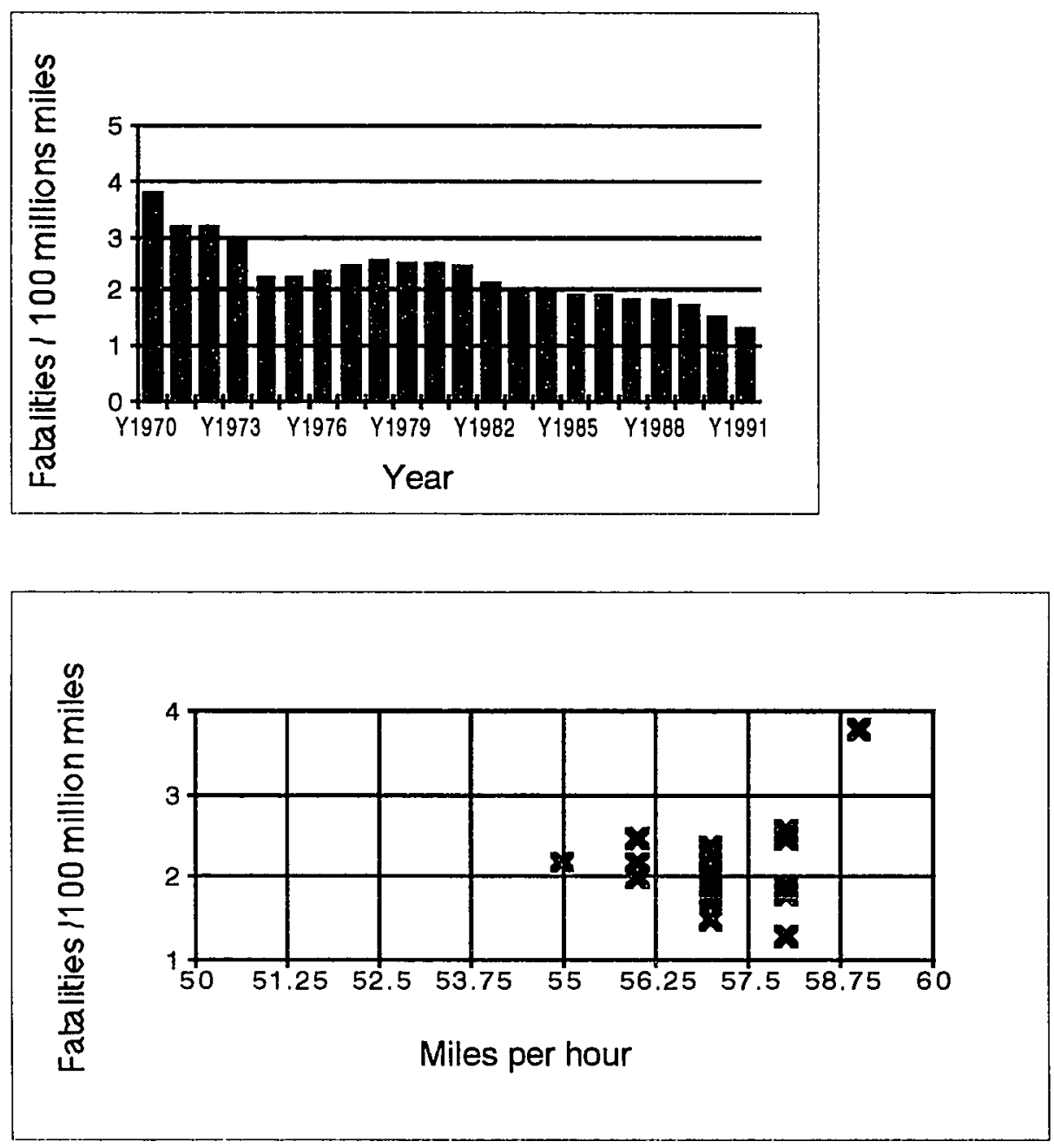
WORKSHEET-18D

Group

The Centers for Disease Control and Prevention reports the following breakdown for 1991's 38,317 firearm deaths in the USA (USA Today, 1993):

\begin{tabular}{|c|c|}
\hline Suicide & 18,526 \\
\hline Homicides & 17,746 \\
\hline Accidents & 1,441 \\
\hline Unknown/Other & 604 \\
\hline
\end{tabular}

The FBI Uniform Crime Reports for the USA, 1992 shows:

\begin{tabular}{|c|c|c|}
\hline Year & No. of all homicides & No. of handgun homicides \\
\hline 1982 & 19,485 & 11,721 \\
\hline 1983 & 18,673 & 10,895 \\
\hline 1984 & 16,689 & 9,819 \\
\hline 1985 & 17,545 & 10,296 \\
\hline 1986 & 19,257 & 11,381 \\
\hline 1987 & 17,963 & 10,612 \\
\hline 1988 & 17,971 & 10,895 \\
\hline 1989 & 18,954 & 11,832 \\
\hline 1990 & 20,045 & 12,847 \\
\hline 1991 & 21,505 & 14,265 \\
\hline 1992 & 22,540 & 14,489 \\
\hline
\end{tabular}

On the construction paper provided write an article for the San Jose Mercury News describing the above data. Include two appropriate graphs and other ideas from your group discussions. Be ready to defend your choice of the two graphs. 
Group
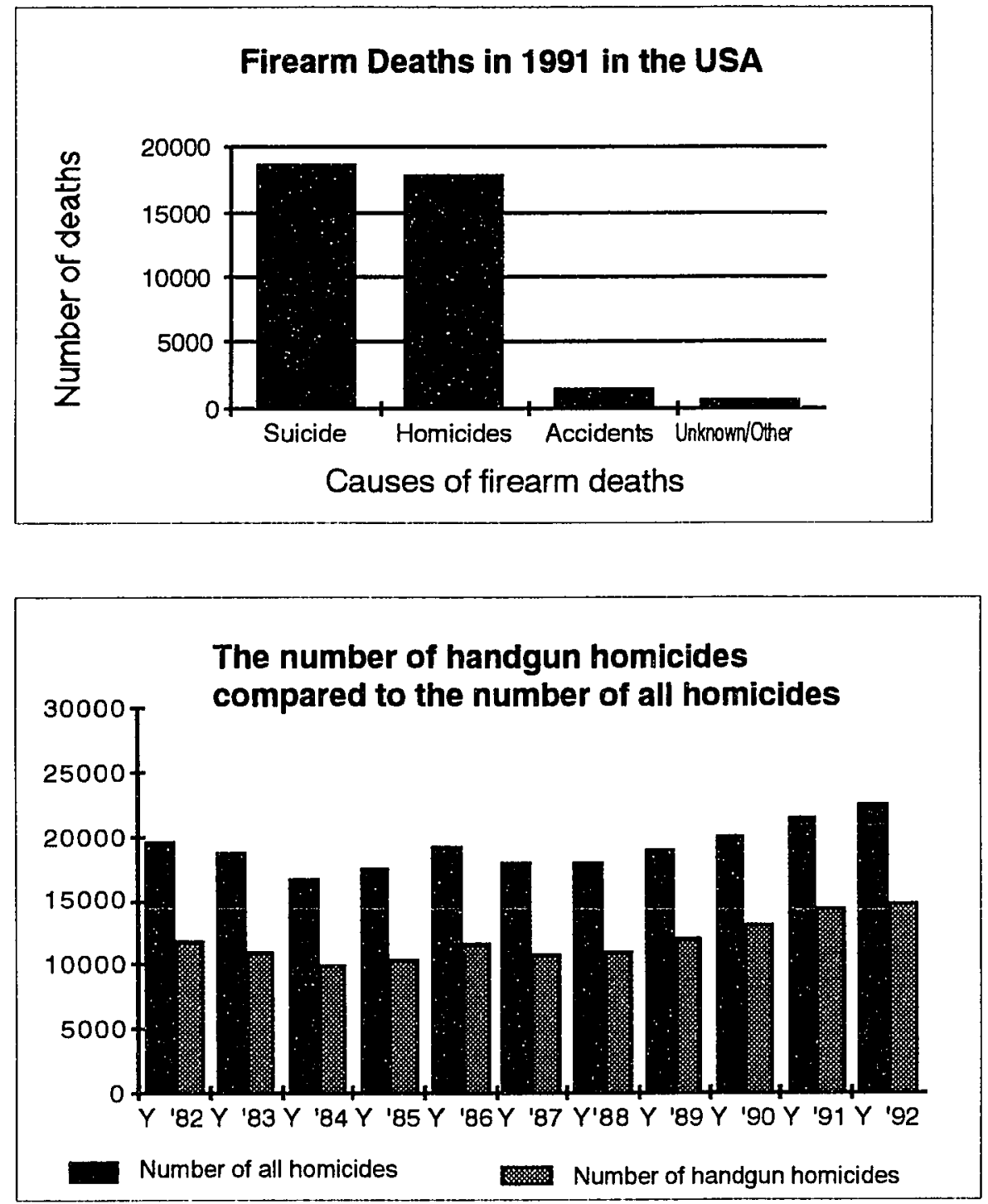
WORKSHEET-18E

Group

The following are some of the Superbowl scores from the 1993 Information Please Almanac.

\begin{tabular}{|c|l|l|l|l|l|}
\hline Year & \multicolumn{1}{|c|}{ Winner } & \multicolumn{1}{|c|}{ Loser } & Year & \multicolumn{1}{|c|}{ Winner } & \multicolumn{1}{|c|}{ Loser } \\
\hline 1992 & Washington 37 & Buffalo 24 & 1982 & SF 49ers 26 & Cincinnati 21 \\
\hline 1991 & Giants 20 & Buffalo 19 & 1981 & Oakland 27 & Philadelphia 10 \\
\hline 1990 & SF 49ers 55 & Denver 10 & 1980 & Pittsburgh 31 & LA Rams 19 \\
\hline 1989 & SF 49ers 20 & Cincinnati 16 & 1979 & Pittsburgh 35 & Dallas 31 \\
\hline 1988 & Washington 42 & Denver 10 & 1978 & Dallas 27 & Denver 10 \\
\hline 1987 & Giants 39 & Denver 20 & 1977 & Oakland 32 & Minnesota 14 \\
\hline 1986 & Chicago 46 & N. England 10 & 1976 & Pittsburgh 21 & Dallas 17 \\
\hline 1985 & SF 49ers 38 & Miami 16 & 1974 & Pittsburgh 16 & Minnesota 6 \\
\hline 1984 & LA Raiders 38 & Washington 9 & 1973 & Miami 24 & Minnesota 7 \\
\hline 1983 & Washington 27 & Miami 17 & 1972 & Miami 14 & Washington 7 \\
\hline
\end{tabular}

On the construction paper provided write an article for the San Jose Mercury News describing the above data. Include two appropriate graphs and other ideas from your group discussions. Be ready to defend your choice of the two graphs. 

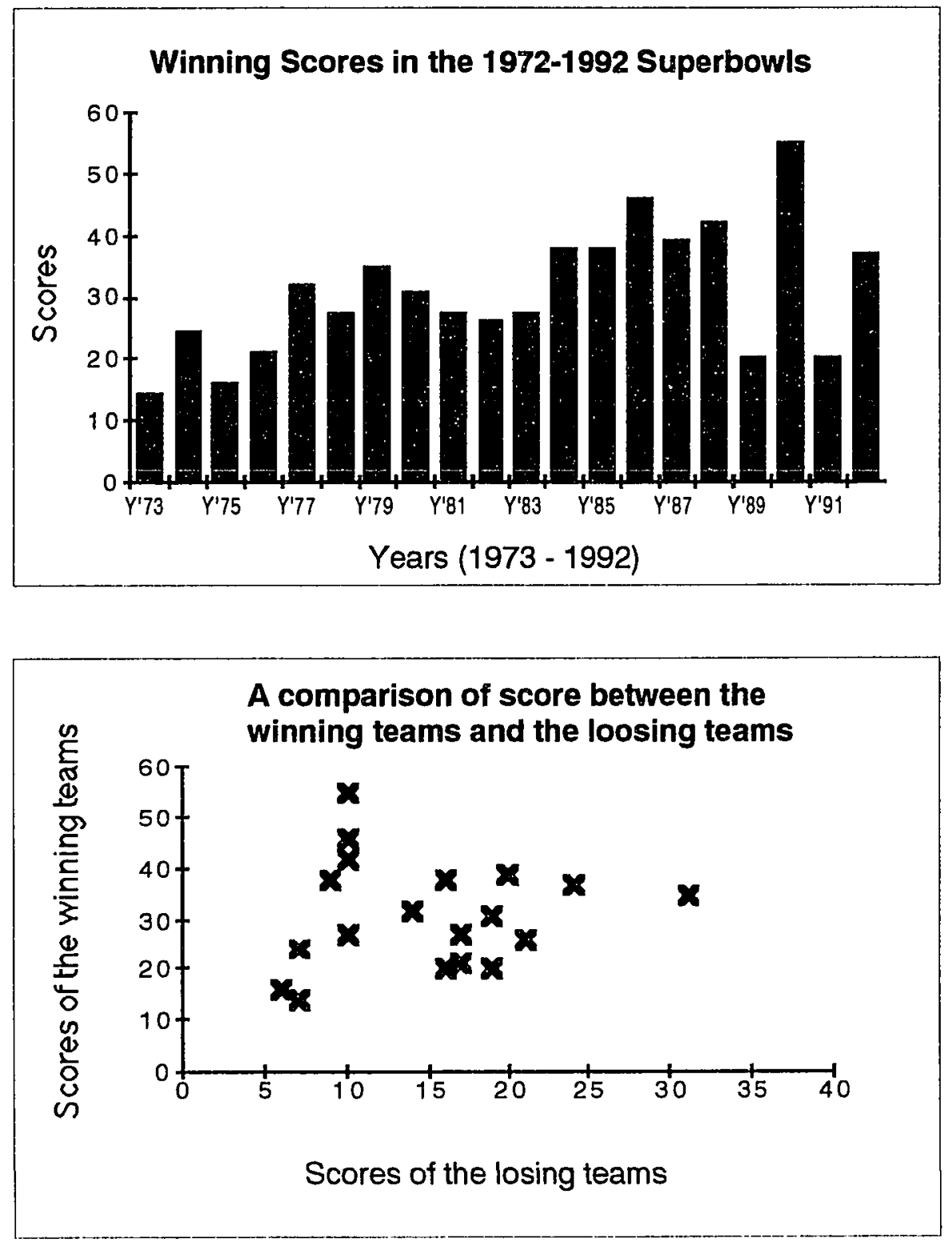


\section{HOMEWORK-18}

Individual

Part A: The following prices for similar CD players were taken from a survey of stores in the San Jose area. As a consumer reporter for the San Jose Mercury News, you must write an article on CD prices in the San Jose area. Be sure to include at least two graphs and any important statistical facts that support your article.

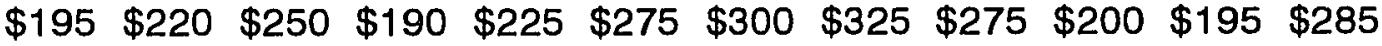

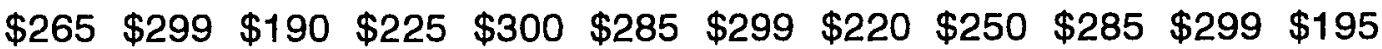

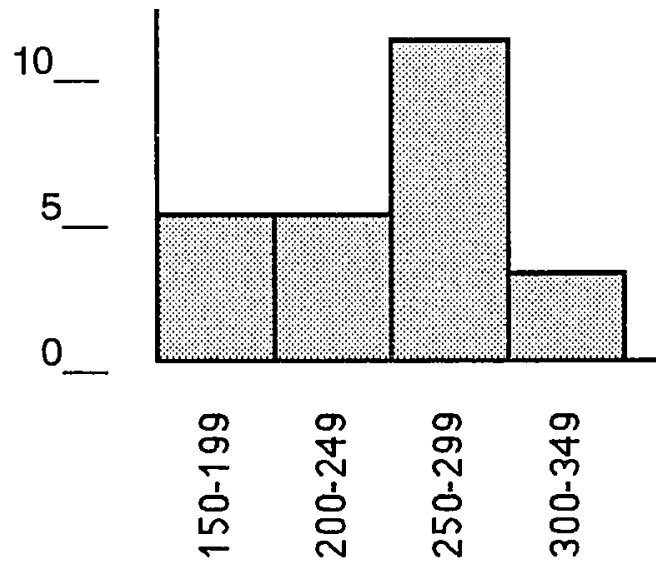

Part B: KSJS, San Jose State University's television station, polled 500 students to find their favorite type of television program. It is your job to write a report to the station manager to suggest what programs the station should run based on the data collected. Be sure to include at least two graphs and any important statistical facts that you notice. 


\begin{tabular}{|l|c|}
\hline \multicolumn{1}{|c|}{ Type of program } & No. of votes \\
\hline Sports & 104 \\
\hline Drama & 66 \\
\hline Game shows & 68 \\
\hline Situation comedies & 150 \\
\hline Musical-variety & 90 \\
\hline News and information & 22 \\
\hline
\end{tabular}
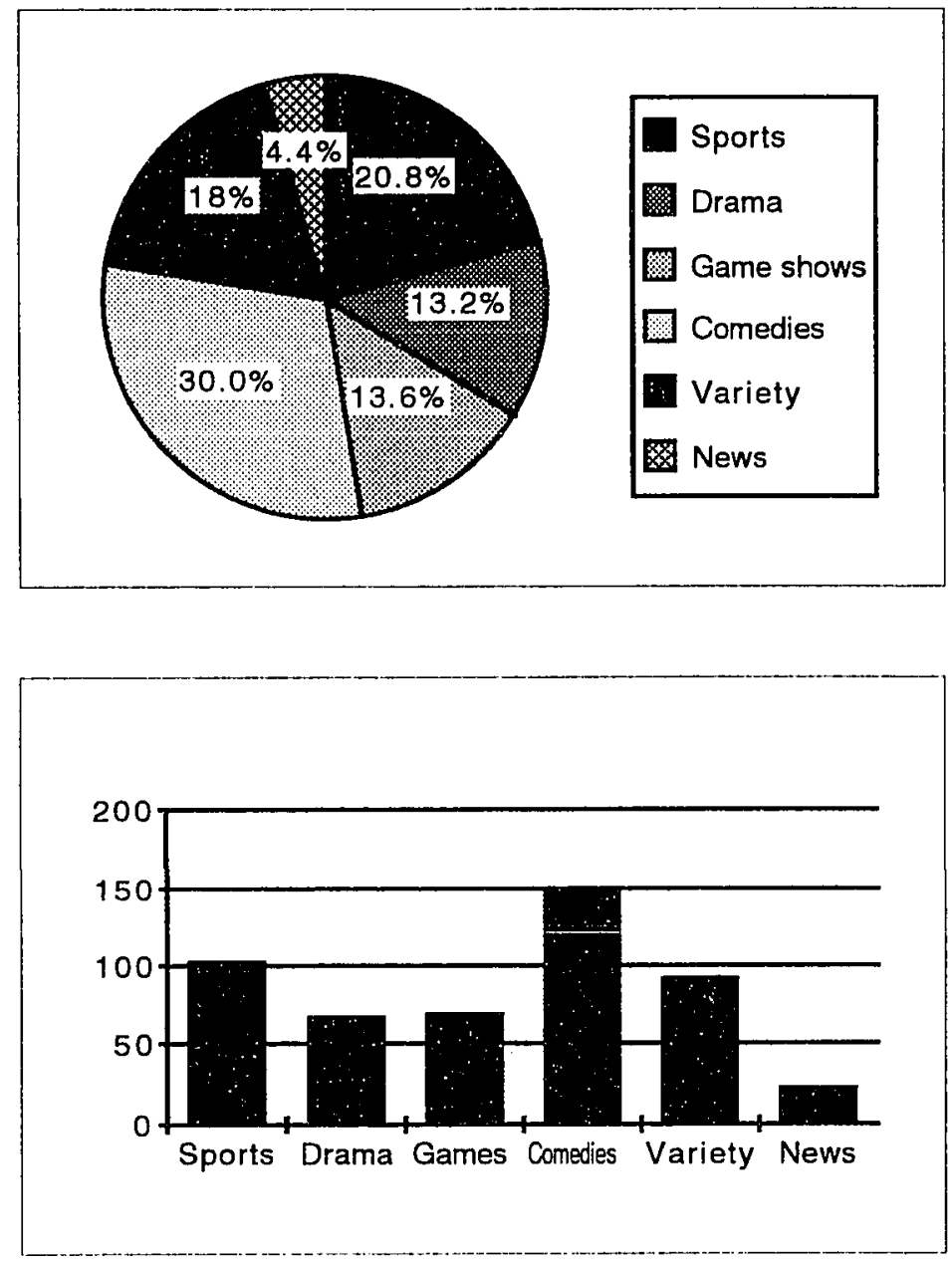
DAY 19 - MISLEADING GRAPHS

\section{Objective}

Recognize how bar graphs and line graphs can be misleading

\section{Materials}

\section{Handouts}

Worksheet-19A, Worksheet-19A graphs

Worksheet-19B, Worksheet-19B graphs

Homework-19

\section{Homework Discussion}

Homework-18: [10 minutes] Give students a few minutes to discuss their homework with their group members. Have representatives of two groups present their answers to the class.

\section{Procedure}

1) Worksheet-19A: [25 minutes] By this time the students have learned how to use graphs to represent data. In this lesson the students will see that graphs may present data factually, yet may still be misleading. Today's lesson focuses on recognizing misleading graphs.

Have the students move into their learning groups. Distribute Worksheet19A (individual) to all students and one copy of Worksheet-19A (group) to each group. To encourage participation from all students, have one student in the group read the questions while other students examine their individual worksheets and provide the answers. The group's answers should be recorded on Worksheet-19A (group) so that the worksheet can be handed in at the end of the class. If some groups complete this worksheet early, you may want to ask them to investigate the following problems and record the results on 
the back of the group's worksheet: Which graph is misleading? Why is it visually misleading?

Hold a 10-minute class discussion. The discussion should cover all questions in the worksheet. If time permits, discuss the two questions mentioned in part (2).

2) Worksheet-19B: [15 minutes] Repeat step (2) with Worksheet-19B. The students again will have 10 minutes to complete this worksheet. Write the following question on the board for any group that finishes early: How can you recognize visually misleading graphs? What other type of graph can be constructed so that it displays misleading information?

For the remaining time, have the class discuss Worksheet-19B. The goal of this worksheet is for students to recognize that the change in intervals of the scale will alter the visual impressions of the graphs, and also statistics can be manipulated so that they emphasize whatever you or someone who controls the data warit.

If time permits, have students orally explain why certain graphs may be misleading or not, and how you can recognize a misleading graph.

3) Homework-19: Distribute Homework-19.

\section{Notes To Teacher}

No notes. 
1) Use Graph $A$.

a. Estimate the attendance at the rock concert in Franklin, in Midway, and in Sunville. 55,000; 60,000;51,000 respectively.

b. What is the difference in attendance between Franklin and Midway? between Midway and Sunville? between Sunville and Franklin? 5,000; 10,$000 ; 4,000$ respectively.

2) Repeat Step 1, but use Graph B instead.

a. 55,000; 60,000; 51,000 respectively.

b. 5,$000 ; 9,000 ; 4,000$ respectively.

3) Examine the bars only.

a. Do the bar graphs in Graph A accurately reflect the difference in attendance among the three cities? Explain. Yes, the bars show that the attendance in Franklin is about $\mathbf{8 0} \%$ of that in Midway, approximately the same as the actual percentage calculated using the numerical data. The same argument can be used for both Midway compared to Sunville, and Franklin compared to Sunville.

b. Do the bar graphs in Graph B accurately reflect the difference in attendance among the three cities? Explain. No, the bars show that the attendance in Franklin is about $50 \%$ of that in Midway despite the fact that the attendance in Franklin is calculated to be $80 \%$ of that in Midway. The same argument can be used to check the cases of Midway compared to Sunville, and Franklin compared to Sunville. 
Group

4) If you want to attract performers to Midway which graph would you use?

Explain. The graph gives a visual impression that attendance in Midway was not only much greater than attendance in either Franklin or Sunville, but was also greater than the combined attendance of the two cities. 


\section{WORKSHEET-19A}

213

Individual
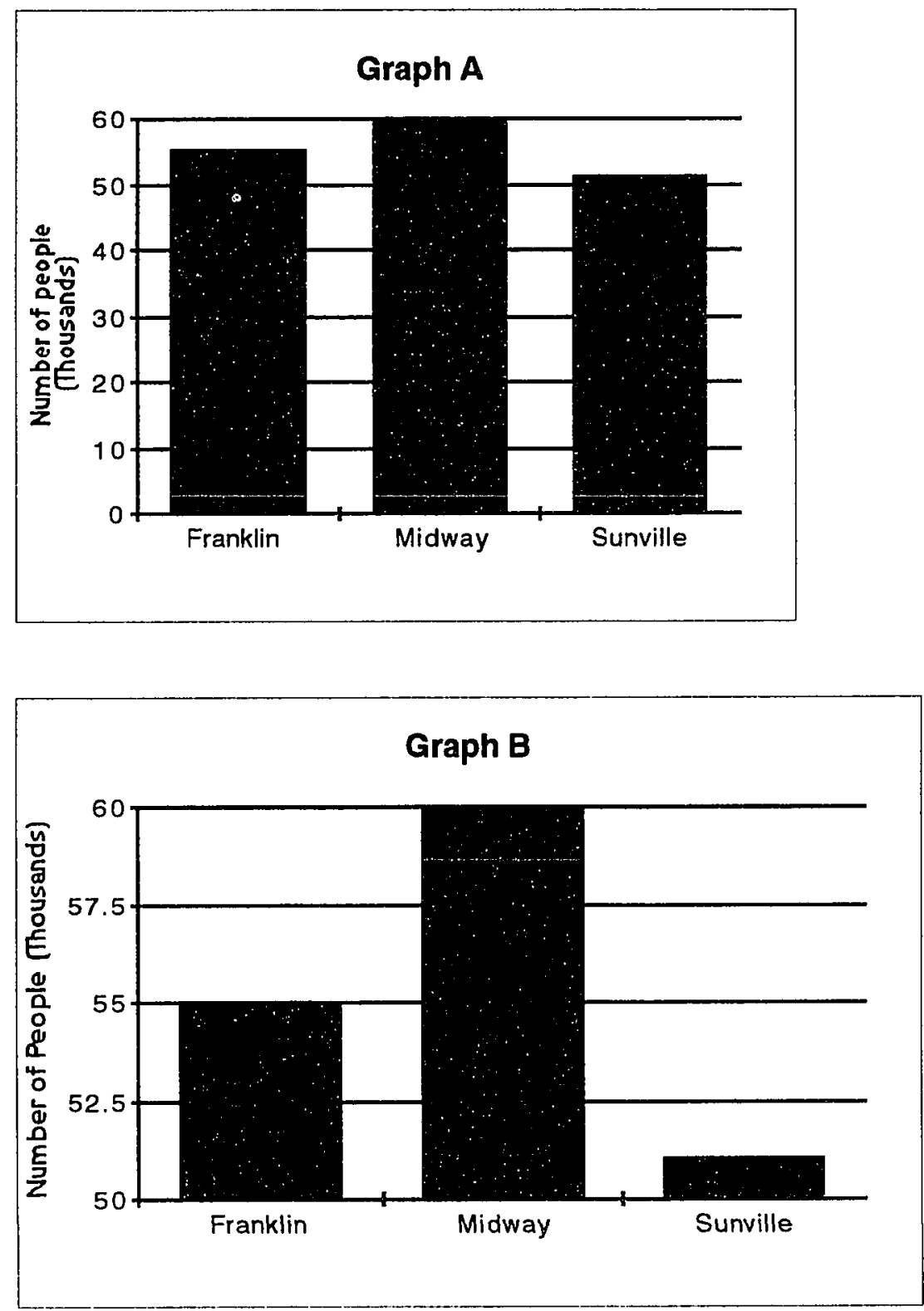
WORKSHEET-19B

Group

1) How far apart (in months) are the horizontal grid lines in Graph C? Graph D? One month.

2) How far apart (in number of subscribers) are the vertical grid lines in Graph C? Graph D? One hundred for Graph C. As for Graph D, the first tick mark is $\mathbf{4 0 0}$ and the rest of the intervals are of 25.

3) Which graph might the magazine owner use to show displeasure at the results of the advertising campaign? Explain. Graph $\mathbf{C}$. The graph shows there is not much improvement during the period from March to August.

4) Which graph might the advertising agency use to attract new clients? Explain. Graph D. The graph seems to show a tremendous improvement during the same period of time.

\begin{tabular}{|l|c|}
\hline Month & No. of subscribers \\
\hline March & 400,000 \\
\hline April & 421,000 \\
\hline May & 418,000 \\
\hline June & 423,000 \\
\hline July & 439,000 \\
\hline August & 464,000 \\
\hline
\end{tabular}



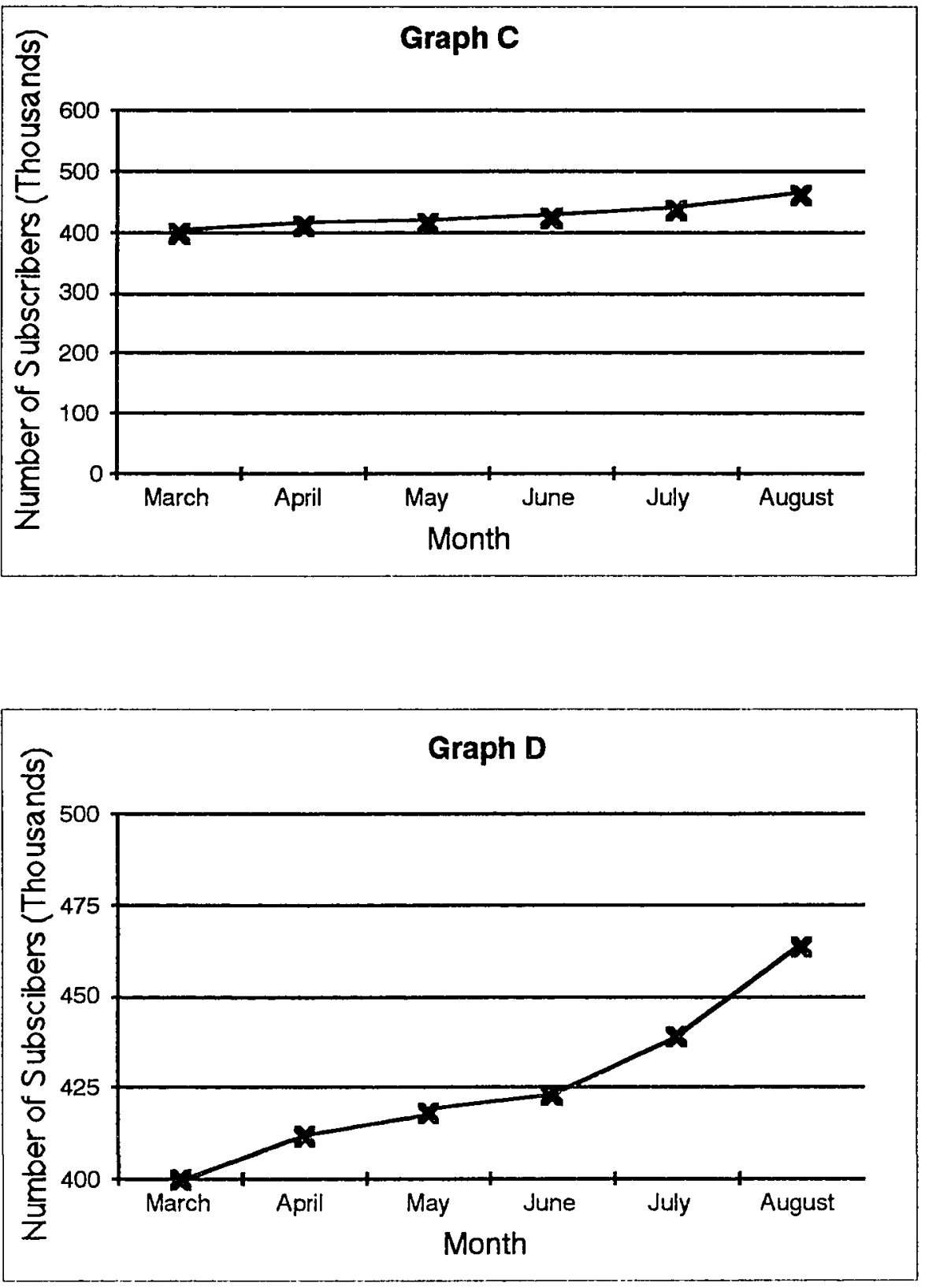


\section{HOMEWORK-19}

216

1) Use the graphs below.
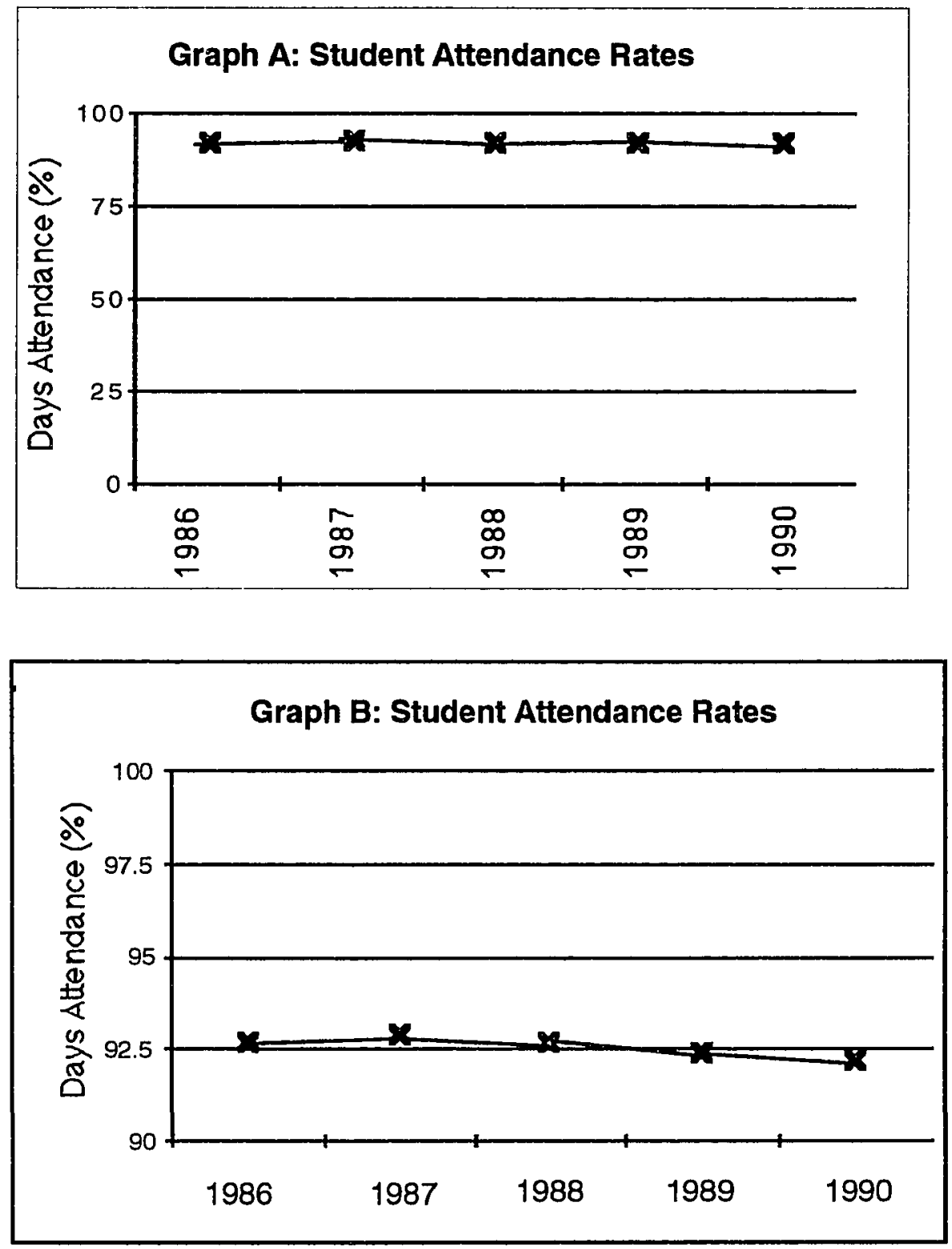
Individual

a. How far apart (in years) are the horizontal grid lines in Graph A? Graph B? One year.

b. How far apart (in percentages) are the vertical grid lines in Graph A? Graph B? 2.5\%.

c. How do the scales of the graphs affect the impressions given by the graphs? In Graph A, student attendance rates do not vary very much. In Graph B, there is a noticeable decline in student attendance rates.

d. When would you use Graph A? Graph B? Someone may want to use Graph A to convince people that the student attendance rate is almost constant. Someone else may want to employ Graph B in showing that there is a large number of students not attending school. 
Individual

2) Use the bar graph. For parts (a) to (c), tell whether each statement is true or false.

\section{. $\quad$ Record Jumping Distance}

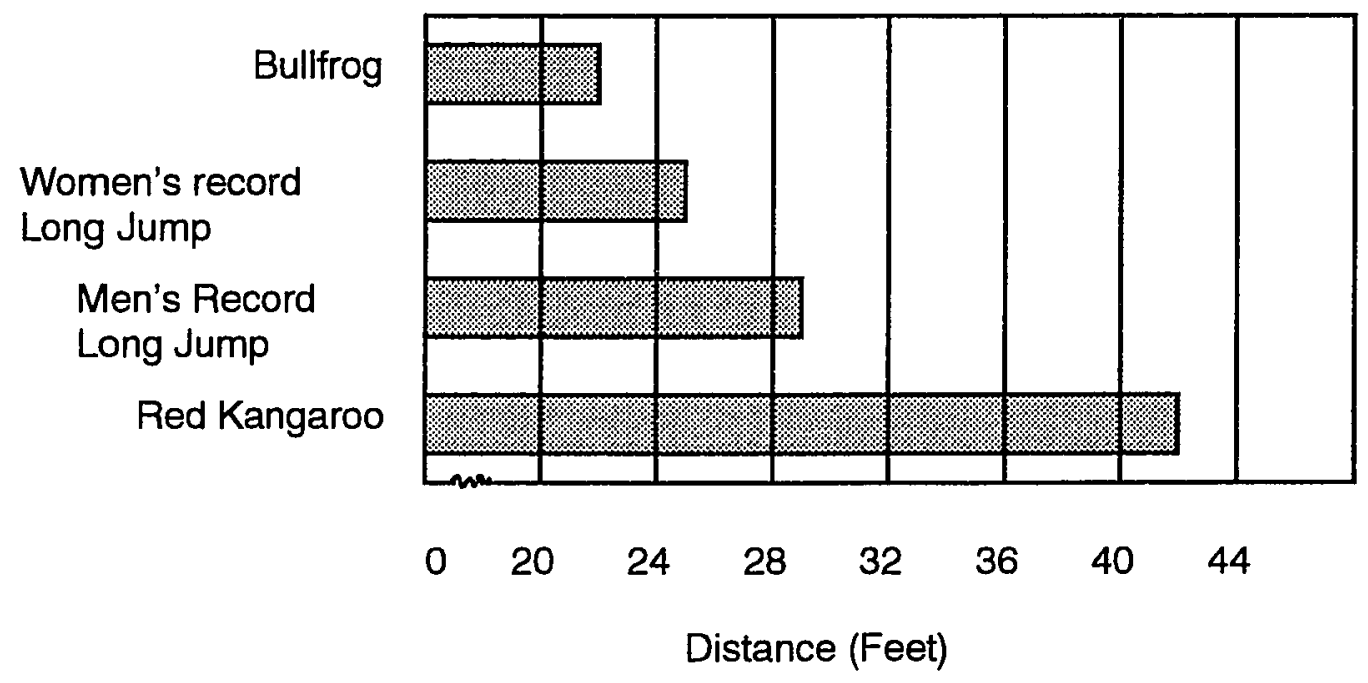

a. The men's record is more than twice the bullfrog's record. False.

b. The red kangaroo's record is about 3 times the women's record.

Faise, the red kangaroo's record is actually less than twice the women's record.

c. The women's record differs from the bullfrog's record by about $3 \mathrm{ft}$.

True.

d. Find the approximate distances jumped by the red kangaroo and the bullfrog. Red kangaroo: 42 feet. Bullfrog: 22 feet. The red kangaroo's record is about twice the bullfrog's record. 
Individual

e. Compare the actual difference between the distances in part (d) with the visual impression given by the graph. The graph gives a visual impression that the red kangaroo's record is four times the bullfrog's record.

f. Draw an accurate graph of the jump distance. How is your graph different from the original graph? Answers vary.

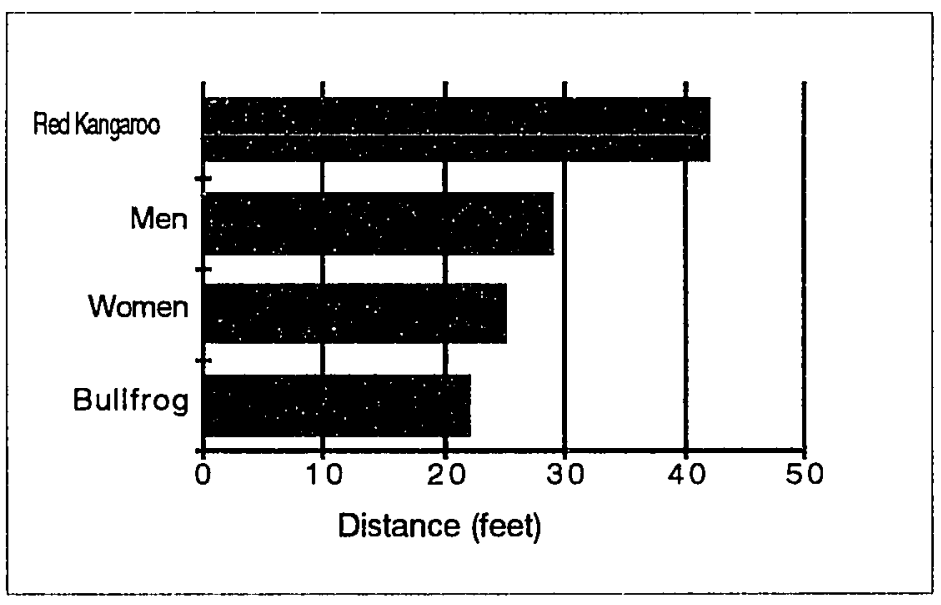

3) Write a paragraph to describe what you think are the advantages and disadvantages of using graphs to present data. See the day-19 lesson plan. 
DAY 20 - the statistical Concepts of the AVERAGE (THE MODE AND THE MEDIAN)

\section{Objectives}

1) Develop the statistical concepts of the mode and the median

2) Develop an algorithm for determining the mode and median of a set of data Materials

Handouts

Worksheet-20 (individual)

Homework-20 (individual)

Other materials

Class activity: 2"x2" squares. We must have enough squares so that each student will have as many squares as the number of letters in that student's last name.

Worksheet-20: Cut the edges pulled off computer paper into 6 (or as many as the number of groups) sets of 9 strips in various lengths. Be sure to have at least one subset of equal-length strips that has more strips than the other subsets. Some of your strips might look like this:

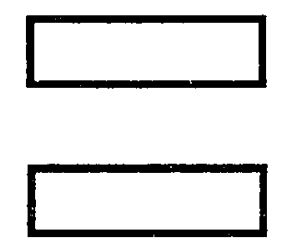




\section{Homework Discussion}

Homework-19: [10 minutes].

\section{Procedure}

1) Class Activity 1: [15 minutes] One of the ways we can describe a set of data is to find one typical value that represents the entire set of data. There are different ways of determining this typical, or "average," value. In this activity and the next lesson's activity, the student will explore the concepts of the 3 common averages known as the mode, the median, and the mean. These 3 values are also called measures of central tendency because they are ways of locating the center of a set of data.

Distribute 2"x2" squares to students. Each student will get as many squares as the number of letters in that student's last name. The students then write their last names on the squares provided, using one square for each letter. In the class activity, ask students to consider the number of letters in their last names, i.e., the number of squares in their hands.

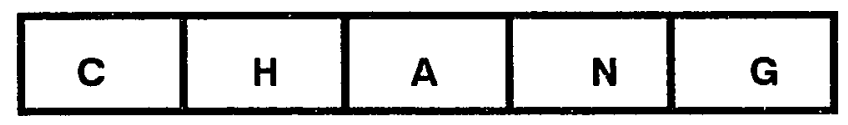

Step 1: The students with their squares in hands move into groups according to the number of squares they hold. Have the students complete the following tasks: a) identify the group(s) with the largest number of people. b) report the number of squares in each person's hand. For example, students report " 5 " if 5 is the number of squares belonging to each member of the largest group. On the overhead write 
"The mode is the number of letters in students' last names that occurs most often. For this set of data, the mode is

Step 2: To show students a set of data can have no mode, one mode, two modes (bi-modal), three modes (tri-modal), remove students from the original groups accordingly so that the new groups show the different types of modes. Be sure to write "The mode of the number of letters in students' last names is __. " for each case, instead of just "The mode is " At the end of this activity, pose the following questions:

a. What is the mode of a set?

b. How many modes can a set of data have?

Writing students' answers on the overhead projector would give the students another opportunity to absorb the information through a different modality.

2) Class Activity 2: [15 minutes]

Step 1: The entire class now lines up in order such that the student with the least number of squares in hand is at one end of the line and the student with the most is at the other. (Here you may want to have an odd number of students so that the middle position is occupied by an actual person.) Bend the line in two so that the student with the least number of squares is paired up with the student with the most number of squares, the student holding the next lowest number of squares is paired up with the student holding the next highest number of squares, and so on. Inform the class that the student with no partner is where the line bends in two at the middle of the line. This student is the point where exactly 
half of the students in the class have more squares than he/she does and half of the students in the class have fewer squares than he/she does. That student's number of squares is the median of the set. On the overhead projector write "The median of the number of letters in students' names is the number of squares of the middle student (number of squares are arranged from the least to the most.) For this set of data, the median is:

Step 2: Now redistribute students so that there is an even number of them and repeat the above procedure. This arrangement will help the students to recognize that the median of a set of data may not be a value in that set of data. You may want to tell students to imagine there is a middle student (student with no partner), and ask themselves "What number of squares should this student have so he/she would fit into the arrangement?" [equal to that of the middle pair or exactly half of the sum of the middle pairs' squares]

3) Worksheet-20: [10 minutes] Distribute one set of strips to each pair and copies of Worksheet-20 to all students. The students will have about 10 minutes, or any amount of time that you see appropriate. However, make sure that you have at least 10 minutes to conduct a class discussion on Worksheet20. Since the median of the data in part $(B)$ is not a value in the set, some students may find it difficult to locate this median. You may want to give them some hints like: the median is the number that stands right in the middle when one pairs up the smallest with the largest, the next smallest with the next largest, and so on. As for the advanced students, you can ask them to develop an 
algorithm to determine the median of a set of data whenever the median is not a member of the set. Distribute Homework-20.

\section{Notes To Teachers}

1) Sometimes the measure of central tendency is the most frequent value, called the mode. If two largest groups have the same number of elements, then we say that the set has two modes, or it is bimodal. If three largest groups have the same number of elements, then the set is trimodal. If all values occur the same number of times, then the set has no mode.

2) Sometimes the typical value of a set of data is the middle value of the data, called the median. When the data are arranged in order, the median is the point where exactly half of the values are greater and half of the values are less. If the set contains an odd number of values, then the median is the middle number. If the set has an even number of values, then the median is half of the sum of the two middle numbers. 
Part A: Compare the length of the strips (The length of each strip is darkened for you.)

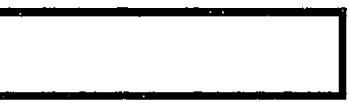

1) How can you tell the mode of the length of the strips? The mode is the most frequent length.

2) Is there more than one mode? Explain. In this case there is no mode. There is only one length that occurs the most number of times.

3) How can you tell the median of the length of the strips ? Arrange the strips from the shortest to the longest. The median is the length of the strip in the middle.

4) Is there more than one median? Explain. There is only one median because there can only be one strip in the middle.

Part B: Here are some test scores from Ms. Broadway's math class: 38, 43, 98, $96,55,95,56,62,64,89,87,65$.

1) What is the mode of the test scores? There is no mode.

2) Is there more than one mode? Explain. There is no mode. All scores only appear once.

3) What is the median of the test scores? 64.5. 
Individual \& Group

4) Is there more than one median? Explain. There is only one median for there can only be one number in the middle.

5) How did you find the median of the test scores? It is the number midway between the 6th score (64) and the 7th score (65). 


\section{HOMEWORK-20}

Individual

1) The Micro-Bitts Computer Company (MBCC) has 20 employees with the following annual salaries. Find the modal salary, and the median salary.

1 President $\$ 100,000$

Mode: $\$ 15,000$

2 Vice-Presidents $\$ 80,000$ each

Median: $\$ 15,000$

1 Plant manager $\$ 40,000$

16 Assembly workers $\$ 15,000$ each

2) Suppose your class surveyed the color of the shirt worn by students in your school on a certain day. Here are the results.

Group 1: white, white, orange, red, blue, blue

Group 2: green, white, white, blue, pink, brown

Group 3: white, white, white, white, red, blue

Group 4: white, yellow, red, blue, orange, black

Group 5: yellow, yellow, white, white, red

Group 6: purple, yellow, orange, blue, brown, black

a. What is the mode of this set of data? White.

b. What is the median of this set of data? No median.

3) The graph below is called a line plot. Each star represents the number of times that a particular value occurs. For example, the two stars above the number 800 means that the value 800 occurs two times in this set of data.

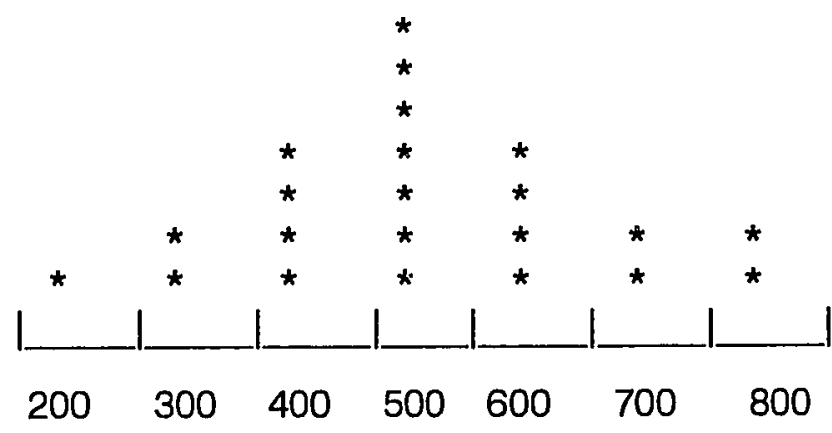


Individual

a. Find the mode of the data. Explain how you find it. There are 7 stars for the mark 500; therefore, 500 is the mode of the data. b. Find the median of the data. Explain how you find it. Answers vary. From the plot: Since there are 22 dots that are already arranged from the smallest value to the largest value, the 11 th and 12th dots represent the median value.

From students' own arrangement: Some students may not notice this and may arrange the plot again, this time with the actual values.

c. What information do you think the above plot shows? Answers vary. For example, a plot of a high school class's SAT scores.

4) Think about what you have learned from the above exercises and in-class activities.

a. Do all sets of data have a mode? Explain.

Numerical and non-numerical data sets have $0,1,2, \ldots$ modes.

b. Do all sets of data have a median? Explain.

Numerical data sets always have a median while nonnumerical data sets do not have a median. 
DAY 21 - DEVELOPING THE STATISTICAL CONCEPT OF THE

\section{MEAN}

\section{Objectives}

1) Explore the concept of the mean

2) Develop an algorithm to calculate the mean

\section{Materials}

Handouts

Worksheet-21 (individual)

Homework-21 (individual)

\section{Other materials}

$2^{\prime \prime} \times 2 "$ squares so that each student will have as many squares as the number of that student's last name.

31 M\&Ms packages or any packages that contain 10 objects in each bag.

\section{Homework Discussion}

Homework-20: [10 minutes]

\section{Procedure}

1) Class Activity 1: [20 minutes] The third typical value that can be used to describe a set of data is called the mean. If the objects in the data set are shared equally, the mean would be the amount each person would have. The word average is often used instead of the more mathematically precise word, mean.

Distribute 2"x2" squares to students. Each student will get as many squares as the number of letters in that student's name. The students then write their last names on the squares provided, using one square for each letter. For example, 


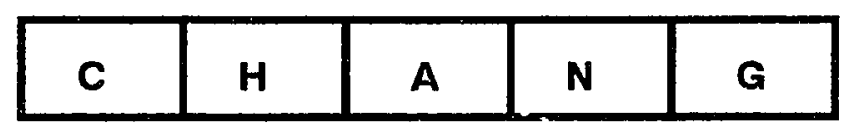

Students should mingle among each other sharing squares using the following rule. If a student has 2 or more squares than another student, they should share the extra squares until either both have the same amount or one student has one square more than the other. Continue this activity until either all students have the same amount of squares or one set of students have a certain amount and a second set of students have just one less square.

Case 1: If every one has the same number of squares, the number of squares in each student's hand is the mean. Write on the overhead: "The mean of the number of letters in students' last names is:

Case 2: If there are 2 sets of students with different amounts then the mean is somewhere between the two numbers. The mean is equal to the sum of the smaller number and a fraction whose numerator is the amount of extra squares and whose denominator is the number of participating students. Have students calculate this fraction. Here, you may want to collect the extra squares and ask students to divide those squares equally among participating students.

If students have some difficulty imagining this division of squares equally, you may want to phrase the problem in terms that are familiar to students. For example, ask students to imagine dividing cakes or pizza among friends.

Write the answer on the overhead projector. This activity allows students to see the relationship between the mean and fair share.

2) Class Activity 2: [15 minutes] To introduce another method for finding a mean, ask the students to solve the following problem. You may want to replace these names with names of students in your class. 
Mai has $70 \mathrm{M} \& M s$, Sofia has $90 \mathrm{M} \& M s$, and June has 50 M\&Ms. How can you find the amount of M\&Ms each of them would have if they decide to share equally without using pencil and paper?

On the chalkboard draw a segment of the number line that includes the numbers 40 through 100 (intervals of 10). Distribute 5 packages of M\&Ms with 10 in each package to June, 7 packages of M\&Ms to Mai, and 9 packages of M\&Ms to Sofia. Have each of them stand under the number that corresponds to the number of M\&Ms they have. The students then share packages of M\&Ms so that at the end they all have the same number of packages. Remind students to move to appropriate numbers after each sharing. At the end of this activity, each of them must have 7 packages of M\&Ms and stand under number 70 on the number line. Write on the board "The mean of the number of M\&Ms is 70."

3) Class Discussion: [5 minutes] Have students define the mean. (Accept any answer that mentions equal share among people.) If students find it difficult to define this term you may want to remind them the result of the first example: the number of squares students have in the beginning and the number of squares students have at the end. Write all students' answers on the overhead projector. With students' help select the best definition.

Challenge question : How would you find the answers in both examples using pencil and paper?

4) Homework-21: Distribute Homework-21. If time permits, let students start on their homework. This homework will be the next day's class discussion. 
Notes To Teachers

The mean: Sometimes the measure of central tendency is the amount that everyone will have if we decide to share equally. To find the mean add the values in the data set and then divide the sum by the number of values added. A set that contains numerical data has exactly one mean. A set that has nonnumerical elements will not have a mean. 
1) Consider the following strips.

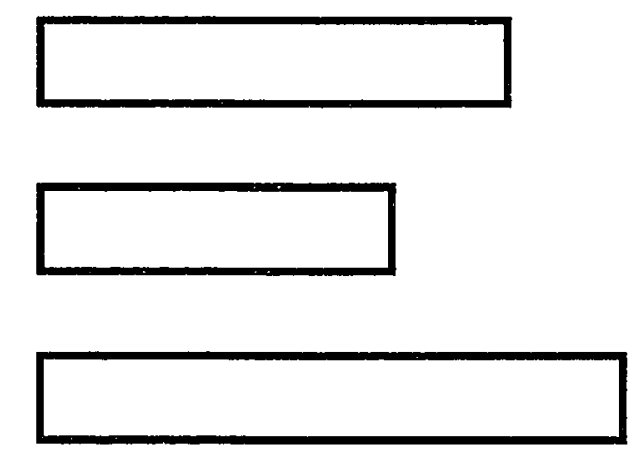

How would you find the mean? Tape all the pieces together end to end. Fold the long strip so there are three equal length. Each length represents the mean.

2) Suppose your class surveyed the color of the shirt worn by students in your school on a certain day. Here are the results.

Group 1: white, white, orange, red, blue, blue

Group 2: green, white, white, blue, pink, brown

Group 3: white, white, white, white, red, blue

Group 4: white, yellow, red, blue, orange, black

Group 5: yellow, yellow, white, white, red

Group 6: purple, yellow, orange, blue, brown, black

What is the mean of this set of data? Since the data are not numerical values, we cannot find the sum of all values. Therefore, this set has no mean. This is true for all non-numerical data.

3) Here are some test scores from Ms. Broadway's math class: $38,43,98,96$, $55,95,56,62,64,89,87,65$. 
Individual

What is the mean test score? How did you find it? The mean test score is approximately 70.7. Divide the sum of all scores by the number of scores.

4) The Micro-Bitts Computer Company (MBCC) has 20 employees with the following annual salaries. Find the mean salary at MBCC.

1 President...............................\$100,000

2 Vice-Presidents...................\$80,000 each

1 Plant manager.......................\$40,000

16 Assembly workers...............\$15,000 each

The mean salary of MBCC is $\$ 42,000$

5)

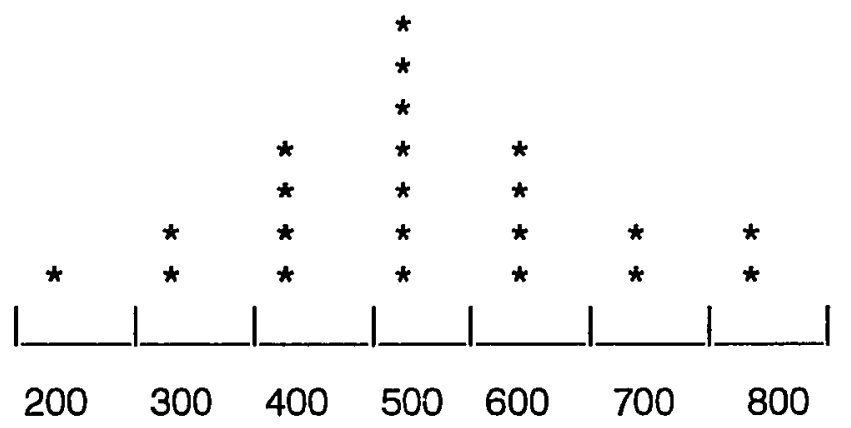

Find the mean of the data. Explain how you find it. The mean value is 513.6.

6) Do all sets of data have a mean? No, a non-numerical data set has no mean.

7) Make up a set of numerical data that has the same number for the mean, median, and mode. Answers vary. For example, one set is 15, 15, 15, $15,15$. 


\section{DAY 22 AND DAY 23 - CALCULATING THE AVERAGE Objectives}

1) Calculate the average: the mean, the median, and the mode

2) Examine how the selection of the mean, the median, or the mode gives different answers to the same question

\section{Materials}

\section{Handouts}

Worksheet-22A (individual)

Worksheet-22B (individual)

Homework-22 (individual)

Other materials

Calculators

\section{Homework Discussion}

\section{Homework-21: [15 minutes]}

\section{Procedure}

1) Worksheet-22A: [20 minutes] In the previous two lessons the students explored the statistical concepts of the three measures of central tendency, by physically demonstrating the meanings of these measures. Today we will reintroduce these three measures in a decision-making, problem-solving environment. The problem below not only gives the students the opportunity to compute the three averages but also shows the students how the selection of measures of average gives different answers to the same question.

Distribute Worksheet-22A to all students. Guide the class through the entire worksheet. 
Worksheet-22A: At Burger Barn, eight employees each earn $\$ 15,000$ per year. The assistant manager earns $\$ 40,000$, and the manager earns $\$ 69,000$. The manager tells a new employee that the average salary is $\$ 23,000$.

Step 1: Define the three measures of central tendency. Show students how to calculate the mode, median, and mean using pencil and paper. Have students copy all information in the space provided.

Step 2: Work with students to answer the questions in the worksheet. Encourage students' participation in class discussion.

2) Worksheet-22B: [the remaining time and the next class meeting] Distribute Worksheet-22B to all students. Have students complete this worksheet as much as possible. This worksheet will be the source for the next day's lesson.

3) Homework-22: Distribute Homework-22.

\section{Notes To Teachers}

The problems used in this lesson not only give the students the opportunity to learn the algorithms for calculating the three measures of central tendency but also show the students how the selection of those values gives different answers to the same question. Since the problems are real-world applications, the students will also have a glimpse of how statistics can be applied in real-life situations. Even though the students have spent several days exploring the concepts of the three measures of central tendency, some students may not have developed procedures for calculating the three averages. Therefore, it is important for the teacher to calculate the averages in Worksheet-22A step by step so that students have the opportunity to clarify their own knowledge. 
At Burger Barn, eight employees each earn $\$ 15,000$ per year. The assistant manager earns $\$ 40,000$, and the manager earns $\$ 69,000$. The manager told a potential employee that the average salary is almost $\$ 23,000$. Did the manager tell the truth?

\section{Part A:}

1) List all salaries (one by one). $15,000 \quad 15,000 \quad 15,000 \quad 15,000$

$\begin{array}{lllllll}15,000 & 15,000 & 15,000 & 15,000 & 15,000 & 15,000 & 15,000 \\ 15,000 & 15,000 & 15,000 & 15,000 & 40,000 & 69,000 & \end{array}$

2) Find the total number of people who work at Burger Barn. 10.

3) Calculate the mode, the median, and the mean of the salaries.

Mode $=\$ 15,000$. Median $=\$ 15,000$. Mean $=\$ 22,900$.

Part B: Answer the following questions.

1) Is the average salary used by the manager the mean, the median, or the mode? The mean.

2) Do you think the new employee will actually earn a salary of ? Why? No, because a new employee is unlikely to earn more money than employees who have been there longer.

3) Did the manager accurately describe the "average" salary at Burger Barn? Explain. No, because the mean does not accurately describe the average salary at Burger Barn. Since the calculation of the mean includes all values, the high salaries given to the manager and the assistant manager affect the mean.

4) If you were one of the eight employees, which statistical measure would you use to describe the "average" salary at the Burger Barn? Explain. 
WORKSHEET - 22B

Individual

\section{A look at the average wage}

The head of the employees' union in the Millstone Manufacturing and Marketing Company, and some employees' representatives were negotiating with $\mathrm{Mr}$.

Millstone, the president of the company.

The head of the employees' union: The cost of living is going up. Our workers need more money. No one in our union earns more than $\$ 18,000$ a year.

Mr. Millstone: It's true that costs are going up. It's the same for us-we have to pay higher prices for raw materials, so we get lower profits. Besides, the average salary in our company is over $\$ 23,000$. I don't see how we can afford a wage increase at this time.

A sales clerk: We sales clerks make only $\$ 10,000$ a year. Most workers in this union make $\$ 15,000$. We want our pay increased to at least that level.

The union official decided to take a careful look at the salary information. The payroll department provided him with the salary information below.

\begin{tabular}{|l|c|l|c|}
\hline \multicolumn{1}{|c|}{ Type of job } & Number employed & Salary & Union member \\
\hline President & 1 & $\$ 250,000$ & No \\
\hline Vice-president & 1 & 130,000 & No \\
\hline Plant Manager & 2 & 55,000 & No \\
\hline Foreman & 6 & 18,000 & Yes \\
\hline Workman & 15 & 15,000 & Yes \\
\hline Payroll Clerk & 3 & 13,500 & Yes \\
\hline
\end{tabular}




\begin{tabular}{|l|c|l|l|}
\hline Secretary & 4 & 12,000 & Yes \\
\hline Sales Clerk & 10 & 10,000 & Yes \\
\hline Custodian & 3 & 8,000 & Yes \\
\hline TOTAL & $\mathbf{4 5}$ & $\ldots$ & .... \\
\hline
\end{tabular}

Part A: Calculate the mean, the mode, and the median of the employees' salaries.

Mean $=$ approximately $\$ \mathbf{2 3 , 0 0 0}$. Mode: $\$ \mathbf{1 5 , 0 0 0}$. Median: $\$ \mathbf{\$ 1 5 , 0 0 0}$ Part B: Answer the questions below.

1) Which measure of central tendency did Mr. Millstone use as his "average" salary at the Millstone Manufacturing Company? The mean.

2) Which measure of central tendency did the sales clerks say is a typical salary at this company? The mode.

3) What is the third measure of central tendency that was not mentioned in the introduction? The median.

4) If the salaries of non-union employees are disregarded, what would be
a. the new median? $\$ \mathbf{\$ 1 5 , 0 0 0}$.

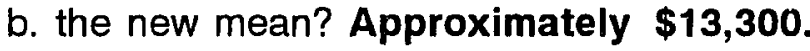
c. the new mode? $\$ 15,000$.

5) Compare the old mean, mode, and median to the new mean, mode, and median.

a. Which measures of central tendency stayed the same? The median and the mode stayed the same.

b. Which measures of central tendency changed? Why did it change?

The mean changed because the four highest salaries were not included. 
Individual

6) Consider the salaries of all employees. Which "old" measure of central tendency do you think accurately describes the typical salary of employees in this company (including non-union members)? Explain. The median. When a set of data has some extreme values (high or low), these values will distort the mean of the set. In this case, the median is a better indicator of the central tendency. 
1) A dress designer wants to create a new unique pattern for a new stretch fabric which has recently become available on the market. This designer believes he can make a lot of money by creating a single pattern out of this stretchable material so that one size fits all. Using the data from a survey of potential customers, what size should he make the dress pattern in order to create a single pattern to fit all dress sizes, with the minimum of stretching or shrinking of the dress?

$18,12,16,3,6,12,10,6,3,8,10,3,6,8,12,10,3,6,8,8,10,10,6,6$.

Mean $=$ approximately size 8. Median $=$ size 8 . Mode $=$ size 6 . The dress designer should make the dress size 8 (the median size) because the median marks the point where half of the data consist of sizes 6 and 3 (two smaller sizes) and half of the data consist of mostly sizes 10, 12 (two larger sizes).

2) The favorite vegetables of the 10 members of the Nguyen family are peas, carrots, beans, peas, carrots, zucchini, broccoli, carrots, broccoli, beans. Decide which measure of central tendency is appropriate for these data. Explain. Since this is a non-numerical set, the only appropriate measure of central tendency is the mode. Thus, the typical vegetable for this family is carrots.

3) A traveling salesperson drives around California selling TV subscriptions. She logs the number of miles that she drives each day. Examine those miles below.

$\begin{array}{llllllllllll}180 & 125 & 161 & 39 & 261 & 125 & 310 & 66 & 43 & 89 & 107 & 143\end{array}$


Individual

$\begin{array}{llllllllllll}96 & 80 & 125 & 10 & 193 & 216 & 178 & 238 & 310 & 170 & 216 & 166\end{array}$

a. Calculate the three measures of central tendency. Mean $=$ approximately 152 miles. Median $=152$ miles. Mode $=125$ miles.

b. Which measure would best represent the average number of miles she drives in a single day? Explain. The median or the mode.

c. Use the measure in part (b) as the number of miles this saleswoman drives every day, estimate how many days before she reaches 30,000 miles on her car? 200 days.

4) Find examples of the use of the word "mean," "median, "or "average" in a local newspaper. If you find "average," can you tell if they used the median, the mean, or mode? If you find "mean" or "median," discuss whether or not the appropriate measure was used. 


\section{CHAPTER 4}

\section{Presentation of the Study's Findings \\ Selection of the Students' Answers}

In the previous chapters, the problem under the study and the literature pertinent to the study were discussed, the development of the unit was described, and the unit itself was introduced. This chapter focuses on the presentation of the data collected during the application of the units. The first part of the chapter presents ten students' answers to some selected questions regarding their understanding of the basic elements of surveys. The second part displays the answers from the selected students' assignments on a traditional junior high topic--mean, median, and mode. The third and final part of this chapter is reserved for the display of some group projects together with some samples of student writing.

The class had 32 students; however, only 10 students were chosen to have their answers examined in detail. There are two reasons for this method of selection. First, examining the answers of the same students throughout the entire evaluation ensures the investigator the opportunity to monitor the development of the selected students' thinking process. Secondly, these students were chosen because they had consistently completed and turned in their assignments. Even though the students were required to keep all work until the end of the unit, many students misplaced theirs. This occurrence led to the unavailability of many students' assignments and group projects. As a result, in order for the investigator to select a considerable amount of usable student work for evaluation, sample students were chosen basically due to their 
consistency of doing and keeping their assignments. As a result, this student sample is not a representative sample.

Students' answers are presented in the following format. For each question, students' code names are listed, followed by the answers given by these students. The students' answers are presented exactly the way they were written in the original assignments. If a student did not answer any part of an assignment, the space reserved for that part is left blank. A class summary for each question is in Appendix B.

\section{Students' Answers to Selected Questions on the Basic Elements of a Survey}

Figure 1a. Students' Examples of Good Survey Questions for Their Chosen Topic.

Suppose you were asked to select one of the following ideas to investigate in a survey of students at your school.
a) your dream car
e) favorite brand of soft drinks
b) favorite school subject
f) things that make you happy
c) favorite recreational place
g) things that make you sad
d) favorite type of music
h) what would you want to change about your math class

Give three examples of good survey questions on your chosen topic. Why are they considered to be good survey questions?

Student 1:

Student 2: 
Student 3: The topic is "favorite brand of your soft drinks." What soft drink is the best? What soft drink is the healthiest? What is the worst soft drink for you?

Student 4:

Student 5:

Student 6: The topic is "What would you want to change about your math class?" Why would you want to change it? Why don't you like it now? Do you like your teacher? Explain

Student 7: The topic is "favorite school subject." On a scale of 1 to 10 , how well do you like math? Which subject do you like better: science or English? Is P.E. your favorite subject? These questions are easy to answer.

Student 8: The topic is "What would you want to change about your math class?" What don't you like about math? Why do you want to change your math class? Why don't you like your math class? It has the qualities of good question.

Student 9: The topic is "your dream car." What is your dream car? Why do you like that car? What color is your dream car? They are good questions because they are related, and are fast and simple.

Student 10:

Figure 1b. Students' Explanations of the Qualities of a Good Survey

Question.

List three qualities of a good survey question.

Student 1: 
Student 2:

Student 3: Don't make the questions long, easy to understand. Do not use extra words. Make sure everyone understand.

Student 4:

Student 5:

Student 6: Short, simple, strait direct question (right to the point).

Student 7: It is fair, specific, and anyone can answer.

Student 8: Not using extra words, everyone can understand, and should be easily understood.

Student 9: First, the question must be clear. It cannot be a complicated answer. And it is fast to answer.

Student 10:

Figure 2. Students' Answers to the Question of Whether a Sample Is a Random Sample.

Which of the following sampling methods produce a random sample from a class of 36 students? Explain.

a) Select the first six students to enter the room.

b) Select those students whose phone numbers end with the digit 4 .

c) Suppose that the classroom has six rows of chairs with six chairs in each row. Assign the rows the digits 1 through 6 . Throw a die and place all the students in the row corresponding to the number on the die in the sample.

d) Suppose the class has 18 boys and 18 girls. Assign each student a number from 1 to 36 . The girls get the numbers 1 to 18 and the boys the numbers from 19 to 36 . Write numbers 1 to 36 on each of the 36 pieces 
of paper and put the pieces in a box. Select six pieces. Place the students with the chosen numbers in the sample.

Student 1: a) Yes.

b) No, because not everyone has the digit 4 last.

c) No, I'm not choosing independently.

d) Yes, because you don't know who's going to get picked.

Student 2:

Student 3:

Student 4:

Student 5:

Student 6: a) No, this is not a random sample. Some people have a farther walk than others.

b) That would be a random sample because everyone has a chance to get picked.

c) No, this is not a random sample.

d) This sample would be the best of all. Everybody gets an even better chance than the others.

Student 7: a) No, not everybody will make it through the same time.

b) Yes, the digit $\mathbf{4}$ is picked randomly.

c) No, there is no independent pick.

d) Yes, the students are being chosen at random.

Student 8:

Student 9: a) No, some people might be far away and some close. 
b) Yes, because it is random and the numbers were chosen randomly.

c) No, the digit is not chosen independently.

d) Yes, everyone has a chance. The people are chosen independently and not together.

Student 10:

\section{Students' Answers to Selected Questions about Their Own Development of Mathematical Procedures}

Figure 3: Students' Procedures for Drawing a Frequency Table.

List the steps of a procedure which can be used to draw a frequency table.

Student 1:

Student 2:

Student 3: You need a tally, you need some results, you need some scores, you need intervals, and a frequency. Make three columns. Make a title for your table.

Student 4: Draw a rectangle and divide it into three groups: interval, tally, and frequency. Make interval numbers starting from 50. For the first line put $50-59$ and $60-69$ on the second line and so on. Then get scores and tally them next to the number the grade goes. Mark the total in the frequency.

Student 5:

Student 6: First they all have to be equal amount between each other. Next it should be continuous. Last they should never 
overlap. Most important is make 3 rows of interval, tally, and frequency. Make a name for the table.

Student 7: You have to have a frequency, a tally, and intervals. You need an interval that is equal.

Student 8: First you have to have an interval, tally, and frequency. Then you need an interval that is equal.

Student 9: First, you need a frequency and a tally. Then you need an interval that is equal. Tally in the second column. Frequency in 3rd column. Make a title for table.

Student 10:

Figure 4. Students' Explanations of the Three Conditions for Choosing the Intervals of a Frequency Table.

Three points to remember when choosing the intervals for a frequency table are that they should be equal, they should be continuous, and they should not overlap. Write a paragraph to explain why each of these points is important.

Student 1:

Student 2:

Student 3: They should be equal to get better results. They should be continuous for better scores or results. If it is overlap the scores won't be reliable. If there not continuous you may miss some number and the tally won't be accurate.

Student 4: If the frequency table is not exact it won't get a precise answer or right answer. If they are not continuous then you would have some grades or numbers left out of the 
frequency table. Your numbers should not overlap for it will still be a wrong number.

Student 5:

Student 6: If they are not equal (some might be 10 or 5) and continuous of being equal to the frequency will be all wrong. If they overlap there will be too many tallies than what you originally have.

Student 7: They should be equal so they can be made reliable, they should be continuous so its reliable, and they should not be overlapped so you can get equal answers.

Student 8:

Student 9: It should be equal because the results will be accurate and reliable. It should be continuous accurate. It shouldn't be overlapped because they cannot have a equal answer.

Student 10:

\section{Students' Answers to Selected Questions on the Mean, Median, and Mode}

Figure 5a. Students' Procedures for Finding the Mode of the Length of the Paper Strips.

Compare the length of the given strips (The students received these strips in no particular order.)

How can you tell the mode of the length of the strips? 


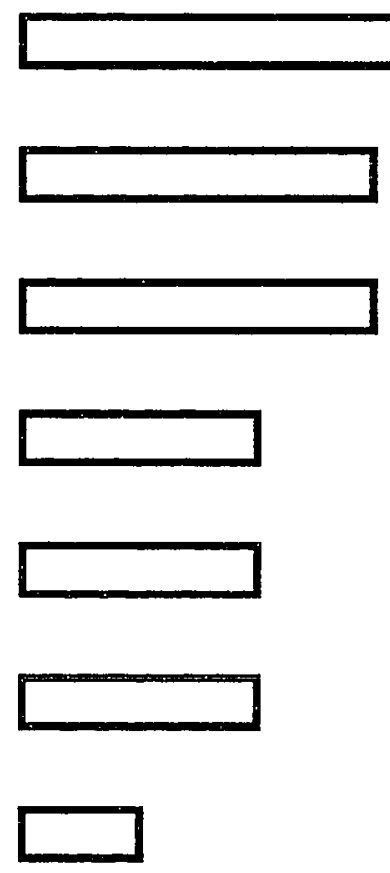

Student 1: The biggest bar is on top which is the mode.

Student 2: I can tell by line in blue, and by the most data collected.

Student 3: By counting how many has the most.

Student 4: The strip with the longest line.

Student 5: Their almost the same size, and the one that shows up the most.

Student 6: The mode is the three squares that are the same length.

Student 7: How long the blue line is.

Student 8: By looking at how long the line is.

Student 9: I could tell by comparing the strips and look for the longest one.

Student 10:

Figure 5b. Students' Answers to the Question of There is More Than One Mode. 
Is there more than one mode? Explain.

Student 1: No, because the strip on top is the only one of its size.

Student 2: No, because there is only one length that occurs the most number of times.

Student 3: There only one mode because there is no other shape that has more than three.

Student 4: No, because there is no other strip that is the same size.

Student 5: No, there is only one because their are only 4 on each side and there's one left over.

Student 6: There is only one mode, no other shape has three.

Student 7: One, one size is the same.

Student 8: No, there is only one mode.

Student 9: No, because their is only one long strip and there isn't a strip that is the same with the longest one.

Student 10:

Figure 5c. Students' Procedures for Finding the Median of the Length of the Paper Strips.

How can you tell the median of the length of the strips?

Student 1: Because it is in the middle.

Student 2: By line up in numerical order or shape.

Student 3: We counted the lengths until we got to the middle.

Student 4: It is the middle strip out of nine.

Student 5: You put them in order, then you take one away from each side and there is one left over.

Student 6: We counted the ends until we got to the middle. 
Student 7: By crossing out the biggest line and smallest line and getting to the middle of the mode.

Student 8: By getting to the middle of the mode.

Student 9: By putting all the strips in length and slowly take one at the bottom and top until there is one left.

Student 10:

Figure 5d. Students' Answers to the Question of Whether There is More than One Median.

Is there more than one median? Explain.

Student 1: Yes, because there are two of the same size.

Student 2: Yes, because in the middle have two rectangles.

Student 3: No, there is one, because the total number is an odd number.

Student 4: No, because there's no other size and no other strip to make it ten.

Student 5: No, there is only one mode and one median.

Student 6: No, there is only one. It is an odd number of shape so there is only one median.

Student 7: Yes, there are two left in the line after crossing out each strip.

Student 8: No, there is only one.

Student 9: Yes, there is two strips that are the same length as the median.

Student 10: 
Figure 5e. Students' Procedures for Finding the Mean of the Length of The Paper Strips.

How would you find the mean of the strips below without using a ruler?

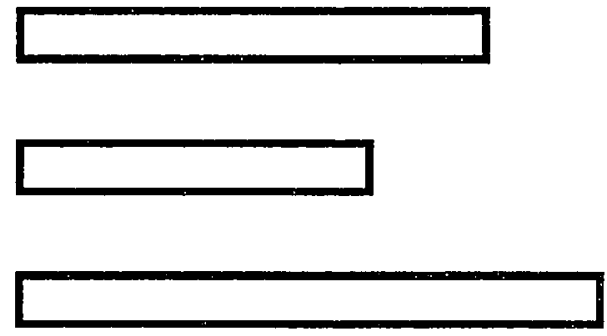

Student 1:

Student 2: First: you got a ruler and measure it, second add all the size of length then divide it by how many rectangles you have, then you find it.

Student 3:

Student 4: You would have to measure the strip. Add all the sizes together, then you would have to divide the answer by three.

Student 5: No matter how many mean strips, you can't find the mean, if you cut the length you'll probably find the mean.

Student 6: Put the small rectangle on top and the top one under. Now count from the side and go all the way to the middle. The answer would be number 2 . (This student labeled the rectangle with the shortest length 1 and the rectangle with the longest length 2.)

Student 7: Measure each strip. Add all the lengths, then divide by 3. 
Student 8:

Student 9: I would find it by taking off a portion of the longest and then insert it to the shortest and then you would have the mean.

Student 10: Add up all the lengths and divide by three.

Figure 6a. Students' Procedures for Finding the Mode of a Set of

Numerical Data.

Here are some test scores from Ms. Broadway's math class: 38, 43, 98,

$96,55,95,56,62,64,89,87,65$. What is the mode of the test scores?

Student 1: 63.

Student 2: There is no mode.

Student 3: There is no mode.

Student 4: There is no mode.

Student 5: No.

Student 6: There is no mode.

Student 7: There is none.

Student 8: There is no mode.

Student 9: 98

Student 10:

Figure 6b. Students' Answers to the Question of Whether There is More than One Mode.

Is there more than one mode? Explain.

Student 1: No, because that was the only number that was correct.

Student 2: No, because it's not the same number, there is no mode.

Student 3: There are no mode, because there's not one of the same kind. 
Student 4: No, all scores only appear once.

Student 5: No, there are none that are the same.

Student 6: No, all of the test scores are different from each other, so there is no mode.

Student 7: No, there are no two same numbers.

Student 8: No, they are no two scores that are alike.

Student 9: No, because there is only one score and there isn't a score that is the same as the highest score.

Student 10:

Figure 6c. Students' Calculations of the Median of a Set of Numerical

Data.

What is the median of the test scores?

Student 1: 50

Student 2: $\quad 64.5$

Student 3: $\quad 64 \frac{1}{2}$

Student 4: 64.5

Student 5: We put them in order.

Student 6: $64 \frac{1}{2}$

Student 7: $\quad 64.5$

Student 8: 64.5

Student 9: 64.5

Student 10:

Figure 6d. Students' Answers to the Question of Whether There is More than One Median.

Is there more than one median? Explain. 
Student 1: No, it's the only number.

Student 2: No, because its not the same number, there can be one number in the middle.

Student 3: There is only one median because the total number is even.

Student 4: There is only one median for there can only be one number in the middle.

Student 5:

Student 6: It is the number between the score and the seven score (65).

Student 7: No, one number is left in the mode in the middle.

Student 8: There is only one. Only one number is in the middle.

Student 9: No, because there is only 1 score that is 64.5 .

Student 10:

Figure 6e. Students' Procedures for Finding the Median of a Set of Numerical Data.

How did you find the median of the test scores?

Student 1: I look in the middle of all the numbers.

Student 2: I can find it by putting the number in order.

Student 3: From highest to lowest, marking off top bottom.

Student 4: It is the number between the 6th score (64) and the 7th score (65).

Student 5:

Student 6: From highest to lowest.

Student 7: It is the number between the 6th and 7 th number in the mode. 
Student 8:

Student 9: By putting the score in numerical order and take one off the top and bottom until there is only one number left.

Student 10:

Figure 6f. Students' Procedures for Finding the Mean of a Set of

Numerical Data.

What is the mean test score? How did you find it?

Student 1:

Student 2: $\quad$ 70.7. I got it by add it all and divide it by 12 .

Student 3:

Student 4: 70 . I got it by adding all the scores then dividing the answers by the number of scores there are.

Student 5: 70.7. You count each side and divide the number of scores.

Student 6: 70.6. I averaged all of the grades and got 70.6.

Student 7: $70 \frac{2}{3}$ Add each number. Then divide the total by 12 .

Student 8:

Student 9: 70.66666667 . I figured it out by adding all the numbers and dividing the answers by 12 .

Student 10: $70 \frac{2}{3}$ (1)Add up all the test scores. (2) Then divide by 12 .

Figure 7a. Students' Procedures for Finding the Mode of a Set of Colors. Suppose your class surveyed the color of the shirt worn by students in your school on a certain day. Here are the results.

Group 1: white, white, orange, red, blue, blue

Group 2: green, white, white, blue, pink, brown

Group 3: white, white, white, white, red, blue 
Group 4: white, yellow, red, blue, orange, black

Group 5: yellow, yellow, white, white, red

Group 6: purple, yellow, orange, blue, brown, black

What is the mode of this set of data?

Student 1: White.

Student 2: White.

Student 3: White.

Student 4: White.

Student 5: White.

Student 6: White.

Student 7: White.

Student 8: White.

Student 9: White.

Student 10: White.

Figure 7b. Students' Procedures for Finding the Median of a Set of

Colors.

What is the median of this set of data?

Student 1: No median.

Student 2: No median.

Student 3: No median.

Student 4: No median.

Student 5: No median.

Student 6: No median.

Student 7: No median.

Student 8: No median. 
Student 9: No median.

Student 10:

Figure 7c. Students' Procedures for Finding the Mean of a Set of Colors.

What is the mean of this set of data?

Student 1:

Student 2: You cannot find the mean of set data.

Student 3:

Student 4: There is no mean.

Student 5: How many colors. You can't do it.

Student 6: There is no mean.

Student 7: There is no mean.

Student 8:

Student 9: There is none.

Student 10: You can only find the mean of numbers.

Figure 8a. Students' Procedures for Finding the Mode of a Set of Data in

\section{a Line Plot Form.}

The graph below is called a line plot. Each star represents the number of times that a particular value occurs. For example, the two stars above the number 800 means that the value 800 occurs two times in this set of data.

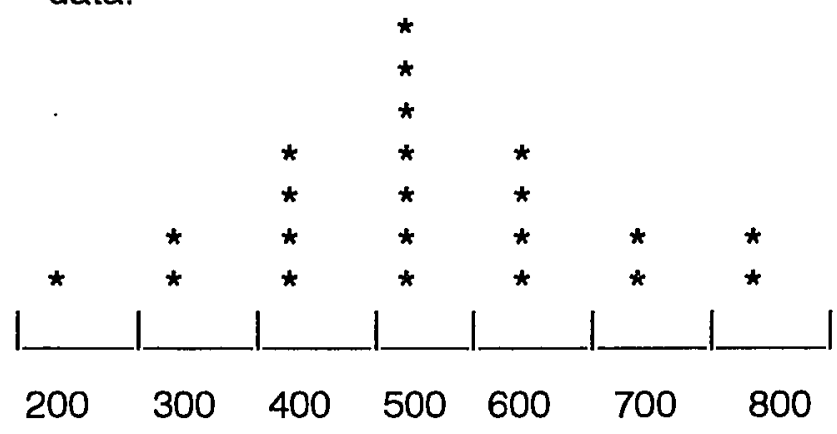


Find the mode of the data. Explain how you find it.

Student 1: 500 . I found it because it has the most stars.

Student 2: The 500 is the mode of data. Because it's most of number in data collected.

Student 3: 500 is the mode. Because it has the most stars, 7 stars.

Student 4: 500 because it appears 7 times because it has 7 stars over it.

Student 5: Somewhere between the 11th and the 12th dot is the median value.

Student 6: I found it by looking for the most stars in one row which is 500.

Student 7: 500. It showed up 7 times.

Student 8: The mode is 500 . I found it by seeing which number has the most stars.

Student 9: 500 . I found it by comparing the data and finds the one that is longest.

Student 10: 500. There are seven stars above the number 500 .

Figure 8b. Students' Procedures for Finding the Median of a Set of Data in a Line Plot Form.

Find the median of the data. Explain how you find it.

Student 1: 11th and 12th stars makes the median value.

Student 2: The median is the 2 each number. Because I put in numerical order.

Student 3: 500 is the median, because you keep on crossing out the sides until you get to the middle. 
Student 4: The median is 500 because I did the top and bottom canceling and the middle number is $\mathbf{5 0 0}$.

Student 5: It would be a lot of work to have to put down all the numbers.

Student 6: The answer is $11 \frac{1}{2}$. I just counted from one end to the other until I got to the middle.

Student 7: It is the number between the 11th and 12th star.

Student 8: It is the number between the 11th and 12th star.

Student 9: 11 and 12. I found it by putting the number in numerical order. And then crossing one on the top and bottom until there is one left.

Student 10: There are 22 stars so it should be between the numbers 11 and 12.

Figure 8c. Students' Procedures for Finding the Mean of a Set of Data in a Line Plot Form.

Find the mean of the data. Explain how you find it.

Student 1:

Student 2: 513.6. I found it by add all the stars by each number.

Student 3:

Student 4: The mean is $1614 \frac{2}{7}$. You multiply the number of stars there are over the number it belongs. Then you add up the answers together. Then you divide it by how many columns there are.

Student 5: The mean value is 5.136 divide the sum of dots. 
Student 6: $\quad 500$ is the answer. I counted all sides and got the middle of 500.

Student 7: 513.63. Add up each number. Divide the total by 22 .

Student 8:

Student 9: 513.63. I found it by adding the number and divide by 22 .

Student 10: 513.63. Add-divide by 22.

Figure 9a. Students' Explanations for Determining Whether All Sets

Have a Mode.

Do all sets have a mode? Explain.

Student 1: Yes, because they do.

Student 2: Yes, we have like white shirt mode, in the person who has 2 mode, and the star.

Student 3: No, because the highest amount could have more than just one.

Student 4: No, there is always a high number.

Student 5: No, not all of them, some of them could.

Student 6: No, if one set had all numbers that weren't the same then there would be no mode.

Student 7: No, some may only have 1 different number in data.

Student 8: No, some of the sets of data had no mode because they only had 1 different number.

Student 9: No, there might be a set of data that are the same.

Student 10: No, some may only have 1 different number in data.

Figure 9b. Students' Explanations for Determining Whether All Sets Have a Median. 
Do all sets have a median? Explain.

Student 1: No, because they all don't have middle numbers.

Student 2: No, because none numbers have no median, only the numerical numbers.

Student 3: No, because if you mark off the sides every time you'll get at least one or two median numbers.

Student 4: No, because there is sometimes no middle number.

Student 5: No, you can't have a number that deals with colors.

Student 6: Yes, if you count from each side and get to the middle you get the median, even if the set numbers are even you got a half median.

Student 7: Yes, it is the numbered average between two numbers.

Student 8: Yes, it's between 2 numbers all the time.

Student 9: Yes, some sets with same number could still be taken off 1 on top and bottom.

Student 10: Yes, it is the number average between 2 numbers.

Figure 9c. Students' Explanations for Determining Whether All Sets Have a Mean.

Do all sets have a mean? Explain.

Student 1:

Student 2: Yes, because I put in the numerical order then I cross out each.

Student 3:

Student 4: No, because it has to be numerical question.

Student 5: No, the data has no mean. 
265

Student 6: No, they might have an even amount of numbers and have two answers. It may be a non-numerical set of data.

Student 7: No, colors cannot have a mean.

Student 8:

Student 9: No, some might be works as colors.

Student 10: Colors cannot have a mean.

Figure 10a. Students' Calculations of the Mean and Median.

The Clinton School District hired five new teachers. Their salaries are $\$ 22,500, \$ 23,500, \$ 48,500, \$ 26,000$, and $\$ 25,500$.

Calculate the mean and the median of the salaries. Show all your work.

Student 1:

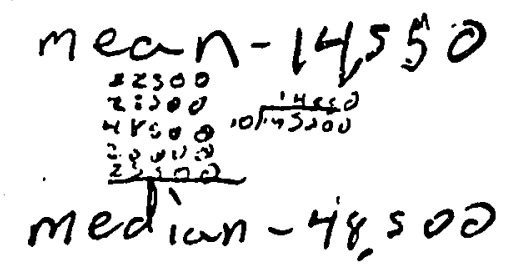

23000300 . 48300,2500025500

Student 2:

mean- \$22,500+\$23,500+\$48,500+\$26,000 $+\$ 25,500=146,000$.

29,200 - J mean he dian $=\$ 25,500$

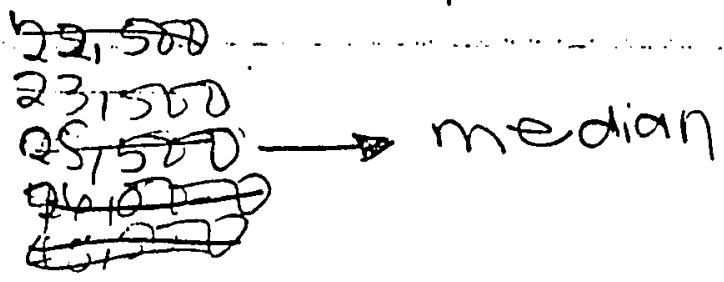


Student 3:

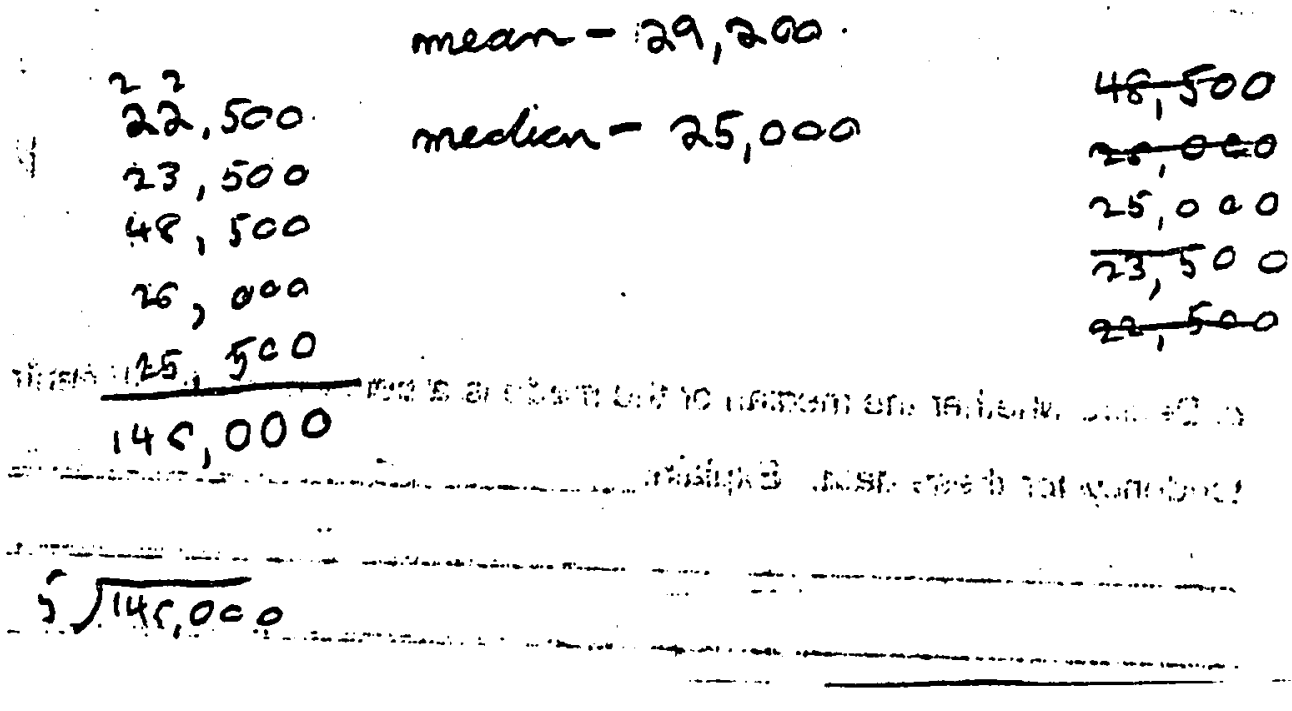

Student 4:

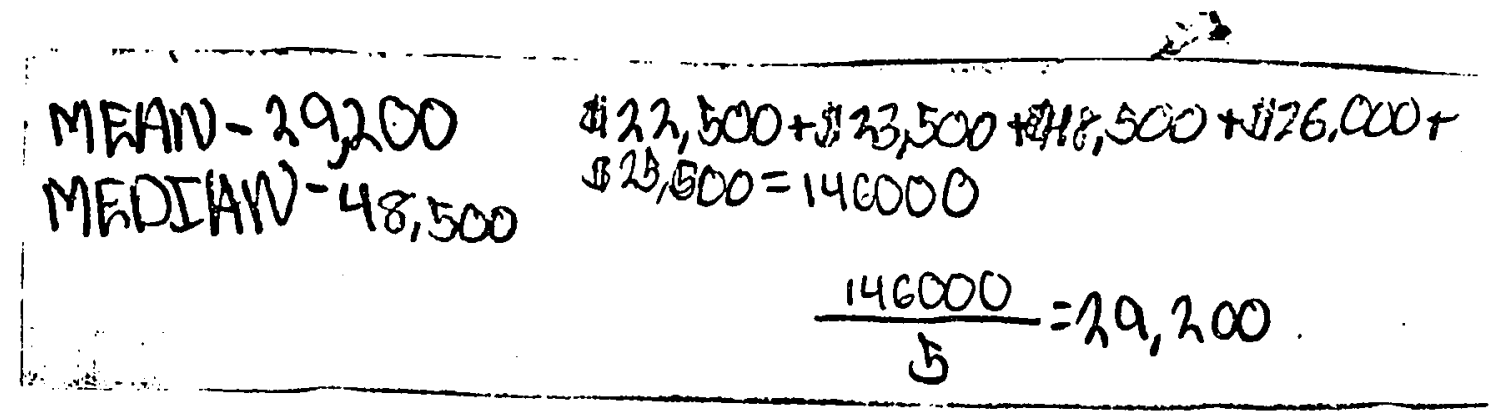


Figure 10b. Students' Explanations for their Select the Appropriate Mean and Mode.

Decide whether the mean or the median is a better measure of central tendency for these data. Explain.

Student 1: Median because that helps find the answer in the center of all data.

Student 2: The median because its better salaries, and its a middle of number of set data.

Student 3: The mean, because the mean averages it out, its more accurate than the median.

Student 4: The mean because it can show the average salary of a person.

Student 5: Because when you use the mean you can use or tell the amount of something on another side.

Student 6: I think the median is better than the mean because it's closer to the salaries than the mean.

Student 7: median. It tells the middle salary of the teachers.

Student 8: The median because it is between the highest and the lowest salaries.

Student 9: Median, the reason is that sometimes there might be 1 or more number which are really high and the rest are low.

Student 10:

\section{Students' Projects and Writing Samples}

Students' Group Projects. Three group projects are displayed in this section. 
Figure 11a. The Group Project of the Students 2, 9, and Two Other

\section{Group Members}

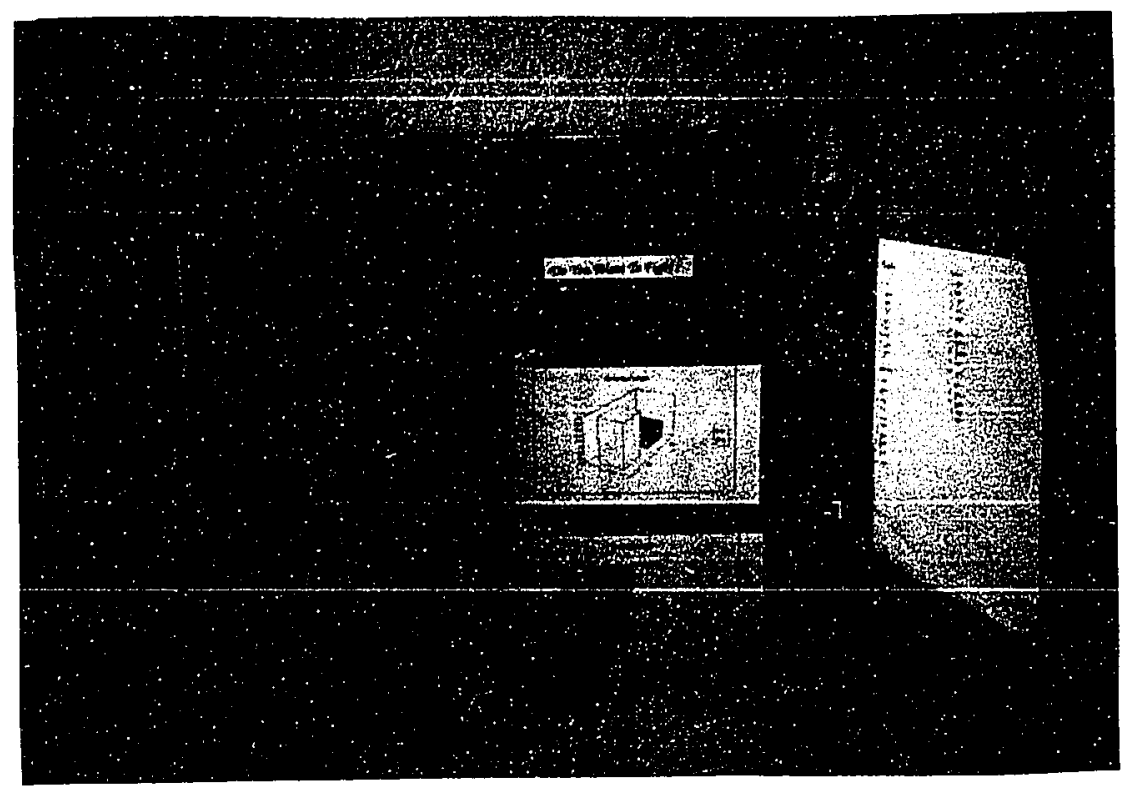

Group report: Our group decided to do a survey on violence in school.

So we decided to ask 40 people "Do you want to fight?" We did this to see if the students like to fight or not.

Our group's survey was collected by interviewing 40 people. We split each person so that everybody interviews 10 people. We interviewed the people at brunch, lunch, and after school.

We only interviewed 35 people. People that were interviewed were also afraid that they would get in trouble if they say yes, so we left them anonymous.

Our findings were astonishing. It had shown that 18 people said they would not fight. While 17 people said they that they would fight. It was inconclusive due to the fact that it was so close that we should have interviewed more people. 
Figure 11b. The Group Project of Students 3, 6, and Two Other Group

Members.

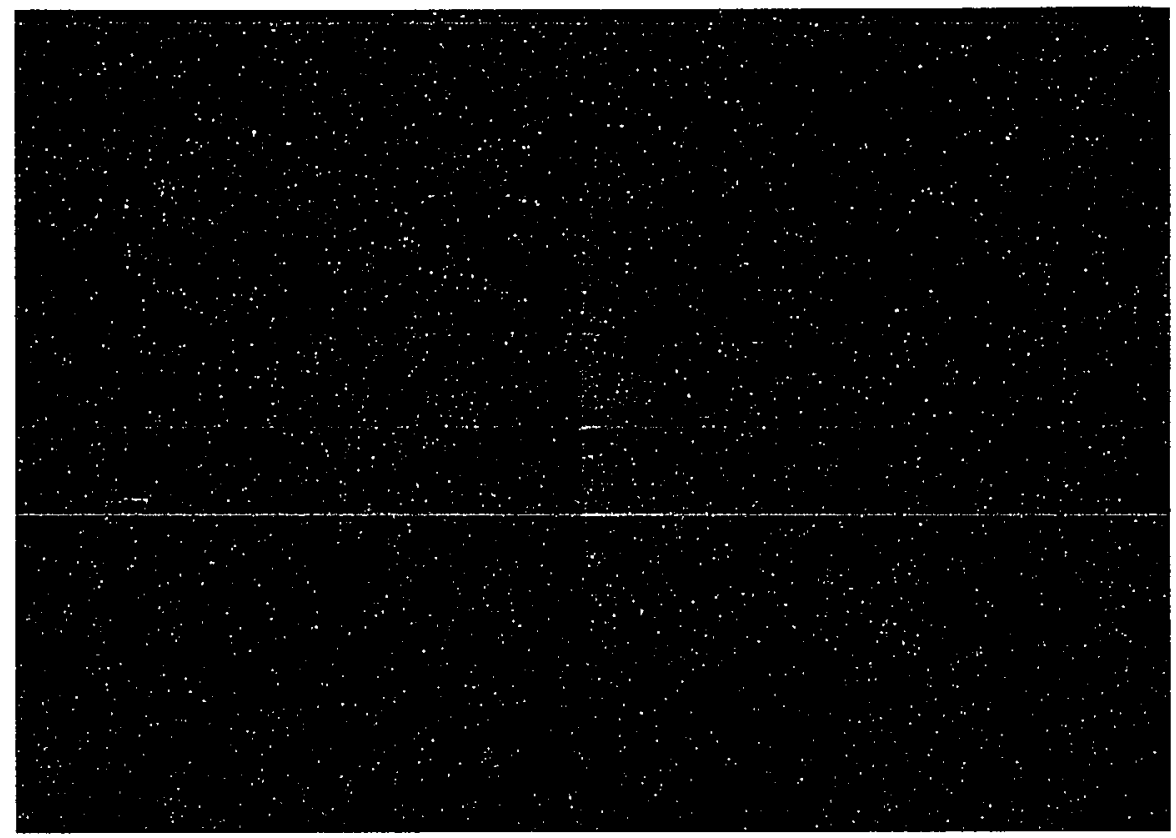

Group report: We asked about 164 people what music they like the best. We contacted the people mostly in person. We surveyed young and old people, boys and girls.

Our results showed that $42 \%$ liked rap music, $36 \%$ liked old school, $21 \%$ liked country, 17\% liked oldies, $14 \%$ liked reggae, 9\% liked Mexican music, $8 \%$ liked modern, $6 \%$ liked classical, and $10 \%$ liked rock. Our advantage is that a lot of people will want to be surveyed. The disadvantage is that people often asked their relatives that were just one culture. 
Figure 11c. The Group Report of the Students 7, 8, and Two Other Group

\section{Members}

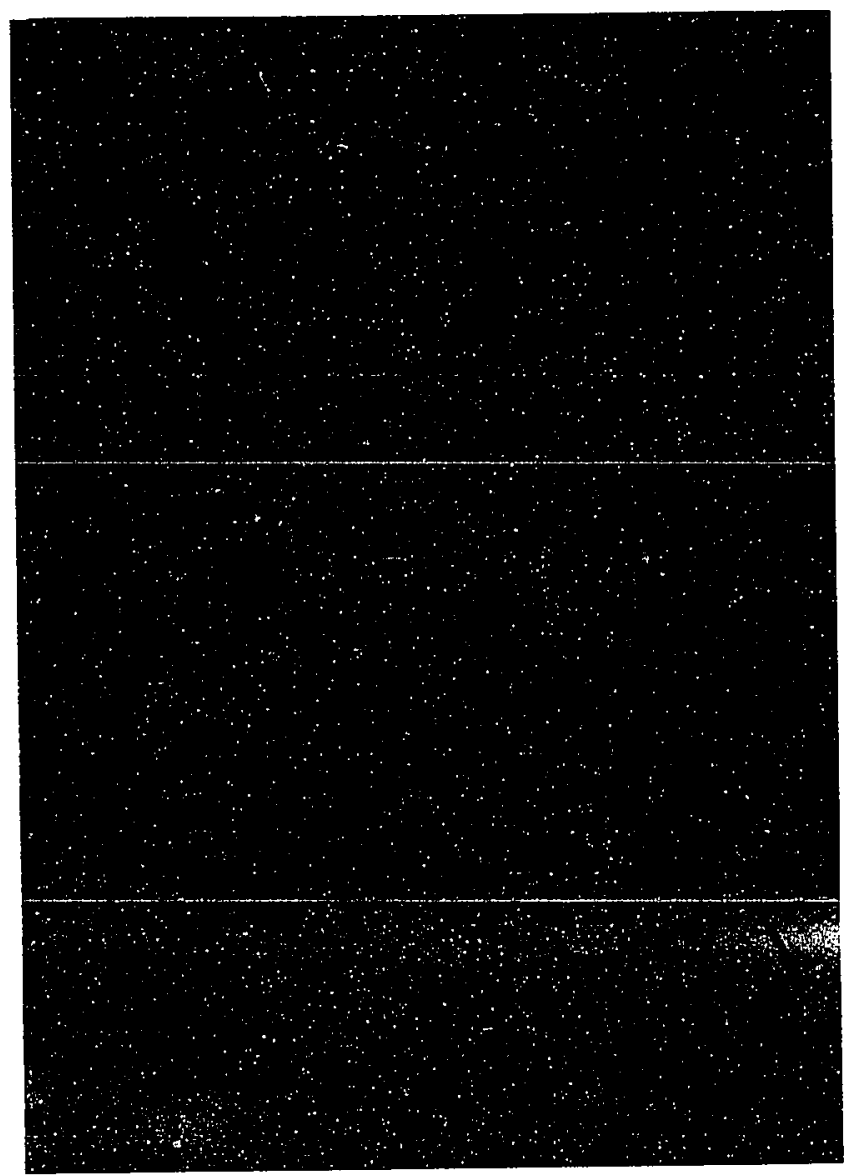

Group report: Our group interviewed 100 people. Our results showed that 52 people had four televisions in their houses, 28 people had three televisions in their houses, 15 people had two televisions in their houses, and 5 people had only one television in their houses. 
271

Samples of students' writing. The following writing samples were individual self-assessment reports on students' roles in their group projects. Four writing samples are displayed in this section.

Figure 12a. A Writing Sample of Student 3

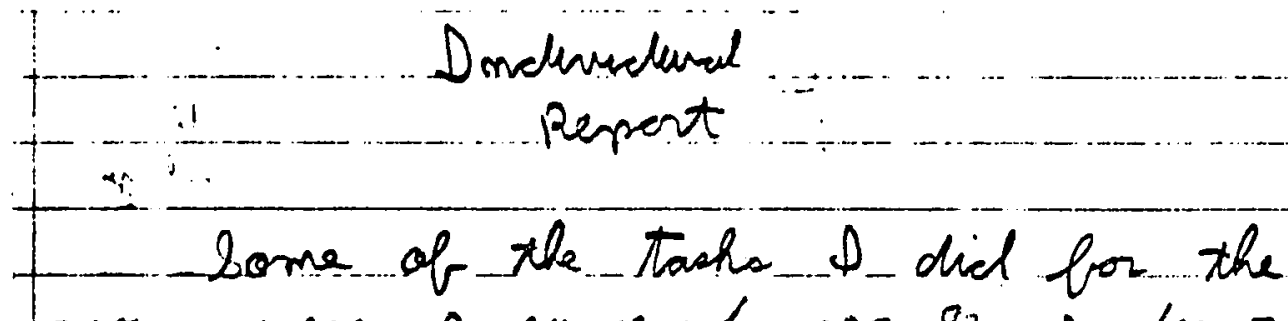

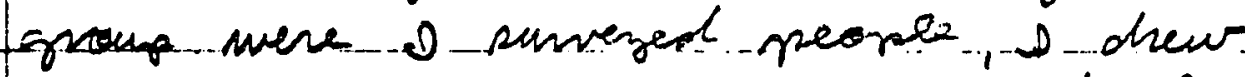
a lon graph, and wow te the report. I Limes of told needle what. They had To do... Th mathematic D learned un as more on how to dhow a han graph clot biota d'.. 'ne been doing ban graphs fer a while and since Dive been plainthan is the rest then doing how wish et Find of relates of caved of told my grange. te do a forte mere stuff ben the project so that it caved improve. - D Think That everyone dive what the ri. sure supposed ta do that west suras said to them, that worked well fer our group. I thing the unit was alright, clibfrent then whet I thrust. 
Figure 12b. A Writing Sample of Student 4

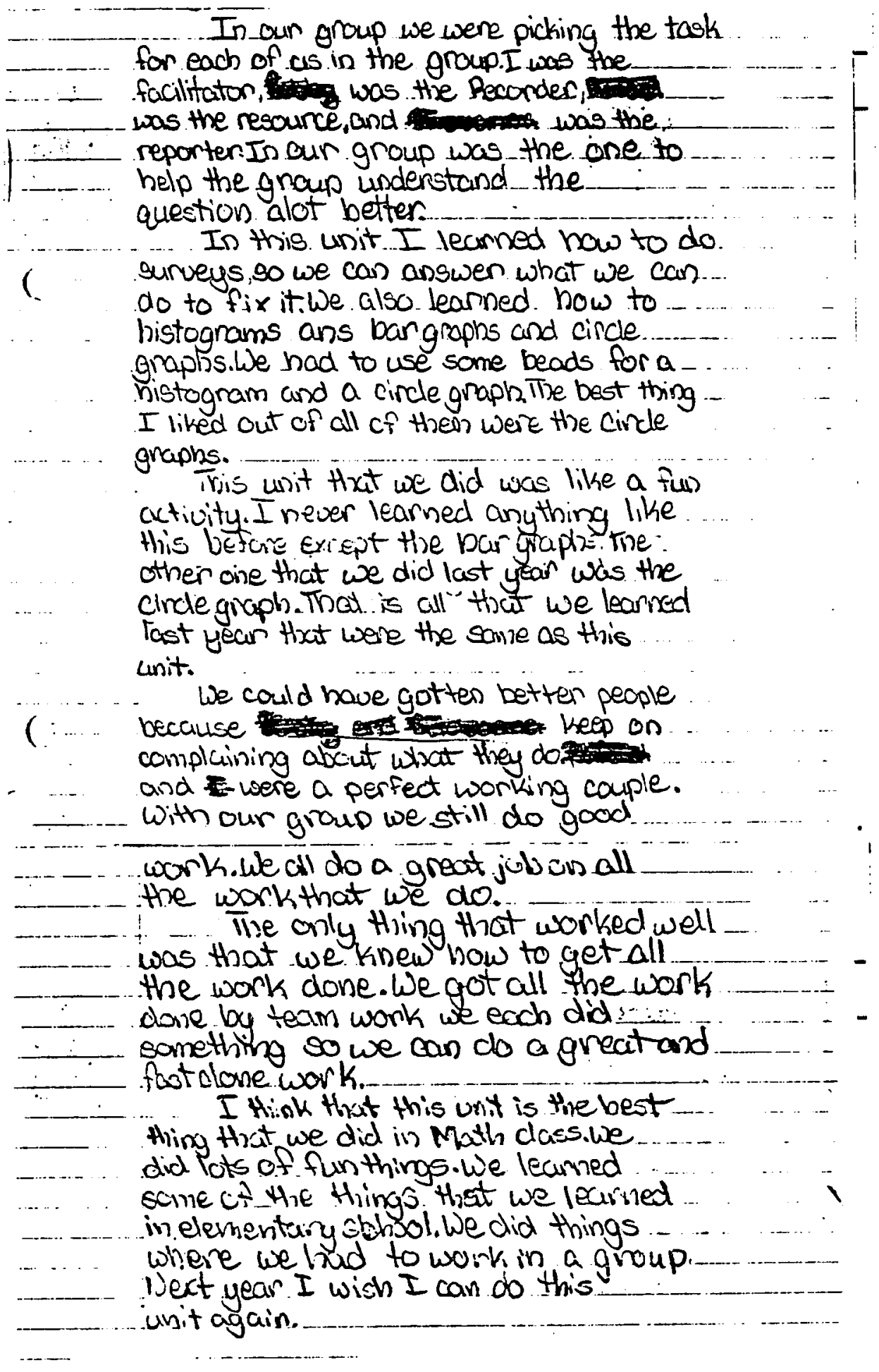


273

Figure 12c. A Writing Sample of Student 6

The task es did was to help complete group assingments, $l$ helped with the survey on music, l tried to snake all of soy group stay focused on whet ene were supposed to be working os n, If a person in my group.

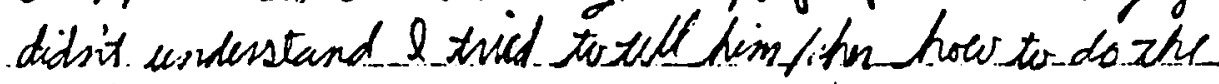
problem.

The mathematics licenced was how to wake G graph and pie graph, learned what a mode, ne an, and' median. live dawned what a tito gram, how to lely up a survey

We the time ur toped and stated war king on this progenond think we war working on differs nt kind of graph with negative solver positive ends that how

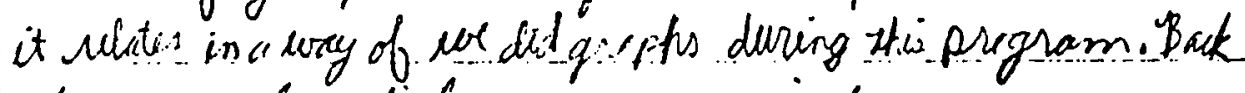
then we ala ind group pargets.

a way of making my group better is by making sure everybody did a certain thing and did it correctly, lcouldive made suse urey body

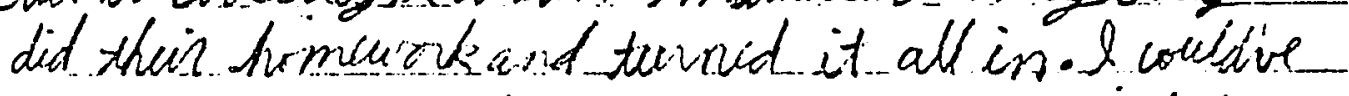

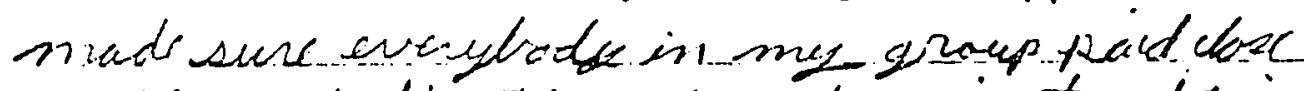

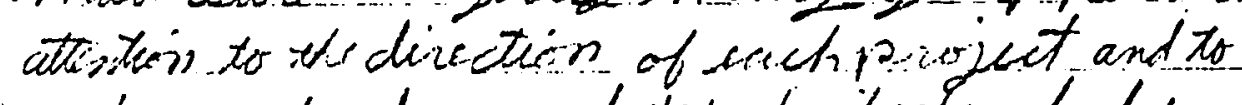

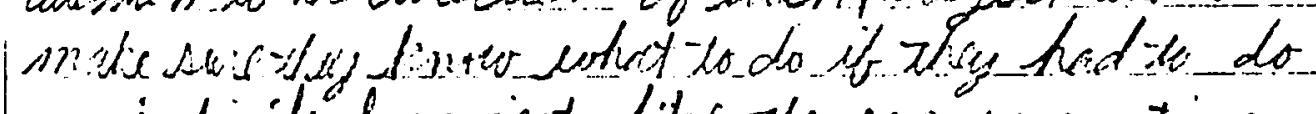
an istivitias project like the curch questions. and w maker sure did all -my work. 
274

Figure 12d. A Writing Sample of Student 7

1 interviewed 25 people. It he

rest of my group interviewed 75 people, 25 people irtervieured each person. 2 was the reporter, so. wrote down all the information and data gathered.

1 learned that by taking samples, $d$ can figure out what the proufation will say Random sampling is to sick people at random. I used the method of ranglom sampling.

havens learned this fiche re. This is all new to r ie sa none of this relates to what di have learned before 1 could have my group ip ht up into parties and have $71 \mathrm{gm}$ work on a rant of a project. I also could have set us a scheduled dates were the soups listens to a different person a different date.

We cooperated well. Everybody agreed on answers. Everybody listened te a person, when he she was sipioging. I think this is a ga ad way to learn something mew. Starting off basically and getting mare complex is easier to learns a his has been a fun unit. a exposed surveying. people and hearing teofites asizions. 
Figure 12e. A Writing Sample of Student 9

In doing this project I had alot of things to do. My main job was to make sure we had all the equipment and tools needed. Plus I also had to make sure everyone had to do their work and not to do nothing. I also had to interview 10 people, gather all of the information, and make the conclusions. Once I gathered all the information I wrote our conclusions and made the graphs.

I learned how to make a graph. I learned that making a survey is not easy and is a bit hard to organize and make one. One of my biggest astonishment is what was the result of our survey. It show about $51 \%$ people would not fight. While $49 \%$ would fight I tought that it would be very low.

This relate to me by showing how a survey is needed Also it shows how a survey is important and what does it shoe in the collected data. 1 learned of how to make a survey and to organize one.

To make our group better we could of had more organized meetings. The reason is that most of us was very disorganized of what to do. And I felt that if we had more meetings we could of been more organized. Another improvement is to supply us with all the materials so that we didn't have to wait to get the supplies.

The thing that worked well was the copperation with most of the people in the group. We agreed to things most of the times. Another good thing is that almost everybody did there fair share of the work in making this survey.

I liked this unit very much. I learned alot of things. I learned several new types of graphs and charts. One exarnple is the histogram. I learned the difference between the bar graphs. I also learned some new terms mode, median, and mean 


\section{CHAPTER 5}

\section{Analysis and Conclusions}

\section{Analysis}

Basic Elements of a Survey. Examination of the selected students' answers to the questions about surveys revealed that students were aware of the basic elements of surveys introduced in the unit; however, there are still some gaps in their knowledge of this topic. In Worksheet-3B of the lesson on developing survey questions, students were asked to develop four guidelines for writing effective survey questions: (1) avoid using words or extra information that may influence or change a person's thinking; (2) use terms that everyone will understand the same way; (3) write questions that are not too long and should be easily understood; and (4) make sure that there is one and only one answer for each survey question. Students were made aware of these guidelines during class discussion; however, they did not use all of them in later assignments. For example, when the students were asked to list three qualities of a good survey question, all five available answers elaborated only the third guideline. Furthermore, a couple of students mentioned "not to use extra words" in writing survey questions, but did not seem to understand how these extra words might affect the results of the survey.

Another important element of a survey that students must know is the survey's method of sampling. The group and class discussions on this topic helped students to understand that for a sample to be random each member of the sample must be independently chosen and equally likely to be chosen. In Figure 2 (see page 246), students were asked to determine whether a sampling method would produce a random sample. Students' answers to this problem 
did not display full understanding of random sampling. The answers to part (c), which was a new example to the students, indicated that students could recognize dependent selection. However, the answers to part (b), showed that either students were not aware of the random assignment of telephone numbers or they might not have thought the choice of " 4 " as having been random. As a result, students either determined this sample as "not random" or simply did not give any answer.

The examination of the selected students' answers revealed some understanding of the basic elements of a survey. Nevertheless, this level of understanding may not withstand the demand of more elaborate surveys.

Statistical Concepts of the Mean, Mode, and Median. One of the purposes of the study was to provide answers to the question "How much will the unit help students to understand the statistical concepts of the mean, median, and mode?" In this unit students are considered to have grasped the concepts of the three measures of central tendency if they can demonstrate through their answers that:

1. The mean is the share that each group member will get if the total is divided equally among members;

2. The median is the point where exactly half of the values are greater and half of the values are lesser;

3. The mode is the most frequently occurring piece of data.

The questions for the analysis of the conceptual understanding of the three averages were chosen so that the sets of data in these questions are both numerical (two are given as a non-ordered list and one is in a line plot form) and non-numerical (one consists of paper strips and the other of colors.) This 
method of question selection ensures that students would have to demonstrate their conceptual understanding of the mean, mode, and median of any sets of data rather than just their understanding of the traditional numerical data sets.

Most students in the sample group had no problem in finding the mode of a set of numerical data or recognizing the lack of it. These students, however, seemed to have problems with the set of paper strips. Among the available answers, only three answers are correct while four of them are incorrect and the remaining two are questionable. When the question "Do all sets have a mode?" arose, most students provided a variation of the statement "If the data set has no repeated value then the set does not have a mode." However, there are still some answers that indicate they are using "most" as the definition of the mode instead of the "most frequent occurring." For example, Student 9's answers in Figures $5 a, 5 b, 6 a$, and $6 b$ (see page $250,251,254$, and 255 ) clearly indicate that this student associated the mode of a set of data with either the longest length or the largest number. This problem of simplifying the definition of the mode from "the most frequent occurring piece of data" to "the most" is the same problem that was discussed in Chapter 2 (Carpenter et al., 1981).

Students in this sample group seemed to have had more difficulty in grasping the statistical concept of the median than that of the statistical concept of the mode. Given a list of numerical data like the one in Figure 6a (see page 254), students could easily find the median for the set. However, problems started to surface when students encountered data in a non-numerical format that are either paper strips or in a line plot form. When students were asked to find the median of a set of paper strips, most students correctly explained how to find the median of the set even without the use of rulers. This mastery of finding 
the median did not transfer into the understanding of its concept. In the next question regarding the multiplicity of the median, four out of nine available answers claimed that the set has two medians because the rectangle next to the real median rectangle is of the same size. The students' performance plummeted when the given data were presented in a line plot form. Instead of using the values represented by the stars in the plot in order to find the median, six students used the ordinal numbers corresponding to the stars' positions as data pieces. For example, in Figure $8 b$ (see page 261), Student 6 claimed that the median is $11 \frac{1}{2}$. Furthermore, the other students, like Students 1,2 , and 7 , claimed the eleventh and twelfth stars are both medians due to the fact that these are the stars remaining after they eliminated pairs of stars from both ends of the plot. On the contrary, these students showed no similar misconception when dealing with lists of non-ordered numerical data in any special presentation like the one in Figure 6c (see page 255). The students' answers to the questions about median clearly show that sampled students had not grasped the concept of the median as the only middle value that separates a number of lesser values from the same number of larger values.

In Figure 9b (see page 263), when the students were asked to generalize the existence of a median in any set of data, half of the sample group claimed that there is a median in any set of data because "if you could count from each side and get to the middle you get the median, even if the set numbers are even you got a half median." The students gave the above generalization even though in a previous question these same students answered "there is no median" to a non-numerical set of data. Students' answers to the question in 
Figure $9 \mathrm{~b}$ imply that either students were careless in doing their work or they were not familiar with making generalizations.

The next section focuses on the students' conceptual understanding of the mean. Most students knew the procedure of calculating the mean of a set of numerical data and were aware that non-numerical data like colors do not have a mean. In the question regarding a set of shirt colors, these students correctly recognized that there is no mean for such a set of data. Furthermore, the majority of the students could make the generalization that only sets of numerical data can have a mean.

The analysis of the data collected implies that all ten students had gaps in their conceptual understanding of the mean, median, or mode; and the majority of them depended heavily on the algorithm of calculating the three measures of central tendency whenever they encountered unfamiliar sets of data. The examination of the students' answers about the mean, mode, and median also showed that students had problems working with sets of paper strips. It is possible that students confused the strips with bar graphs. As a result, their answers given in terms of bar graphs seemed to be unreasonable in terms of length, the intended feature used in the lessons. Also students might look at the area of the strips instead of the intended length. These possible reasons call for the revision of the lessons on the mean, mode, and median for future use.

Group Projects. Even though there were eight groups in the class, only five of them turned in their group projects. The topics range from a survey on violence in school to a survey on favorite types of music. Only two group projects fulfilled all the requirements that consist of a written report, a list of data 
collected, one or two graphs, and the group members' individual reports. The other three group projects were the products of last-minute rush.

\section{Conclusions}

Evaluation of the Study. Based on the findings of this unit as reported in Chapter 4 and the investigator's observations, the following conclusions seem to be reasonable.

Many students found the mathematics projects to be a positive learning experience. Not only did the students have the opportunity to participate in an activity that is different from the traditional mathematics activities, but they actually applied the mathematical concepts and procedures into some real world problems. This activity is consistent with the NCTM's goal of connecting mathematics with real world problems (NCTM, 1989). Furthermore, the group projects also required students to employ their communication skills in developing survey questions and reporting survey information. As a result, the group projects afforded the opportunity for students to gain the mathematical power discussed in the Standards (NCTM, 1989).

As a part of their group projects, students had to write individual reports that described their roles in the surveys, the mathematics that they learned, and their self and group evaluation. Through these reports, many students observed how the group projects had helped them develop the responsibility to their own groups. As these students worked on their projects, they realized that the completion of the projects required that students not only take charge of their task but also provide support to other group members when needed. This admission revealed a positive step towar $d$ the development of effective cooperative learning. 
Another positive result from the group projects is the way the projects showed the process and the ideas behind the surveys to be at least as important as the numerical results. This approach to the projects may encourage students to pay more attention to thinking about the process and the mathematical ideas than getting the correct numbers.

Despite these highlights in the study, there are also some discouraging results. As mentioned in the analysis of the data collected, some students still showed little conceptual understanding of the three measures of central tendency. These students often depended on the algorithms for calculating these measures regardless of the given situations. This dependency on the algorithms and rote memorization is not the result that many mathematics educators want for students in the current age of reform.

The findings of the study also indicated that most students were unable to use inductive reasoning. These are discouraging signs for mathematics teachers for the skill of reasoning inductively is definitely needed for higher mathematics.

Limitations of the Study. Instruction in mathematics is affected by a number of factors, each of which has a limiting effect on the study. Before the results of this study can be used for any purpose, the following limitations must be taken into account.

1. This study was confined to one seventh-grade class of 32 students.

2. There were three Limited English Proficient students who had not shared a common, traditional arithmetic background in the elementary schools that fed to the middle schools. The unavailability of 
the unit in these students' native language further limited the amount of mathematics that these students learned during this period of time.

3. Due to various factors, instructional materials were limited to the lessons for days $1,2,3,4,5,6,7,8,10,12,13,20,21,22$, and 23.

Suggestions for Future Implementation. The data collected revealed that this study had not fully achieved its purposes. As a consequence, aspects of the study should be addressed in any future implementation by either modifying teaching practices or by revising the unit itself.

Revision of lessons. The analysis of the students' answers about the mean, mode, and median indicated that many students might confuse the rectangular strips with the bar graphs. They also might examine the area or the width of the strips instead of the length of the strips as the lessons intended. To eliminate this problem, the paper strips can be replaced by equilateral triangles.

Cooperative Learning. Even though students worked in groups most of the time, only a few of them truly benefited from this cooperative learning format. Many students seemed uncomfortable working with classmates of the opposite sex. Groups of same sex students did not fare much better. They often socialized with each other rather than discussing the problems at hand. According to Johnson and Johnson (1990), the effectiveness of cooperative learning depends on students' ability to build teams and possess social skills. Teaching these skills would help to reduce the unnecessary socialization and increase the needed learning. 
Group and Class Discussion. Another practice in the application of the unit that should be addressed in any future implementation is the group and class discussions. This unit was designed so that students would have the opportunity to work and discuss mathematical problems with their group members or classmates before consulting the teacher. Thus, the teacher must make students aware that their group members and their classmates are their first source of information. The teacher should schedule plenty of time for thorough discussions and refrain from giving away answers so easily.

Revision of Students' Work. One vital practice for improving communication skills and more importantly, for increasing the understanding and retention of the material being introduced, was not emphasized in the teaching and grading of the lessons. That is the revision of student assignments. Since this was not established as a regular routine, not many students agreed to revise their work to make it better. Revision of incorrect assignments to produce better results not only forces students to examine their mistakes but also creates another opportunity for students to practice writing mathematics.

Group Projects. The teacher must allot time for the planning of group projects. Many students expressed the desire to have more time for meetings to plan for the group projects. Since these were middle school students, they might not be able to get in touch with each other outside of school. Thus, more meetings to plan for the group projects should be scheduled. It is also important that the teacher provide one or 
two lessons on how to do projects. This will ensure that no one will have an advantage over another in doing the group projects.

Grade Level. Due to the unit's emphasis on the reading of the provided materials and the outside materials for the assignments, this unit seems to be most appropriate for eighth graders. However, this unit can be adapted to use in seventh-grade mathematics classes by reducing the amount of teaching materials and incorporating additional instruction.

Despite some of its shortcomings, this statistics unit presents an attempt to teach students to understand statistical concepts and apply them through realistic mathematics projects. 


\section{References}

August Boeger Junior High School. (1993). August Boeger Junior High School 1993-1994 School Based Coordinated Plan. San José, CA: Author.

Barr, G.V. ( 9980, May). Some students ideas on the median and mode. Teaching Statistics 2, pp. 38-41.

California State Department of Education. (1992). Mathematics framework for California public schools: Kindergarten through grade twelve. Sacramento, CA: Author.

Carpenter, T.P., Corbitt, M.K., Kepner, H.S., Lindquist, M.M., \& Reys, R.E. (1981). Results from the second mathematics assessment of the National Assessment of Education Progress. Reston, VA: National Council of Teachers of Mathematics.

Crosswhite, F.J., Dossey, J.A., Swafford, J.O., McKnight, C.C., \& Cooney, T.J. (1985). Second international mathematics survey report for the United States. Champaign, IL: U.S. National Coordinating Center for the Second International Mathematics Study.

Flanders, J.R. (1987, September). How much of the content in mathematics textbook is new? Arithmetic Teacher, pp. 18-23.

Futures: Statistics and Sports Performance. PBS Video.

Gardella, F.J., Fraze, P.R., Meldon, J.E., Weingarden, M.S., \& Campbell, C. (1992). Mathematical connections: A bridge to algebra and geometry. Boston, MA: Houghton Mifflin Company.

Guns by the numbers. (1993, December). USA Today, p. 4A.

Johnson, D.W., \& Johnson, R.T. (1990). Using cooperative learning in math. In N. Davidson (Ed.), Cooperative learning in mathematics: $A$ handbook for 
teachers (pp. 103-125). Menlo Park, CA: Addison-Wesley Innovative Division.

Johnson, O. (Ed.). (1992). The 1993 information please almanac. Boston, MA: Houghton Mifflin Company.

McKnight, C.C., Crosswhite, F.J., Dossey, J.A., Kifer, E., Swafford, J.O., Travers, K.J., \& Cooney, T.J. (1987). The underachieving curriculum: Assessing U.S. school mathematics from an international perspective.

Champaign, IL: U.S. National Coordinating Center for the Second International Mathematics Study.

Minton, L. (1993, May). Whom do high school students admire most? Parade Magazine, p. 18.

National Council of Teachers of Mathematics. (1989). Curriculum and evaluation standards for school mathematics. Reston, VA: Author.

National Research Council. (1989). Everybody counts: A report to the Nation on the future of mathematics education. Washington, DC: Author.

Rade, L. (1985). Statistics. In R. Morris (Ed.), Studies in mathematics education: Vol. 4. The education of secondary school teachers of mathematics (pp. 97-107). Tournai, Belgium: United Nations Educational, Scientific and Cultural Organisation.

Regents, University of California. (1989). Assessment in mathematics: An overview of assessment techniques that promote learning. Berkeley, CA: Author.

Schoenfeld, A. (1989). Problem solving in context(s). In R.I. Charles \& E.A. Silver (Eds.), Research agenda for mathematics education: Vol. 3. The 
teaching and assessing of mathematical problem solving (pp. 82-92). Reston, VA: National Council of Teachers of Mathematics.

Zawojewski, J.S. (Ed.). (1991). Curriculum and evaluation standards for school mathematics addenda series, grades 5-8: Dealing with data and chance. Reston, VA: National Council of Teachers of Mathematics. 


\section{APPENDIX A \\ Student Assessment Packet \\ Written classwork and homework \\ Classwork and homework will be given daily. \\ Quizzes (pairs and individual)}

There will be two types of quizzes: quizzes taken by pairs and quizzes taken by individuals. Teachers must prepare two versions for each quiz, one for the pair quiz and one for the individual quiz. On quiz day, randomly form students into pairs at different locations of the room. Each pair of students will be given two copies of the quiz: one for rough work and the other one for the final product. Both students will be awarded the same mark. After students turn in their pair quiz, they will receive a copy of the individual quiz. Each student will receive two marks for each quiz.

Classwork, homework and quizzes will be assessed based on the following rubric.

\section{Demonstrated Competence}

Exemplary Response...Rating $=6$. Gives complete response with a clear, coherent, unambiguous, and elegant explanation; includes a clear and simplified diagram; communicates effectively to the identified audience; shows understanding of mathematical ideas and processes; identifies all important elements of the problem; may include examples and counterexamples; presents strong and supportive arguments.

Competent Response...Rating = 5. Gives a fairly complete response with reasonably clear explanations; may include an appropriate diagram; communicates effectively to the identified audience; shows understanding of 
mathematical ideas and processes; identifies most important elements of the problem; presents solid supporting arguments.

\section{Satisfactory Response}

Minor Flaws But Satisfactory...Rating $=4$. Completes the problem satisfactorily, but the explanation may be muddled; argumentation may be incomplete; diagram may be inappropriate or unclear; understands the underlying mathematical ideas; uses mathematical ideas effectively.

Serious Flaws But Nearly Satisfactory...Rating $=3$. Begins the problem appropriately but may fail to complete or may omit significant parts of the problem; may fail to show full understanding of mathematical ideas and processes; makes major computational errors; may misuse or fail to use mathematical terms; response may reflect an inappropriate strategy for solving the problem.

\section{Inadequate Response}

Begins, But Fails to Complete Problem...Rating $=2$. Explanation is not understandable; diagram may be unclear; shows no understanding of the problem situation; may make major computational errors.

Unable to Begin Effectively...Rating $=1$. Words do not reflect the problem; drawings misrepresent the problem situation; copies part of the problem but without attempting a solution; fails to indicate which information is appropriate to problem.

No Attempt...Rating $=0$. 


\section{Mathematics projects}

\section{A. General guidelines}

1. As a group select a topic of interest. Decide on how mathematics can be applied to your topic by writing a statement or a problem that needs to be investigated using data. Your statement or problem must be worded so that the information is collected in an organizable and workable way. Write a detailed report on your findings.

2. Be sure to keep your group's ongoing assessment recording on the log sheet provided.

3. You must supply your own materials for the group project.

4. Your group's project must:

a. include: the statement or the problem, survey questions (if you have survey questions), description of how the data were collected, report of the data, analysis of the data, graphs, findings and conclusion.

b. be displayed on a $1 \mathrm{~m} \times 1 \mathrm{~m}$ poster or cardboard (at most posters or cardboards for each project.)

c. be presented to the class after the last day of this unit; specific date will be determined by your teacher.

5. For your individual report, write a report assessing your role in this group's project. Be as complete as possible. You self-assessment report may be written by answering the following questions:

a. What tasks did you do for the group?

b. What mathematics did you learned?

c. How does this relate to what you learned before? 
d. What could you have done to make your group work better?

e. What worked well in your group?

f. What do you think about this unit?

6. At the end of the day of the project's presentation, you must turn

in:

a. your group's project, and

b. your individual report.

B. Possible topics

There are several sources to find topics and data; may of them are available in libraries. Here are some suggested sources: periodicals (Consumer Reports, Time, Newsweek, Sports Illustrated, Business Week, Seventeen, Money), Consumer Catalogs, Almanacs. If you are at loss for a topic, you may want to examine the following topics that might give you some ideas. Don't feel like you need to choose from this list!

1. Colors and types of automobiles

2. Safe-driving records

3. Comparisons of costs at different stores

4. Students' height, weight, and age relationships

5. Rainfall, temperature, and weather records

6. Political surveys

7. Tardiness and absenteeism at school

8. Time of births in families

9. Age of pennies in circulation

10. Salaries and averages in professional sports 
11. Comparison of places to live

12. Comparison vacation spots

\section{Assessment}

All reports will be assessed using the Well Done, Acceptable,

Revision Needed, Re-Start categories.

A Well-Done (4 pts) report includes an understanding of the statistical and graphical concepts, survey process, mathematical thinking, use of tools and techniques, and a well-written work.

An Acceptable (3 pts) report must include most of the parts of a well done report, but the writing and drawing may be of a lesser quality. Reports must demonstrate an understanding of statistics, graphs, and surveys.

A Revision Needed (2 pts) report is not complete or lacks organization. The report will be returned to be revised and resubmitted.

A Re-Start (1 pt) report means the groups either have not started or the work misses the mark. Groups starts over with a time-extension due date.

Suggestion: Show your teacher your rough draft of the report a week before due date for comments. This will help you to correct any mistakes before turning in the final draft.

I. The group's project will be evaluated on the following criteria:

1. Originality: Does the project show originality in plan and execution? Your project should not look like another group's project.

2. Evidence of effort and time expended: Does your project appear as though you spent time planning and executing it or does it appear to have been thrown together in the last minutes? 
3. Relevance to the topic: Your project should illustrate the application of mathematics principles.

4. Development of the project (your log sheet): Complete chronological report of your group's activities.

5. Neatness: Your project should be neat and attractive so that it will command the attention of the viewers.

II. The criteria for the group's presentation are:

1. Student's posture

2. Student's audibility and enunciation

3. Student's eye contact

4. Introduction, body, and conclusion of speech

5. Number of facts given

6. Neatness

7. Originality

8. Conducting of post-presentation discussion

III. Your individual report will be evaluated based on:

1. Completeness,

2. Evidence of efforts and time expended, and

3. Neatness. 
Daily observation checklist (Individual)

Date:

Specific Skills

Student $1 \quad$ Student $2 \quad$ Student $3 \quad$ Student 4

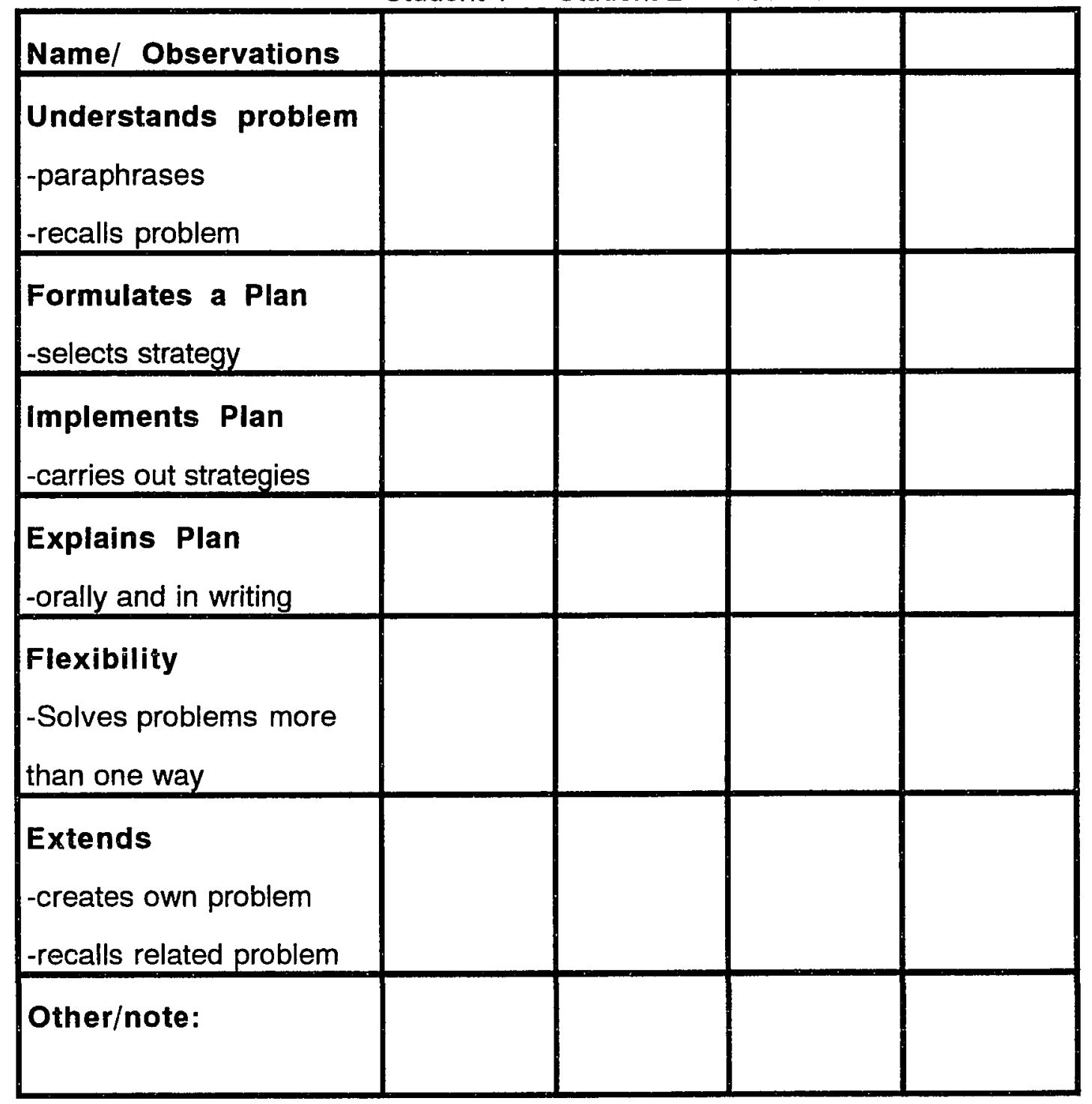


Daily observation checklist (Individual)

Attitudes (Interaction and Participation)

Student $1 \quad$ Student $2 \quad$ Student $3 \quad$ Student 4

\begin{tabular}{|l|l|l|l|l|}
\hline Name/ Observations & & & & \\
\hline Cooperates & & & & \\
\hline Shares/Collaborates & & & & \\
-tries, contributes ideas & & & & \\
\hline Questions Peers & & & & \\
-encourages other to & & & & \\
participate & & & & \\
\hline Stays on Task & & & & \\
-perseveres & & & & \\
\hline Takes Risks & & & & \\
\hline
\end{tabular}




\section{Daily observation checklist (Group)}

Date:

Group:

\begin{tabular}{|l|l|}
\hline Dividing task among members & \\
\hline $\begin{array}{l}\text { Taking time to ensure that all members } \\
\text { understand the task }\end{array}$ & \\
\hline Using time in a productive way & \\
\hline Using more than one process & \\
\hline Remembering to record results & \\
\hline $\begin{array}{l}\text { Considering and using the suggestions and } \\
\text { ideas of others }\end{array}$ & \\
\hline Reporting the group result to the class & \\
\hline
\end{tabular}




\section{APPENDIX B}

\section{Inventory of the Students' Answers to the Selected Questions in Chapter 4}

This appendix consists of the inventory of all available answers to the selected questions in Figures 1a to 10b in Chapter 4.

\section{Table B-1}

Tally for Figure 1a.

\begin{tabular}{cccc}
\hline & Answers \\
\hline Correct & Incorrect & Not clear & No answer \\
5 & 5 & 3 & 5
\end{tabular}

\section{Table B-2}

Tally for Figure $1 \mathrm{~b}$.

\begin{tabular}{cccc}
\hline & \multicolumn{3}{c}{ Answers } \\
\hline Correct & Incorrect & Not clear & No answer \\
8 & 2 & 0 & 13
\end{tabular}




\section{Table B-3}

Tally for Figure 2.

\begin{tabular}{ccccc}
\hline \multicolumn{5}{c}{ Answers } \\
\hline Part & Correct & Incorrect & Not clear & No answer \\
a & 7 & 1 & 0 & 7 \\
b & 3 & 3 & 0 & 9 \\
c & 5 & 0 & 0 & 10 \\
d & 5 & 1 & 0 & 8
\end{tabular}

\section{Table B-4}

Tally for Figure 3.

\begin{tabular}{cccc}
\hline & Answers \\
\hline Correct & Incorrect & Not clear & No answer \\
10 & 1 & 2 & 4
\end{tabular}

\section{Table B-5}

Tally for Figure 4.

\section{Answers}

\begin{tabular}{cccc}
\hline Correct & Incorrect & Not clear & No answer \\
5 & 5 & 1 & 5
\end{tabular}


Table B-6

Tally for Figure $5 \mathrm{a}$.

\begin{tabular}{cccc}
\hline & \multicolumn{3}{c}{ Answers } \\
\hline Correct & Incorrect & Not clear & No answer \\
7 & 7 & 2 & 2
\end{tabular}

Table B-7

Tally for Figure 5b.

\begin{tabular}{cccc}
\hline & \multicolumn{3}{c}{ Answers } \\
\hline Correct & Incorrect & Not clear & No answer \\
6 & 6 & 4 & 2
\end{tabular}

Table B-8

Tally for Figure $5 \mathrm{c}$.

\section{Answers}

\begin{tabular}{cccc}
\hline Correct & Incorrect & Not clear & No answer \\
6 & 0 & 9 & 2
\end{tabular}


Table B-9

Tally for Figure 5d.

\begin{tabular}{cccc}
\hline & Answers \\
\hline Correct & Incorrect & Not clear & No answer \\
5 & 1 & 7 & 2
\end{tabular}

\section{Table B-10}

Tally for Figure $5 \mathrm{e}$.

\begin{tabular}{cccc}
\hline & Answers & \\
\hline Correct & Incorrect & Not clear & No answer \\
6 & 0 & 0 & 4
\end{tabular}

\section{Table B-11}

Tally for Figure 6a.

\begin{tabular}{cccc}
\hline & Answers \\
\hline Correct & Incorrect & Not clear & No answer \\
9 & 4 & 0 & 1
\end{tabular}




\section{Table B-12}

Tally for Figure $6 \mathrm{~b}$.

\begin{tabular}{cccc}
\hline & Answers \\
\hline Correct & Incorrect & Not clear & No answer \\
11 & 1 & 1 & 5
\end{tabular}

\section{Table B-13}

Tally for Figure $6 \mathrm{c}$.

\begin{tabular}{cccc}
\hline & Answers \\
\hline Correct & Incorrect & Not clear & No answer \\
10 & 1 & 1 & 6
\end{tabular}

\section{Table B-14}

Tally for Figure 6d.

\begin{tabular}{cccc}
\hline \multicolumn{4}{c}{ Answers } \\
\hline Correct & Incorrect & Not clear & No answer \\
7 & 2 & 3 & 7
\end{tabular}


Table B-15

Tally for Figure 6e.

\begin{tabular}{cccc}
\hline & \multicolumn{3}{c}{ Answers } \\
\hline Correct & Incorrect & Not clear & No answer \\
3 & 0 & 5 & 9
\end{tabular}

Table B-16

Tally for Figure $6 f$.

\begin{tabular}{cccc}
\hline & \multicolumn{3}{c}{ Answers } \\
\hline Correct & Incorrect & Not clear & No answer \\
12 & 4 & 2 & 3
\end{tabular}

Table B-17

Tally for Figure $7 \mathrm{a}$.

\begin{tabular}{cccc}
\hline & Answers \\
\hline Correct & Incorrect & Not clear & No answer \\
10 & 0 & 0 & 0
\end{tabular}


Table B-18

Tally for Figure $7 \mathrm{~b}$.

\begin{tabular}{cccc}
\hline & \multicolumn{3}{c}{ Answers } \\
\hline Correct & Incorrect & Not clear & No answer \\
9 & 0 & 0 & 0
\end{tabular}

Table B-19

Tally for Figure $7 c$.

Answers

\begin{tabular}{cccc}
\hline Correct & Incorrect & Not clear & No answer \\
13 & 3 & 0 & 7
\end{tabular}

\section{Table B-20}

Tally for Figure 8a.

Answers

\begin{tabular}{cccc}
\hline Correct & Incorrect & Not clear & No answer \\
9 & 1 & 0 & 0
\end{tabular}


Table B-21

Tally for Figure 8b.

\begin{tabular}{cccc}
\hline & Answers \\
\hline Correct & Incorrect & Not clear & No answer \\
6 & 1 & 3 & 0
\end{tabular}

Table B-22

Tally for Figure 8c.

Answers

\begin{tabular}{cccc}
\hline Correct & Incorrect & Not clear & No answer \\
4 & 3 & 0 & 3
\end{tabular}

Table B-23

Tally for Figure 9a.

\begin{tabular}{cccc}
\hline & Answers \\
\hline Correct & Incorrect & Not clear & No answer \\
6 & 2 & 2 & 0
\end{tabular}


Table $\mathbf{B - 2 4}$

Tally for Figure 9b.

\begin{tabular}{cccc}
\hline & \multicolumn{3}{c}{ Answers } \\
\hline Correct & Incorrect & Not clear & No answer \\
4 & 5 & 1 & 0
\end{tabular}

\section{Table B-25}

Tally for Figure 9c.

\begin{tabular}{cccc}
\hline & \multicolumn{3}{c}{ Answers } \\
\hline Correct & Incorrect & Not clear & No answer \\
7 & 3 & 6 & 8
\end{tabular}

\section{Table B-26}

Tally for Figure 10a.

\begin{tabular}{ccccc}
\hline \multicolumn{5}{c}{ Answers } \\
\hline Part & Correct & Incorrect & Not clear & No answer \\
a & 8 & 6 & 0 & 4 \\
b & 4 & 7 & 0 & 7
\end{tabular}




\section{Table B-27}

Tally for Figure 10b.

\begin{tabular}{cccc}
\hline & \multicolumn{3}{c}{ Answers } \\
\hline Correct & Incorrect & Not clear & No answer \\
6 & 8 & 5 & 4
\end{tabular}

